RENATO MANZAN DE ANDRADE

UM ROTEIRO PARA O ENSINO DE QUALIDADE DE ARQUITETURA DE SOFTWARE GUIADO POR REQUISITOS NÃO FUNCIONAIS 

RENATO MANZAN DE ANDRADE

\section{UM ROTEIRO PARA O ENSINO DE QUALIDADE DE ARQUITETURA DE SOFTWARE GUIADO POR REQUISITOS NÃO FUNCIONAIS}

Tese apresentada à Escola Politécnica da Universidade de São Paulo para obtenção do título de Doutor em Ciências 

RENATO MANZAN DE ANDRADE

\section{UM ROTEIRO PARA O ENSINO DE QUALIDADE DE ARQUITETURA DE SOFTWARE GUIADO POR REQUISITOS NÃO FUNCIONAIS}

Tese apresentada à Escola Politécnica da Universidade de São Paulo para obtenção do título de Doutor em Ciências

Área de Concentração:

Engenharia de Computação e Sistemas Digitais

Orientador:

Prof. Dr. Paulo Sérgio Cugnasca 
Este exemplar foi revisado e corrigido em relação à versão original, sob responsabilidade única do autor e com a anuência de seu

orientador.

São Paulo, de de

Assinatura do autor:

Assinatura do orientador:

Catalogação-na-publicação

Andrade, Renato Manzan de

Um roteiro para o ensino de qualidade de arquitetura de software guiado por requisitos não funcionais / R. M. Andrade -- versão corr. -- São Paulo, 2015. $279 \mathrm{p}$.

Tese (Doutorado) - Escola Politécnica da Universidade de São Paulo. Departamento de Engenharia de Computação e Sistemas Digitais.

1.Arquitetura de software 2.Arquitetura de software (Educação) 3.Arquitetura de software (Qualidade) I.Universidade de São Paulo. Escola Politécnica. Departamento de Engenharia de Computação e Sistemas Digitais II.t. 
À minha esposa Patricia e à minha filha Ísis pela compreensão nas minhas ausências durante a elaboração deste trabalho.

Aos meus pais, José Luiz e Maria Eunice, pela dádiva da existência e pelos valores na formação do meu caráter. Ao grande amigo, Prof. Dr. Reginaldo Arakaki, pela confiança, oportunidade de trabalho e parceria de mais de 10 anos na pesquisa na área de arquitetura de software. 



\section{AGRADECIMENTOS}

Ao grande amigo e orientador no início e em grande parte deste trabalho, Prof. Dr. Reginaldo Arakaki, pelas oportunidades e portas abertas não somente na academia como na indústria, pela amizade sincera, confiança e orientação segura e aberta desde 2003.

Ao amigo e orientador na fase final deste trabalho, Prof. Dr. Paulo Sérgio Cugnasca, pelas valiosas orientações, que tanto contribuíram para a conclusão deste trabalho.

Ao amigo, Prof. Dr. Jorge Risco, por me ensinar a essência de um trabalho de pesquisa.

Ao amigo, Prof. Dr. Wilson Ruggiero, por me ensinar que não se admite conhecer nada na superficialidade.

À Prof. Dra. Stela Conceição Bertholo Piconez, por me mostrar que, na essência, um professor é um provocador cognitivo.

Aos Professores Doutores Carlos Eduardo Paes, Jorge Risco e Reginaldo Arakaki pelas inúmeras contribuições durante a Banca de Qualificação deste trabalho.

Aos engenheiros Júlio Henrique dos Nogueira e Oliveira Guimarães, Bruno Medeiros e Fernando Tsuda, incansáveis amigos da disciplina de Laboratório de Engenharia de Software II, aos sábados de manhã, pela convivência, amizade e apoio durante todos esses anos.

Aos amigos do Instituto de Pesquisas Tecnológicas (IPT), especialmente Wellington Durães, José Carlos Cordeiro, Flávio Moreni e Massami Horai pelas discussões proveitosas sobre arquitetura de software. E ao Adilson Nascimento por toda a ajuda durante todos os anos que frequentei o IPT.

Ao amigo Antônio Viera da Silva Neto, do Grupo de Análise de Segurança (GAS), e à Sra. Ana Maria, da Biblioteca da Engenharia Elétrica, pelas orientações na fase final da elaboração deste trabalho. 
A todos os alunos que contribuíram com críticas e sugestões de melhoria, por meio da participação nas aplicações do roteiro de ensino de qualidade de arquitetura de software proposto neste trabalho. 


\section{RESUMO}

A qualidade da arquitetura de software pode impactar diretamente a satisfação do usuário, uma vez que define se os atributos de qualidade serão atingidos, principalmente os requisitos não funcionais. Apesar disso, os conceitos de qualidade de arquitetura de software não são tratados com a devida importância pelos currículos dos cursos de graduação e pós-graduação dos cursos de Computação. A ausência de conhecimento sobre qualidade de arquitetura de software, dos trade-offs entre atributos de qualidade e de como medir esses atributos durante o ciclo de desenvolvimento de software faz com que egressos dos cursos de Computação somente aprendam que os atributos de qualidade de arquitetura são fatores crucias para o sucesso de um projeto da pior forma possível, ou seja, após muitos projetos fracassados em sua vida profissional, colocando em risco toda sua trajetória de carreira. Este trabalho de pesquisa propõe um método experimental (roteiro) para o ensino de qualidade de arquitetura de software guiado por atributos de qualidade, principalmente requisitos não funcionais, utilizando uma abordagem prática, iterativa e dirigida pelo processo de negócio com o objetivo de auxiliar no processo de aprendizagem da importância dos atributos de qualidade de arquitetura de software e medição desses atributos durante todo o ciclo de vida de um sistema. Para a elaboração do roteiro de ensino proposto foram utilizadas normas relacionadas à qualidade do produto e do processo de software, modelos de referência para sistemas de processamento distribuído, métodos de avaliação de arquiteturas de software e teorias pedagógicas relacionadas ao processo de ensino/aprendizagem. Para avaliação do roteiro de ensino proposto, o mesmo foi aplicado em disciplinas de graduação e pós-graduação em Engenharia de Computação, mais especificamente em disciplinas da área de Engenharia de Software.

Palavras-chave: Arquitetura de software, Qualidade de arquitetura de software, Ensino de arquitetura de software. 



\begin{abstract}
The software architecture quality directly affects user satisfaction, since it defines if quality criteria will be achieved, especially regarding the non-functional requirements. However, software architecture quality concepts are not handled with due importance by undergraduate and graduate computer curricula. The lack of knowledge about software architecture quality, quality attribute trade-offs and how to measure these attributes during the software development cycle makes computer graduates/engineers only learn that software architecture quality is a key to a successful project in the worst way possible, i.e., after many failed projects in their professional lives, jeopardizing their entire career trajectory. This research proposes a experimental method (roadmap) for teaching software architecture quality guided by quality attributes, primarily by non-functional requirements, using an iterative and practical approach, driven by business process. This will help to teach the importance of software architecture quality and of measuring these attributes throughout the system life cycle. For developing the proposed roadmap, standards related to software product and process quality, reference models for distributed processing systems, methods for software architectures evaluation and pedagogical theories related to the learning process were used. To evaluate the proposed roadmap, it was applied in undergraduate and graduate Computer Engineering courses, specifically in Software Engineering disciplines.
\end{abstract}

Keywords: software architecture, software architecture quality, software architecture education. 



\section{LISTA DE ILUSTRAÇÕES}

Figura 1 - Relacionamento entre os pontos de vista do RM-ODP

Figura 2 - Elementos arquiteturais do modelo RM-ODP orientados pelo processo de negócio.

Figura 3 - Metamodelo de qualidade.

Figura 4 - Relação entre as normas ISO/IEC 9126 e ISO/IEC 14598

Figura 5 - Estrutura da norma ISO/IEC 9126

Figura 6 - Relacionamento entre qualidade interna, externa e de uso

Figura 7 - Características e subcaracterísticas de qualidade definidas na ISO/IEC 9126-1

Figura 8 - Etapas do processo de avaliação do produto de software. .62

Figura 9 - Método iterativo para projeto de arquitetura de software .65

Figura 10 - Exemplo de árvore de utilidade (utility tree) ......................................77

Figura 11 - Relação entre a etapa 5 e demais etapas do ATAM..............................82

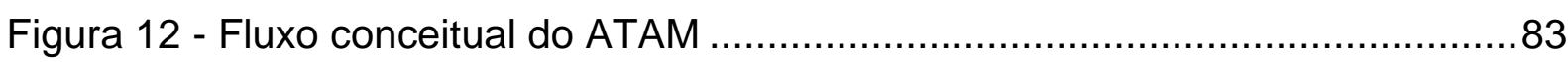

Figura 13 - Ciclo de Desenvolvimento de software ............................................104

Figura 14 - Relação entre objetivo de negócio e arquitetura de software

Figura 15 - Etapas do Roteiro proposto de ensino de qualidade de arquitetura de software guiado por requisitos não funcionais utilizando sistemas existentes

Figura 16 - Roteiro de ensino de qualidade de arquitetura de software guiado por requisitos não funcionais adaptado para o desenvolvimento de sistemas novos ...138

Figura 17 - Exemplo de temas de trabalho em uma aplicação do roteiro de ensino em uma disciplina de graduação com o uso de um sistema existente (Pet Store).. 157

Figura 18 - Exemplo de solução proposta por alunos do Grupo "Pool sem filas" (com timeout)

Figura 19 - Aplicação 1 - Respostas dos alunos sobre o nível de conhecimento de medidas em geral.

Figura 20 - Aplicação 1 - Respostas dos alunos sobre o nível de conhecimento de medidas de arquitetura de software

Figura 21 - Aplicação 1 - Respostas dos alunos sobre o nível de conhecimento de medidas estáticas...

Figura 22 - Aplicação 1 - Respostas dos alunos sobre o nível de conhecimento de medidas dinâmicas.

Figura 23 - Aplicação 1 - Respostas dos alunos sobre o nível de conhecimento de medidas para melhoria da arquitetura de software

Figura 24 - Aplicação 1 - Respostas dos alunos sobre o nível de conhecimento de conceitos de qualidade 
Figura 25 - Aplicação 1 - Respostas dos alunos sobre o nível de conhecimento da relação entre arquitetura de software e qualidade.

Figura 26 - Aplicação 1 - Diagrama das filas e threads do sistema e medições dinâmicas.

Figura 27 - Arduino Uno utilizado durante as aulas da disciplina PCS2420

Figura 28 - Dados exibidos pelo módulo de GPS

Figura 29 - Interligação física dos componentes do trabalho "Segurança de automóveis e do proprietário".

Figura 30 - Diagrama de componentes elaborado na prova de conceito do trabalho "Automação residencial"....

Figura 31 - Aplicação 2 - Respostas dos alunos sobre o nível de conhecimento de medidas em geral

Figura 32 - Aplicação 2 - Respostas dos alunos sobre o nível de conhecimento de medidas de arquitetura de software.

Figura 33 - Aplicação 2 - Respostas dos alunos sobre o nível de conhecimento de medidas estáticas .

Figura 34 - Aplicação 2 - Respostas dos alunos sobre o nível de conhecimento de medidas dinâmicas

Figura 35 - Aplicação 2 - Respostas dos alunos sobre o nível de conhecimento de medidas para melhoria da arquitetura de software

Figura 36 - Aplicação 2 - Respostas dos alunos sobre o nível de conhecimento de conceitos de qualidade

Figura 37 - Aplicação 2 - Respostas dos alunos sobre o nível de conhecimento da relação entre arquitetura de software e qualidade.

Figura 38 - Aplicação 2 - Telas para celular e navegadores web de um sistema de segurança de veículos.

Figura 39 - Criticidade do atributo de qualidade disponibilidade em sistemas comercias e industriais segundo a arquitetura corporativa PERA (WILLIAMS, 1993)

Figura 40 - Aplicação 3 - Respostas dos alunos sobre o nível de conhecimento de medidas em geral

Figura 41 - Aplicação 3 - Respostas dos alunos sobre o nível de conhecimento de medidas de arquitetura de software.

Figura 42 - Aplicação 3 - Respostas dos alunos sobre o nível de conhecimento de medidas estáticas .

Figura 43 - Aplicação 3 - Respostas dos alunos sobre o nível de conhecimento de medidas dinâmicas

Figura 44 - Aplicação 3 - Respostas dos alunos sobre o nível de conhecimento de medidas para melhoria da arquitetura de software

Figura 45 - Aplicação 3 - Respostas dos alunos sobre o nível de conhecimento de conceitos de qualidade 
Figura 46 - Aplicação 3 - Respostas dos alunos sobre o nível de conhecimento da relação entre arquitetura e qualidade.

Figura 47 - Aplicação 3 - Diagrama de classes de um sistema de geolocalização baseado no RM-ODP

Figura 48 - Percentual dos comentários individuais dos alunos classificados por categoria. 



\section{LISTA DE TABELAS}

Tabela 1 - Documentação de arquitetura

Tabela 2 - Disciplinas do curso de Engenharia de Computação e respectivos tópicos que abordam conceitos relacionados à arquitetura de software e à qualidade de arquitetura de software

Tabela 3 - Disciplinas do curso de Ciência da Computação e respectivos tópicos que abordam conceitos relacionados à arquitetura de software e à qualidade de arquitetura de software.

Tabela 4 - Tópicos das disciplinas do curso de Engenharia de Computação considerados requisitos pelo roteiro proposto

Tabela 5 - Tópicos das disciplinas do curso de Ciência da Computação considerados requisitos pelo roteiro proposto 102

Tabela 6 - Mapeamento entre os princípios técnicos do roteiro e tópicos das disciplinas dos cursos de Engenharia de Computação e Ciência da Computação relacionados com arquitetura de software e qualidade de arquitetura de software.116

Tabela 7 - Mapeamento entre os princípios pedagógicos do roteiro com as teorias de aprendizagem ou com tópicos das disciplinas dos cursos de Engenharia de Computação e Ciência da Computação.

Tabela 8 - Princípios pedagógicos do roteiro baseados na prática de aplicação do mesmo desde 2005.

Tabela 9 - Mapeamento entre etapas do roteiro proposto para sistemas existentes e sistemas novos.

Tabela 10 - Mapeamento entre os princípios do roteiro proposto e disciplinas do curso de Engenharia Elétrica com ênfase em Computação da Escola Politécnica da USP

Tabela 11 - Aplicação 1 - Mapeamento entre as atividades do roteiro e o plano da disciplina Laboratório de Engenharia de Software em curso de graduação.....

Tabela 12 - Aplicação 1 - Respostas consolidadas dos alunos aos 3 questionários de avaliação do roteiro proposto

Tabela 13 - Cenários considerados pelos alunos que trabalharam no tema Cenários de conveniência para pessoas da 3 a . idade

Tabela 14 - Aplicação 2 - Mapeamento entre as atividades do roteiro e o plano da disciplina Laboratório de Engenharia de Software em curso de graduação.

Tabela 15 - Aplicação 2 - Respostas consolidadas dos alunos aos 3 questionários de avaliação do roteiro proposto

Tabela 16 - Mapeamento entre os princípios do roteiro proposto e disciplinas do curso de Mestrado profissionalizante em Engenharia de Software do IPT .....

Tabela 17 - Mapeamento entre as atividades do roteiro e o plano da disciplina de Arquitetura de Software do curso de pós-graduação

Tabela 18 - Resultado da avaliação arquitetural dos atributos de qualidade de um sistema de seguros 
Tabela 19 - Aplicação 3 - Respostas consolidadas dos alunos aos três questionários de avaliação do roteiro proposto

Tabela 20 - Percentual médio das respostas dos alunos em cada aplicação do roteiro proposto.

Tabela 21 - Percentual das respostas aos questionários de avaliação dos 167 alunos que participaram da aplicação do roteiro em disciplinas de graduação e pósgraduação

Tabela 22 - Percentual das respostas somando-se as respostas de nível de conhecimento Fraco + Médio e Bom + Ótimo.

Tabela 23 - Percentual das respostas aos questionários dos 121 alunos de graduação que participaram do roteiro

Tabela 24 - Número de alunos que participaram do roteiro por turma no período entre 2007 e 2014.

Tabela 25 - Ementa da disciplina Arquitetura de Software do curso de pósgraduação (Mestrado profissionalizante) em Engenharia de Computação oferecido pelo

Tabela 26 - Diferenças entre as características e subcaracterísticas entre as normas ISO/IEC 25010 e ISO/IEC 9126-1 (ISO/IEC 25010, 2011) 


\section{LISTA DE SIGLAS E ABREVIAÇÕES}

$A B C$

ABNT

ACM

$A D L$

AES

AHP

AJAX

API

AQOSA

ATAM

CASE

CMMI - ACQ

CMMI - PPQA

CESUPA

CTIC-UFPA

COTS

EJB

GPS

HTML

HTTP

IDE

IEC

IEEE-CS

$\mathrm{IHC}$

IoT

IPT

ISO

ITA

ITU

J2EE

JDK
Architectural Business Cycle

Associação Brasileira de Normas Técnicas

Association for Computing Machinery

Achitecture Description Languages

Advanced Encryption Standard

Analytic Hierarchy Process

Asynchronous JavaScript and XML

Application Programming Interface

Automated Quality-driven Optimization of Software Architecture

Architecture Trade-off Analysis Method

Computer-Aided Software Engineering

Capability Maturity Model Integration for Acquisition

Capability Maturity Model Integration - Process and Product Quality Assurance

Centro Universitário do Estado do Pará

Centro de Tecnologia da Informação e Comunicação da Universidade Federal do Pará

Commercial Off-The-Shelf

Enterprise Java Beans

Global Positioning System

HyperText Markup Language

Hypertext Transfer Protocol

Integrated Development Environment

International Eletrotechnical Commission

Institute of Electrical and Electronics Engineers - Computer Society

Interação Humano-Computador

Internet of Things

Instituto de Pesquisas Tecnológicas

International Organization for Standardization

Instituto Tecnológico de Aeronáutica

International Telecommunication Union

Java 2 Enterprise Edition

Java Development Kit 
JPA

MAISA

MCT

MPS-BR

MVC

OUNL-EML

OMG

PBL

PERA

PoC

PMBoK

PRODEPA

RFID

RM-ODP

RUP

SOA

$S Q L$

TCP

TIC

VLSI

UEFS

UFPA

UML

UNAMA

UFPE

UnB

USP

UP

$X M L$

$X P$
Java Persistence API

Metrics for Analysis and Improvement of Software Architectures

Ministério de Ciência e Tecnologia

Melhoria de Processos do Software Brasileiro

Model-view-controller

Open Universiteit Nederland-Educational Modeling Language

Object Management Group

Problem Based Learning

Purdue Enterprise Reference Architecture

Proof of Concept

Project Management Body of Knowledge

Processamento de Dados do Estado do Pará

Radio-frequency identification

Reference Model-Open Distributed Processing

Rational Unified Process

Software Oriented Architecture

Structure Query Language

Transmission Control Protocol

Tecnologia de informação e comunicação

Very-large-scale integration

Universidade Estadual de Feira de Santana

Universidade Federal do Pará

Unified Modeling Language

Universidade da Amazônia

Universidade Federal de Pernambuco

Universidade de Brasília

Universidade de São Paulo

Unified Process

Extensible Markup Language

Extreme programming 


\section{SUMÁRIO}

1. INTRODUÇÃO

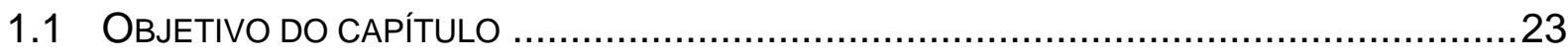

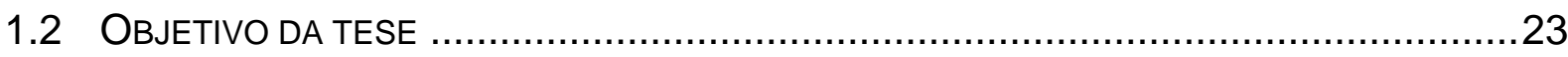

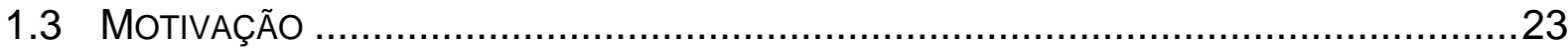

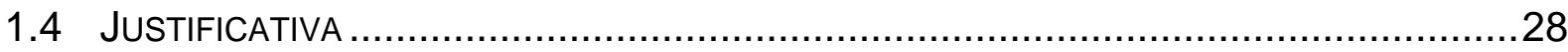

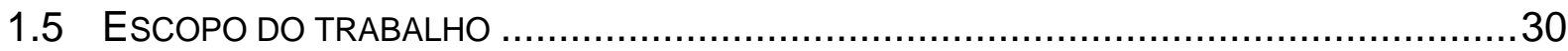

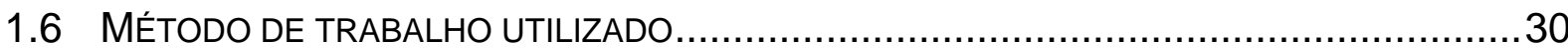

1.7 INICIATIVAS MUNDIAIS E NO BRASIL SOBRE ENSINO DE QUALIDADE DE ARQUITETURA DE

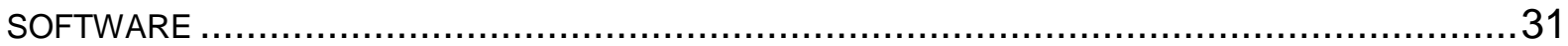

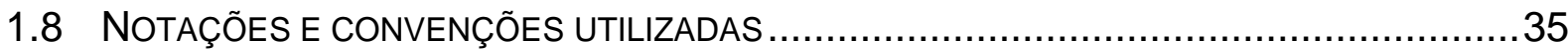

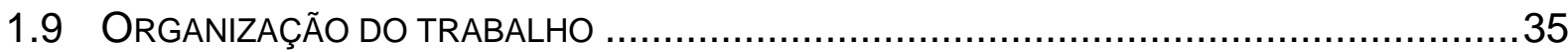

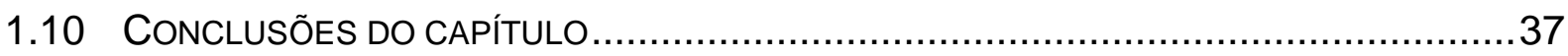

2. CONCEITOS DE ARQUITETURA DE SOFTWARE, QUALIDADE DE SOFTWARE E AVALIAÇÃO DE ARQUITETURA DE SOFTWARE.........................39

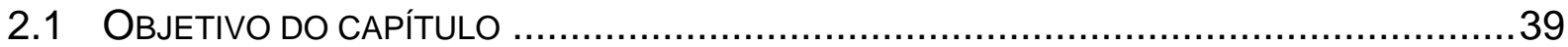

2.2 FUNDAMENTOS CONCEITUAIS DE ARQUITETURA DE SOFTWARE ..............................39

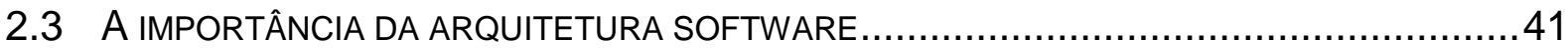

2.4 ISO/IEC 10746 (REFERENCE MOdEL - OPEN DISTRIBUTED PROCESSING) ..............43

2.4.1 Ponto de vista da Empresa (Enterprise viewpoint) .........................................44

2.4.2 Ponto de vista da Informação (Information viewpoint)...................................45

2.4.3 Ponto de vista da Computação (Computational viewpoint) .............................45

2.4.4 Ponto de vista da Engenharia (Engineering viewpoint) ...............................46

2.4.5 Ponto de vista da Tecnologia (Technology viewpoint) ...................................46

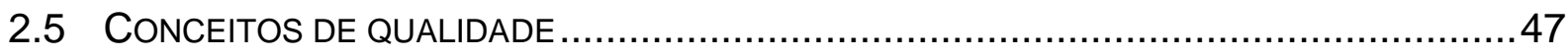

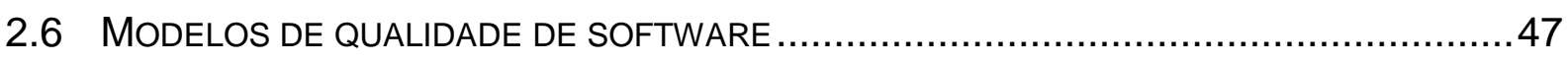

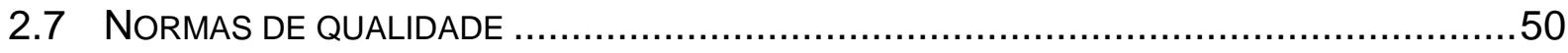

2.7.1 Qualidade do produto de software - ISO/IEC 9126 .....................................51

2.7.2 Avaliação do produto de software - ISO/IEC 14598-5 .................................60

2.8 ARQUITETURA DE SOFTWARE E REQUISITOS NÃO FUNCIONAIS...............................63

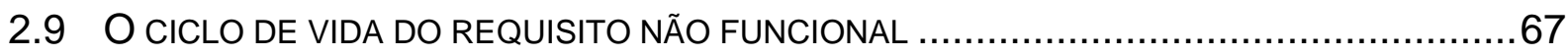

2.10 MÉTOdOS DE AVALIAÇÃO DE ARQUITETURA DE SOFTWARE .................................69

2.11 ARCHITECTURE TRADE-OFF ANAL YSIS METHOD (ATAM) ..................................73

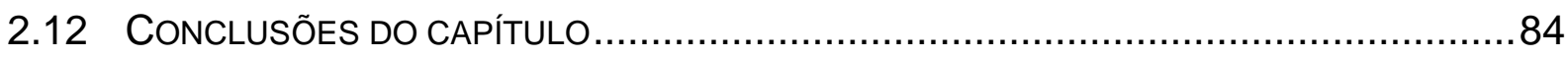




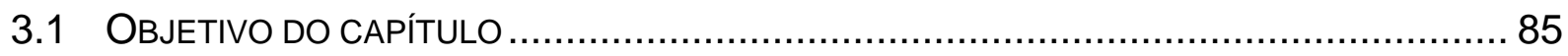

3.2 TEORIAS DE APRENDIZAGEM UTILIZADAS NO ROTEIRO DE ENSINO …...................... 85

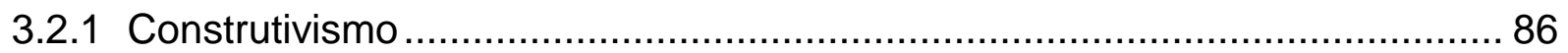

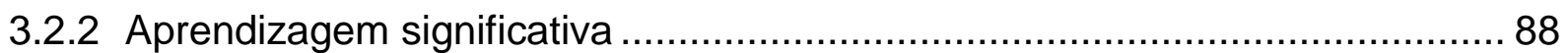

3.2.3 Aprendizagem baseada em problemas ……........................................ 91

3.3 IMPORTÂNCIA DO APRENDIZADO DE QUALIDADE DE ARQUITETURA DE SOFTWARE ...... 94

3.3.1 Currículo de Engenharia de Computação ................................................ 94

3.3.2 Currículo de Ciência da Computação …………....................................... 97

3.4 REQUISITOS PARA O ENSINO DE QUALIDADE DE ARQUITETURA DE SOFTWARE

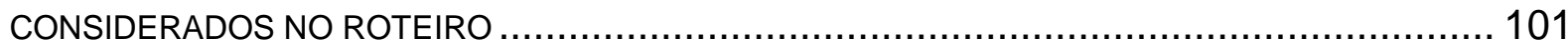

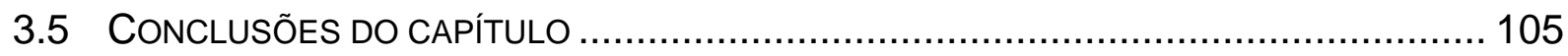

4. PROPOSTA DE UM ROTEIRO PARA O ENSINO DE QUALIDADE DE ARQUITETURA DE SOFTWARE GUIADO POR REQUISITOS NÃO FUNCIONAIS.

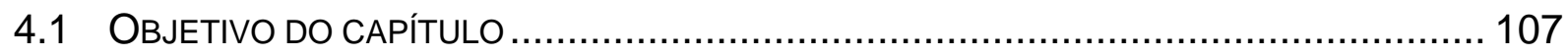

4.2 PROCESSO DE CRIAÇÃO dO ROTEIRO DE ENSINO DE QUALIDADE DE ARQUITETURA DE

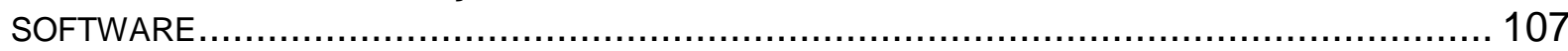

4.3 CONTRIBUIÇÃO DAS REFERÊNCIAS TEÓRICAS NA ELABORAÇÃO DO ROTEIRO DE ENSINO

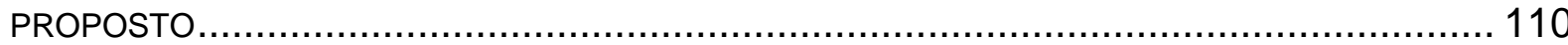

4.4 PROPOSTA DE UM ROTEIRO DE ENSINO DE QUALIDADE DE ARQUITETURA DE SOFTWARE

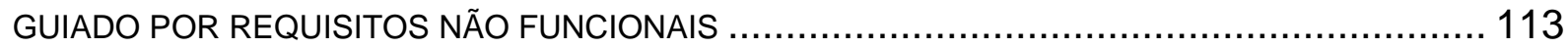

4.4.1 Princípios técnicos e pedagógicos considerados na elaboração do roteiro proposto .............................................................................................. 114

4.4.2 Etapas do roteiro de ensino para o ensino de qualidade de arquitetura de software guiado por requisitos não funcionais ................................................ 129

4.5 ADAPTAÇÃO DO ROTEIRO DE ENSINO DE QUALIDADE DE ARQUITETURA DE SOFTWARE GUIADO POR REQUISITOS NÃO FUNCIONAIS PARA SISTEMAS NOVOS ............................ 137

4.6 CONCLUSÕES DO CAPÍTULO .............................................................. 140

5. APLICAÇÃO DO ROTEIRO PROPOSTO PARA O ENSINO DE QUALIDADE DE ARQUITETURA DE SOFTWARE ...............................................................141

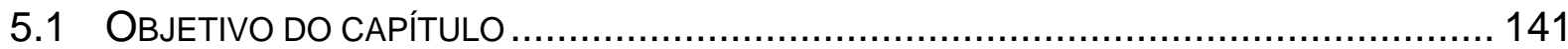

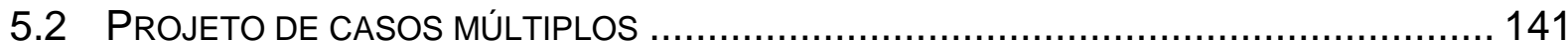

5.3 ESTRUTURA GERAL DAS APLICAÇÕES DO ROTEIRO DE ENSINO PROPOSTO ............... 142

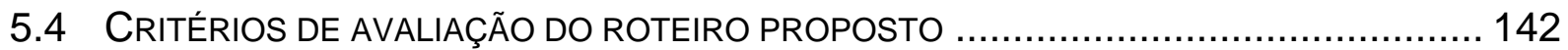

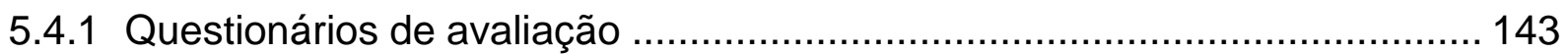

5.4.2 Avaliação dos artefatos produzidos pelos alunos .................................... 147 
5.4.3 Comentários dos alunos sobre o roteiro de ensino proposto

5.5 APLICAÇÃO DO ROTEIRO DE ENSINO DE QUALIDADE DE ARQUITETURA DE SOFTWARE 149

5.5.1 Mapeamento entre princípios do roteiro de ensino e disciplinas do curso de graduação em Engenharia de Computação 150

5.5.2 Aplicação 1 - Disciplina de Laboratório de Engenharia de Software em curso de graduação em Engenharia Elétrica com ênfase em Computação utilizando um sistema existente 154

5.5.3 Aplicação 2 - Disciplina de Laboratório de Engenharia de Software em curso de graduação em Engenharia Elétrica com ênfase em Computação considerando o desenvolvimento de um sistema novo

5.5.4 Mapeamento entre princípios do roteiro de ensino e disciplinas do curso de pósgraduação em Engenharia de Computação

5.5.5 Aplicação 3 - Disciplina de Arquitetura de Software em curso de pós-graduação em Engenharia de Computação utilizando um sistema existente

5.6 ANÁLISE COMPARATIVA DAS APLICAÇÕES DO ROTEIRO DE ENSINO.........................211

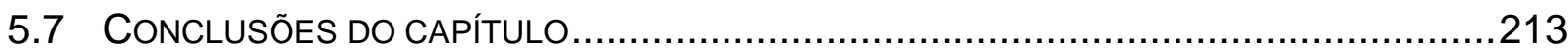

6. CONCLUSÕES

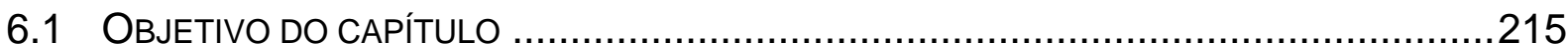

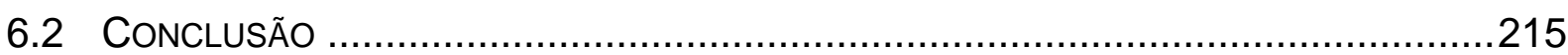

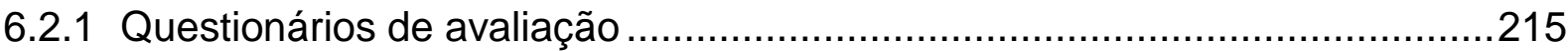

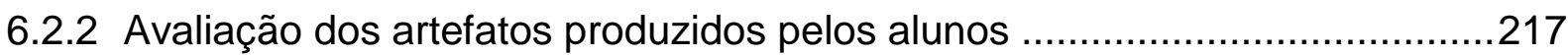

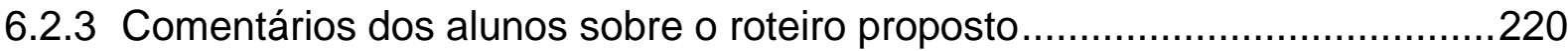

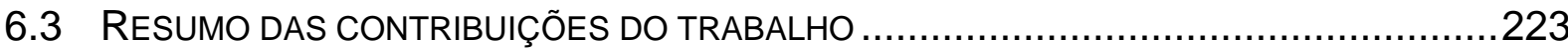

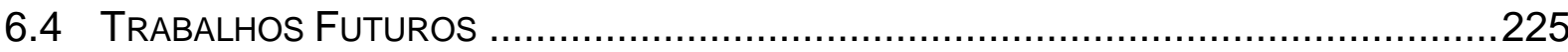

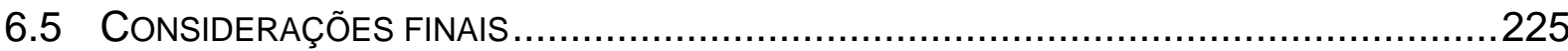

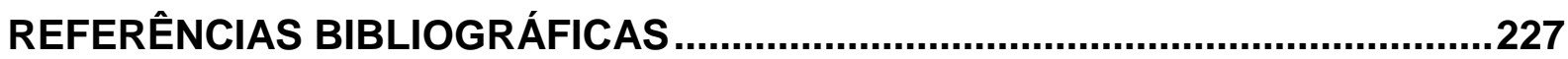

APÊNDICE A - QUESTIONÁRIO UTILIZADO NO ROTEIRO DE ENSINO ...........243

APÊNDICE B - RESULTADO DAS AVALIAÇÕES POR TURMA ….....................245

APÊNDICE C - TÓPICOS DAS DISCIPLINAS .................................................247

APÊNDICE D - TECNOLOGIAS E FERRMAENTAS UTILIZADAS .......................261

APÊNDICE E - TRABALHO DOS ALUNOS …...............................................265

APÊNDICE F - COMENTÁRIOS DOS ALUNOS ...........................................267 
APÊNDICE G - DIFERENÇAS ENTRE ISO/IEC 9126-1 E ISO/IEC 25010 


\section{INTRODUÇÃO}

\subsection{OBjetivo do capítulo}

O objetivo do capítulo é apresentar os objetivos da pesquisa e as justificativas que motivaram o desenvolvimento deste trabalho. A metodologia utilizada, a estruturação do trabalho e as iniciativas mundiais e no Brasil correlatas com esta pesquisa também são apresentadas.

\subsection{OBjetivo da tese}

O objetivo principal desta tese é propor um método experimental (roteiro) para o ensino de qualidade de arquitetura de software guiada por atributos de qualidade, principalmente requisitos não funcionais, utilizando uma abordagem prática, iterativa e dirigida pelo processo de negócio. Tal roteiro tem por finalidade auxiliar no processo de aprendizagem da importância dos atributos de qualidade de arquitetura de software e medição desses atributos durante todo o ciclo de vida de um sistema. Como objetivo secundário, espera-se que, com a aplicação desse roteiro, os alunos das disciplinas da área de Engenharia de Software sejam capazes de verificar se o nível de qualidade atingido pela arquitetura de software implementada atende aos requisitos do processo de negócio.

Na elaboração do roteiro são consideradas duas dimensões: a de engenharia, relacionada aos conceitos de arquitetura de software, atributos de qualidade e medição desses atributos, e a de pedagogia, que versa sobre os processos de ensino/aprendizagem, principalmente nas disciplinas de engenharia. Essas duas dimensões definem os campos de pesquisa para a elaboração do roteiro de ensino de qualidade de arquitetura de software guiado por requisitos não funcionais.

\subsection{MOTIVAÇÃO}

Qualidade é vista como um fator crítico de sucesso de negócio e satisfação do cliente. A falta de qualidade de um sistema de software pode resultar em perdas 
financeiras, usuários insatisfeitos, danos para o ambiente e até mesmo em mortes (JONES; BONSIGNOUR, 2011).

Os sistemas de software estão entre os produtos mais amplamente utilizados pela humanidade e possuem as mais altas taxas de falhas na história, principalmente devido à baixa qualidade (JONES; BONSIGNOUR, 2011). Os anais literários de computação e engenharia são ricos de exemplos relacionados à baixa qualidade dos sistemas de software. Alguns exemplos podem ser citados, como: Therac-25, um sistema para exames de radiologia controlados por computador, deixou sete pessoas seriamente feridas e sete pessoas mortas devido ao excesso de radiação (LAPORTE; APRIL, 2007); a falta da implementação de uma exceção em um comando condicional "se... então" sem a cláusula "senão" resultou na queda de um avião de combate F-18; erros de software causaram a reversão do resultado de uma eleição no estado de Oregon (NEUMANN, 1995); mais de 100.000 pessoas foram afetadas em 1978 deixando de receber o valor de 234 bilhões de dólares americanos por uma falha no sistema de Segurança Social dos Estados Unidos, que não aceitava nomes com caracteres não anglo-saxônicos, e também mulheres que alteraram seus nomes após o casamento foram impactadas pela falha do software (LUCERO, 1997). Todos esses exemplos estão relacionados à qualidade de software.

Atributos de qualidade de sistemas são primariamente determinados pela arquitetura de software do sistema. Isso significa que em sistemas de software, a obtenção dos atributos de qualidade como desempenho, disponibilidade e modificabilidade depende muito mais da arquitetura geral do sistema do que práticas do nível de codificação, como escolha da linguagem de programação, algoritmos e estruturas de dados. Isso não quer dizer que a escolha de algoritmos ou estruturas computacionais não sejam importantes, mas tais escolhas são menos cruciais para o sistema do que a escolha da arquitetura (CHUNG; NIXON; YU, 1995).

Requisitos não funcionais são cruciais para o sucesso de um sistema de software. Esses atributos de qualidade devem ser considerados o mais cedo possível no ciclo de desenvolvimento de software e propriamente considerados na arquitetura de software do sistema, antes do início do projeto detalhado (DIAZ-PACE; CAMPO, 2008). Além disso, é fundamental que esses atributos sejam passíveis de medição, 
pois esse é um modo bastante efetivo de se melhorar a qualidade do software (BHATTI, 2005).

As duas principais fontes de referência para a qualidade de um sistema de software são as necessidades de negócio definidas pelos participantes ${ }^{1}$, seus interesses ${ }^{2}$ e o domínio da aplicação. $O$ arquiteto de software precisa entender essas fontes de referência e suas influências no sistema para projetar uma arquitetura que suporte os requisitos de qualidade desejados. Entretanto, dependendo do tipo de software e seu contexto, diferentes tipos de sistemas possuem atributos de qualidade relevantes distintos. Em um sistema de software complexo, a manutenibilidade pode ser um dos mais importantes atributos de qualidade, enquanto que, em um sistema de tempo real, o atributo de desempenho pode influenciar a maioria das decisões arquiteturais.

É desejável que o sistema tenha seus atributos de qualidade satisfeitos direcionados pelo processo de negócio, embora, na maioria das vezes tais atributos sejam contraditórios (segurança $\mathrm{x}$ usabilidade, desempenho $\mathrm{x}$ manutenibilidade). Arquitetos de software devem ser capazes analisar os trade-offs ${ }^{3}$ entre múltiplos atributos conflitantes para atender da melhor forma às necessidades de negócio.

Dessa forma, a qualidade da arquitetura é um ponto crítico para o desenvolvimento de um sistema que atenda aos seus objetivos de uma forma confiável e previsível (ANJOS; ZENHA-RELA, 2011).

Essas questões arquiteturais afetaram profundamente o perfil do engenheiro de software, impondo novos desafios à educação, pois, devido à importância dos sistemas de software na sociedade, a demanda por engenheiros de software bem preparados tem aumentado nos últimos anos (BAGERT et al., 1999).

Segundo notícia publicada no site Veja Educação, em razão da informatização, as organizações estão cada vez mais dependentes de desenvolvedores de software,

\footnotetext{
${ }^{1}$ Nesta tese, o termo participante refere-se ao termo stakeholder definido no padrão ISO/IEC/IEEE 42010, Systems and software engineering - Architecture description (ISO/IEC/IEEE, 2011).

${ }^{2}$ Nesta tese, o termo interesse refere-se ao termo concern definido no padrão ISO/IEC/IEEE 42010, Systems and software engineering - Architecture description (ISO/IEC/IEEE, 2011).

${ }^{3}$ Por ser um termo já disseminado na área de Engenharia de Software, nesta tese será mantido o termo em inglês trade-off para definir o equilíbrio de um conjunto de fatores que não são totalmente atingíveis simultaneamente (MERRIAM-WEBSTER, 2003).
} 
analistas de segurança de redes e sistemas de informação. Uma pesquisa feita pela Associação Brasileira das Empresas de Tecnologia da Informação e Comunicação constatou que, só no estado de São Paulo, em 2014, seria necessário o triplo dos profissionais de Tecnologia de Informação e Comunicação (TIC) para atender a demanda. Esse resultado foi obtido a partir de uma estimativa do cruzamento de dados dos Ministérios do Trabalho e da Educação em sete estados brasileiros (Bahia, Minas Gerais, Paraná, Pernambuco, Rio de Janeiro, Rio Grande do Sul e São Paulo) e no Distrito Federal. Ainda na mesma reportagem, José Pastore, professor da Faculdade de Economia e Administração USP, declara (MAGGI, 2013):

A atividade dos profissionais de TIC passou a integrar as demais áreas da economia. Contudo, o Brasil ainda está atrasado na formação desses profissionais, o que gera escassez de talentos. É preciso melhorar a formação deles já que a perspectiva é que o mercado continue muito 'comprador'.

Segundo Shaw (2000), o conceito de qualidade de arquitetura de software costuma ser apresentado ao aluno de graduação / pós-graduação de forma muito superficial, fazendo com que ele somente aprenda que os atributos de qualidade de arquitetura são fatores crucias para o sucesso de um projeto da pior forma possível, ou seja, após muitos projetos fracassados em sua vida profissional, colocando em risco toda sua trajetória de carreira.

Um dos desafios à educação em cursos de Engenharia de Computação e Ciência de Computação nas disciplinas de Engenharia de Software ${ }^{4}$ é preparar os

\footnotetext{
${ }^{4}$ Segundo o relatório Computing Curricula 2005 - the overview report (SHACKELFORD et al., 2006), a Engenharia de Software emergiu de uma área da Ciência da Computação. Conforme o uso de sistemas computacionais foi ampliando-se para um escopo cada vez maior de problemas complexos, a criação de sistemas se tornou mais difícil e com a implementação de programas cada vez maiores e mais complexos, não é possível para somente uma pessoa entender o sistema computacional todos e suas partes que podem interagir entre si de forma não planejada.

Com o passar dos anos, constatou-se que a elaboração de software de boa qualidade é muito difícil, muito cara e muito necessária, o que levou à criação da Engenharia de Software, um termo cunhado em uma conferência da Organização do Tratado do Atlântico Norte (OTAN) ocorrida na Alemanha em 1968. Enquanto a Ciência da Computação, como as demais ciências, tem como objetivo a criação de novos conhecimentos, a Engenharia de Software tem o seu foco direcionado para a definição de métodos para projetar e construir sistemas da forma que operem da forma esperada pelos seus usuários.

$\mathrm{Na}$ visão de um currículo do Curso de Engenharia de Computação proposta pelo IEEE/ACM, a Engenharia de Software é a disciplina que trata da aplicação de teorias, conhecimento e práticas para construir de forma eficiente e eficaz, sistemas de software que satisfaçam os requisitos dos usuários. A Engenharia de Software é aplicável a sistemas pequenos, médios e grandes e abrange todas as fases do ciclo de vida da construção de um sistema de software (ACM/IEEE-CS JOINT TASK FORCE ON COMPUTING CURRICULA, 2004).

De acordo com as recomendações curriculares para os cursos de Engenharia de Computação e Ciência de Computação sugeridas pela ACM/IEEEE (ACM/IEEE-CS JOINT TASK FORCE ON COMPUTING CURRICULA, 2004, 2013), em ambos os cursos, os conceitos relacionados à Arquitetura de Software fazem parte da área de conhecimento de Engenharia de Software. No contexto deste trabalho, a Engenharia de Software refere-se às disciplinas desta área de conhecimento, as quais incluem os tópicos relacionados à arquitetura de software.
} 
estudantes com uma forte base de Arquitetura de Software em seus currículos, capacitando-os para desenvolver, medir os atributos de qualidade e distribuir aplicações cada vez mais complexas de uma forma eficiente (SHAW, 2000). Por esta razão, os conceitos de arquitetura de software estão se tornando cada vez mais importantes, dada sua influência significativa na qualidade do software produzido e no processo de desenvolvimento.

O roteiro proposto neste trabalho foi elaborado a partir das referências teóricas apresentadas nos Capítulos 2 e 3 e da aplicação prática do roteiro em sala de aula em disciplinas da área de Engenharia de Software desde 2005. Durante as aulas iniciais dos cursos nos quais o roteiro foi aplicado, o professor e os monitores das disciplinas constataram que os alunos desconheciam os conceitos de qualidade e sua importância no processo de desenvolvimento de software. Muitas vezes, talvez por falta de maturidade ou experiência prática em projetos reais, os alunos afirmavam que técnicas de engenharia de software para obtenção e gerência da qualidade apenas burocratizam o processo de desenvolvimento. Além disso, o conceito de arquitetura de software era entendido pela maioria dos alunos como sendo apenas diagramas ilustrando a distribuição de componentes lógicos ou físicos, com pouca ou nenhuma relação com o processo de negócio. Da mesma forma, a relação de trade-offs entre atributos de qualidade era desconhecida pelos alunos. A ausência desses conhecimentos sobre qualidade de arquitetura e seus impactos na qualidade resultante do sistema pode potencialmente prejudicar sua formação e, consequentemente, sua trajetória profissional. É importante frisar que, mesmo na aplicação do roteiro proposto para alunos de pós-graduação, as mesmas deficiências em relação à percepção sobre qualidade de arquitetura também foram notadas pelos professores e monitores.

Espera-se que um aluno submetido ao roteiro proposto neste trabalho assimile a importância da qualidade de arquitetura, da extração dos atributos de qualidade do processo de negócio, da medição dos atributos e trade-offs entre eles, e possa aplicar esses conhecimentos em sua trajetória profissional.

A motivação para a realização deste trabalho é a contribuição, por meio de uma abordagem prática, na educação em arquitetura de software, focando nos aspectos 
de qualidade, o que pode potencialmente elevar o nível de aprendizado dos estudantes e, consequentemente, formar melhores profissionais.

\subsection{JUSTIFICATIVA}

A demanda crescente de software de alta qualidade cada vez mais complexos faz com que os requisitos não funcionais sejam corretamente elicitados, especificados e mensurados na arquitetura de software de um sistema (CAPILLA; ALI BABAR; PASTOR, 2012). Porém, profissionais de Engenharia de Software muitas vezes não conseguem produzir sistemas computacionais com os benefícios trazidos pela definição de uma arquitetura de software. O desconhecimento de conceitos arquiteturais pode estar diretamente atrelado a modelos educacionais que não os enfatizaram fortemente (HILBURN; HUMPHREY, 2002).

Embora arquitetura de software e sua influência sobre os requisitos não funcionais já seja amplamente reconhecida como importante para a qualidade do sistema, em muitos casos os currículos das disciplinas da área de Engenharia de Software não mapeiam corretamente os desafios que os estudantes encontrarão em suas vidas profissionais. Tipicamente, a primeira experiência de um estudante em um sistema de software complexo acontece apenas quando o mesmo já se encontra no mercado de trabalho (BLAKE, 2003).

Segundo Shaw (2000), a maioria dos currículos existentes aborda fortemente algoritmos e estruturas de dados, tópicos extremamente importantes, mas que sem uma abordagem arquitetural, não possibilitam o nível de abstração adequado para a construção de sistemas complexos com qualidade.

Durante a graduação, os estudantes de Engenharia de Computação e Ciência da Computação são expostos a poucos exemplos arquiteturais, geralmente em disciplinas como Sistemas Operacionais e Compiladores, em que a arquitetura costuma ser apresentada de forma extremamente teórica, o que prejudica o aprendizado e impossibilita a percepção da importância de uma arquitetura, pois geralmente os graduandos não conseguem perceber uma abstração relativamente elevada a partir de um ponto de vista puramente teórico. Essa abordagem faz com que o aprendizado dos alunos se torne centrado em código-fonte (SHAW, 2000). 
Estudantes geralmente possuem uma sólida base em programação, porém raramente conhecem conceitos arquiteturais e suas influências na qualidade, métricas de software, produtividade, custo e manutenção do software (ROSCA; TEPFENHART; MCDONALD, 2003).

Com um aprendizado centrado em código, os estudantes tendem a criar um modelo mental simplista da natureza do software, no qual o maior nível de abstração aprendido se resume somente a código fonte, e um problema é resolvido com um programa.

Um modelo mental é a representação da organização do conhecimento na mente humana. Mesmo sem uma orientação de como um modelo mental deve ser criado, o aluno o cria automaticamente para lidar com os conhecimentos aprendidos (GRUNDY; HOSKING; MUGRIDGE, 1998). Um estudante comum está acostumado a codificar pequenos programas sem uma orientação arquitetural, o que contribui para a construção de um modelo mental simplista (BUCCI; LONG; WEIDE, 1998).

Estudantes com esse modelo mental tendem a iniciar a codificação imediatamente após receber a especificação do problema a ser resolvido, resultando em uma séria lacuna na formação acadêmica: há uma expectativa que recémformados saibam construir sistemas complexos, porém os mesmos não dispõem dos pré-requisitos conceituais para fazê-lo de forma efetiva (BLAKE, 2003).

Esse problema também ocorre nas empresas, nas quais muitos profissionais, mesmo após anos de experiência, ainda não compreenderam adequadamente o valor da arquitetura de software, dos atributos de qualidade, trade-offs e medições, notadamente os requisitos não funcionais e, dessa forma, acabam por desenvolver sistemas de baixa qualidade.

A necessidade de formação de engenheiros de computação com conhecimentos de arquitetura de software, de suas influências nos atributos de qualidade e como medi-los de forma efetiva estabelecem as justificativas necessárias para a realização desta tese. Elevando-se o patamar de ensino de qualidade de arquitetura de software, poder-se-á contribuir para a formação de melhores 
profissionais de computação, o que repercutirá positivamente nos sistemas elaborados e, consequentemente, nos usuários desses sistemas.

\subsection{ESCOPO DO TRABALHO}

O roteiro de ensino proposto neste trabalho abrange o ensino de qualidade de arquitetura de software guiado por requisitos não funcionais para alunos de graduação e pós-graduação em Engenharia de Computação, por meio do estudo e implementação de estilos e táticas arquiteturais, considerando também a medição dos atributos de qualidades de uma arquitetura definidos pelas necessidades do processo de negócio.

No contexto deste trabalho, um roteiro é método experimental composto por um conjunto de etapas, suportadas por princípios de engenharia e pedagogia, que tem como objetivo auxiliar no processo de aprendizagem de conceitos de qualidade de arquitetura de software, principalmente os requisitos não funcionais.

Outros pontos pertinentes à área de Arquitetura de Software, como o processo de definição de uma arquitetura, formalização da descrição arquitetural utilizando-se Architecture Description Languages (ADL) e documentação da arquitetura não constituem o escopo deste trabalho.

\subsection{MÉTOdO DE TRABALHO UTILIZADO}

Para atingir o objetivo desta pesquisa, o seguinte método de trabalho foi executado:

1. Pesquisa Bibliográfica;

2. Proposição do roteiro para o ensino de qualidade de arquitetura de software guiado por requisitos não funcionais;

3. Aplicação do roteiro proposto em cenários de ensino de graduação e pós-graduação;

4. Avaliação do roteiro proposto.

A fase de pesquisa bibliográfica corresponde ao estudo das referências basilares na área de ensino de Engenharia de Computação, qualidade de software, 
medição de atributos de qualidade de software e teorias pedagógicas aplicadas ao ensino de engenharia.

A proposição do roteiro para 0 ensino de qualidade arquitetura de software guiado por requisitos não funcionais compreende a elaboração das etapas do roteiro propriamente dito, considerando os aspectos de engenharia e pedagogia estudados.

$\mathrm{Na}$ terceira fase, detalham-se as aplicações do roteiro em cenários de ensino de graduação e pós-graduação em Engenharia de Computação;

Na quarta e última fase, faz-se a avaliação do roteiro proposto e análise dos resultados coletados durante a terceira fase.

\subsection{INICIATIVAS MUNDIAIS E NO BRASIL SOBRE ENSINO DE QUALIDADE DE ARQUITETURA DE SOFTWARE}

Conforme Shaw (2000), percebe-se que há uma pressão da sociedade para que o desenvolvimento de software, como atividade de engenharia, se profissionalize, com o aumento do nível de qualidade da formação de engenheiros de computação e, consequentemente, dos sistemas computacionais. Algumas iniciativas acadêmicas enfatizam o ensino de arquitetura de software como fator de extrema importância na formação dos alunos.

Uma dessas iniciativas, denominada MAISA (Metrics for Analysis and Improvement of Software Architectures), é um projeto de pesquisa do Departamento de Ciência da Computação da Universidade de Helsinki, que desenvolve métodos e ferramentas para analisar automaticamente a qualidade da arquitetura de software (VERKAMO, 2004).

A Universidade VRIJE, na Holanda, através de seu Departamento de Ciências da Computação, já tem introduzido em seus cursos de computação o conceito de 
trade-offs entre atributos de qualidade de uma arquitetura de software usando técnicas de what-if analysis ${ }^{5}$ (LAGO; VLIET, 2005).

O uso de técnicas de auditoria de qualidade baseadas na Garantia da Qualidade de Processo e Produto do CMMI (CMMI PPQA - Capability Maturity Model Integration Process and Product Quality Assurance) costuma ser utilizada nas disciplinas relacionadas aos projeto de software (PÁDUA, 2009).

O Departamento de Engenharia de Software e Ciência da Computação da Universidade de Karlskrona na Suécia possui um grupo que desenvolve pesquisas com o objetivo de definir uma técnica para descrever arquiteturas considerando-se os requisitos de qualidade (WOHLIN, 2010).

A Faculdade de Ciências da Universidade de Leiden, na Holanda, vem desenvolvendo um framework chamado AQOSA (Automated Quality-driven Optimization of Software Architecture), que integra técnicas de modelagem, métodos de análise de atributos de qualidade e algoritmos de otimização para a melhoria dos requisitos não funcionais de uma arquitetura de software de forma automatizada (CHAUDRON, 2011).

Em seus cursos de engenharia, a Universidade de Brasília (UnB) vem adotando diversas normas relacionadas à qualidade de software, entre elas: a ISO/IEC 9126-1 Software engineering - Product quality, ISO/IEC 15504-1: Information Technology Process Assessment - Part 1 - Concepts and Vocabulary, a ISO/IEC 12207 Systems and software engineering - Software life cycle processes e a NBR ISO 9000:2000 Sistemas de gestão da qualidade e garantia da qualidade - Fundamentos e Vocabulário, como o objetivo de preparar profissionais que saibam construir software de qualidade baseado nas normas citadas (FIGUEIREDO et al., 2010).

O Laboratório de Engenharia de Software, pertencente à Universidade Federal do Pará (UFPA), implementou um programa de Residência em Arquitetura de Software, no qual alunos participantes atuaram nas universidades e empresas conveniadas ao programa com o objetivo formar profissionais/especialistas com forte

\footnotetext{
5 What-if analysis pode ser descrita como uma técnica que utiliza intensa simulação de dados com o objetivo de verificar o comportamento de um sistema complexo sob determinado conjunto de hipóteses (Golfarelli, Rizzi, Proli, 2006).
} 
embasamento teórico e experiência prática como residentes na área de Arquitetura de Software, promovendo maior integração entre as empresas e academia. Nos cursos realizados entre 2008 e 2010, as seguintes entidades participaram do programa: Centro Universitário do Estado do Pará (CESUPA), Centro de Tecnologia da Informação e Comunicação da UFPA (CTIC-UFPA), Universidade da Amazônia (UNAMA), Processamento de Dados do Estado do Pará (PRODEPA) e AmazonCorp (REIS et al., 2011). Esse programa recebeu o 1ํlugar no Prêmio Dorgival Brandão Júnior da Qualidade e Produtividade em Software, prêmio concedido pelo Ministério de Ciência e Tecnologia (MCT) - Ciclo 2010 (MOREIRA, 2012).

O Curso de Engenharia de Computação da Escola Politécnica da Universidade de São Paulo é uma habilitação em Engenharia oferecida dentro das grandes Áreas de Engenharia. No esquema Cooperativo, tem-se na Área Elétrica, a habilitação Engenharia de Computação. O curso é composto por 13 períodos sendo, os quatro primeiros, equivalentes aos dois primeiros anos do curso, ministrados em regime semestral. A partir do terceiro ano, passa a alternar cinco módulos acadêmicos e quatro módulos de estágio. Nos módulos de estágio, o aluno desenvolve atividades de estágio, em período integral, com dedicação exclusiva, em empresas e instituições conveniadas com a Escola Politécnica da Universidade de São Paulo. Nessa modalidade de curso é possível utilizar a metodologia de ensino cooperativa, que promove o aprendizado contínuo por meio de aulas e aprendizagem baseadas no trabalho, o que viabiliza a integração entre empresas e a instituição de ensino na formação de profissionais habilitados para enfrentar o dinamismo do mercado de trabalho, que exige rápida adequação do engenheiro e conhecimentos atualizados das inovações tecnológicas (ESCOLA POLITÉCNICA DA USP, 2014).

Há mais de 40 anos, a ACM (Association for Computing Machinery) e IEEE-CS (Institute of Electrical and Electronics Engineers - Computer Society) elaboram em conjunto um documento contendo recomendações curriculares para os cursos de Engenharia de Computação e Ciências da Computação (ACM/IEEE-CS JOINT TASK FORCE ON COMPUTING CURRICULA, 2004, 2013). Ambos os documentos descrevem a percepção da importância dos atributos de qualidade em arquiteturas de software. Segundo esse documento, os alunos dos cursos citados devem saber os seguintes conceitos, não somente limitados a: 
- Conceitos de qualidade de software;

- Propriedades dos requisitos de qualidade incluindo validação, completude e viabilidade;

- Requisitos não funcionais e suas relações com a qualidade de software;

- Conceitos de arquitetura de software;

- Atributos de qualidade internos e modelos para os mesmos: eficiência e desempenho, redundância e tolerância a falhas e rastreabilidade dos requisitos;

- Atributos de qualidade externos e modelos para os mesmos: funcionalidade, confiabilidade; eficiência e desempenho, usabilidade, manutenibilidade e portabilidade;

- Medições e análise da qualidade do sistema;

- Trade-offs entre diferentes aspectos de qualidade.

Considerando esses conceitos citados, um aluno egresso dos cursos de Engenharia de Computação e Ciências da Computação estaria apto a:

- Conduzir uma revisão de um conjunto de requisitos de software para determinar sua qualidade;

- Discutir e selecionar a arquitetura de software apropriada para um sistema, dado um cenário de uso;

- Discutir e selecionar o paradigma de projeto apropriado, para um determinado cenário de uso;

- Investigar o impacto da arquitetura de software selecionada no projeto e no sistema de software resultante;

- Criar modelos apropriados para a estrutura e comportamento do software, a partir da especificação de requisitos;

- Identificar o estilo de arquitetura do software utilizado, dado um projeto de alto nível, diferenciando estilos de arquitetura de software, como por exemplo layers, pipes-and-filter, client-server, blackboard, broker, model-view-controller, etc.

- Investigar o impacto da escolha da arquitetura de software no projeto e na qualidade de um sistema; 
- Aplicar modelos para qualidades internas e externas no projeto de software para atingir um trade-off aceitável entre os atributos de qualidade conflitantes;

- Analisar o projeto de software a partir da perspectiva de um atributo de qualidade interno;

- Analisar o projeto de software a partir da perspectiva de um atributo de qualidade externo.

Segundo (NORTHROP, 2006), é imprescindível que os estudantes de Engenharia de Computação saibam os princípios fundamentais de arquitetura de software e como utilizá-los de maneira efetiva, pois cada faceta da sociedade depende de software e, para aumentar a qualidade dos sistemas produzidos, é preciso ensinar aos estudantes como projetar a arquitetura do software de alta qualidade.

\subsection{NOTAÇÕES E CONVENÇÕES UTILIZADAS}

Os diagramas apresentados neste trabalho pesquisa foram elaborados utilizando a linguagem de modelagem UML (Unified Modeling Language) padronizada pela OMG (Object Management Group) (OBJECT MANAGEMENT GROUP, 2013).

\subsection{ORGANIZAÇÃO DO TRABALHO}

Este trabalho de pesquisa está organizado da seguinte maneira:

- No Capítulo 1 é apresentado o objetivosdeste trabalho, as principais motivações e justificativas que levaram ao desenvolvimento desta tese, bem como a metodologia utilizada na pesquisa. Também são apresentadas algumas iniciativas mundiais no ensino de qualidade de arquitetura e as notações utilizadas;

- O Capítulo 2 descreve os fundamentos conceituais sobre arquitetura de software, qualidade de software, normas de qualidade do produto de software, relacionamento entre atributos de qualidade e arquitetura de software e métodos de avaliação de qualidade software;

- O Capítulo 3 apresenta a base pedagógica da pesquisa dentro do contexto do ensino de qualidade de arquitetura de software; 
- No Capítulo 4, que constitui a proposta do autor do trabalho, é descrito o roteiro de ensino de qualidade de arquitetura de software guiado por requisitos não funcionais, baseando-se na fundamentação teórica tratada nos capítulos anteriores;

- São apresentadas, no Capítulo 5, as aplicações do roteiro de ensino, assim como os resultados coletados durante a aplicação do roteiro e análise desses resultados;

- No Capítulo 6 são feitas considerações finais sobre o trabalho, enumerando as principais conclusões desta pesquisa, pontos de melhoria e possíveis trabalhos futuros derivados;

- O Apêndice A reproduz o questionário utilizado na avaliação do nível de conhecimento dos alunos que participaram das disciplinas em que o roteiro de ensino proposto foi aplicado;

- Os resultados das avaliações do nível conhecimento dos alunos, coletados durante as aplicações do roteiro de ensino são apresentados no Apêndice B;

- O Apêndice $C$ descreve os tópicos das disciplinas dos cursos de Engenharia de Computação e Ciência de Computação que abordam conceitos relacionados à arquitetura de software e à qualidade de arquitetura de software. Neste apêndice, também são descritas as disciplinas utilizadas no mapeamento dos princípios técnicos do roteiro e as ementas das disciplinas nas quais o roteiro foi aplicado;

- As principais tecnologias de implementação, componentes e ferramentas utilizadas durante as aulas nas quais o roteiro de ensino foi aplicado são listadas no Apêndice $D$;

- No Apêndice E são apresentados alguns trechos dos trabalhos elaborados pelos alunos que foram submetidos à aplicação do roteiro de ensino proposto;

- O Apêndice F reproduz os comentários dos alunos sobre a experiência com o roteiro de ensino;

- Por fim, no Apêndice G são listadas as diferenças entre as normas International Organization for Standardization (ISO) e International Electrotechnical Commission (IEC) 9126-1 Software engineering - 
Product quality (ISO/IEC, 2001), utilizada neste trabalho, e sua nova versão ISO/IEC 25010 - Systems and software engineering - Systems and software Quality Requirements and Evaluation (SQuaRE) - System and software quality models (ISO/IEC, 2011).

\subsection{CONCLUSÕES DO CAPÍTULO}

Neste capítulo foram apresentados os objetivos da pesquisa, bem como suas principais motivações, justificativas, abrangência do trabalho e o método de trabalho utilizado. A estrutura do trabalho foi delineada e algumas iniciativas mundiais para 0 ensino de qualidade de arquitetura de software foram também elencadas. 


\section{CONCEITOS DE ARQUITETURA DE SOFTWARE, QUALIDADE DE SOFTWARE E AVALIAÇÃO DE ARQUITETURA DE SOFTWARE}

\subsection{OBJETIVO dO CAPÍTULO}

O objetivo deste capítulo é apresentar os conceitos sobre arquitetura de software, qualidade de software, modelos de referência para sistemas distribuídos, normas de qualidade do produto de software, relacionamento entre atributos de qualidade e arquitetura de software e métodos de avaliação da qualidade de arquitetura de software. Esse embasamento teórico será utilizado nos capítulos posteriores, sustentando a dimensão de engenharia do roteiro de ensino proposto.

\subsection{FUNDAMENTOS CONCEITUAIS DE ARQUITETURA DE SOFTWARE}

O termo arquitetura de software é largamente utilizado em vários contextos dentro da Engenharia de Software, o que reflete o crescimento de sua importância, porém a variedade de contextos nos quais é utilizado é um indício de que o conceito de arquitetura de software ainda não está muito bem definido (KRUCHTEN, 2003). Seguem algumas definições do termo arquitetura de software:

Para Perry e Wolf (1992), a arquitetura de software representa a organização de coleções de componentes interconectados que obedecem a determinadas restrições quanto à forma de interação.

Segundo Shaw e Garlan (1996), arquitetura de software pode ser definida como uma representação do sistema em termos de componentes computacionais e seus relacionamentos.

Para Hofmeister, Nord e Soni (2000), a arquitetura de software é a ponte entre os requisitos do sistema e sua implementação, servindo como um guia para todas as atividades do processo de desenvolvimento de software.

A arquitetura de software auxilia no gerenciamento da complexidade do software de acordo com Jazayeri, Ran e Linden (2000) e, segundo os mesmos 
autores, a satisfação dos requisitos funcionais e não funcionais de um sistema de software é o objetivo principal da definição da arquitetura de software.

Segundo Garlan (2000), a arquitetura de software desempenha um papel fundamental nos seguintes aspectos do processo de desenvolvimento:

- Análise: a definição da arquitetura de software facilita a tarefa de análise em um projeto, pois inclui verificação de consistência, conformidade com atributos de qualidade e análise de dependências;

- Entendimento comum: a arquitetura de software simplifica a compreensão de sistemas complexos, por meio de níveis de abstração;

- Reutilização: a arquitetura de software promove o reuso em diversos níveis - especificações, classes, componentes e frameworks;

- Construção: a arquitetura de software provê subsídios para o desenvolvimento, destacando os componentes arquiteturais, suas interfaces e dependências entre eles;

- Evolução e Manutenção: a definição da arquitetura permite identificar as ramificações e os impactos das mudanças, o que auxilia na manutenção corretiva e evolutiva;

- Gerenciamento: projetos de sucesso consideram a arquitetura de software como elemento chave no processo de desenvolvimento, pois possibilita o entendimento mais claro dos requisitos, das estratégias de implementação e de potenciais riscos.

A definição proposta por Putman (2001) considera que a arquitetura de software consiste de regras e conceitos bem definidos relacionados a todos os aspectos do sistema, desde requisitos funcionais, passando pelos não funcionais e comportamento semântico do sistema.

Segundo a definição proposta pelo Rational Unified Process (RUP) (KRUCHTEN, 2003), a arquitetura de software deve considerar os seguintes aspectos:

- A organização de um sistema de software; 
- A seleção dos elementos estruturais e suas interfaces, que compõem o sistema e definem a colaboração entre eles, estabelecendo o comportamento do sistema;

- O estilo arquitetural que orienta a organização dos elementos e suas interfaces, a colaboração entre eles e a forma de composição.

De acordo com Sommerville, (2011), uma arquitetura representa o framework fundamental para a estruturação de um sistema de software. Atributos de um sistema como desempenho, segurança e disponibilidade são influenciados pela arquitetura de software utilizada.

Segundo a norma ISO/IEC/IEEE 42010:2011 - Systems and software engineering - Architecture description, arquitetura de software abrange os conceitos fundamentais ou propriedades de um sistema incorporados em seus elementos, relacionamentos e princípios de projeto e evolução (ISO/IEC/IEEE, 2011).

Bass, Clements e Kazman (2012) definem a arquitetura de um sistema computacional como a "estrutura de estruturas", as quais englobam componentes, suas propriedades externas e seus relacionamentos, criando uma abstração do sistema que suprime detalhes de componentes que não afetam a forma como eles são usados.

\subsection{A IMPORTÂNCIA DA ARQUITETURA SOFTWARE}

A partir da década de 90, definição da arquitetura de software em um sistema computacional tem recebido muita atenção dentro da área de Engenharia de Software, devido à sua criticidade como um dos fatores de sucesso mais importantes nos projetos de sistemas computacionais (GARLAN, 2000).

A arquitetura de software é considerada um dos mais importantes artefatos do processo de desenvolvimento de software pelas seguintes razões (BASS; CLEMENTS; KAZMAN, 2012):

- Abstração comum do sistema: várias perspectivas devem ser consideradas para a construção de um sistema. Usuários, analistas, desenvolvedores, integradores, testadores e gerentes de projeto 
possuem uma visão diferente do processo de construção de software. A arquitetura de software representa uma abstração comum que unifica os vários pontos de vista;

- Decisões iniciais de projeto: a definição arquitetura de software de um sistema orienta uma série de decisões de projeto que devem ser tomadas nas primeiras fases do processo de desenvolvimento de software, sendo um ponto de referência comum para as demais atividades que serão executadas posteriormente a sua definição;

- Reutilização de software: a arquitetura de software define um modelo da estrutura do sistema de software e da colaboração entre os diversos componentes. Esse modelo pode ser aplicado em outros projetos cujos requisitos são similares, possibilitando a reutilização em larga escala;

- Gerenciamento da complexidade: a decomposição do sistema em partes menores, promovida pelos componentes que fazem parte da arquitetura de software, auxilia no gerenciamento da complexidade do software;

- Mitigação dos riscos: a reutilização de uma arquitetura de software previamente validada pode reduzir os riscos de um novo projeto no qual a mesma arquitetura será reutilizada;

- Sistemas evolutivos: uma arquitetura de software possibilita a inserção de novas funcionalidades no sistema sem alterações radicais, ou seja, são suficientemente flexíveis para incorporar as prováveis evoluções subsequentes do sistema.

A arquitetura de software também serve como um ponto de referência para as demais atividades que são executadas no projeto de software após sua definição, sendo a manifestação antecipada das decisões de projeto, pois influencia fatores como tempo de desenvolvimento, custo e manutenção, definição das restrições de implementação, enfatizando os atributos de qualidade que o sistema deve possuir para atender às necessidades de negócio (BASS; CLEMENTS; KAZMAN, 2012).

A arquitetura de software também pode ser utilizada como um instrumento de planejamento e gestão, auxiliando os gestores do sistema na tomada de decisões e minimizando riscos e incertezas de projetos de software (PAULISH; BASS, 2001). 


\subsection{ISO/IEC 10746 (REFERENCE ModeL - OPEN DISTRIBUtED PROCESSING)}

A implementação de arquitetura de software está diretamente relacionada ao uso de técnicas de abstração. A utilização de abstrações simplifica o problema, pois provê uma separação de interesses e responsabilidades que facilita 0 desenvolvimento de sistemas de software (MALVEAU; MOWBRAY, 2004).

O modelo de referência proposto pela norma ISO/IEC $10746^{6}$ é um padrão para a modelagem de arquiteturas distribuídas que por meio da separação de conceitos, simplifica a especificação de sistemas de processamento distribuídos heterogêneos (PUTNAM, 2001).

Um processamento distribuído é caracterizado por entidades de software e hardware que estão fisicamente separadas. Um sistema de processamento distribuído é composto de componentes de software separados que são interconectados com o propósito de compartilhar informação e processamento (AVELINO, 2005). O modelo de referência definido pelo Reference Model - Open Distributed Processing (RM-ODP) surgiu como resultado da união de dois organismos internacionais de padronização, a ISO/IEC e a ITU (International Telecommunication Union). O modelo RM-ODP apresenta um conjunto de conceitos padronizados que permite definir uma arquitetura de sistema que tenha de forma integrada recursos de suporte a distribuição, interrelacionamento, interoperabilidade e portabilidade para aplicações distribuídas.

Dada a amplitude de seus conceitos, o RM-ODP oferece um framework genérico para qualquer arquitetura, sendo aplicável a sistemas empresariais complexos, sistemas mais simples ou para produtos de software.

Segundo o modelo RM-ODP, um sistema distribuído pode ser descrito em cinco níveis de abstração, denominados ponto de vista (viewpoints). De acordo com Avelino (2005), o propósito para a utilização de pontos de vista provém do fato de que, em qualquer sistema de processamento de informação, existe um certo número de

\footnotetext{
${ }^{6}$ A norma ISO/IEC 10746 é composta pelas seguintes partes: ISO/IEC 10746-1:1998 - Information technology -- Open Distributed Processing -- Reference model: Overview (ISO/IEC, 1998b), ISO/IEC 10746-2:2009 - Information technology -- Open distributed processing -- Reference model (ISO/IEC, 2009a): Foundations, ISO/IEC 10746-3:2009 - Information technology -Open distributed processing -- Reference model: Architecture (ISO/IEC, 2009b) e ISO/IEC 10746-4:1998 - Information technology -- Open Distributed Processing -- Reference Model: Architectural semantics (ISO/IEC, 1998c).
} 
categorias de participantes, os quais tem diferentes interesses no sistema. Para tratar da diversidade de interesses, o modelo RM-ODP preconiza a utilização de cinco pontos de vista integrados, em que cada um reflete um conjunto de restrições, que poderão ser derivados em requisitos que o sistema deve atender, permitindo assim a modelagem através de cinco pontos de vista complementares. Na Figura 1, os cinco pontos de vista do RM-ODP e as relações entre eles são representados.

Figura 1 - Relacionamento entre os pontos de vista do RM-ODP

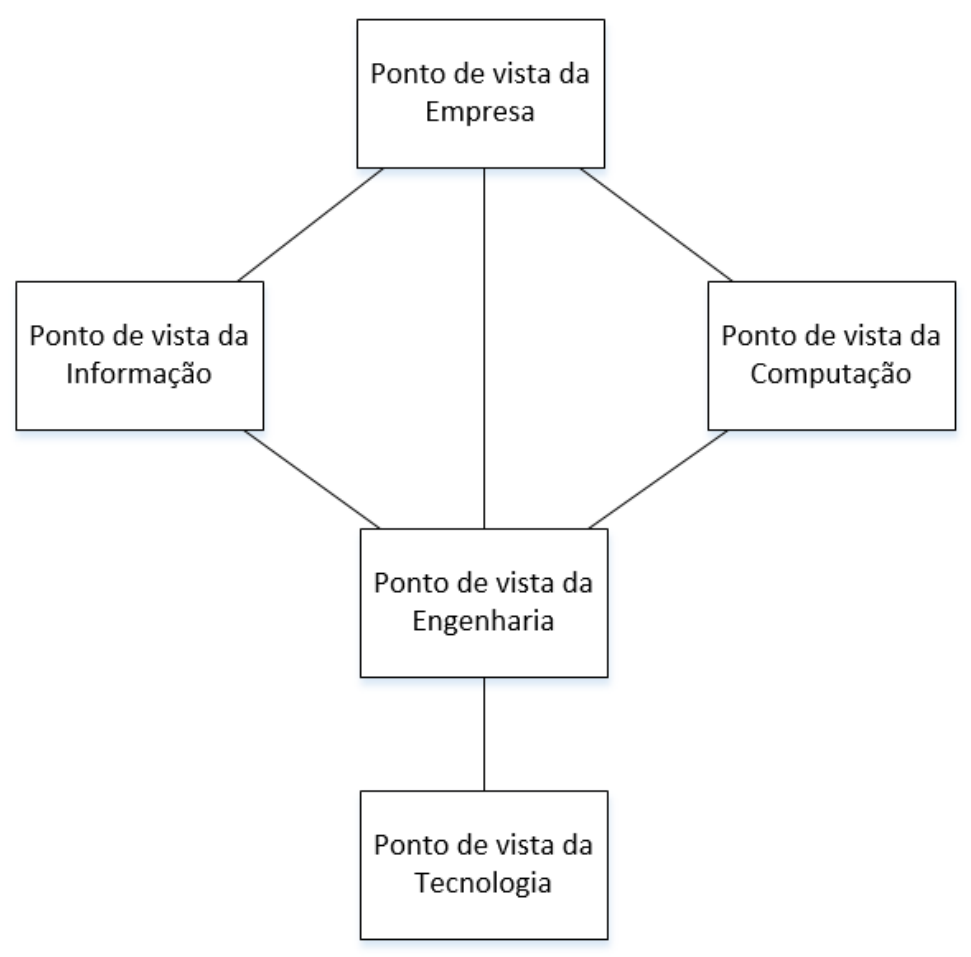

Fonte: adaptado de Raymond (1995)

Os cinco pontos de vista não devem analisados como camadas independentes e nenhum ponto de vista é mais importante que outro. Apesar de serem separados, todos os pontos de vista são inter-relacionados e consistentes, para que cada um deles represente um ou mais aspectos de um sistema. Segue uma descrição dos pontos de vista propostos pelo RM-ODP (PUTMAN, 2001).

\subsubsection{Ponto de vista da Empresa (Enterprise viewpoint)}

O ponto de vista da empresa descreve os objetivos da organização na qual o sistema será utilizado, com foco nos processos de negócio da organização que serão 
parcialmente ou totalmente automatizados pelo sistema. O ponto de vista da empresa representa o modelo de negócio sob a perspectiva dos participantes do negócio (business stakeholders), representando os objetivos internos e externos do negócio (BECERRA, 1998). Esse ponto de vista auxilia na definição de uma arquitetura que satisfaça as necessidades de negócio e também serve como base para a avaliação do software construído pelos participantes do negócio (PUTMAN, 2001).

\subsubsection{Ponto de vista da Informação (Information viewpoint)}

Esse ponto de vista descreve o conteúdo da informação do processo de negócio. É definida a semântica da informação e a semântica do processamento da informação no sistema (estruturas de dados, restrições, fluxo de dados), isto é, descrevem-se quais os tipos de informações que são manipulados, quais são as restrições ao acesso às informações e quais são as restrições das interfaces de comunicação (AVELINO, 2005).

O modelo de informação é representado por objetos abstratos que expressam os elementos de informação manipulados pelo sistema. A atividade de modelagem da informação consiste em identificar: as estruturas de informação do sistema, restrições e transformações que devem ocorrer nessas estruturas e o fluxo dessa informação. Essas informações devem ser completamente independentes da forma como serão implementadas, bem como não devem haver restrições relacionadas com a forma de como essas informações são representadas no sistema real, nem aos meios utilizados para manipulação dessas informações.

\subsubsection{Ponto de vista da Computação (Computational viewpoint)}

Representa o particionamento do sistema em módulos funcionais que executam as funções do sistema e podem ser implementados de forma distribuída. Reflete o particionamento lógico da aplicação distribuída, baseado nos tipos de serviços oferecidos pelas partes do sistema e no fluxo de informações entre suas interfaces. Nesse ponto de vista surge o importante conceito de componentes da aplicação, que possuem uma interface computacional, que define a forma de interação, o comportamento das interfaces e os contratos; uma especificação 
comportamental, que especifica os estados e serviços executados pelo componente; e requisitos externos, geralmente impostos por restrições da visão de empresa.

\subsubsection{Ponto de vista da Engenharia (Engineering viewpoint)}

A partir dos requisitos de negócio definidos no ponto de vista da Empresa, da estrutura e comportamento dos dados mapeados no ponto de vista da Informação, da organização dos componentes representados no ponto de vista da Computação, definem-se no ponto de vista da Engenharia as táticas para a implementação da arquitetura. A tática consiste em uma decisão de projeto em que dado um cenário de atributo de qualidade, a ocorrência de estímulos específicos é processada para que se obtenham respostas desejadas. Segundo Bass, Clements e Kazman (2012), para que as respostas desejadas sejam obtidas em relação aos requisitos não funcionais, é necessário o uso de táticas considerando padrões arquiteturais.

\subsubsection{Ponto de vista da Tecnologia (Technology viewpoint)}

Descreve a tecnologia selecionada para implementar as táticas definidas no ponto de vista da Engenharia. As táticas arquiteturais são implementadas através de mecanismos arquiteturais. Neste ponto de vista são escolhidos as tecnologias e produtos a serem utilizados na implementação, assim como o hardware necessário para o processo de implantação do sistema. Cabe ressaltar que, apesar da especificação dos outros pontos de vista do RM-ODP serem independente da tecnologia, as escolhas tecnológicas realizadas nesta etapa devem ser analisadas de modo estratégico, uma vez que, dependendo do tipo de aplicação (ou de restrições estratégicas do domínio), os demais pontos de vista do modelo RM-ODP podem ser influenciadas pelas decisões adotadas no ponto de vista da tecnologia (BECERRA, 1998).

No modelo RM-ODP, as decisões tomadas durante o projeto de desenvolvimento de software são guiadas pelo processo de negócio, conforme ilustrado na Figura 2. 
Figura 2 - Elementos arquiteturais do modelo RM-ODP orientados pelo processo de negócio

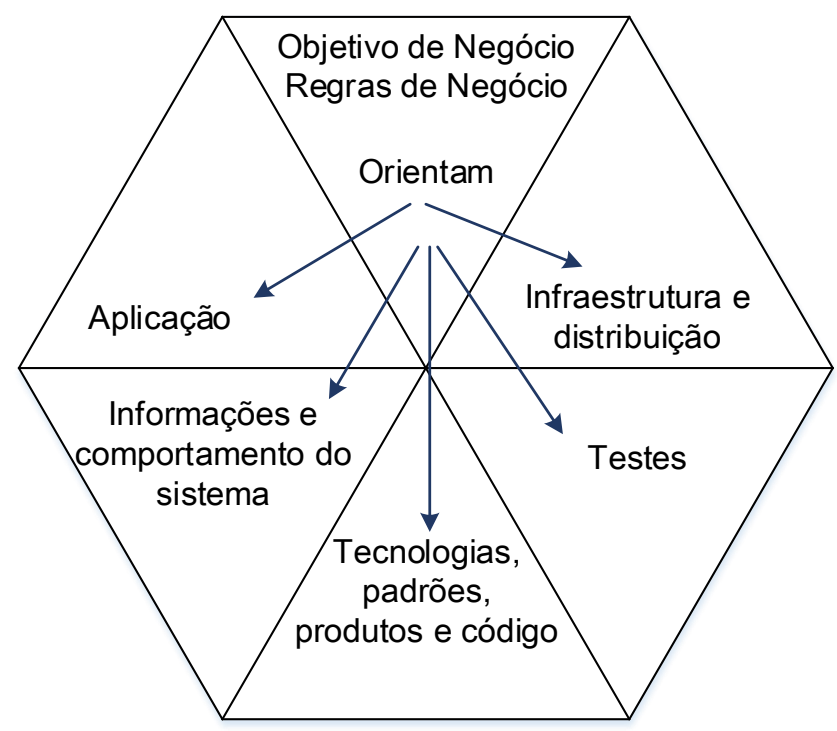

Fonte: adaptado de Putman (2001)

\subsection{CONCEITOS DE QUALIDADE}

De acordo com a norma ISO 9000 - Quality management systems Fundamentals and vocabulary - a qualidade pode ser definida como a totalidade das características de uma entidade que the confere a capacidade de satisfazer às necessidades explícitas e implícitas do cliente. A entidade constitui um produto que pode ser um bem ou serviço. As necessidades explícitas são as próprias condições e objetivos propostos pelo produtor. Já as necessidades implícitas incluem as diferenças de percepção entre os usuários, as implicações éticas, as questões de segurança e outras visões subjetivas (ISO, 2005).

\subsection{Modelos de QUALIDADE DE SOFTWARE}

Tratando-se de software, a visão mais estreita de qualidade refere-se à ausência de bugs no produto, mas para aumentar a satisfação do cliente com o produto de software, outros dimensões de qualidade devem ser levados em conta no planejamento e desenvolvimento de um sistema (KAN, 2002). 
Segundo a norma (IEEE, 1998a), a qualidade permeia todos os aspectos do desenvolvimento de software, desde a elicitação dos requisitos ${ }^{7}$, até o ciclo de operação do sistema em produção.

Modelos de qualidade auxiliam o arquiteto de software no planejamento da arquitetura, pois elencam os principais atributos de qualidade que um sistema de software deve exibir. Atributos de qualidade podem ser representados por meio de modelos de qualidade, que agregam características que relacionam vários atributos de qualidade, bem como identificam práticas de engenharia para endereçá-los e métricas apropriadas para medi-los ou observá-los.

Cada modelo usa uma terminologia diferente, porém compartilham conceitos semelhantes, como por exemplo, atributos de qualidade internos e externos. Um metamodelo de qualidade pode ser utilizado como base para se descrever vários modelos de qualidade, no qual cada modelo de qualidade, com suas características específicas, atributos de qualidade e métricas é uma instância do metamodelo. A Figura 3 ilustra, usando a linguagem UML, um metamodelo de qualidade (ALBIN, 2003).

\footnotetext{
${ }^{7}$ Elicitação de requisitos: processo de busca, descoberta, aquisição e elaboração dos requisitos para o desenvolvimento de sistemas de software (ZOWGHI; COULIN, 2005).
} 
Figura 3 - Metamodelo de qualidade

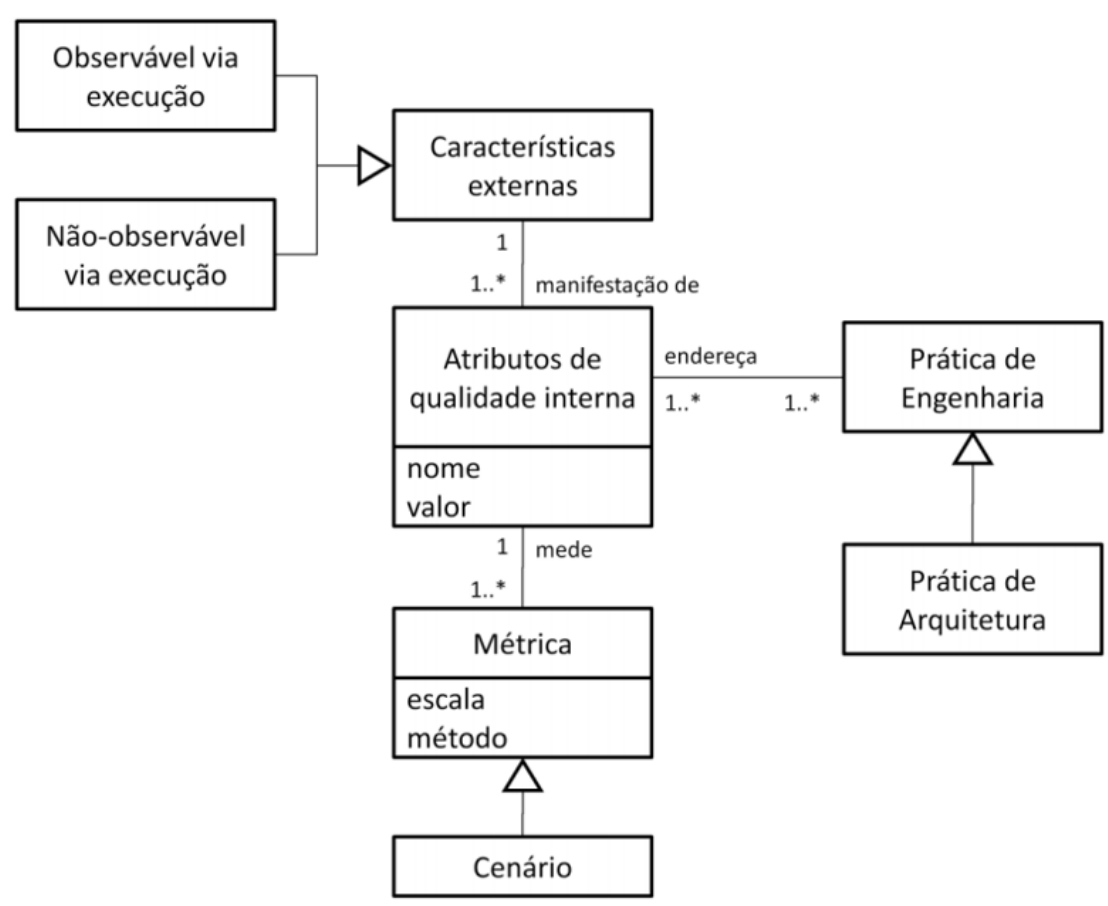

Fonte: adaptado de Albin (2003)

Nesse metamodelo, a qualidade de um sistema é caracterizada pelos seus vários atributos de qualidade, que são propriedades de um processo ou de um produto que podem ter um valor mensurável e observável (ALBIN, 2003).

Atributos de qualidades podem ser classificados em funcionais, que descrevem o que o sistema faz, e não funcionais, que derivam-se das restrições impostas pela solução de como os atributos funcionais serão atendidos (DOORNBOS; LOO, 2012). A interdependência entre requisitos funcionais e não funcionais requer que ambos os tipos de atributos de qualidade sejam considerados durante todo o ciclo de desenvolvimento do software (KIM et al., 2008). Por esta razão, Kalmar et al. (2011) afirmam que a definição e implementação da arquitetura de software não deva ser somente uma fase do projeto, mas sim uma atividade contínua durante todo o projeto.

Além disso, os atributos de qualidade estão relacionados a uma ou mais métricas, que podem ser definidas como medida quantitativa do grau que o sistema, componente ou processo possui de um determinado atributo. Uma medição representa o conjunto de operações que tem por objetivo determinar o valor de uma 
medida. Já a medida é a variável à qual se atribui um valor como resultado de uma medição (IEEE, 1990).

\subsection{NORMAS DE QUALIDADE}

Normatização é a atividade que, considerando os problemas potenciais ou existentes, estabelece disposições destinadas à utilização comum e repetitiva em um determinado contexto. Segue uma descrição dos principais objetivos da normalização (CÔRTES; CHIOSSI, 2001):

- Adequação ao propósito: é a capacidade de um produto, processo ou serviço atender a um propósito definido sob condições definidas;

- Compatibilidade: é a capacidade de entidades serem usadas em conjunto, sob condições especificas, para atender requisitos pertinentes;

- Controle de variedade: é a capacidade de um produto, insumo ou fornecedor ser utilizado em lugar de outro, sem modificação, para atender aos mesmos requisitos;

- Segurança: é o estado no qual riscos de danos pessoais ou materiais estão limitados a um nível aceitável;

- Proteção do meio ambiente: prevenção de danos, inaceitáveis ao meio ambiente, decorrentes da utilização de produtos, processos ou serviços;

- Proteção do produto: é a proteção de um produto contra situações climáticas ou outras condições adversas durante seu uso, transporte e armazenamento.

O alcance geográfico, político ou econômico de uma norma define o seu nível, podendo ser internacional, nacional, regional ou territorial. Duas importantes entidades de nível internacional têm a função de normalização, sendo o mais antigo o International Eletrotechnical Commission (IEC), que cuida da normalização na área de eletricidade/eletrônica e o International Organization for Standardization (ISO). A associação ISO/IEC vem produzindo normas gerais de uso em todas as áreas, o que tem trazido grande repercussão na globalização da economia. O Brasil é representado na ISO/IEC pela Associação Brasileira de Normas Técnicas (ABNT), entidade de âmbito nacional na área de normalização. 
2.7.1 Qualidade do produto de software - ISO/IEC 9126

De acordo com Rocha, Maldonado e Weber (2001), a qualidade de produto de software representa o conjunto de características que devem ser alcançadas em um determinado nível, para que o produto atenda às necessidades dos usuários. É por intermédio desse conjunto de características que a qualidade do produto é descrita e avaliada.

As normas de qualidade de software ISO/IEC 14598 - Avaliação do produto de software e ISO/IEC $9126^{8}$ - Software Engineering - Product quality - Part 1: Quality model tratam da qualidade do produto de software A norma ISO/IEC 14598 trata de modelo de avaliação da qualidade dos atributos e critérios definidos na ISO/IEC 9126. A norma ISO/IEC 14598 trata de modelo de avaliação da qualidade dos atributos e critérios definidos na ISO/IEC 9126. A Figura 4 ilustra as relações entre as séries ISO/IEC 9126 (ISO/IEC, 2001) e ISO/IEC 14598 (ISO/IEC, 1999).

Figura 4 - Relação entre as normas ISO/IEC 9126 e ISO/IEC 14598

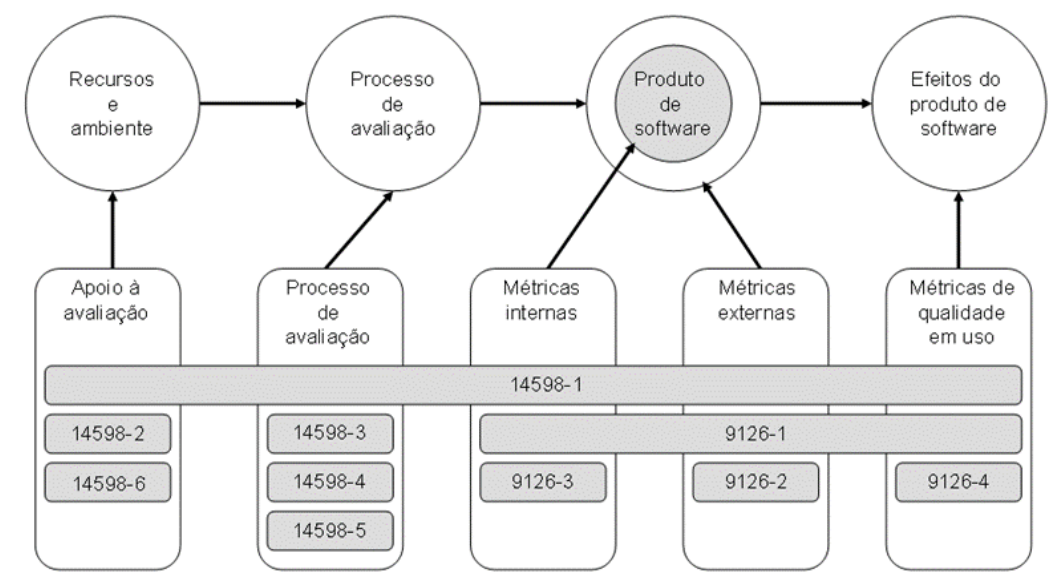

Fonte: adaptado de ISO/IEC (2001)

$\mathrm{Na}$ Figura 4, é possível visualizar o relacionamento entre o processo e o produto de software. A qualidade do produto de software depende da qualidade do

\footnotetext{
${ }^{8}$ Durante o desenvolvimento deste trabalho, a norma ISO/IEC 9126-1 Software engineering - Product quality foi revisada pela ISO/IEC e, em 13/09/2012, foi substituída pela norma ISO/IEC 25010 - Systems and software engineering - Systems and software Quality Requirements and Evaluation (SQuaRE) - System and software quality models (ISO/IEC, 2011). Visando manter a coerência com as aplicações do roteiro proposto realizadas antes de 13/09/2012, o uso da norma ISO/IEC 9126-1 foi mantido neste trabalho. No Apêndice $G$ são listadas as diferenças entre essas duas normas. Essas diferenças não afetam a essência do roteiro de ensino proposto neste trabalho.
} 
processo de avaliação utilizado e sofre influências dos recursos e do ambiente no qual o uso do mesmo é realizado.

Uma vez que a aceitação do software é dada pelo usuário final, a qualidade do produto e seus efeitos produzidos, quando da utilização do software, é o principal motivador para o aprofundamento na pesquisa na área de qualidade de software. A qualidade em uso provê uma ligação entre os fatores humanos associados com a melhoria do produto, uma vez que está intimamente ligada a requisitos de negócio. Ela fornece meios potenciais para o desenvolvimento de sistemas que irão estar adequados às necessidades de seus usuários (BEVAN, 1999).

A norma ISO/IEC 9126 propõe um modelo de qualidade do produto de software e foi desenvolvida como uma tentativa de se identificar os atributos-chave de qualidade de software (PRESSMAN; MAXIM, 2014).

O modelo de qualidade proposto pela ISO/IEC 9126 permite que a qualidade do produto de software seja especificada e avaliada em diferentes perspectivas pelos envolvidos com aquisição, requisitos, desenvolvimento, uso, avaliação, apoio, manutenção, garantia de qualidade e auditoria de software. Ela pode, por exemplo, ser utilizada por desenvolvedores, adquirentes, pessoal de garantia de qualidade e avaliadores independentes, particularmente os responsáveis por especificar e avaliar qualidade do produto de software. Seguem alguns exemplos de usos do modelo de qualidade definido na ISO/IEC 9126-1 (ISO/IEC, 2001):

- Validar a completitude de uma definição de requisitos;

- Identificar requisitos de software;

- Identificar objetivos de projeto de software;

- Identificar objetivos para teste de software;

- Identificar critérios para garantia de qualidade;

- Identificar critérios de aceitação para produtos finais de software.

A família ISO/IEC 9126 é composta por quatro documentos, identificados como ISO/IEC 9126-1 - Software engineering - Product quality, ISO/IEC 9126-2 - Software engineering - Product quality External metrics, ISO/IEC 9126-3 - Software engineering - Product quality - Internal metrics e ISO/IEC 9126-4 - Software engineering - Product 
quality - Part 4: Quality in use metrics. A Figura 5 representa a estrutura da norma ISO/IEC 9126.

Figura 5 - Estrutura da norma ISO/IEC 9126

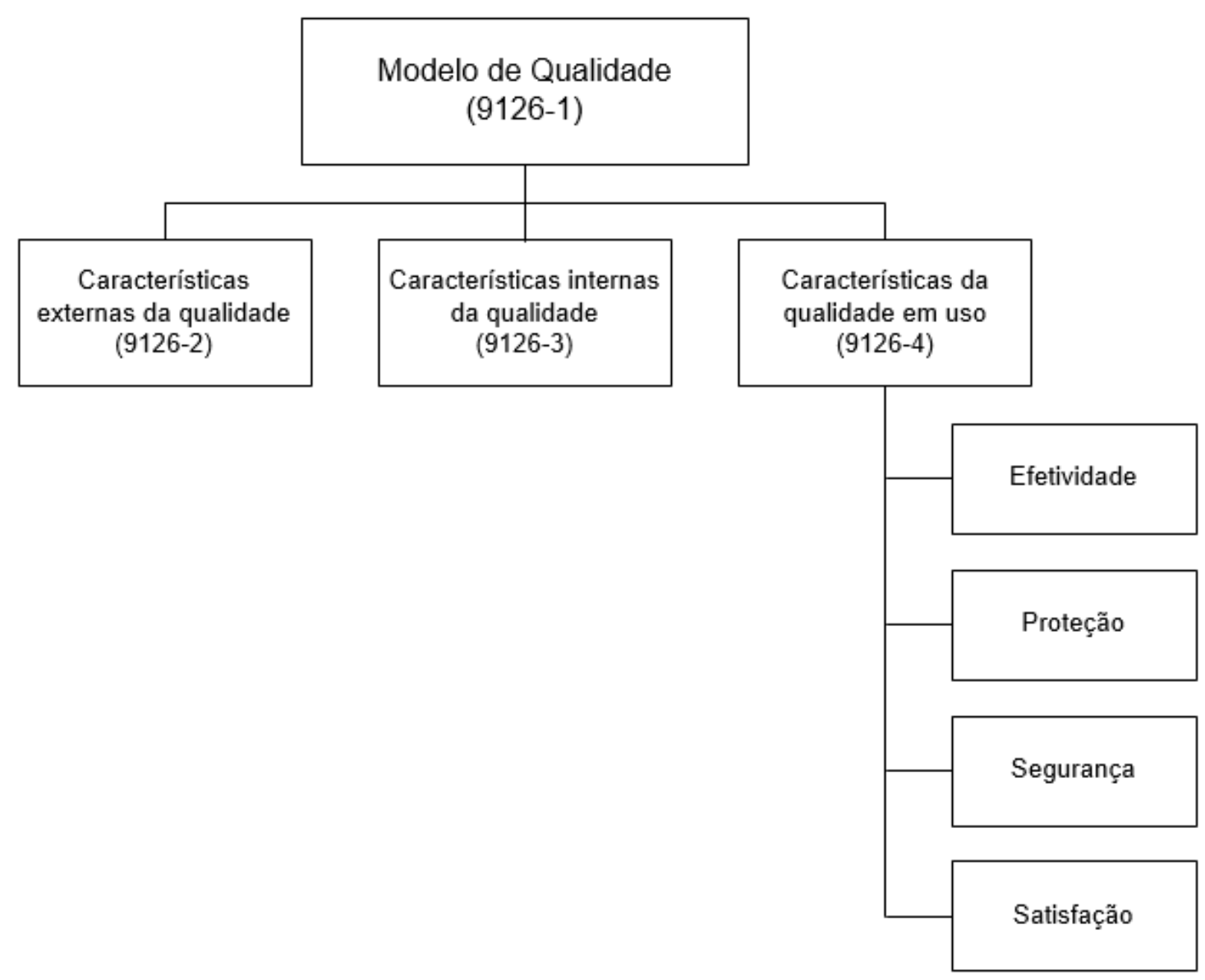

Fonte: adaptado de ISO/IEC (2001)

São apresentadas, a seguir, algumas definições importantes de conceitos relacionados com a Figura 5:

- Qualidade interna: é a totalidade das características do produto de software do ponto de vista interno. A qualidade interna é medida e avaliada com relação aos requisitos de qualidade interna. Detalhes da qualidade do produto de software podem ser melhorados durante a implementação do código, revisão e teste, mas a natureza fundamental da qualidade do produto de software representada pela qualidade interna mantém-se inalterada, a menos que seja reprojetada; 
- Qualidade externa: é a totalidade das características do produto de software do ponto de vista externo. É a qualidade que aparece quando o software é executado, o qual é tipicamente medido e avaliado enquanto está sendo testado num ambiente simulado, com dados simulados e usando métricas externas. Durante os testes, convém que a maioria dos defeitos seja descoberta e eliminada. Entretanto, alguns defeitos podem permanecer após o teste;

- Qualidade em uso: é a visão da qualidade do produto de software do ponto de vista do usuário, quando este produto é usado em um ambiente e um contexto de uso especificados. Ela mede o quanto os usuários podem atingir seus objetivos em um determinado ambiente, e não as propriedades do software em si. O nível de qualidade no ambiente do usuário pode ser diferente daquele no ambiente do desenvolvedor, por causa das diferenças entre necessidades e capacidades de diferentes usuários e diferenças entre os ambientes de hardware e de apoio. $O$ usuário avalia somente aqueles atributos do software que são usados em sua tarefa e para ele a qualidade é medida em termos do resultado do uso do software, e não das propriedades do próprio software; ou seja, para o usuário, qualidade em uso é determinada pelo efeito combinado da qualidade externa e interna. Algumas vezes, atributos de software especificados por um usuário final, durante a fase de análise de requisitos, não mais atendem aos requisitos do usuário quando 0 produto é usado, devido à mudança de requisitos do usuário e à dificuldade em especificar as necessidades implícitas. Os atributos de qualidade em uso são categorizados em quatro características, em um contexto de uso especificado:

- Eficácia: capacidade do produto de software de permitir que seus usuários atinjam metas especificadas com acurácia e completude;

- Produtividade: capacidade do produto de software de permitir que seus usuários empreguem quantidade apropriada de recursos em relação à eficácia obtida; 
- Segurança: capacidade do produto de software de apresentar níveis aceitáveis de riscos de dados a pessoas, negócios, software, propriedades ou ao ambiente;

- Satisfação: capacidade do produto de software de satisfazer usuários.

A obtenção da qualidade em uso é dependente da obtenção da qualidade externa, a qual, por sua vez, é dependente da obtenção da qualidade interna. Atributos internos adequados do software são pré-requisitos para atingir o comportamento externo requerido e, o comportamento externo adequado do software é um prérequisito para obter a qualidade em uso, conforme Figura 6 :

Figura 6 - Relacionamento entre qualidade interna, externa e de uso

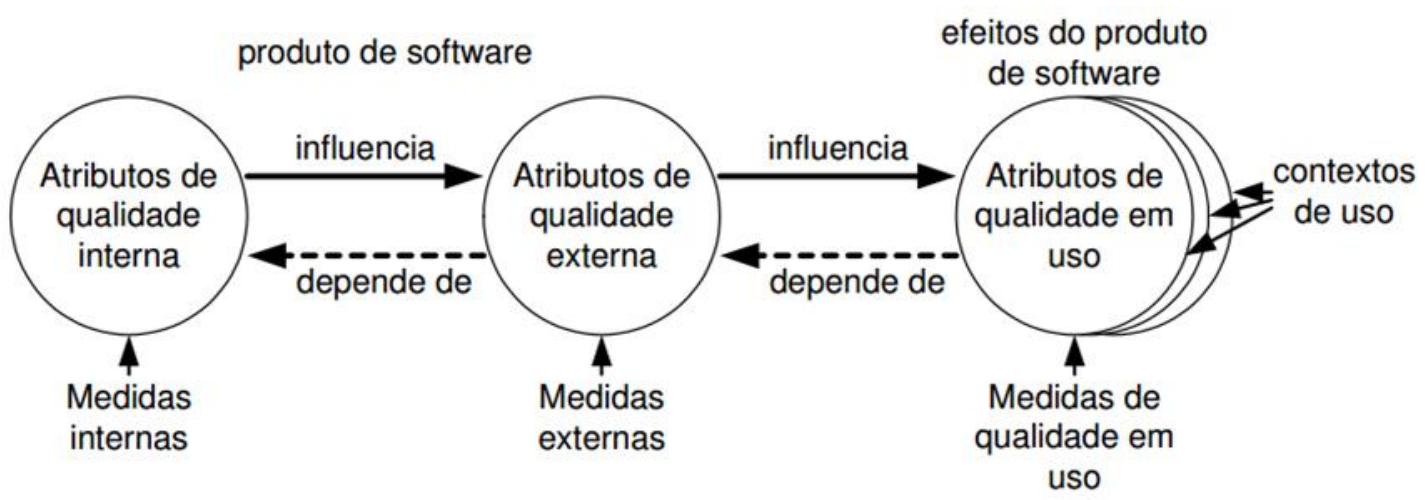

Fonte: adaptado de ISO/IEC (2001)

O conjunto de normas ISO/IEC 9126 define seis características de qualidade de software, que podem ser utilizadas para se avaliar a qualidade do produto de software. As características de qualidade de software presentes na norma foram definidas segundo os seguintes requisitos (ISO/IEC, 2001):

- Cobrir conjuntamente todos os aspectos de qualidade de software resultantes da definição de qualidade da ISO;

- Descrever a qualidade do produto com um mínimo de sobreposição;

- Ficar o mais próximo possível da terminologia estabelecida;

- Formar um conjunto de não mais de seis a oito características, por questões de clareza e manuseio; 
- Identificar áreas de atributos de produtos de software para posterior refinamento.

A Figura 7 ilustra as características e subcaracterísticas de qualidade definidas na ISO/IEC 9126-1.

Figura 7 - Características e subcaracterísticas de qualidade definidas na ISO/IEC 9126-1

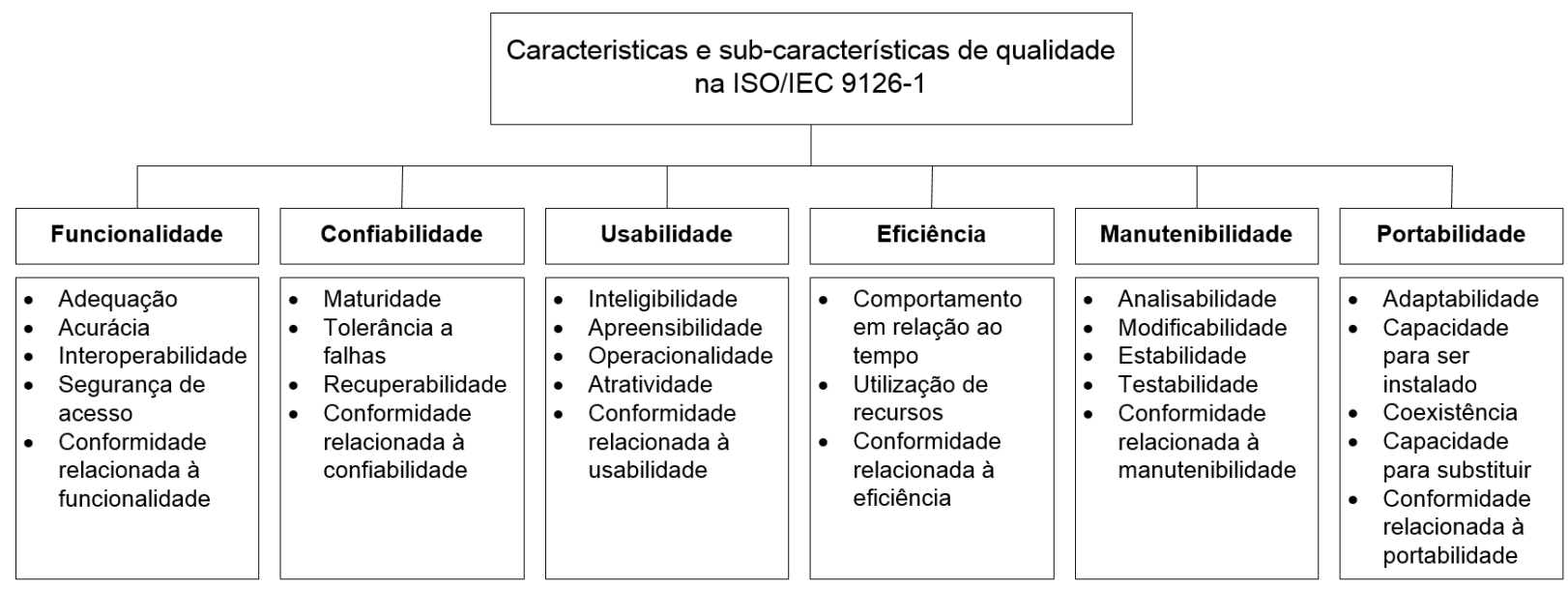

\section{Fonte: adaptado de ISO/IEC (2001)}

Essas características visam abranger todos os aspectos de qualidade externa e interna de um software, de maneira que seja possível ser especificado qualquer requisito de qualidade por meio de uma delas. A seguir, são detalhadas estas características e suas respectivas subcaracterísticas (ISO/IEC, 2001):

- Funcionalidade: capacidade do produto de software de prover funções que atendem às necessidades explícitas e implícitas, quando o software estiver sendo utilizado sob condições especificadas.

- Adequação: capacidade do produto de software de prover um conjunto apropriado de funções para tarefas e objetivos do usuário especificados;

- Acurácia: Capacidade do produto de software de prover, com grau de precisão necessário, resultados ou efeitos corretos ou conforme acordados; 
- Interoperabilidade: capacidade do produto de software interagir com um ou mais sistemas especificados;

- Segurança de acesso: capacidade do produto de software de proteger informações e dados, de forma que pessoas ou sistemas não autorizados não possam lê-los nem modificá-los e que não seja negado acesso às pessoas ou sistemas autorizados;

- Conformidade relacionada à funcionalidade: capacidade do produto de software de estar de acordo com normas, convenções ou regulamentações previstas em leis e prescrições similares relacionadas à funcionalidade.

- Confiabilidade: capacidade do produto de software de manter um nível de desempenho especificado, quando usado em condições especificadas.

- Maturidade: capacidade do produto de software de evitar falhas decorrentes de defeitos no software;

- Tolerância a falhas: capacidade do produto de software de manter um nível de desempenho especificado em casos de defeitos no software ou de violação de sua interface especificada;

- Recuperabilidade: capacidade do produto de software de restabelecer seu nível de desempenho especificado e recuperar os dados diretamente afetados no caso de uma falha;

- Conformidade relacionada à confiabilidade: capacidade do produto de software de estar de acordo com normas, convenções ou regulamentações previstas em leis e prescrições similares relacionadas à confiabilidade.

- Usabilidade: capacidade do produto de software de ser compreendido, aprendido, operado e atraente ao usuário, quando usado sob condições especificadas.

- Inteligibilidade: capacidade do produto de software de possibilitar ao usuário compreender se o software é apropriado e como ele pode ser usado para tarefas e condições de uso específicas;

- Apreensibilidade: capacidade do produto de software de possibilitar ao usuário aprender sua aplicação; 
- Operacionalidade: capacidade do produto de software de possibilitar ao usuário operá-lo e controlá-lo;

- Atratividade: capacidade do produto de software de ser atraente ao usuário;

- Conformidade relacionada à usabilidade: capacidade do produto de software de estar de acordo com normas, convenções, guias de estilo ou regulamentações previstas em leis e prescrições similares relacionadas à usabilidade.

- Eficiência: capacidade do produto de software de apresentar desempenho apropriado, relativo à quantidade de recursos usados, sob condições especificadas.

- Comportamento em relação ao tempo: capacidade do produto de software de fornecer tempos de resposta e de processamento, além de taxas de transferência, apropriados, quando o software executa suas funções, sob condições estabelecidas;

- Utilização de recursos: capacidade do produto de software de usar tipos e quantidades apropriados de recursos, quando o software executa suas funções sob condições estabelecidas;

- Conformidade relacionada à eficiência: capacidade do produto de software de estar de acordo com normas e convenções previstas em leis e prescrições similares relacionadas à eficiência.

- Manutenibilidade: capacidade do produto de software de ser modificado.

- Analisabilidade: capacidade do produto de software de permitir o diagnóstico de deficiências ou causas de falhas no software, ou adaptações do software devido a mudanças no ambiente e nos seus requisitos ou especificações funcionais;

- Modificabilidade: capacidade do produto de software de permitir que uma modificação especificada seja implementada;

- Estabilidade: capacidade do produto de software de evitar efeitos inesperados decorrentes de modificações no software;

- Testabilidade: capacidade do produto de software de permitir que o software, quando modificado, seja validado; 
- Conformidade relacionada à manutenibilidade: capacidade do produto de software de estar de acordo com normas ou convenções previstas em leis e prescrições similares relacionadas à manutenibilidade.

- Portabilidade: capacidade do produto de software de ser transferido de um ambiente para outro.

- Adaptabilidade: capacidade do produto de software de ser adaptado para diferentes ambientes especificados, sem necessidade de aplicação de outras ações ou meios além daqueles fornecidos para essa finalidade pelo software considerado;

- Capacidade para ser instalado: capacidade do produto de software para ser instalado em um ambiente especificado;

- Coexistência: capacidade do produto de software de coexistir com outros produtos de software independentes, em um ambiente comum, compartilhando recursos comuns;

- Capacidade para substituir: capacidade do produto de software de ser usado em substituição a outro produto de software especificado, com o mesmo propósito e no mesmo ambiente;

- Conformidade relacionada à portabilidade: capacidade do produto de software de estar de acordo com normas ou convenções previstas em leis e prescrições similares relacionadas à portabilidade.

Métricas externas, descritas na ISO/IEC 9126-2, utilizam medidas de um produto de software derivadas de medidas do comportamento do sistema do qual o software é uma parte, por meio de teste, operação e observação do software executável ou do sistema. Antes de adquirir ou utilizar um produto de software, convém que ele seja avaliado utilizando-se métricas baseadas nos objetivos de negócio e relacionadas ao uso, exploração e gestão do produto num ambiente técnico e organizacional especificado. Métricas externas oferecem a usuários, avaliadores, executores de teste e desenvolvedores os benefícios de poderem avaliar a qualidade do produto de software durante seu teste ou operação (ISO/IEC, 2003a).

A norma ISO/IEC 9126-3 fornece exemplos de métricas internas que podem ser aplicadas a um produto de software não executável, tais como uma especificação 
ou código-fonte, respectivamente, durante o projeto e a codificação. Convém que, no desenvolvimento de um produto de software, os produtos intermediários sejam avaliados utilizando-se métricas internas, as quais medem propriedades intrínsecas, incluindo aquelas que podem ser derivadas de um comportamento simulado. $O$ propósito básico das métricas internas é assegurar que a qualidade externa e a qualidade em uso requeridas sejam alcançadas. Métricas internas oferecem a usuários, avaliadores, executores de teste e desenvolvedores os benefícios de poderem avaliar a qualidade do produto de software e considerar questões relativas à qualidade bem antes do produto de software tornar-se executável (AZUMA, 2004).

Métricas internas podem ser aplicadas em artefatos criados durante o ciclo de desenvolvimento de software, como por exemplo documentos de definição de requisitos, especificação de projeto ou código fonte. Essas métricas permitem avaliar a qualidade intermediária dos entregáveis de um projeto de software e, dessa forma, estimar a qualidade do produto final, permitindo a identificação de problemas relacionados à qualidade e a tomada de ações corretivas o mais rápido possível (ISO/IEC, 2003b).

A ISO/IEC 9126-4 define que as métricas de qualidade em uso medem o quanto um produto atende às necessidades de usuários especificados para que atinjam metas especificadas com eficácia, produtividade, segurança e satisfação, em um contexto de uso especificado. A avaliação de qualidade em uso valida a qualidade do produto de software em cenários de uso específicos (ISO/IEC, 2004).

\subsubsection{Avaliação do produto de software - ISO/IEC 14598-5}

A norma ISO/IEC 14598-5 - Information technology - Software product evaluation, na sua quinta parte - Process for evaluators - define um processo para avaliar produtos de software (ISO/IEC, 1998a).

$\mathrm{Na}$ análise de requisitos de avaliação, definem-se os objetivos da avaliação, quais partes serão avaliadas e qual o modelo de qualidade que será utilizado. Recomenda-se que seja usada em conjunto com o modelo de qualidade definido na ISO 9126-1. 
Durante a atividade de especificação da avaliação, os padrões e critérios utilizados para a avaliação são definidos por meio da seleção das métricas, do estabelecimento de níveis de pontuação e do estabelecimento de critérios de julgamento (GUIMARÃES, 2008).

O objetivo principal da avaliação de um produto de software é fornecer resultados quantitativos sobre a qualidade do produto de software que sejam compreensíveis, aceitáveis e confiáveis por quaisquer das partes interessadas. A sistemática avaliação de um produto utilizando uma metodologia objetiva traz potenciais benefícios, como por exemplo (ISO/IEC, 1998a):

- Para adquirentes de produtos de software, resultados de avaliação podem ser usados como dados objetivos para decisões de aquisição;

- Para os fornecedores de um produto, o benefício de uma avaliação pode atribuir confiança no valor do produto; além disso, o relatório de avaliação pode ser usado com finalidades comerciais;

- A disseminação da avaliação do produto de software pode ajudar no uso da qualidade como argumento de marketing;

- Os resultados da avaliação de um produto podem ser utilizados por seu desenvolvedor, visando a realização de ações corretivas, como a melhoria do software ou efetuando a tomada de decisões sobre a estratégia de evolução do produto.

O processo de avaliação é concebido de forma genérica podendo ser aplicado a qualquer fase do ciclo de vida do produto. O processo de avaliação encontra-se subdividido em quatro fases principais, como representado na Figura 8 . Segundo a norma ISO/IEC 14598-5 - Information technology - Software product evaluation, as etapas do processo de avaliação são (ISO/IEC, 1998a):

- Estabelecer requisitos de avaliação: nesta etapa o propósito da avaliação é estabelecido, assim como os artefatos a serem avaliados. $O$ modelo de qualidade também é especificado.

- Especificar a avaliação: as métricas são selecionadas, seus respectivos níveis de pontuação definidos e critérios de julgamento são estabelecidos nesta etapa; 
- Projetar a avaliação: o plano de avaliação é elaborado nesta etapa do processo de avaliação;

- Executar a avaliação: nesta etapa são realizadas a obtenção das medidas, a comparação dos resultados com os critérios e o julgamento dos resultados.

Figura 8 - Etapas do processo de avaliação do produto de software

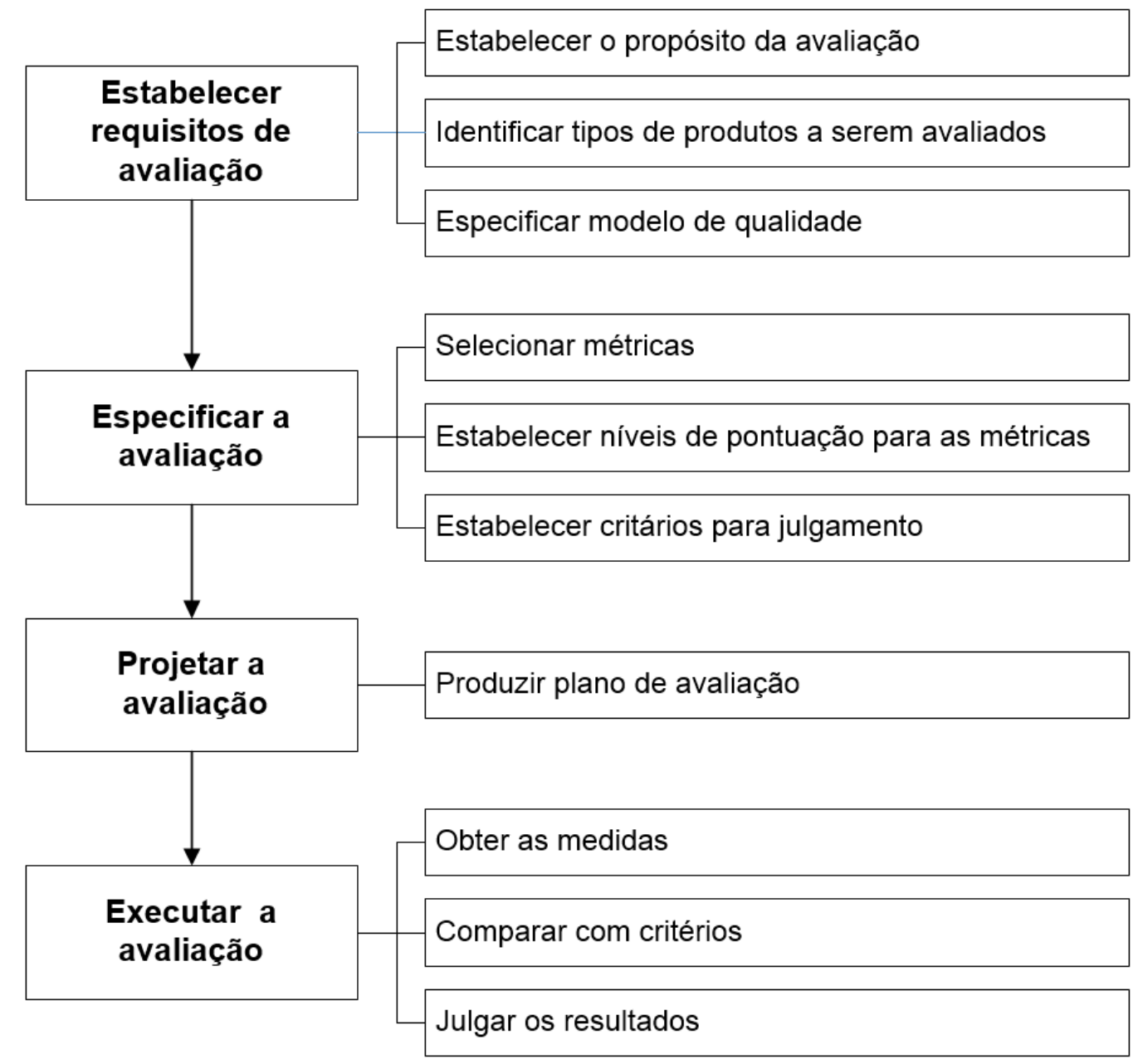

Fonte: adaptado de ISO/IEC (1998a)

A avaliação de um produto de software pode ser realizada em qualquer um dos processos de ciclo de vida do software. A avaliação pode ocorrer em um dos seguintes processos: aquisição, fornecimento, desenvolvimento, operação ou manutenção (ISO/IEC/IEEE, 2008). 
A decisão de submeter um produto de software para avaliação deve, preferencialmente, ser tomada o mais cedo possível no processo de desenvolvimento do produto. Caso seja realizada logo no início do processo de desenvolvimento do software, é possível inserir nesse processo as medições e testes a serem realizados para a avaliação. Isso asseguraria uma maior probabilidade de o produto satisfazer aqueles requisitos considerados no processo de avaliação, assim como minimizaria o risco de ocorrência de custos extras ou inesperados (ISO/IEC, 1998a).

\subsection{ARQUITETURA DE SOFTWARE E REQUISITOS NÃO FUNCIONAIS}

A arquitetura de software pode ser vista como uma ferramenta de gerência da complexidade do software, tendo um papel fundamental na satisfação dos requisitos funcionais e não funcionais (JAZAYERI; RAN; LINDEN, 2000).

A arquitetura de software é também um ponto de referência comum para as demais atividades que são executadas após sua definição, pois a arquitetura é a manifestação antecipada das decisões de projeto. Deve-se ocupar de fatores como tempo de desenvolvimento, custo de desenvolvimento e manutenção e das restrições de implementação, enfatizando os atributos de qualidade que o sistema deve ter e medindo-os através de avaliações, visando a satisfação das qualidades necessárias (BASS; CLEMENTS; KAZMAN, 2012).

A arquitetura de software abrange não somente os requisitos funcionais. Alguns requisitos são implícitos nos objetivos do processo de negócio de uma organização, pois considerações do negócio devem ser acomodadas na arquitetura de software. Esses requisitos implícitos englobam os requisitos funcionais que, em suma, relacionam-se com as capacidades do sistema e influenciam a qualidade do sistema resultante (BASS; CLEMENTS; KAZMAN, 2012). Segundo Gorton (2011), os requisitos não funcionais definem como os requisitos funcionais serão atendidos.

Bosch e Molin (1999) definem um método para obtenção da qualidade de arquitetura por meio de transformações sucessivas da arquitetura de software de um sistema realizadas em uma sequência de iterações nas quais avaliam-se os requisitos não funcionais. Baseada na especificação de requisitos de um sistema, que servem de entrada no método proposto, um projeto arquitetural é elaborado considerando os 
requisitos funcionais, o que resulta em uma primeira versão do projeto da arquitetura de software do sistema.

Esse projeto é avaliado em relação aos requisitos não funcionais e, para cada um deles, um valor estimado é dado, por meio de técnicas qualitativas ou quantitativas. Compara-se os valores estimados de cada requisito não funcional com os valores da especificação de requisitos.

Se todas as estimativas forem iguais ou superiores às requeridas pelo sistema, o método é finalizado. Caso contrário, inicia-se a etapa de transformação arquitetural. Nesta etapa, definem otimizações para os requisitos não funcionais requeridos pelo sistema. O conjunto de uma ou mais otimizações resultam em uma nova versão do projeto da arquitetura de software, que passa por nova avaliação.

O método é repetido até que que o projeto da arquitetura resultante atenda aos requisitos não funcionais ou até que não seja mais possível otimizar a solução. Esse método, conforme representado na Figura 9, é executado idealmente até que todos os requisitos não funcionais sejam atendidos. 
Figura 9 - Método iterativo para projeto de arquitetura de software

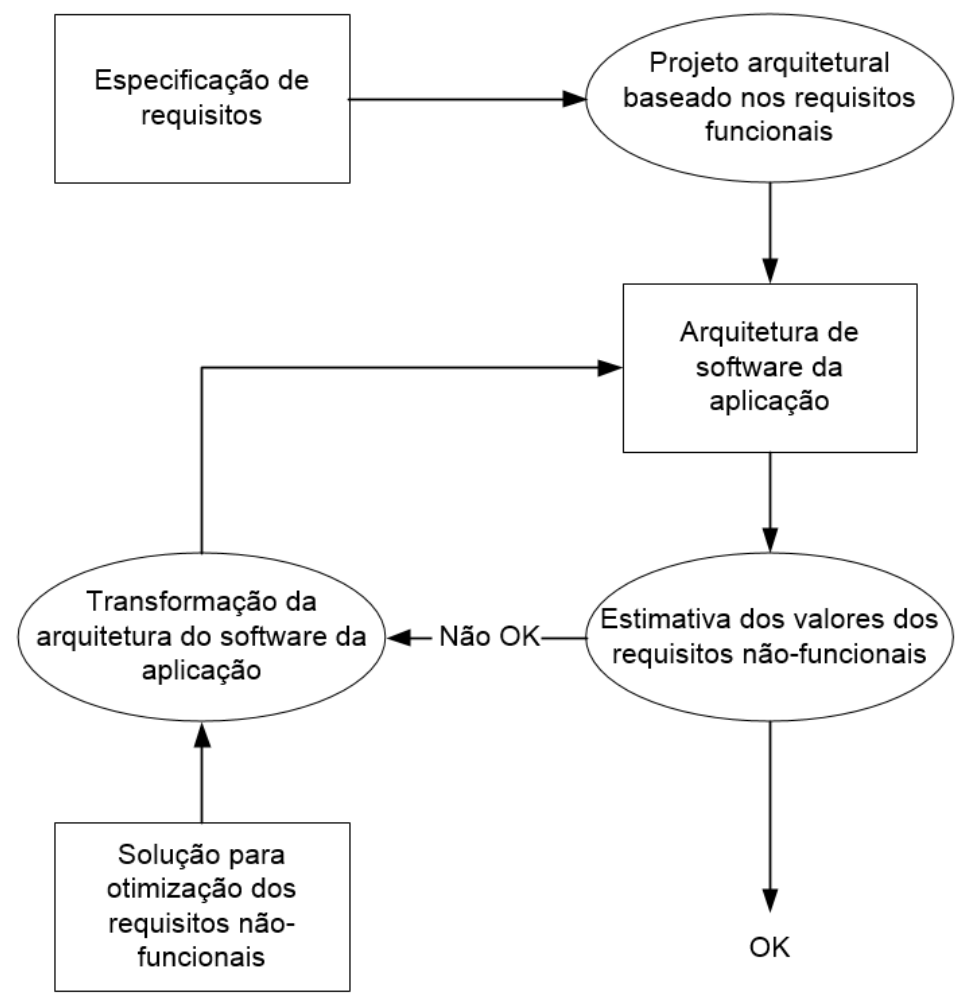

Fonte: adaptado de Bosch e Molin (1999)

Entretanto, ao tratar cada atributo de qualidade de forma isolada em uma iteração, não analisando conjuntamente os trade-offs envolvidos nas decisões de arquitetura, o processo de Bosch, embora de simples compreensão, é de difícil execução, podendo consumir muito tempo até que a arquitetura satisfaça a todos os requisitos (GRUNSKE, 2006).

Quando o usuário estabelece os requisitos de um software, em geral, ele se preocupa com as funcionalidades de negócio, pois são estas que atendem diretamente suas necessidades. No entanto, os requisitos não funcionais, ou requisitos intrínsecos, são de fundamental importância para garantir a qualidade do produto de software como um todo, tais como infraestrutura de hardware, software, comunicação e segurança (PINNA, 2004).

Lattanze (2009) considera que a arquitetura de software pode ser definida principalmente em função dos requisitos não funcionais, que por sua vez suportam os requisitos funcionais. Tanto Bass, Clements e Kazman (2012) como Qin; Xing e Zheng 
(2008) afirmam que a arquitetura de software reflete as primeiras decisões do projeto que repercutirão em todo o sistema, principalmente nos requisitos de qualidade. Portanto, a arquitetura é um artefato de software que permite representar as características gerais do sistema e analisar e avaliar a qualidade do sistema.

Há um consenso sobre o fato de que os atributos de qualidade de um sistema de software são em grande parte restringidos por sua arquitetura. Como consequência, os requisitos de qualidade mais importantes para o sucesso de um sistema de software devem orientar o projeto da arquitetura de software $(\mathrm{BOSCH}$; MOLIN, 1999).

Usualmente, as necessidades de negócio determinam quais atributos de qualidade devem ser atingidos e, consequentemente, considerados na arquitetura de um sistema de software. Frequentemente a funcionalidade do sistema abrange implicitamente vários requisitos não funcionais. Desse modo, pode-se afirmar que os requisitos de qualidade funcionais e os não funcionais são ortogonais, visto que uma dada funcionalidade pode ser alcançada por vários requisitos não funcionais (BASS; CLEMENTS; KAZMAN, 2012).

Como a arquitetura influencia a qualidade do software, o uso de métricas para avaliação arquitetural é de fundamental importância para avaliar uma arquitetura de software. Definir a qualidade de software de um sistema é equivalente a definir uma lista de atributos de qualidade de software para este sistema e identificar um conjunto de métricas de software associadas.

Dessa forma, a lista desejada de atributos de qualidade deve ser claramente definida, senão a avaliação da qualidade torna-se subjetiva (BROY, 2013). Verifica-se que, sem a devida elaboração, os requisitos de qualidade ficam sujeitos à má interpretação, uma vez que conceito de qualidade é subjetivo. Assim, o uso de métricas de software pode ajudar a reduzir essa subjetividade. O propósito de métricas de software é fazer avaliações por todo o ciclo de vida do software para verificar se os requisitos de qualidade de software estão sendo atendidos. $O$ uso de métricas de software reduz a subjetividade na avaliação e controla a qualidade do software, porque fornece uma base quantitativa para tomar decisões quanto à qualidade do software. Porém, o uso de métricas de software não elimina a necessidade de 
julgamento humano nas avaliações de um software (CLEMENTS; KAZMAN; KLEIN, 2002).

Projetar uma arquitetura que atinja os requisitos de qualidade demandados pelo processo de negócio é uma das tarefas que mais demanda esforços de um arquiteto de software. Por essa razão, faz-se necessário que o arquiteto de software tenha um ótimo conhecimento sobre requisitos de qualidade e as abordagens arquiteturais para implementar sistemas que os satisfaçam (HARRISON; AVGERIOU, 2007).

\subsection{O CICLO DE VIDA DO REQUISITO NÃO FUNCIONAL}

O ciclo de desenvolvimento de software é iniciado com a elicitação dos requisitos da aplicação, que podem ser classificados em funcionais, relacionados com as funções do sistema, e não funcionais, definidos pelas características da solução que são necessárias para atendimento dos requisitos funcionais. Apesar de não estarem diretamente relacionadas aos requisitos funcionais explicitamente solicitados pelo usuário, muitas vezes a implementação dos requisitos não funcionais definem as características de qualidade externa, ou seja, visíveis pelos usuários.

Por essa interdependência entre requisitos funcionais e não funcionais, ambos devem ser considerados desde o início do desenvolvimento do sistema. Entretanto, na prática, os requisitos não funcionais geralmente não são levados em consideração ou em casos melhores são considerados em fases tardias do processo de desenvolvimento de software, enquanto os requisitos funcionais são considerados durante todo o processo, o que torna mais difícil a satisfação dos requisitos não funcionais, visto que são suportados por requisitos não funcionais (KIM et al., 2008).

Segundo Chung e Leite (2009), muitas vezes os requisitos não funcionais não são levados em consideração adequadamente por três principais razões:

- A disciplina de Engenharia de Software ainda é uma área relativamente nova, não tendo ainda a cultura da preocupação com os atributos não funcionais de forma consolidada, se comparada às engenharias mais tradicionais; 
- A pressão pela construção de sistemas cada vez mais rápida, para atender às necessidades do mercado, fazem com que os profissionais de TI preocupem-se apenas com a parte funcional do sistema, visando atender ao time-to-market ${ }^{9}$;

- Devido à natureza mais abstrata dos requisitos não funcionais, a maior parte da atenção dos engenheiros de computação foca-se principalmente nas notações e técnicas para definição e implementação dos requisitos funcionais que um sistema deve prover.

Como uma prática frequentemente observada, os requisitos não funcionais são deixados em segundo plano, ou mesmo ignorados, em relação aos requisitos funcionais, porque são vistos como questões de natureza estritamente técnica ou consideradas óbvias, que devem ser avaliadas somente em um sistema já implementado (HRUSCHKA, 2012).

Essa prática tem se mostrado inadequada, visto que não faz sentido a realização de testes dos requisitos não funcionais sem que os mesmos tenham sido previamente entendidos e implementados de forma planejada e com frequentes avaliações.

Ainda, segundo Chung; Nixon e Yu (1995), a maioria dos problemas reais tem mais características diretamente relacionadas aos requisitos não funcionais do que a funcionais, como por exemplo: baixa produtividade, processamento lento, alto custo, baixa qualidade e clientes insatisfeitos.

Essa negligência no tratamento dos requisitos não funcionais geralmente resulta no desenvolvimento de sistemas de má qualidade e de difícil manutenção, dado que a arquitetura de software não foi planejada para atender a esses requisitos (FRANCH; BOTELLA, 1998). Além disso, os efeitos dessa negligência no tratamento de requisitos não funcionais são muitas vezes observados quando o sistema já se encontra em produção, ou seja, muito tarde para corrigir. Nesses casos, a percepção

\footnotetext{
9 Time-to-market: período de tempo necessário para projetar e fabricar um produto antes que o mesmo esteja disponível no mercado (COMBLEY, 2011).
} 
do usuário da qualidade do sistema como um todo não é boa, mesmo que os requisitos funcionais estejam satisfeitos.

Para evitar essa negligência em relação aos requisitos não funcionais, os mesmos devem ser elicitados segundo as necessidades do processo de negócio, desde o início da fase de elicitação de requisitos. Dessa forma, será maior a probabilidade de o sistema satisfazer às necessidades de negócio e aos requisitos não funcionais que os apoiam. Como esteio conceitual para auxiliar no ensino orientada pelos processos de negócio, utilizou-se a norma ISO/IEC 10746 (Reference Model - Open Distributed Processing - RM-ODP) (ISO/IEC, 1998b), descrita no item 2.4, na elaboração do roteiro.

\subsection{MÉTOdOS DE AVALIAÇÃO DE ARQUITETURA DE SOFTWARE}

Segundo Clements; Kazman e Klein (2002), uma implementação de uma arquitetura abrange praticamente todos os atributos de qualidade de um sistema. Sendo assim, se as decisões arquiteturais determinam os atributos de qualidade de um sistema, então é possível avaliar essas decisões e seus impactos nos atributos de qualidade. Uma arquitetura inadequada precipitará o desastre em um projeto de software, dado que os requisitos de qualidade não serão atingidos, além dos estouros de prazos e orçamentos. Consequentemente, a avaliação arquitetural é a forma mais barata de se evitar um desastre em um projeto de software.

A complexidade de um software é determinada não somente por seus requisitos funcionais, definidos na norma IEEE 830 (1998) - Recommended Practice for Software Requirements Specifications como o conjunto de ações fundamentais que ocorrem no software ao aceitar e processar entradas e processar e gerar saídas, mas também por seus requisitos não funcionais (IEEE, 1998b).

Os requisitos não funcionais, tais como desempenho, disponibilidade, usabilidade, modificabilidade, entre outros, devem ser considerados durante o processo de desenvolvimento de sistemas, constituindo um importante critério para decisões de projeto. No contexto da disciplina de Engenharia de Software, um requisito não funcional consiste em um requisito que não descreve as funcionalidades que o software realiza, mas como o software as realiza. Cabe ressaltar que a 
importância de um determinado requisito não funcional pode ser considerada relativa, dependendo do sistema a ser considerado. A prioridade atribuída a um requisito não funcional depende da importância deste requisito em relação ao contexto de negócio no qual o software será utilizado (CHUNG; LEITE, 2009).

Cabe à arquitetura de software orientar a implmentação dos atributos de qualidade dos sistemas de software, independentemente de sua categoria. As decisões arquiteturais têm um profundo impacto no alcance dos atributos de qualidade. Assim, para que possa haver uma avaliação de arquitetura de software, é necessário ter se estabelecido previamente os atributos de qualidade desejados motivados pelas regras de negócio (BARBACCI et al., 2003).

Segundo Clements; Kazman e Klein (2002), os principais objetivos da avaliação de arquitetura de software são:

1. Identificar antecipadamente as insuficiências decorrentes de decisões tomadas nas fases de levantamento dos requisitos ou fases de projeto iniciais. Insuficiência significa pontos nos quais a arquitetura não atinge as expectativas dos participantes com respeito a um ou mais atributos de qualidade. Quanto mais cedo as insuficiências forem encontradas, menores serão os custos e a quantidade de recursos necessários para sua eliminação. Já que a arquitetura descreve todo o sistema de software, insuficiências existentes não encontradas causam erros em saídas posteriores do desenvolvimento, como a implementação ou, no pior dos casos, no produto final. Por conseguinte, mudanças causadas por insuficiências que foram descobertas tardiamente também causarão mudanças necessárias nas saídas dos produtos de software elaborados durante todo 0 ciclo de desenvolvimento;

2. Comparar alternativas arquiteturais relativas a um ou mais atributos de qualidade. Pode haver muitas arquiteturas candidatas à realização de um sistema de software que implementam a mesma funcionalidade, mas endereçam os atributos de qualidade de forma diferente; 


\section{Avaliar se uma arquitetura possui riscos para certos atributos de} qualidade, ou seja, não os satisfazem. Avaliações de arquitetura de software podem ser usadas em um ou mais estágios do processo de desenvolvimento de software, podendo ser empregadas para comparar e identificar pontos fortes e fracos de diferentes situações arquiteturais no processo de desenvolvimento de software. Podem, também, ser utilizadas para avaliação de sistemas já ativos, antes que manutenções ou novas melhorias sejam implementadas (MATTSSON; GRAHN; MÅRTENSSON, 2006).

Ainda segundo Mattsson; Grahn e Mårtensson (2006), os métodos de avaliação de arquitetura de software podem ser divididos em quatro categorias:

- Baseados em experiência: este método se baseia na experiência prévia ou conhecimento do assunto dos desenvolvedores ou consultores;

- Baseados em simulação: este método de avaliação depende da implementação de componentes da arquitetura de software a ser avaliada. A simulação pode ser usada para a avaliação de requisitos de qualidade;

- Modelagem matemática: baseiam-se em provas ou métodos matemáticos para, principalmente, avaliações em atributos como desempenho ou confiabilidade dos componentes da arquitetura. Modelagens matemáticas podem ser combinadas com simulações para estabelecer estimativas mais precisas de desempenho dos componentes do sistema;

- Baseados em cenários: métodos baseados em cenários tendem a avaliar requisitos de qualidade específicos, caracterizando situações que forçam a descrição desses requisitos de qualidade. Os cenários das situações desejadas são usados para se abordar uma vasta gama de requisitos de qualidade, documentando-se as respostas obtidas. Bachmann et al. (2005) destaca a importância do uso de cenários na avaliação de soluções arquiteturais, avaliações essas baseadas em cenários de atributos de qualidade. Brito et al. (2009) afirma que cenários comportamentais possibilitam a realização de análises de trade-offs entre os atributos de qualidade, com o objetivo de identificar quais atributos de qualidade influenciam diretamente as metas de negócio, podendo, por conta disto, ser priorizados durante a avaliação da 
arquitetura e, posteriormente, durante a construção do sistema. Bass; Clements e Kazman (2012) afirmam que há dois tipos de cenários:

- Cenários gerais: são independentes do sistema a ser avaliado, podendo pertencer a qualquer sistema. Um dos usos de cenários gerais é habilitar a comunicação entre participantes sobre requisitos de qualidade;

- Cenários concretos: são caracterizações dos cenários gerais, e são específicos para um sistema em particular. Cada cenário concreto pode ser significativo no projeto de software e detalhes de resposta para estímulos são suficientes para possibilitar a execução de testes em relação a um determinado requisito não funcional.

Esta divisão em categorias não busca elencar se existe superioridade de uma categoria em relação às outras, mesmo porque métodos que nelas se baseiam têm aplicações diferentes, visando à avaliação de um requisito de qualidade específico ou todo um conjunto deles.

Avaliar ou reavaliar uma arquitetura de software é uma forma de se evitar tais problemas e, para que a avaliação possa acontecer, devem-se envolver dois grupos de pessoas, que seriam a equipe de avaliação e os interessados na arquitetura. Desse modo, os três principais objetivos de uma avaliação de arquitetura de software são (NASCIMENTO NETO, 2012):

- Identificar e refinar os atributos de qualidade;

- Identificar e refinar as decisões arquiteturais do projeto;

- Avaliar as decisões arquiteturais para determinar se satisfazem aos atributos de qualidade.

Há vários métodos de avaliação de arquitetura de software. O estudo de Babar; Zhu e Jeffery (2004) apresenta alguns dos principais métodos que são comparados segundo um conjunto de critérios.

Métodos de avaliação de arquitetura podem ser aplicados em duas fases do projeto, segundo Clements; Kazman e Klein (2002): 
Em estágios iniciais do projeto: é realizada quando existem apenas fragmentos da descrição arquitetural de forma que questionários, checklists e métodos baseados em cenários são mais usados para avaliação porque, nessa fase, não há informação tangível suficiente disponível para a coleta de medições ou para simular o comportamento do software. As bases principais desse tipo de avaliação são a experiência dos desenvolvedores e cenários baseados em requisitos que estão nos documentos de requisitos;

Em estágios finais do projeto: é realizada em estágios mais tardios do processo de desenvolvimento, quando há ao menos um projeto detalhado disponível, no qual métricas mais concretas possam ser coletadas, o que significa que técnicas de métricas arquiteturais são usadas para avaliar a arquitetura de software com respeito a um ou mais atributos de qualidade.

Devem-se usar técnicas de avaliação pelo menos nas fases iniciais e finais para acompanhar o controle de qualidade do software. Por meio dessas avaliações, busca-se evidenciar que os requisitos de qualidade foram considerados e implementados na arquitetura.

O resultado final de uma avaliação de arquitetura de software é um documento cuja forma e conteúdo podem variar, mas que deve responder a duas questões essenciais: (1) se a arquitetura está adequada para o projeto para o qual foi projetada, e (2) qual de duas ou mais arquiteturas seria a mais apropriada para o sistema em questão (CLEMENTS; KAZMAN; KLEIN, 2002).

\subsection{ARCHITECTURE TRADE-OFF ANALYSIS METHOD (ATAM)}

Todo projeto, em qualquer disciplina, envolve o conceito de trade-off. Apesar disso, técnicas para otimização dos trade-offs são raramente utilizadas. Decisões arquiteturais geralmente são feitas baseadas em razões não técnicas, como por exemplo: estratégia de negócio, número de usuários que o sistema deve atender, tempo de resposta esperado, restrições de tempo, custo e escopo, etc. Grande parte do trabalho do arquiteto de software está relacionado com a definição e com o projeto de arquitetura que possa atingir os requisitos de qualidade demandados pelo processo de negócio. Para ser significativo, o requisito de qualidade deve ser específico de 
como a aplicação deve atingir um determinado objetivo do negócio (GORTON, 2011). Um problema comumente encontrado na documentação de arquitetura de software é o uso de sentenças genéricas, como por exemplo: "a aplicação deve ser escalável". Essa sentença, além de ser imprecisa, pode suscitar diferentes interpretações, pois nesse sistema hipotético, a escalabilidade está relacionada às conexões simultâneas feitas pelo usuário? Ou refere-se a escalabilidade do volume de dados gerenciado por esta aplicação? Ou ainda a implantação para uma base maior de usuários? Ou a todas as três alternativas? Sem a elaboração precisa, a interpretação de sentenças como essa são deixadas no campo da intuição (CLEMENTS; KAZMAN; KLEIN, 2002). A definição de como a escalabilidade deve ser suportada no sistema em questão é crucial do ponto de vista arquitetural, dado que diferentes soluções podem ser construídas de acordo com o que o processo de negócio necessita. Uma sentença mais elaborada seria: "deve ser possível escalar a implantação de um parque de inicialmente 100 estações de trabalho, geograficamente distribuídas, para 10.000 estações sem um aumento de esforço e custo para a instalação e configuração". Essa sentença representa um cenário arquitetural, que além de preciso, é mensurável e já endereça um possível conjunto de táticas e tecnologias que podem ser utilizadas na implementação da arquitetura (CHUNG; NIXON; YU, 1995).

Um método de avaliação de arquitetura que tem como base a utilização de cenários de atributos de qualidade é o ATAM (Architecture Trade-off Analysis Method) (CLEMENTS; KAZMAN; KLEIN, 2002). O método consiste na avaliação de arquitetura baseando-se em requisitos não funcionais. Seu principal objetivo é identificar as consequências de decisões arquiteturais nos atributos de qualidade do sistema, identificando possíveis trade-offs entre esses diferentes atributos. Vale ressaltar que o ATAM não é feito para prover análises precisas, pois o seu propósito é descobrir riscos decorrentes de decisões arquiteturais.

O resultado da análise arquitetural em relação a um determinado requisito não funcional é composto por riscos, não-riscos, pontos de sensibilidade de arquitetura e pontos de trade-off, descritos a seguir (CLEMENTS; KAZMAN; KLEIN, 2002):

- Riscos: decisões de arquitetura que podem provocar efeitos negativos em relação a um determinado atributo de qualidade; 
- Não-riscos: decisões de arquitetura que podem provocar efeitos positivos em relação a um determinado atributo de qualidade;

- Pontos de sensibilidade de arquitetura: são propriedades críticas para alcançar um determinado atributo de qualidade. Na área de segurança (security), por exemplo, o nível de confidencialidade em uma rede virtual privada pode apresentar como ponto de sensibilidade a quantidade de bits utilizada na criptografia;

- Pontos de trade-off: são propriedades de uma decisão de arquitetura que afetam mais de um atributo de qualidade. Pontos de trade-off são importantes para a análise da arquitetura, pois devem ser analisados os efeitos de uma determinada decisão em mais de um atributo de qualidade.

$\mathrm{Na}$ aplicação do método, é destacada a importância do envolvimento dos participantes durante a geração de cenários de atributo de qualidade, dado que os cenários de qualidade são priorizados em função dos processos de negócio. Em Clements; Kazman e Klein (2002), é citado que a qualidade da avaliação de uma arquitetura de software depende em grande parte da capacidade dos participantes atuarem ativamente na identificação e avaliação cenários de atributos de qualidade mais importantes. O resultado de uma avaliação baseada em cenários de atributos de qualidade depende da seleção dos cenários e de sua relevância para identificar suposições críticas a respeito da arquitetura de software (DOBRICA; NIEMELÁ, 2002).

O método ATAM é composto de nove etapas, detalhadas a seguir, conforme a referência descrita em Software Engineering Institute (2003):

1. Apresentação do método ATAM: consiste em reuniões para apresentar o método a todos os envolvidos no projeto. O processo de avaliação é explicado a todos os participantes, reservando-se um tempo para responder perguntas pertinentes e o que esperar das próximas atividades. Deve-se descrever:

- Os passos do método;

- As técnicas que serão utilizadas para identificação e análise da arquitetura; 
- As saídas da avaliação como os cenários identificados e priorizados, as árvores de utilidade e o conjunto de abordagens arquiteturais identificadas.

2. Apresentação dos objetivos do negócio: apresentação dos objetivos do negócio que motivaram o desenvolvimento. Os participantes da avaliação devem entender o contexto do sistema e as metas principais que orientam seu desenvolvimento. Nesta etapa, o gerente do projeto apresenta um resumo do sistema sob o ponto de vista de negócio, que deve descrever:

- As funções mais importantes do sistema;

- Qualquer restrição, seja técnica, empresarial, econômica, política pertinente ao sistema;

- As metas de negócio e o contexto relevantes ao projeto;

- Os participantes mais importantes;

- Os atributos de qualidade mais importantes e desejados para a arquitetura.

3. Apresentação da arquitetura de software proposta: descrição da arquitetura de software proposta pelo arquiteto de software, relacionando-a aos objetivos do negócio e aos respectivos atributos de qualidade. $\mathrm{Na}$ apresentação, o arquiteto de software descreve a arquitetura em um nível apropriado de detalhes e a seguinte pauta deve ser coberta:

- Restrições técnicas como o hardware e sistema operacional a ser usado;

- Outros sistemas com os quais o sistema irá interagir;

- Abordagens estruturais usadas para satisfazer aos atributos de qualidade estabelecidos.

4. Identificação dos elementos da arquitetura de software: nesta etapa as possíveis abordagens arquiteturais são identificadas, mas não analisadas;

5. Geração da árvore de utilidade dos atributos de qualidade (utility tree): Nesta etapa, a equipe de avaliação, juntamente com o gerente de projeto ou cliente, trabalha para identificar, refinar e priorizar os atributos de qualidade 
mais importantes para a arquitetura por meio de cenários. Isto é alcançado por meio da árvore de utilidade, que utiliza uma abordagem top-down para mapear atributos de qualidade relacionados ao domínio do problema em cenários concretos. A Figura 10 ilustra uma árvore de utilidade.

Figura 10 - Exemplo de árvore de utilidade (utility tree)

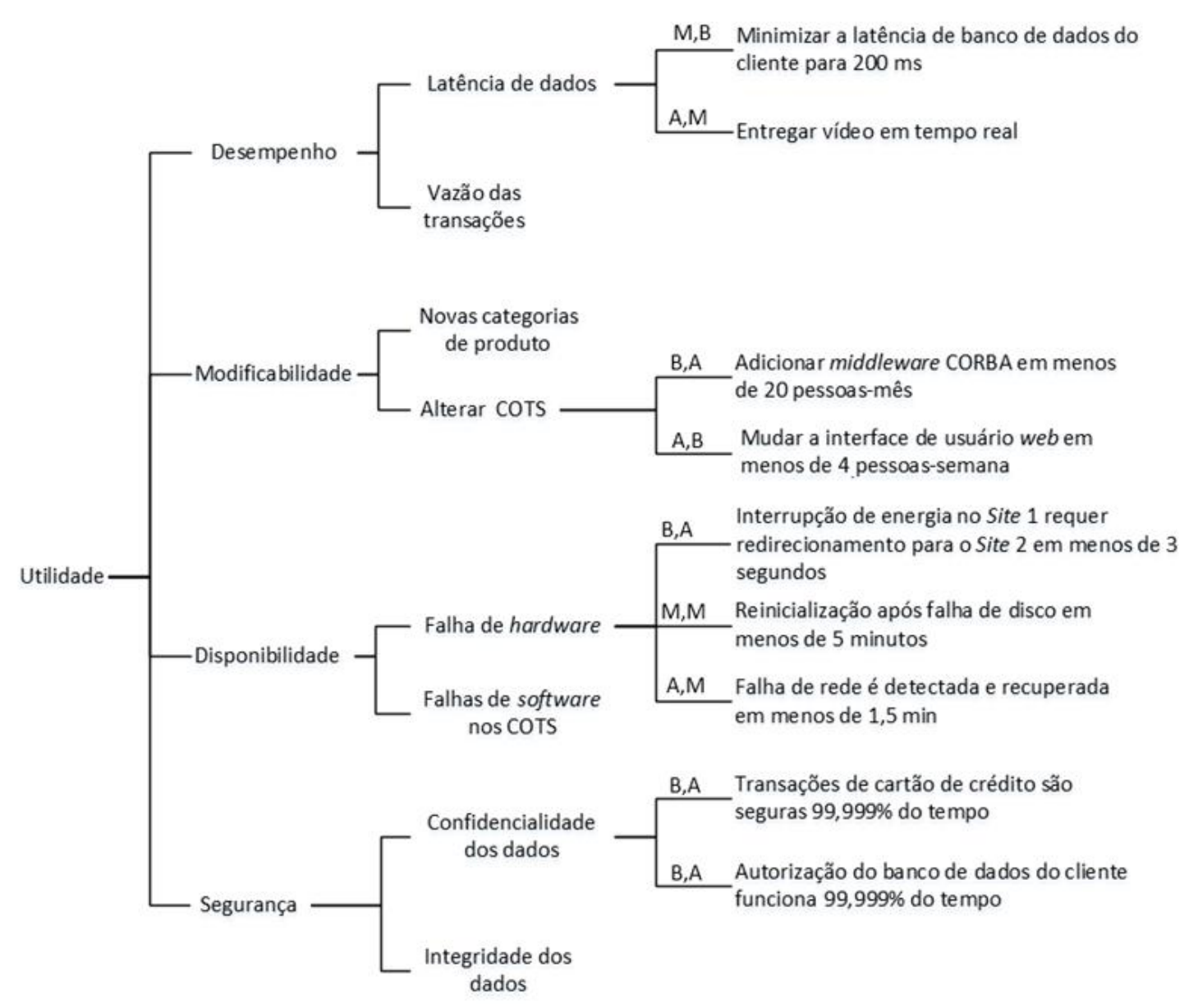

Fonte: Adaptado de Clements; Kazman e Klein (2002)

O primeiro nível da árvore (raiz) equivale à utilidade da árvore a ser analisada. Os nós do segundo nível equivalem aos atributos de qualidade a serem considerados na avalição da arquitetura. $O$ terceiro nível corresponde a refinamentos dos atributos de qualidade descritos no segundo nível, considerando características relacionadas a cada requisito não funcional. Dentre os exemplos deste refinamentos presentes em Clements; Kazman e Klein (2002), são citadas a decomposição do atributo de qualidade desempenho em latência de dados e vazão das transações, e a decomposição do atributo disponibilidade em possíveis categorias de falhas, tais 
como falhas de hardware e de componentes de software, do inglês, Commercial offthe-shelf (COTS). O último nível da árvore (folhas) é composto por cenários concretos relacionados aos atributos de qualidade. Uma vez que todos os cenários estejam preenchidos, os mais importantes segundo a perspectiva de negócio são rotulados com duas marcações ordenadas de priorização com os seguintes valores: A - Alto, M - Médio e B - Baixo, segundo o seguinte critério: a primeira marcação é relativa à importância do cenário para o sucesso do sistema, enquanto a segunda está associada ao grau de dificuldade para se atender o cenário. Dessa forma, cenários com marcações $(A, A)$ são fortes candidatos para análise mais detalhada durante a avaliação da arquitetura de software. A elaboração da árvore de utilidade orienta os envolvidos na avalição para a definição de abordagens arquiteturais que satisfaçam os cenários prioritários. Além disso, força que os atributos de qualidade sejam definidos precisamente. Descrições geralmente vistas em documentos de arquitetura, como por exemplo: "O sistema deve ser robusto e rápido" não são aceitos, visto que não são testáveis. Uma lista de cenários priorizados é esperada como saída da geração da árvore de utilidade e servirá para as demais fases do ATAM.

6. Análise de abordagens arquiteturais - Fase 1: a partir dos cenários de qualidade elencados e priorizados na árvore de utilidade gerada no item anterior, as abordagens de arquitetura que referenciam esses cenários são analisadas. Durante esta etapa, riscos, pontos de sensibilidade e trade-offs são analisados.

Para a documentação das análises realizadas, o método ATAM propõe a seguinte estrutura (CLEMENTS; KAZMAN; KLEIN, 2002):

- Número do cenário: identificação do cenário;

- Cenário: um cenário extraído da árvore de utilidade (etapa 5);

- Atributo: atributo de qualidade envolvido no cenário;

- Ambiente: suposições relevantes sobre o ambiente no qual o sistema reside;

- Estímulo: um enunciado preciso do estímulo de atributo de qualidade incorporado pelo cenário, como por exemplo falha, ameaça, modificação, etc.; 
- Resposta: um enunciado preciso da resposta de atributo de qualidade, como por exemplo: tempo de resposta, medida da dificuldade de modificação, etc.;

- Para cada decisão arquitetural envolvida, os seguintes tópicos são descritos:

- Lista de decisões arquiteturais;

- Pontos de sensibilidade;

- Trade-offs;

○ Riscos;

○ Não-riscos.

- Racionalização: serve como um memorial qualitativo ou quantitativo, que descreve as razões pelas quais as decisões arquiteturais contribuem para atingir os requisitos de qualidade;

- Diagramas de arquitetura de software: um ou mais digramas que auxiliem no entendimento da racionalização.

A Tabela 1 representa o formato proposto por (CLEMENTS; KAZMAN; KLEIN, 2002) para a documentação de arquitetura: 
Tabela 1 - Documentação de arquitetura

Número do Cenário:

Cenário: Descrição do cenário extraído da árvore de utilidades.

Atributo: Atributo de qualidade relacionado ao cenário.

Ambiente: Premissas relevantes sobre o ambiente no qual o sistema será implantado.

Estímulo: uma declaração precisa do estímulo no qual o cenário de atributo de qualidade está relacionado (por exemplo, uma função invocada, uma falha, uma ameaça, uma modificação, etc.).

Resposta: uma declaração precisa da resposta relacionada aos atributos de qualidade (por exemplo, tempo de resposta, medida da complexidade de modificação, etc.).

\begin{tabular}{|l|l|l|l|l|}
\multicolumn{1}{|c|}{$\begin{array}{c}\text { Decisões } \\
\text { Arquiteturais }\end{array}$} & \multicolumn{1}{c|}{$\begin{array}{c}\text { Pontos de } \\
\text { Sensibilidade }\end{array}$} & \multicolumn{1}{c|}{ Trade-offs } & Riscos & Não-riscos \\
\hline $\begin{array}{l}\text { Lista de decisões } \\
\text { arquiteturais } \\
\text { relevantes para os } \\
\text { cenários que afetam } \\
\begin{array}{l}\text { a resposta do } \\
\text { atributo de } \\
\text { qualidade. }\end{array}\end{array}$ & $\begin{array}{l}\text { Pontos de } \\
\text { sensibilidade } \\
\text { associados a cada } \\
\text { decisão de } \\
\text { arquitetura no } \\
\text { cenário em questão. }\end{array}$ & $\begin{array}{l}\text { Pontos de trade-off } \\
\text { relacionados a cada } \\
\text { decisão, com o } \\
\text { impacto em relação } \\
\text { aos demais } \\
\text { atributos de } \\
\text { qualidade. }\end{array}$ & $\begin{array}{l}\text { Descrições } \\
\text { relacionadas ao } \\
\text { efeito negativo de } \\
\text { uma decisão } \\
\text { arquitetural (ou a } \\
\text { ausência da } \\
\text { decisão) no cenário } \\
\text { analisado. }\end{array}$ & $\begin{array}{l}\text { Descrições } \\
\text { relacionadas ao positivo de } \\
\text { efeito decisão } \\
\text { arquitetural no } \\
\text { cenário analisado. }\end{array}$ \\
\hline
\end{tabular}

Racionalização: racional ${ }^{10}$ quantitativo e/ou qualitativo indicando as razões pelas quais a lista de decisões arquiteturais contribui para atingir os atributos de qualidade representado pelo cenário.

Diagramas de Arquitetura de software: diagrama ou diagramas de visões arquiteturais que representam informações que dão suporte à racionalização prévia, acompanhados por um texto explicativo caso seja necessário.

Fonte: Adaptado de Clements; Kazman e Klein (2002)

7. Priorização de cenários: o maior número possível de participantes é reunido para, por meio de um brainstorming, definir novos cenários e priorizá-los. Nesta etapa, podem ser identificados novos cenários de atributos de qualidade, que podem ser adicionados à árvore de utilidade. Uma vez adicionados à lista, os participantes votam nos cenários que irão compor uma lista final de cenários priorizados. Nesta etapa, três tipos de cenários são abordados:

\footnotetext{
${ }^{10}$ Racional (rationale): registro da explicação, justificativa ou razões que levaram à tomada de uma decisão sobre a arquitetura de software de um determinado sistema. O racional de uma decisão pode incluir as premissas, as alternativas e os trade-offs considerados, potenciais consequências da decisão tomada e citações de fontes para informações adicionais (ISO/IEC/IEEE, 2011).
} 
- Cenários de casos de uso: definem o modo como os participantes esperam que o sistema seja utilizado;

- Cenários de crescimento: representam como a arquitetura poderá acomodar mudanças em médio prazo;

- Cenários exploratórios: representam formas extremas de crescimento, por que podem sobrecarregar a arquitetura com muitas mudanças em médio prazo.

8. Análise de abordagens arquiteturais - Fase 2: da mesma forma como realizado na etapa 6 , a equipe de avaliação mapeia os cenários adicionados e priorizados na etapa 7 ;

9. Apresentação de resultados: baseando-se nas informações coletadas nas etapas anteriores, é gerado um relatório detalhando toda informação e possíveis decisões arquiteturais a serem utilizadas.

A essência do método está contida nas etapas 5, 6 e 7. A etapa 5 do método ATAM corresponde à etapa de geração de cenários de atributos de qualidade, sendo estes agrupados na árvore de utilidade. Nessa etapa, os responsáveis pela avaliação se reúnem com os responsáveis por decisões de projeto (equipe de arquitetos de software, gerentes e representantes do cliente) para a geração de cenários, passo de fundamental importância no método, uma vez que na etapa 5 é que são gerados cenários que representam requisitos não funcionais a serem considerados na avaliação da arquitetura (CLEMENTS; KAZMAN; KLEIN, 2002).

A Figura 11 representa a interação entre a etapa 5 e as demais etapas do método ATAM. A geração dos cenários de atributos de qualidade baseia-se nos objetivos de negócio e atributos de qualidade de maior relevância para o processo de negócio identificados na etapa 2, e elementos da arquitetura de software são identificadas na etapa 4 . Os cenários dos atributos de qualidade identificados na etapa 5 , assim como os elementos da arquitetura de software servem como entrada para a etapa 6, na qual as abordagens arquiteturais propostas são avaliadas (VASCONCELLOS NETO, 2009): 
Figura 11 - Relação entre a etapa 5 e demais etapas do ATAM

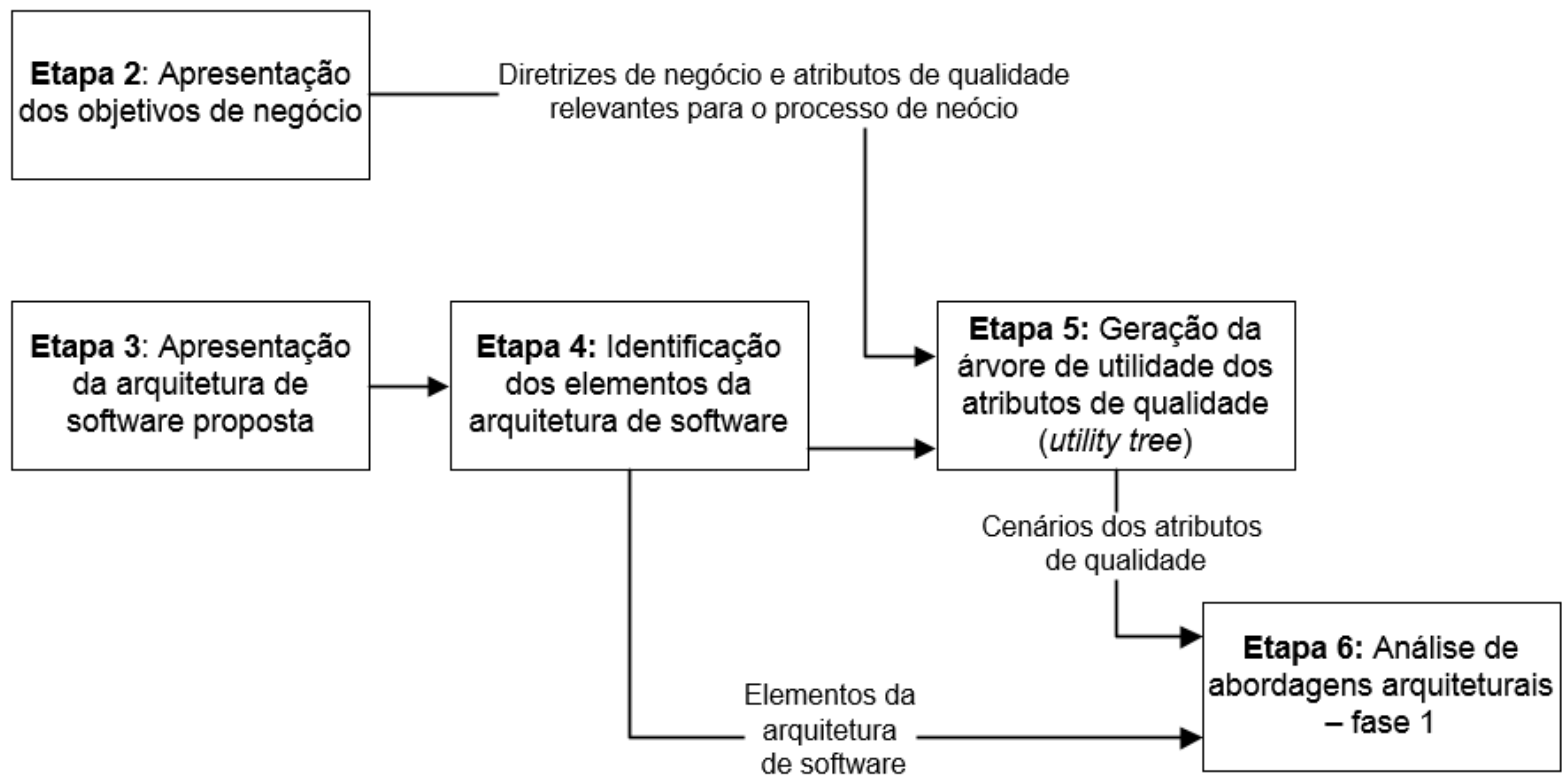

Fonte: Adaptado de Vasconcellos Neto (2009)

No fluxo conceitual do ATAM, os objetivos de negócios são elicitados em reuniões com os participantes do projeto (stakeholders). Esses objetivos são refinados em atributos de qualidade e em cenários arquiteturais. Para suportar cada cenário arquitetural, tomam-se decisões arquiteturais, que são derivadas de abordagens arquiteturais, que por sua vez derivam-se do plano de arquitetura de software. A análise dos cenários e das decisões resulta em identificação de riscos, não-riscos, pontos de sensibilidade e trades-offs na arquitetura de software. Os riscos são sintetizados em um conjunto de categorias de risco, que podem impactar um ou mais objetivos de negócio. Esse fluxo está representado na Figura 12. 
Figura 12 - Fluxo conceitual do ATAM

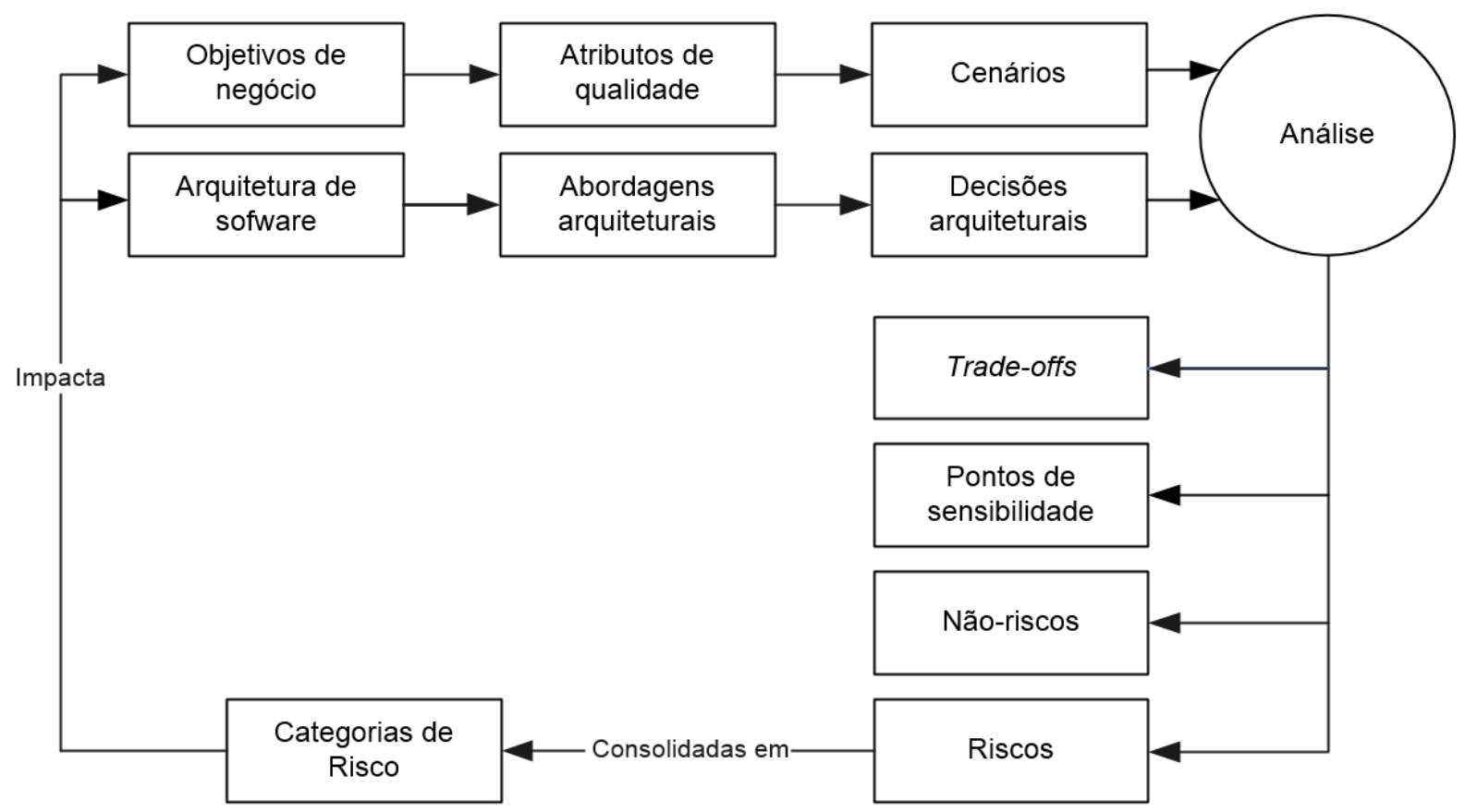

Fonte: Adaptado de Software Engineering Institute (2003).

Com a aplicação do método ATAM para avaliação de arquiteturas de software, os seguintes benefícios são esperados (SOFTWARE ENGINEERING INSTITUTE, 2003):

- Requisitos de atributos de qualidade definidos de forma mais clara e precisa;

- Melhoria na documentação da arquitetura;

- Embasamentos documentados para tomada de decisões arquiteturais;

- Identificação dos riscos no início do ciclo de vida de desenvolvimento;

- Melhoria na comunicação entre os diversos participantes do sistema.

Além dos benefícios listados, pode-se afirmar que o resultado mais importante de um método de avaliação de arquitetura são melhores arquiteturas de software. $O$ ATAM auxilia o arquiteto de software na elicitação de requisitos de qualidade, considerando várias dimensões, analisando os efeitos de cada requisito de forma isolada e de forma integrada (SOFTWARE ENGINEERING INSTITUTE, 2003).

Outra possível alternativa, além do ATAM, para avaliação dos atributos de qualidade de uma arquitetura de software seria a utilização do Método de Análise 
Hierárquica, do inglês, Analytic Hierarchy Process (AHP). O AHP é um método matemático para auxilio em tomadas de decisão que parte do princípio que um determinado sistema pode ser representado por meio de uma estrutura hierárquica (LUDESCHER, 2011).

Uma hierarquia é uma abstração da estrutura de um sistema para estudar as interações funcionais de seus componentes e seus impactos no sistema total. Essa abstração pode tomar várias formas interacionadas, todas descendentes de um objetivo geral (SAATY, 1991). O método AHP poderia ser utilizado para priorizar os atributos de qualidade mais relevantes para o processo de negócio. $O$ detalhamento do uso do AHP no roteiro proposto não faz parte do escopo deste trabalho. Para a elaboração do roteiro proposto, o método de avaliação de arquitetura ATAM foi utilizado, pois o conceito de trade-offs entre atributos de qualidade é um dos principais critérios de avaliação utilizado pelo ATAM.

\subsection{CONCLUSÕES DO CAPÍTULO}

Neste capítulo foi descrito um breve histórico sobre conceitos de arquitetura de software e sua importância, modelo de referência de computação distribuída, conceitos de qualidade de software, normas de qualidade do produto de software, normas de avaliação de produto de software, a relação entre arquitetura de software e requisitos não funcionais, o ciclo de vida do requisito não funcional e métodos de avaliação de arquiteturas de software, detalhando-se o ATAM. Esses conceitos constituem o referencial teórico de engenharia utilizados na elaboração do roteiro proposto de ensino de qualidade de arquitetura de software guiados por requisitos não funcionais. No próximo capítulo, são discutidos os aspectos pedagógicos utilizados na concepção do roteiro de ensino proposto neste trabalho. 


\section{ENSINO DE QUALIDADE DE ARQUITETURA DE SOFTWARE}

\subsection{OBJETIVO dO CAPÍTULO}

O objetivo deste capítulo é embasar a pesquisa, com a dimensão pedagógica do roteiro de ensino de arquitetura de software centrada em requisitos não funcionais. Para isso, apresentam-se as teorias pedagógicas utilizadas na elaboração do roteiro.

\subsection{TEORIAS DE APRENDIZAGEM UTILIZADAS NO ROTEIRO DE ENSINO}

O objetivo do roteiro proposto nesta tese é auxiliar no processo de aprendizagem de qualidade de arquitetura de software guiado por requisitos não funcionais e, por esta razão, é necessário o suporte de teorias pedagógicas de aprendizagem que orientem o processo de ensino/aprendizagem.

Segundo Rosa (2007), sabe-se que é por meio da aprendizagem que o homem muda e transforma o meio. De maneira geral, na maioria das definições do termo aprendizagem, nota-se que vários autores destacam a questão da mudança que, de alguma forma, permanece e é perceptível pelo comportamento. Apresenta-se a seguir, algumas definições de aprendizagem.

De acordo com Campos (1986), a aprendizagem pode ser definida como uma modificação sistemática do comportamento, por efeito da prática ou da experiência, com um sentido de progressiva adaptação ou ajustamento.

Já de acordo com Gagné (1980), a aprendizagem é inferida quando ocorre uma mudança ou modificação no comportamento, mudança essa que permanece por períodos relativamente longos na vida do indivíduo.

A aprendizagem pode ser definida como uma mudança no comportamento que resulta tanto da prática quanto de experiência anteriores (FREEDMAN; KAPLAN; SADOCK, 1997).

É importante também explicitar a aprendizagem como algo que deve ser significativo na vida do indivíduo, na qual se sobressai a qualidade do envolvimento 
pessoal, permanente e que vai ao encontro das necessidades do sujeito. Sabe-se que aquilo que não é tomado como significativo tende a ser abandonado. Assim sendo, e considerando-se a aprendizagem na situação de sala de aula, em que eventos de aprendizagem devem ser favorecidos, torna-se importe referendar a necessidade de estratégias de ensino que aumentem as oportunidades do aprendiz vislumbrar o verdadeiro significado, atingindo o desenvolvimento e posterior mudança, a partir do que lhe é proposto (ROSA, 2007).

As teorias de aprendizagem buscam reconhecer a estratégia envolvida nos atos de ensinar e aprender, partindo do reconhecimento da evolução cognitiva do homem, e tentam explicar a relação entre o conhecimento pré-existente e o novo conhecimento (SANTORO; BORGES; SANTOS, 1999). É importante frisar que no escopo desta pesquisa, as teorias pedagógicas foram somente utilizadas ou referenciadas, visto que o escopo deste trabalho de pesquisa é a proposição de um roteiro de ensino de qualidade de arquitetura de software.

Para a realização desta pesquisa, as teorias de aprendizagem construtivista, aprendizagem significativa e aprendizagem baseadas em problemas foram pesquisadas, e estão detalhadas a seguir.

\subsubsection{Construtivismo}

O Construtivismo, criado na década de 50 pelo biólogo suíço Jean Piaget, pode ser definido como uma filosofia de aprendizado baseada na premissa que, por meio de reflexões sobre as experiências, o conhecimento é construído pelo próprio estudante. Para a construção do conhecimento, o aprendiz cria um modelo mental que o auxilia na estruturação e no uso do conhecimento. $O$ aprendizado ocorre quando o estudante necessita ajustar o seu modelo mental para acomodar novas experiências (CUNNINGHAN; THOMAS; KNUTH, 1993).

Segundo o Construtivismo, a aprendizagem é definida como um processo de reestruturação de conceitos prévios com a assimilação de conceitos novos, permitindo a elevação do nível de abstração do conhecimento através da reorganização dos modelos mentais, que são gerados por meio da interação contínua entre o indivíduo e o meio (POZO, 1998; VICHIDO; ESTRADA; SANCHEZ, 2003). 
Segundo essa teoria, a aprendizagem ocorre mediante desequilíbrios ou conflitos cognitivos. Na relação com a realidade, os sujeitos (alunos) são defrontados com os elementos externos (conhecimentos novos) e sofrem um desequilíbrio nos esquemas cognitivos (conhecimentos prévios). Em seguida a esse estranhamento inicial, ocorre um processo de assimilação, que consiste na interpretação da informação nova com base na referência anterior. Finalmente, acontece a acomodação, quando ocorre a adaptação de novos conceitos ou ideias às suas estruturas existentes, modificando-as. Piaget defende que a relação de equilíbrio entre assimilação e acomodação se rompe em três níveis de complexidade (POZO, 1998):

- Primeiro nível: os conhecimentos prévios tentam se equilibrar com os novos;

- Segundo nível: os esquemas se assimilam e se acomodam reciprocamente;

- Terceiro nível: integração hierárquica de esquemas previamente diferenciados.

Essa posição de Piaget enfatiza que a construção do conhecimento acontece mediante a reorganização dos esquemas cognitivos, produzindo mudanças, integrando-as às novas estruturas conceituais do indivíduo.

A teoria construtivista estimula a criação de simulações de ambientes para que o estudante possa resolver problemas reais e criar seu próprio modelo mental que acomode o novo conhecimento adquirido. Neste ambiente, o professor deixa de atuar como transmissor do conhecimento e atua como orientador e facilitador do aprendizado, preocupando-se em prover ambientes e ferramentas que ajudem os alunos a interpretar as múltiplas perspectivas de análise do problema, auxiliando na consolidação do conhecimento (DUFFY et al., 1993).

De acordo com a teoria construtivista, o conhecimento é construído por intermédio das interações do sujeito (aluno) com o meio que o cerca, buscando compreender novos conceitos e relacioná-los com a realidade, sendo esta uma característica intrínseca de espécie humana.

Estas reflexões acontecem numa relação dialógica, com participação ativa dos alunos no processo de crescimento cognitivo, que leva o aluno a aprender a aprender, a construir seus próprios significados (CARVALHO, 2001). 
De acordo com Piaget, o desenvolvimento cognitivo é um processo que se realiza em todo o ser humano e tem um caráter sequencial, isto é, ocorre em uma série de estágios, sendo cada um deles necessário. Logo cada um deles resulta necessariamente do estágio precedente (exceto o primeiro) e, simultaneamente, prepara o estudante para o estágio seguinte (ROSA, 2007).

Cada estágio de desenvolvimento compreende a realização de uma estrutura cognitiva, e enquanto o aluno incorpora o conhecimento de uma estrutura, já constrói a estrutura seguinte, que será mais complexa e abrangente (ROSA, 2007).

Um ambiente de aprendizado construtivista permite que o aluno eleve o nível de abstração de aprendizado à assimilação de novos conhecimentos, os quais devem ser ministrados em um nível crescente de abstração, o que permite a consolidação do conhecimento. Nesse processo incremental, de constante reformulação dos modelos mentais, o professor deve motivar os alunos a analisar, compreender, interpretar e aplicar o novo conhecimento em uma simulação de um problema real (DICK, 1992).

Segundo Cronjé (1997), o conhecimento é construído pela execução de atividades baseadas em problemas do mundo real. Tais atividades, ministradas em um nível crescente de complexidade, possibilitam a realização de experiências por parte dos alunos que auxiliam no aprendizado.

\subsubsection{Aprendizagem significativa}

A teoria da aprendizagem significativa pode ser classificada como construtivista-cognitivista. Pode-se afirmar que é construtivista porque entende que $o$ conhecimento é construído pelo sujeito da aprendizagem e que é cognitivista porque estuda a construção do conhecimento do sujeito levando em conta a sua interação com o meio físico e social e as consequências advindas disso para a organização interna das suas estruturas cognitivas, que pode ser entendida como o conteúdo total de ideias/conceitos de um indivíduo e de sua organização.

Essa teoria foi elaborada por David Paul Ausubel na década de 60 e tem como principal conceito aprendizagem significativa, que segundo Ausubel é o mecanismo humano, por excelência, para adquirir e armazenar a vasta quantidade de ideias e 
informações representadas em qualquer campo de conhecimento (AUSUBEL; NOVAK; HANESIAN, 1980).

A teoria de aprendizagem de Ausubel considera a aprendizagem significativa como finalidade do processo educativo, por meio de conceitos prévios construídos pelo aprendiz em sua vida cotidiana. Se toda a psicologia educacional fosse reduzida a um único princípio, o fator isolado mais importante que influencia a aprendizagem é aquilo que o aprendiz já conhece, ou seja, o processo de ensino/aprendizagem deve se desenvolver a partir da identificação dos conhecimentos prévios dos estudantes, considerando-os como condição para que ocorra a aprendizagem (NUNES, 2011).

Ainda segundo Nunes (2011), durante a aprendizagem significativa, um novo conteúdo é incorporado aos conceitos existentes na estrutura cognitiva do aprendiz, assim adquirindo um significado para ele. Quando isso ocorre, é observado que o aprendiz consegue generalizar e expressar o conteúdo em sua própria linguagem. Para isto, a nova informação deve ancorar-se em conceitos ou proposições relevantes (integradoras), já existentes na estrutura cognitiva do aprendiz.

Quando o conteúdo escolar a ser aprendido não consegue ligar-se a algo conhecido pelo estudante, ou seja, quando as novas informações são aprendidas sem interagir com conceitos relevantes existentes na estrutura cognitiva do estudante, então ocorre a aprendizagem mecânica (ou automática). Nesse caso, a nova informação é armazenada isoladamente ou por meio de associações arbitrárias na estrutura cognitiva do estudante, não havendo interação entre a nova informação e aquela já armazenada. O estudante só consegue expressar as novas ideias repetindo as mesmas palavras, memorizadas, sem ter, de fato, assimilado os conteúdos envolvidos (NUNES, 2011).

A aprendizagem mecânica e a aprendizagem significativa não são dicotômicas, mas, sim, um contínuo. Muitas vezes, um estudante pode aprender algo mecanicamente e só mais tarde perceber que esse conteúdo se relaciona com algum conhecimento anterior já aprendido. A aprendizagem mecânica é necessária quando um estudante adquire informações numa área de conhecimento completamente nova para ele. 
Segundo Nunes (2011), é importante enfatizar que, na aprendizagem significativa, as novas informações, mesmo que não tenham feito todas as pontes possíveis com os conceitos existentes na estrutura cognitiva do estudante, podem progressivamente ir se interconectando umas com as outras, por meio do trabalho intelectual do estudante, que busca e estabelece essas relações.

Para que a aprendizagem seja significativa, são necessárias duas condições, uma relacionada ao estudante e outra ao material empregado. Quanto ao estudante, faz-se necessário que ele tenha uma predisposição para aprender, relacionando o material novo com o conhecimento existente na sua estrutura cognitiva. Quanto ao material a ser aprendido, é necessário que seja potencialmente significativo para o estudante.

Essas duas condições não são excludentes, pois de nada adianta o material ser potencialmente significativo se a intenção do estudante for simplesmente de memorizá-lo. E, de modo contrário, mesmo que o estudante esteja disposto a aprender de maneira significativa, se o material não for potencialmente significativo, a aprendizagem não ocorrerá.

Não é fácil evidenciar a ocorrência da aprendizagem significativa, pois uma compreensão verdadeira de um conceito ou proposição implica o domínio de significados claros, precisos, diferenciados e transferíveis para outras situações. Verificar se uma aprendizagem ocorreu, apenas pedindo ao estudante que diga os atributos de um conceito ou proposição, implicará no risco de se obter apenas respostas mecanicamente memorizadas. Para evitar esse problema e constatar se 0 estudante desenvolveu as habilidades necessárias à aquisição de uma verdadeira aprendizagem real e significativa, Ausubel sugere a formulação de perguntas e apresentação de problemas usando recursos e situações diferentes daquelas utilizadas anteriormente na instrução inicial e que exijam uma transformação do conhecimento existente (NUNES, 2011).

O aprendizado significativo acontece quando uma informação nova é adquirida, mediante um esforço deliberado por parte do aprendiz em ligar a informação nova com conceitos ou proposições relevantes preexistentes na sua estrutura cognitiva (AUSUBEL; NOVAK; HANESIAN, 1980). 


\subsubsection{Aprendizagem baseada em problemas}

A aprendizagem baseada em problemas, do inglês, Problem Based Learning $(\mathrm{PBL})$, é uma metodologia de ensino/aprendizagem caracterizada pelo uso de problemas da vida real para estimular o desenvolvimento do pensamento crítico e das habilidades de solução de problemas e a aquisição de conceitos fundamentais de uma determinada área do conhecimento (RIBEIRO, 2008).

Segundo Schmidt (1993) apud Ribeiro (2008), Boud e Feletti (1998), a metodologia PBL teve sua origem na Escola de Medicina na Universidade McMaster, localizada no Canadá, no fim dos anos 60 , tendo como base o método de casos de ensino da Escola de Direito da Universidade de Harvard na década de 20 e no modelo desenvolvido na Universidade Case Western Reserve, ambas nos Estados Unidos, para o ensino da medicina nos anos 50 .

A adoção do PBL é justificada por seus idealizadores como uma resposta à percepção dos professores de que os alunos estavam saindo do curso com muitos conceitos, mas pouca capacidade de utilizá-los e integrá-los à prática cotidiana (RIBEIRO; ESCRIVÃO FILHO, 2009) apud (BARROWS, 2006).

Em um ambiente educacional orientado pela metodologia PBL, as competências profissionais - conhecimentos, habilidades e atitudes - não são trabalhadas individualmente. Seu desenvolvimento é decorrente do processo integrado de problemas encontrados, ou passíveis de ser encontrados, na prática profissional futura dos alunos, portanto permeados por aspectos interpessoais, sociais, históricos, éticos, econômicos, ambientais, etc. (RIBEIRO, 2007).

$\mathrm{Na}$ abordagem de ensino/aprendizagem baseada em problemas, antes da teoria ser ensinada aos alunos, um problema é apresentado, para que em pequenos grupos possam explorá-lo e levantar hipóteses, auxiliados por um professor que os estimula a utilizar o conhecimento prévio, e os corrigem, se necessário (RIBEIRO, 2005).

É da natureza humana aprender frente a problemas a serem resolvidos. A aprendizagem baseada em problemas espelha a sequência natural da aprendizagem 
humana filogeneticamente determinada. Em primeiro lugar, a situação-problema deve ser reconhecida; então, naturalmente, o estoque de memórias do indivíduo é acessado. $O$ indivíduo busca os conhecimentos que já possui e que podem estar relacionados ao problema. Dessa forma, a aprendizagem baseada em problemas deriva-se do construtivismo (MARINI FILHO, 2006).

Ainda, segundo Marini Filho (2006), a partir da compreensão do problema e da evocação dos conhecimentos que os alunos já adquiriram, os alunos devem:

- Identificar objetivos de aprendizagem;

- Definir estratégias de estudo e informações a serem buscadas;

- Implementar as pesquisas necessárias;

- Compartilhar os resultados de suas buscas;

- Procurar, quando pertinente, o auxílio de profissionais, professores, especialistas ou outras pessoas que possam contribuir com os objetivos do estudo;

- Discutir opiniões e redefinir, sempre que necessário, todo o processo, até chegarem a conceitos e conclusões compartilhados, referentes não só ao problema em questão, mas a todo o conhecimento necessário para a sua compreensão e eventual solução;

- Avaliar seu próprio desempenho, o desempenho de seus colegas e do grupo na realização da tarefa proposta.

Ao professor cabe o papel de apresentar os problemas, de forma que os alunos possam deles se apropriar, estimular a busca, desafiar o intelecto e provocar a controvérsia construtiva. Desenvolver nos alunos habilidades para a aprendizagem autodirigida e, como consequência, a aptidão para aprender por toda a vida, é um objetivo atribuído à abordagem baseada em problemas (MARINI FILHO, 2006)

Em um processo de aprendizagem guiado pela metodologia PBL, estudantes em pequenos grupos devem explorar uma situação-problema relacionado a uma determinada disciplina e, por meio dessa exploração, espera-se dos alunos que examinem seus gaps de conhecimento e avaliem quais conhecimentos devem ser adquiridos para resolver o problema apresentado (SAVIN-BADEN; MAJOR, 2004). 
A situação-problema proposta em uma abordagem de ensino PBL necessariamente apresenta algumas características, que satisfazem os fundamentos e objetivos educacionais inerentes ao método (RIBEIRO, 2008):

- Deve ser de fim aberto, ou seja, comportar várias respostas igualmente válidas (mesmo não havendo uma resposta correta única, pode haver uma melhor solução);

- Deve ser relevante ao exercício profissional dos alunos;

- Deve ser típico, quer dizer, pode ser facilmente encontrado na prática profissional.

Os problemas propostos devem ser reais ou potencialmente reais e envolver, explícita ou implicitamente, muitas das variáveis sociais e ambientais inerentes ao contexto profissional real e devem ser concebidos de forma a desafiar a capacidade intelectual/emocional e a destreza dos alunos, mas sem frustrar sua capacidade de resolvê-los. Além disso, o problema deve sempre gerar um produto concreto, o que facilita sua apreciação pelos próprios alunos (RIBEIRO; ESCRIVÃO FILHO, 2009).

No Brasil, instituições de ensino de Engenharia de Computação e Ciência de Computação têm utilizado abordagens de ensino baseadas em PBL, como por exemplo: Instituto Tecnológico de Aeronáutica (ITA) (NOBRE et al., 2006), (COUTINHO et al., 2012); Universidade de São Paulo (USP) (KALATZIS, 2008), (RIBEIRO; ESCRIVÃO FILHO, 2009), Universidade Federal de Pernambuco (UFPE) (CAVALCANTI et al., 2008), (SANTOS et al., 2009), (OLIVEIRA; RODRIGUES; GARCIA, 2012) (DOS SANTOS; FURTADO; LINS, 2014); Universidade Estadual de Feira de Santana (UEFS) (ANGELO; CRISTINA; PIRES, 2013).

As teorias consideradas no roteiro de ensino se relacionam, pois tanto a teoria de aprendizado significativo e aprendizagem baseada em problemas basearam-se no modelo construtivista dos processos cognitivos humanos, dado que no processo de assimilação de conhecimentos, o estudante adquire conceitos e organiza-se a sua estrutura cognitiva. 


\subsection{IMPORTÂNCIA DO APRENDIZADO DE QUALIDADE DE ARQUITETURA DE SOFTWARE}

Aplicações de software modernas envolvem adaptabilidade, escalabilidade, interoperabilidade, distribuição e portabilidade. Conforme 0 tamanho e a complexidade das aplicações crescem, o problema do design ultrapassa o nível de complexidade dos algoritmos e das estruturas de dados da computação, englobando a organização dos diversos componentes que compõem o sistema, seus protocolos de comunicação, a divisão das funcionalidades entre os elementos do sistema, os mecanismos para a implementação dos requisitos não funcionais, entre outros (SHAW; GARLAN, 1996).

A escolha de estilos arquiteturais e a implementação entre diversas alternativas que satisfaçam os requisitos funcionais e não funcionais constituem o nível arquitetural de design (SHAW; GARLAN, 1996).

Os documentos Computer Science Curricula 2013 (ACM/IEEE-CS JOINT TASK FORCE ON COMPUTING CURRICULA, 2013) e Curriculum Guidelines for Undergraduate Degree Programs in Computer Engineering (ACM/IEEE-CS JOINT TASK FORCE ON COMPUTING CURRICULA, 2004), ambos propostos pela The Joint Task Force on Computing Curricula e IEEE Computer Society - Association for Computing Machinery oferecem uma visão muito mais ampla de Engenharia de Software, baseada em fundamentos teóricos e conceituais de várias disciplinas da Ciência da Computação e Engenharia de Computação.

A proposta dos documentos citados visa formar profissionais de computação que sejam capazes de relacionar a teoria com a prática, e as decisões arquiteturais com impactos na qualidade do sistema.

\subsubsection{Currículo de Engenharia de Computação}

Segundo o currículo proposto em conjunto por ACM/IEEE-CS Joint Task Force on Computing Curricula (2004), Engenharia de Computação pode ser definida como a disciplina que incorpora a ciência e tecnologia de projeto, construção, implementação e manutenção de software e hardware de componentes de sistemas computacionais e sistemas controlados por computadores. Esse curso tem sido 
tradicionalmente visto como uma combinação de Ciência da Computação e Engenharia Elétrica, porém tem evoluído ao longo das últimas três décadas como um curso à parte, mas ainda intimamente ligado à Ciência da Computação e Engenharia Elétrica. Engenharia de Computação possui bases solidamente fundamentadas nas teorias e princípios da computação, matemática, ciência e engenharia e aplica essas teorias e princípios para resolver problemas relacionados ao projeto de hardware, software, redes e processos.

De acordo com Cugnasca, Melnikoff e Camargo Jr. (2014) apud ACM/IEEE-CS JOINT TASK FORCE ON COMPUTING CURRICULA (2004), o currículo proposto, de um curso de Engenharia de Computação é composto por 18 matérias: algoritmos, arquitetura e organização de computadores, engenharia de sistemas de computadores, circuitos e sinais, sistemas de banco de dados, lógica digital, estruturas discretas, processamento digital de sinais, eletrônica, sistemas embarcados, interação humano-computador, redes de computadores, sistemas de programação, fundamentos de programação, probabilidade e estatística, tópicos sociais e profissionais, engenharia de software e projeto e fabricação de circuitos Verylarge-scale integration (VLSI). As disciplinas do curso contêm os conteúdos definidos nas matérias, dessa forma, tópicos de uma matéria podem ser ministrados em uma ou mais disciplinas.

O currículo resultante proposto pelo ACM/IEEE-CS Joint Task Force on Computing Curricula (2004) possui um balanceamento entre teoria e prática. Dessa forma, os estudantes devem considerar um problema significativo e associá-lo a uma disciplina e, após resolver o problema, os alunos têm a oportunidade de mostrar sua capacidade para fornecer uma solução. Tipicamente, a solução deve envolver a concepção, projeto e implementação de algum projeto ou produto que contenha componentes de hardware e/ou software.

A experiência do projeto, muitas vezes, inclui equipes interdisciplinares, o que reflete as práticas da indústria. Idealmente, a experiência do projeto deve incorporar padrões de engenharia e restrições realistas para representar o que pode ocorrer em um ambiente real (ACM/IEEE-CS JOINT TASK FORCE ON COMPUTING CURRICULA, 2004). 
Outro ponto importante é a experiência de laboratório, uma parte essencial do currículo de Engenharia da Computação. Como em qualquer currículo de engenharia, é importante que os alunos de Engenharia de Computação tenham oportunidades para observar, explorar e manipular características e comportamentos de dispositivos reais, sistemas e processos (ACM/IEEE-CS JOINT TASK FORCE ON COMPUTING CURRICULA, 2004).

Ainda segundo o currículo proposto pela ACM/IEEE-CS Joint Task Force on Computing Curricula (2004), em disciplinas de laboratório, os alunos são motivados a realizar atividades práticas, da natureza da engenharia, o que fornece uma base para outros elementos importantes da atividade prática. Trabalhos práticos em um ambiente de laboratório ajudam os alunos a desenvolver a confiança em sua capacidade técnica. Atividades de laboratório também deve incluir o uso de ferramentas e técnicas de simulação para projetar sistemas computacionais. A utilização de simuladores para modelar sistemas reais permite aos estudantes 0 estudo do comportamento de um sistema antes de implementá-lo.

Como complemento às habilidades técnicas, o aluno de Engenharia de Computação também deve aprender conhecimentos não técnicos associados com o processo de negócio (ACM/IEEE-CS JOINT TASK FORCE ON COMPUTING CURRICULA, 2004).

Os tópicos das disciplinas do curso de Engenharia de Computação que abordam conceitos relacionados à arquitetura de software e à qualidade de arquitetura de software foram listados na Tabela 2. Esses itens foram abordados diretamente ou indiretamente pelo roteiro de ensino e aprendizado proposto. Considerando-se o ensino de qualidade de arquitetura de software, os tópicos mais significativos para a elaboração do roteiro em cada disciplina foram sufixados com o símbolo [S], enquanto que os tópicos que podem ser considerados pré-requisitos para a aplicação do roteiro proposto neste trabalho foram sufixados com o símbolo [P].

Os detalhes das disciplinas listadas, contendo os tópicos ministrados em cada uma delas, encontram no Apêndice $C$. 
Tabela 2 - Disciplinas do curso de Engenharia de Computação e respectivos tópicos que abordam conceitos relacionados à arquitetura de software e à qualidade de arquitetura de software

\begin{tabular}{|c|c|}
\hline $\begin{array}{l}\text { Disciplina do Curso de } \\
\text { Engenharia de Computação }\end{array}$ & $\begin{array}{l}\text { Tópicos das disciplinas que abordam conceitos relacionados à } \\
\text { arquitetura de software e à qualidade de arquitetura de software }\end{array}$ \\
\hline \multirow{4}{*}{$\begin{array}{l}\text { Fundamentos de } \\
\text { Programação }\end{array}$} & Análise e projeto orientados a objeto [P] \\
\hline & Programação orientada a eventos e programação concorrente [S] \\
\hline & Padrões de Projeto [S] \\
\hline & Tratamento de Exceções [P] \\
\hline \multirow{14}{*}{$\begin{array}{l}\text { Engenharia de Sistemas de } \\
\text { Computação }\end{array}$} & Diferentes modelos de ciclos de vida: pontos fortes de cada um deles [S] \\
\hline & $\begin{array}{l}\text { Avaliação de diversas alternativas de projeto e como a escolha da estratégia } \\
\text { de projeto afeta o sistema resultante [S] }\end{array}$ \\
\hline & Exemplos de trade-offs em sistemas computacionais [S] \\
\hline & Elicitação de requisitos funcionais e não funcionais [S] \\
\hline & Abordagens para extração de requisitos funcionais e não funcionais [S] \\
\hline & Quantificação dos requisitos não funcionais [S] \\
\hline & Conceitos de prototipação e simulação [S] \\
\hline & Elementos qualidade em projetos de software [S] \\
\hline & Importância do uso de padrões e referências [S] \\
\hline & Modelos de maturidade, padrões e referências [S] \\
\hline & $\begin{array}{l}\text { Diferentes abordagens de projetos de arquitetura de software: pontos fortes e } \\
\text { fracos [S] }\end{array}$ \\
\hline & Testes de sistema e diagnostico de falhas [P] \\
\hline & Tipos de manutenção: corretiva e evolutiva [P] \\
\hline & $\begin{array}{l}\text { Natureza multidisciplinar associada ao desenvolvimento de sistemas } \\
\text { computacionais [S] }\end{array}$ \\
\hline \multirow{12}{*}{ Engenharia de Software } & $\begin{array}{l}\text { Construção de sistemas computacionais que satisfaçam os requisitos do } \\
\text { usuário [S] }\end{array}$ \\
\hline & Ciclo de vida de um sistema de software [P] \\
\hline & $\begin{array}{l}\text { Uso de técnicas de projeto de software em estágios iniciais da programação } \\
\text { [S] }\end{array}$ \\
\hline & Requisitos funcionais e não funcionais [S] \\
\hline & Arquitetura de software [S] \\
\hline & Projeto para reutilização de software [S] \\
\hline & Prototipação [S] \\
\hline & Técnicas de inspeção [S] \\
\hline & $\begin{array}{l}\text { Uso de técnicas para medição para controle de qualidade do sistema em } \\
\text { desenvolvimento [S] }\end{array}$ \\
\hline & $\begin{array}{l}\text { Avaliação de ferramentas, métodos e abordagens mais adequadas para } \\
\text { determinados cenários de desenvolvimento de software [S] }\end{array}$ \\
\hline & Verificação e validação [P] \\
\hline & Uso de métricas [S] \\
\hline
\end{tabular}

Fonte: Autor

\subsubsection{Currículo de Ciência da Computação}

De acordo com Shackelford et al. (2006), a Ciência da Computação possui uma vasta abrangência de conceitos, desde fundamentos teóricos de computação e 
fundamentos de algoritmos ao desenvolvimento em áreas como robótica, visão computacional, sistemas inteligentes, bioinformática, entre outras.

Pelo currículo do curso de Ciência da Computação proposto no documento Computer Science Curricula 2013 - Curriculum Guidelines for Undergraduate Degree Programs in Computer Science (ACM/IEEE-CS JOINT TASK FORCE ON COMPUTING CURRICULA, 2013), um aspecto fundamental do curso é a compreensão da interação entre teoria e prática e os elos de ligação entre eles. Os graduandos devem entender como aplicar o conhecimento adquirido para resolver problemas reais, devendo ser capazes de projetar e melhorar um sistema baseado em uma avaliação quantitativa e qualitativa da sua funcionalidade, usabilidade e desempenho.

Os alunos devem considerar várias soluções para um determinado problema e entender que a seleção entre elas não é uma atividade puramente técnica, envolvendo aspectos de negócios, uma vez que estas soluções terão um impacto real na vida das pessoas. $O$ graduado nesse curso também deve ser capaz de comunicar a sua solução para os demais colegas, incluindo o porquê e como uma solução resolve o problema e quais premissas foram assumidas.

O entendimento das diversas perspectivas de um sistema também faz parte da formação dos graduados de um programa de Ciência da Computação, que devem ser capazes de pensar em vários níveis de detalhe e abstração. Esse entendimento deve transcender os detalhes de implementação dos vários componentes computacionais, para abranger o nível de arquitetura de software e os processos envolvidos na sua construção e análise. Modelagem e simulação de sistemas reais também representam um conhecimento essencial para cientistas da computação para avaliação de comportamento de sistemas e validação de modelos.

Para garantir que os graduados possam aplicar com sucesso o conhecimento que adquiriram nas disciplinas, todos egressos dos programas de Ciência da Computação devem ser envolvidos em pelo menos um projeto substancial. Na maioria dos casos, essa experiência deveria ser um projeto de desenvolvimento de software, que possa desafiar os alunos, envolvendo aspectos de avaliação de diversas alternativas técnicas, cada uma com seus respectivos trade-offs. Dessa forma, os 
estudantes têm a oportunidades para desenvolver suas habilidades interpessoais de comunicação como parte de sua experiência do projeto.

Os tópicos das disciplinas do curso de Ciência da Computação que abordam conceitos relacionados à arquitetura de software e à qualidade de arquitetura de software foram listados na Tabela 3. Esses itens foram abordados diretamente ou indiretamente pelo roteiro de ensino e aprendizado proposto. Considerando-se o ensino de qualidade de arquitetura de software, os tópicos mais significativos para a elaboração do roteiro em cada disciplina foram sufixados com o símbolo [S], enquanto que os tópicos que podem ser considerados pré-requisitos para a aplicação do roteiro foram sufixados com o símbolo [P].

Os detalhes das disciplinas listadas, contendo os tópicos ministrados em cada uma delas, encontram no Apêndice C. 
Tabela 3 - Disciplinas do curso de Ciência da Computação e respectivos tópicos que abordam conceitos relacionados à arquitetura de software e à qualidade de arquitetura de software

\begin{tabular}{|c|c|}
\hline $\begin{array}{l}\text { Disciplina do Curso de Ciência da } \\
\text { Computação }\end{array}$ & $\begin{array}{c}\text { Tópicos das disciplinas que abordam conceitos } \\
\text { relacionados à arquitetura de software e à qualidade de } \\
\text { arquitetura de software }\end{array}$ \\
\hline \multirow{3}{*}{ Linguagens de Programação } & Análise e projeto orientados a objeto [P] \\
\hline & \begin{tabular}{|lllll}
$\begin{array}{l}\text { Programação orientada a } \\
\text { concorrente [S] }\end{array}$ & eventos e programação \\
\end{tabular} \\
\hline & Tratamento de exceções [P] \\
\hline \multirow{4}{*}{$\begin{array}{l}\text { Fundamentos de Desenvolvimento de } \\
\text { Software }\end{array}$} & Conceitos de especificação de requisitos de software [S] \\
\hline & Programação defensiva [S] \\
\hline & Revisão de código [S] \\
\hline & Fundamentos de testes e geração de testes [P] \\
\hline Ciência computacional & Ferramentas e técnicas de simulação [S] \\
\hline \multirow{20}{*}{ Engenharia de Software } & $\begin{array}{l}\text { Introdução a modelos de processos de software (cascata, } \\
\text { incremental e ágil) [P] }\end{array}$ \\
\hline & Conceitos de qualidade de software [S] \\
\hline & Modelos de maturidade de software [S] \\
\hline & Métricas de processo de software [S] \\
\hline & Ferramentas para testes estáticos e dinâmicos [P] \\
\hline & Elicitação de requisitos funcionais e não funcionais [S] \\
\hline & $\begin{array}{l}\text { Requisitos não funcionais e seu relacionamento com } \\
\text { qualidade de software [S] }\end{array}$ \\
\hline & $\begin{array}{lll}\text { Aceitabilidade de certezas/incertezas relacionadas a } \\
\text { sistemas de software e seu comportamento [S] }\end{array}$ \\
\hline & Prototipação [S] \\
\hline & Validação de requisitos [S] \\
\hline & $\begin{array}{l}\text { Princípios de projeto de sistemas, níveis de abstração } \\
\text { (projeto arquitetural e projeto detalhado) [S] }\end{array}$ \\
\hline & Padrões de Projetos [S] \\
\hline & $\begin{array}{l}\text { Projeto de atributos de qualidade: eficiência, desempenho, } \\
\text { tolerância a falha, funcionalidade, confiabilidade [S] }\end{array}$ \\
\hline & Medição e análise da qualidade do projeto [S] \\
\hline & Trade-offs entre diferentes aspectos de qualidade [S] \\
\hline & $\begin{array}{l}\text { Mecanismos para construção de sistemas de software com } \\
\text { qualidade [S] }\end{array}$ \\
\hline & Verificação e validação [P] \\
\hline & Inspeções [S] \\
\hline & \begin{tabular}{|lccccc}
$\begin{array}{l}\text { Papéis e responsabilidades em } \\
\text { desenvolvimento de software [S] }\end{array}$ & uma & equipe & de \\
\end{tabular} \\
\hline & Resolução de conflitos em times [S] \\
\hline
\end{tabular}

Fonte: Autor 


\subsection{REQUISITOS PARA O ENSINO DE QUALIDADE DE ARQUITETURA DE SOFTWARE CONSIDERADOS NO ROTEIRO}

Tanto a teoria construtivista como a de aprendizagem significativa afirmam que o aprendizado se consolida sobre as bases já existentes no aluno (AUSUBEL; NOVAK; HANESIAN, 1980; ROSA, 2007). Portanto, para que o aprendizado sobre qualidade de arquitetura de software se concretize de forma efetiva, o roteiro proposto tem como pré-requisitos o ensino de tópicos fundamentais da área de Engenharia de Software, como por exemplo: modelagem de negócios, orientação a objetos e o ciclo de vida de desenvolvimento de software, além de conhecimentos de programação. Esses tópicos fazem parte tanto do currículo do curso de Ciências da Computação, como do curso de Engenharia de Computação propostos pela The Joint Task Force on Computing Curricula e IEEE Computer Society - Association for Computing Machinery (ACM/IEEE-CS JOINT TASK FORCE ON COMPUTING CURRICULA, 2004, 2013).

A Tabela 4 e Tabela 5 listam os pré-requisitos do roteiro proposto nas disciplinas do curso de Engenharia de Computação e Ciência da Computação respectivamente, propostos pela The Joint Task Force on Computing Curricula e IEEE Computer Society - Association for Computing Machinery (ACM/IEEE-CS JOINT TASK FORCE ON COMPUTING CURRICULA, 2004, 2013). Essas telas contém os tópicos que foram sufixados com o símbolo $[\mathrm{P}]$ na Tabela 2 e na Tabela 3 : 
Tabela 4 - Tópicos das disciplinas do curso de Engenharia de Computação considerados requisitos pelo roteiro proposto

\begin{tabular}{|l|l|}
\hline \multicolumn{1}{|c|}{$\begin{array}{c}\text { Disciplina do Curso de Engenharia de } \\
\text { Computação }\end{array}$} & $\begin{array}{c}\text { Tópicos das disciplinas que abordam conceitos } \\
\text { relacionados à arquitetura de software e à qualidade } \\
\text { de arquitetura de software }\end{array}$ \\
\hline \multirow{2}{*}{ Fundamentos de Programação } & Análise e projeto orientados a objeto [P] \\
\cline { 2 - 2 } & Tratamento de Exceções [P] \\
\hline \multirow{2}{*}{ Engenharia de Sistemas de Computação } & Testes de sistema e diagnostico de falhas [P] \\
\cline { 2 - 2 } & Tipos de manutenção: corretiva e evolutiva [P] \\
\hline \multirow{2}{*}{ Engenharia de Software } & Ciclo de vida de um sistema de software [P] \\
\cline { 2 - 2 } & Verificação e validação [P] \\
\hline
\end{tabular}

Fonte: Autor

Tabela 5 - Tópicos das disciplinas do curso de Ciência da Computação considerados requisitos pelo roteiro proposto

\begin{tabular}{|l|l|}
\hline $\begin{array}{l}\text { Disciplina do Curso de Ciência da } \\
\text { Computação }\end{array}$ & \multicolumn{1}{|c|}{$\begin{array}{c}\text { Tópicos das disciplinas que abordam conceitos } \\
\text { relacionados à arquitetura de software e à qualidade } \\
\text { de arquitetura de software }\end{array}$} \\
\hline \multirow{2}{*}{ Linguagens de Programação } & Análise e projeto orientados a objeto [P] \\
\cline { 2 - 2 } & Tratamento de exceções [P] \\
\hline $\begin{array}{l}\text { Fundamentos de Desenvolvimento de } \\
\text { Software }\end{array}$ & Fundamentos de testes e geração de testes [P] \\
\hline \multirow{2}{*}{ Engenharia de Software } & $\begin{array}{l}\text { Introdução a modelos de processos de software (cascata, } \\
\text { incremental e ágil) [P] }\end{array}$ \\
\cline { 2 - 2 } & Ferramentas para testes estáticos e dinâmicos [P] \\
\cline { 2 - 2 } & Verificação e validação [P] \\
\hline
\end{tabular}

Fonte: Autor

O propósito da modelagem de negócio (domínio do problema) é auxiliar no entendimento, na análise, na melhoria, na substituição ou na automatização de um processo de negócio, além de prover um mecanismo de abstração que enfatize as características relevantes do problema em questão. $\mathrm{O}$ conceito de modelagem de negócio é crucial para que o aluno compreenda o contexto do problema que deverá ser parcial ou totalmente automatizado por meio de um sistema de software.

O entendimento de conceitos de modelagem orientada a objetos, os quais englobam princípios de abstração, encapsulamento, hierarquia e tipos, descritos em $\mathrm{BOOCH}$ et al. (2009), também foi considerado um requisito para o ensino de qualidade de arquitetura de software, pois os conceitos de qualidade de arquitetura de software 
são ministrados no roteiro proposto utilizando-se sistemas orientados a objetos. Os seguintes diagramas da UML foram utilizados durante a aplicação do roteiro proposto:

- Diagrama de classes: modela a visão estática (estrutural) do sistema, por meio de um conjunto de classes, interfaces e seus relacionamentos;

- Diagrama de sequência: modela a visão dinâmica (comportamental) do sistema, enfatizando o aspecto temporal na troca de mensagens entre objetos por meio de cenários de utilização do sistema;

- Diagrama de componentes: representa a organização e as dependências entre um conjunto de componentes, endereçando a visão de implementação estática do sistema;

- Diagrama de Implantação: visão estrutural de um conjunto de nós (elementos de infraestrutura) e de seus relacionamentos.

O ensino do ciclo de desenvolvimento de software auxilia o aprendizado de arquitetura de software na medida em que esclarece ao aluno que a atividade de desenvolvimento de software engloba outras tarefas além da codificação. Para isso, é necessário enfatizar a importância do ciclo de desenvolvimento de software, que abrange um conjunto de atividades para transformar os requisitos do usuário em um sistema de software, composto pelas seguintes fases $(\mathrm{BOOCH}$; RUMBAUGH; JACOBSON, 2005):

- Engenharia de Sistema: modelagem do processo de negócio, atividade essencial para o entendimento do domínio do problema, independentemente de idiossincrasias tecnológicas;

- Análise de Requisitos: modelagem orientada a objetos do sistema utilizandose os diagramas da UML, provendo um entendimento detalhado dos requisitos;

- Projeto: etapa na qual ocorre o dimensionamento do sistema, ou seja, especificações técnicas de hardware e software, componentes, arquiteturas, considerando-se os requisitos funcionais e não funcionais do sistema computacional em construção;

- Codificação: implementação dos subsistemas que compõem o sistema de software, suas dependências, interfaces, componentes e arquiteturas; 
- Validação: planejamento e aplicação dos testes, incluindo testes de integração e de sistema. Antes da entrega do sistema, é necessária a homologação por parte do cliente.

A Figura 13 descreve o ciclo de desenvolvimento descrito, destacando os artefatos produzidos em cada fase:

Figura 13 - Ciclo de Desenvolvimento de software

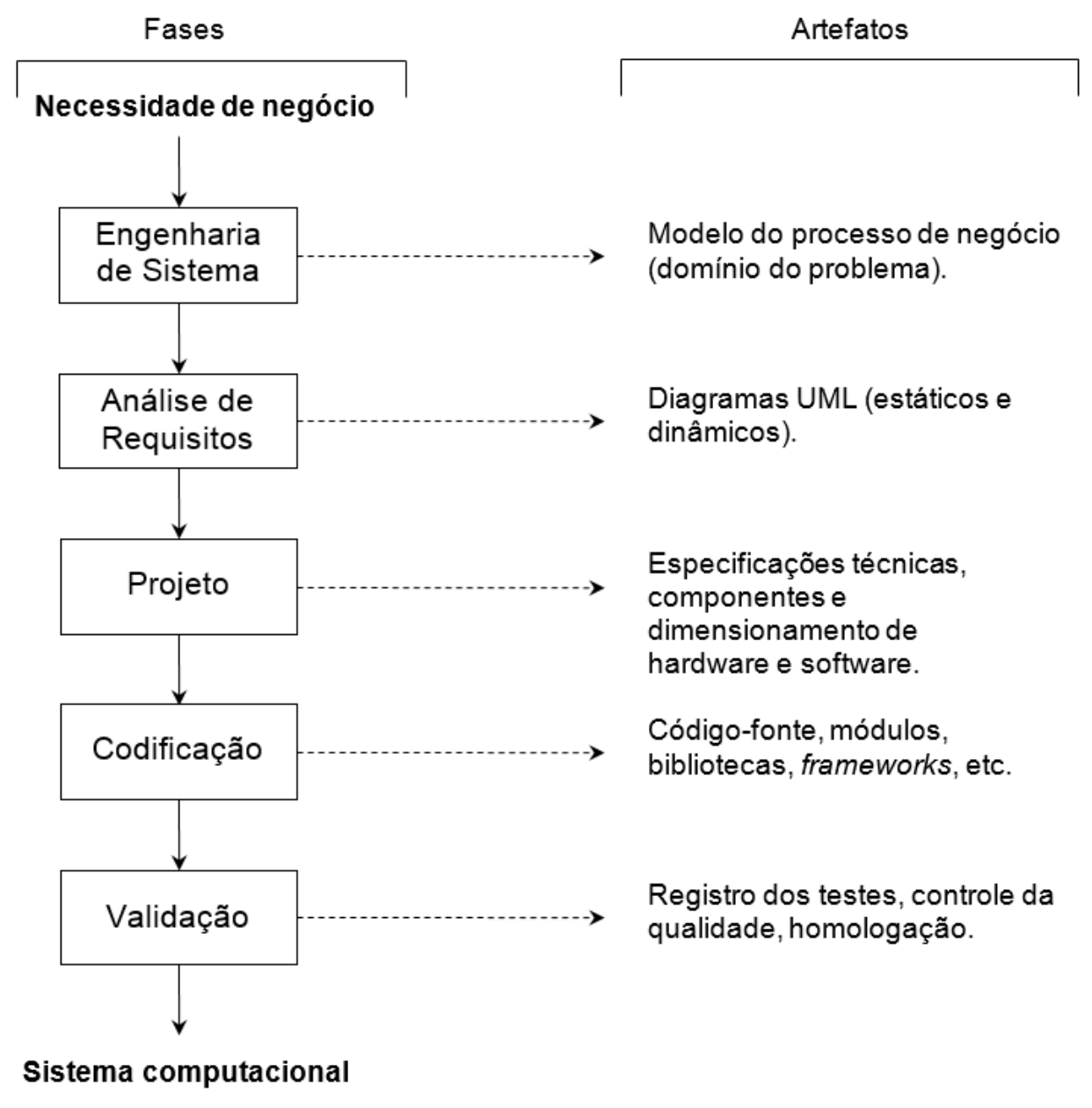

Fonte: Adaptado de Booch; Rumbaugh e Jacobson (2005)

Considerando-se as mudanças que ocorrem durante 0 processo de desenvolvimento de um sistema de software (mudanças nos requisitos, tecnológicas e mercadológicas), o ciclo de desenvolvimento representado na Figura 13 deve ser aplicado utilizando-se uma abordagem iterativa e incremental, o que potencialmente 
traz os seguintes benefícios (BOOCH; RUMBAUGH; JACOBSON, 2005; KRUCHTEN, 2003):

- Identificação dos riscos e criticidades nas fases iniciais do projeto;

- Estabelecimento de uma arquitetura para direcionar o desenvolvimento do sistema;

- Estabelecimento de planos de contingência para melhor lidar com requisitos e mudanças inevitáveis;

- Construção incremental do sistema, o que diminui a probabilidade de mudanças radicais em estágios tardios do projeto, quando tais mudanças seriam muito caras;

- Possibilidade de validações periódicas por parte do usuário, aumentando as chances da construção do "sistema correto".

\subsection{CONCLUSÕES DO CAPÍTULO}

Neste capítulo, foram apresentados os aspectos pedagógicos que orientaram na concepção da proposta do roteiro de ensino. Os aspectos de engenharia e de pedagogia, estudados nos Capítulos 2 e 3, respectivamente, constituem a base teórica para a elaboração do roteiro de ensino proposto neste trabalho, apresentado no próximo capítulo. 


\section{PROPOSTA DE UM ROTEIRO PARA O ENSINO DE QUALIDADE DE ARQUITETURA DE SOFTWARE GUIADO POR REQUISITOS NÃO FUNCIONAIS}

\subsection{OBjetivo do capítulo}

O objetivo deste capítulo é propor um roteiro para o ensino de qualidade de arquitetura de software guiado por requisitos não funcionais que representa a contribuição principal deste trabalho de pesquisa. São descritas as contribuições das referências teóricas estudadas nos Capítulos 2 e 3 na elaboração do roteiro, assim como os princípios técnicos e pedagógicos que nortearam sua definição. Por fim, detalham-se as etapas da aplicação do roteiro em disciplinas dos cursos de graduação e pós-graduação em Engenharia de Computação.

\subsection{PROCESSO dE CRIAÇÃO DO ROTEIRO DE ENSINO DE QUALIDADE DE ARQUITETURA DE SOFTWARE}

A ideia para a elaboração de um roteiro de ensino de qualidade de arquitetura de software nasceu em meados de 2003, quando o autor desta tese, iniciou a atividade de monitoria em várias disciplinas do curso de Engenharia Elétrica da Escola Politécnica da USP sob orientação do Prof. Dr. Reginaldo Arakaki, co-orientador deste trabalho e orientador da dissertação de Mestrado.

Os interesses de pesquisa do orientado e orientador convergiram com a proposição de uma pesquisa para a definição de um framework para o ensino de arquitetura de software, tema de pesquisa da dissertação de Mestrado defendida em 2005 (ANDRADE, 2005).

A pesquisa proposta na dissertação de Mestrado teve como objetivo a proposição de um framework para o ensino de arquitetura de software, visando à aprendizagem dos conceitos teóricos e principalmente práticos de arquitetura de software e, contribuindo para o desenvolvimento da percepção de sua importância em sistemas computacionais. 
Para o ensino de arquitetura de software, foram elaborados kits de estudo para o aprendizado de arquitetura de software. A concepção do kit de estudo foi baseada no meta-modelo pedagógico definido pela Open Universiteit Nederland - Educational Modeling Language (OUNL-EML) (KOPER; MANDERVELD, 2004). Os kits elaborados possuem um nível de crescente de complexidade, oferecendo a possibilidade de um aprendizado incremental. Os seguintes kits de estudo foram elaborados (ANDRADE; ARAKAKI, 2005):

- Instalação e configuração da plataforma de desenvolvimento e produção;

- Modelo Model-View-Controller (MVC);

- Arquitetura de 2 camadas;

- Modelos de Componentes;

- Acesso aos dados;

- Arquitetura de 3 camadas;

- Arquitetura de $n$ camadas.

Nas aplicações do framework de ensino de arquitetura proposto no Mestrado, foram realizados dois tipos de experimentos suportados pelos kits de estudo (ANDRADE, 2005):

- Construção de todo o sistema de software pelos alunos: os conceitos de arquitetura de software eram ministrados durante a construção de um sistema de software pelos alunos da disciplina, divididos em grupos. O experimento considerando a construção de um sistema de software pelos alunos foi aplicado duas vezes no ano de 2003, e os resultados foram aquém do esperado, pois o processo de ensino/aprendizagem dos conceitos de arquitetura de software foi prejudicado, devido ao tempo gasto em atividade de instalação e configuração do ambiente distribuído utilizado na disciplina, pois a maioria dos alunos não tinha familiaridade com o desenvolvimento de sistemas para ambientes distribuídos. A título de exemplo, em uma das disciplinas, a instalação e configuração do ambiente por alguns grupos de alunos demorou 5 aulas de um total de 15 , impactando o processo de ensino/aprendizagem.

- Utilização de um sistema pronto para o ensino de arquitetura de software: o kit de estudo Arquitetura de $\mathrm{n}$ camadas foi utilizado como base para o ensino 
dos conceitos de arquitetura de software. Nesse tipo de experimento, os alunos recebiam um projeto pronto preparado pelo professor e monitor da disciplina. O processo de configuração e instalação foi feito em apenas uma aula para todos os grupos dos alunos. Dessa forma, foi possível explorar várias perspectivas conceituais e práticas de arquitetura de software tendo como base um sistema conhecido por todos os alunos. $O$ processo de ensino/aprendizagem de arquitetura de software foi mais efetivo nesse modelo de experimento. Desde 2004, o autor utiliza sistemas prontos para o ensino de conceitos de arquitetura de software.

Com o uso de sistemas prontos no processo de ensino/aprendizagem, o foco pedagógico das disciplinas nas quais o framework foi aplicado, alterou-se de uma abordagem focada na implementação de arquiteturas de software para uma abordagem centrada na avaliação e melhoria da qualidade da arquitetura de software de um sistema existente.

A partir dessa mudança de abordagem, em 2007, o autor iniciou a pesquisa de fundamentos teóricos que embasassem uma proposta direcionada para o ensino de qualidade de arquitetura de software guiada pelos atributos de qualidade, principalmente requisitos não funcionais, e como as relações entre eles afetam a arquitetura do software e a qualidade do sistema resultante.

Pode-se afirmar que o roteiro para o ensino proposto neste trabalho está relacionado com a pesquisa realizada no Mestrado, também voltada para o ensino de arquitetura de software. Nesta tese, a proposta é mais específica, tendo como objetivo a proposição de um roteiro para o ensino de qualidade de arquitetura guiado por requisitos não funcionais, considerando medições dos atributos de qualidade ao longo do ciclo de vida do desenvolvimento do software e extração desses atributos do processo de negócio.

Diferentemente da pesquisa do Mestrado, que foi baseada em um meta-modelo de aprendizagem genérico, a fundamentação teórica do roteiro proposto nesta tese baseia-se em normas de qualidade, em um modelo de referência de sistemas distribuídos e em métodos para avaliação de arquitetura de software, detalhados no Capítulo 2. 
A elaboração preliminar do roteiro proposto neste trabalho iniciou-se em 2005 e vem sendo aplicado em disciplinas de cursos de graduação e pós-graduação em Engenharia de Computação desde então. As aplicações do roteiro são descritas no Capítulo 5.

A descrição da proposta de roteiro de ensino de qualidade de arquitetura de software guiado por requisitos não funcionais está estruturada da seguinte forma:

- Item 4.3 - Contribuição das referências teóricas na elaboração do roteiro de ensino proposto;

- Item 4.4 - Proposta de um roteiro de ensino de qualidade de arquitetura de software guiado por requisitos não funcionais;

- Item 4.5 - Adaptação do Roteiro de ensino de qualidade de arquitetura de software guiado por requisitos não funcionais para sistemas novos.

\subsection{CONTRIBUIÇÃO DAS REFERÊNCIAS TEÓRICAS NA ELABORAÇÃO DO ROTEIRO DE ENSINO PROPOSTO}

O roteiro de ensino de qualidade de arquitetura de software proposto nesta tese foi baseado nos conceitos descritos nos itens 2.4 - ISO/IEC 10746 (Reference Model - Open Distributed Processing), 2.6 - Modelos de qualidade de software, 2.7.1 Qualidade do produto de software - ISO/IEC 9126, 2.7.2 - Avaliação do produto de software - ISO/IEC 14598-5 e 2.11 - Architecture Trade-off Analysis Method (ATAM), suportados pelas teorias pedagógicas descritas no Capítulo 3. Seguem as contribuições de cada um desses conceitos na elaboração do roteiro:

- Modelos de qualidade de software: de acordo com o glossário do IEEE (IEEE, 1990), a Engenharia de Software representa a aplicação de uma abordagem sistemática, disciplinada e quantificável para desenvolver, operar e manter sistemas de software. Em outros campos do conhecimento, e mesmo em outras engenharias, o ato de medir é uma das ferramentas analíticas de grande importância. Em engenharias mais tradicionais (consolidadas) que a Engenharia de Software, as métricas são reconhecidas como parte inerente do processo de negócio, das atividades de engenharia do dia-a-dia e como obrigatórias para melhorar a tomada de decisões (ABRAN, 2010). Por essas 
razões, os conceitos de métricas de atributos de qualidade, descritos no metamodelo de qualidade em Albin (2003) são de grande importância no processo de ensino/aprendizagem de qualidade de arquitetura, uma vez que permite lidar com os atributos de qualidade de um sistema de software, de forma evidenciada e mensurável.

- Qualidade do produto de software - ISO/IEC 9126: o modelo de qualidade de software proposto pela ISO/IEC 9126, por meio da definição das 6 características e 27 subcaracterísticas de qualidade servem como base para o roteiro na definição do que deve ser medido, por meio das métricas internas, externas e em uso.

- Avaliação do produto de software - ISO/IEC 14598-5: os conceitos de requisitos da avaliação do produto de software, seleção das métricas, critérios para julgamento das métricas e comparação dos resultados obtidos com os esperados, descritos no processo de avaliação de produto de software, foram utilizados no roteiro visando a obtenção de resultados qualitativos sobre a qualidade da arquitetura de software.

- Architecture Trade-off Analysis Method (ATAM): a possibilidade de avaliação de vários atributos de qualidade na mesma execução do ATAM, o foco nos requisitos de qualidade derivados do processo de negócio, a possibilidade de análise de trade-offs entre os requisitos de qualidade e a definição explícita e clara do cenário de cada requisito de qualidade na árvore de qualidade tornam o método ATAM uma das principais referências conceituais utilizadas no roteiro de ensino, sendo que o foco em requisitos não funcionais proposto pelo roteiro proposto deriva-se dos conceitos do ATAM.

- ISO/IEC 10746 - RM-ODP: os pontos de vista propostos pelo RM-ODP atuam como elemento estruturador do roteiro, pois os conceitos definidos pelo RMODP abrangem todo o ciclo de definição, implementação e manutenção de uma arquitetura de software. Seguem as contribuições de cada um dos pontos de vista do RM-ODP para a elaboração do roteiro proposto neste trabalho:

- Ponto de vista da Empresa: no contexto do roteiro de ensino de arquitetura de qualidade, o entendimento do ponto de vista da Empresa permite que os alunos avaliem as necessidades de negócio, seus requisitos funcionais e, principalmente, não funcionais na definição e/ou 
manutenção de arquiteturas de software. O entendimento dos processos de negócio e de sua criticidade é um fator crucial para todas as decisões arquiteturais que serão tomadas durante o projeto, uma vez que esses processos representam a razão pela qual o software será construído (AVGERIOU et al., 2011);

- Ponto de vista da Informação: no roteiro, o ponto de vista da informação auxilia na definição dos requisitos do sistema em função da informação armazenada e manipulada pelo processo de negócio e pelo sistema (BECERRA, 1998);

- Ponto de vista da Computação: muitos alunos não conhecem técnicas para a organização de módulos e componentes arquiteturais, o que na maioria das vezes, resulta na construção de sistemas altamente acoplados $^{11}$, com baixo grau de coesão ${ }^{12} \mathrm{e}$, consequentemente, baixa manutenibilidade. O ponto de vista da computação, no contexto do roteiro, auxilia, no processo de ensino/aprendizagem, orientando a organização dos componentes de uma arquitetura para que a mesma seja implementável e satisfaça os objetivos definidos no ponto de vista da Empresa;

- Ponto de vista da Engenharia: no roteiro proposto, o ponto de vista da Engenharia busca enfatizar, no processo de ensino/aprendizagem, a escolha e a avaliação das táticas arquiteturais e suas consequências na obtenção dos atributos de qualidade de uma arquitetura. Além disso, permite a avaliação dos trade-offs entre requisitos não funcionais resultantes do uso de uma ou mais táticas arquiteturais;

- Ponto de vista de Tecnologia: este ponto de vista representa a etapa de implementação da arquitetura, em que os alunos, após a finalização do código-fonte, podem avaliar, através de medições, se a arquitetura de software implementada atendeu aos requisitos de qualidade do sistema.

\footnotetext{
${ }^{11}$ Acoplamento: corresponde à forma e ao grau de interdependência entre módulos de software (ISO/IEC/IEEE, 2010).

12 Coesão: trata-se da forma e grau em que as tarefas executadas por um único módulo de software estão relacionadas a outros módulos (ISO/IEC/IEEE, 2010).
} 
4.4 PROPOSTA DE UM ROTEIRO DE ENSINO DE QUALIDADE DE ARQUITETURA DE SOFTWARE GUIADO POR REQUISITOS NÃO FUNCIONAIS

Conforme Santos (1999), os objetivos de ensino não devem equivaler à especificação de conteúdo, mas à identificação de situações-problema que permitem que os alunos interajam e sistematizem seus conhecimentos disponíveis e necessários para a resolução de um problema. Fundem-se assim, no ensino, os processos científico e pedagógico: uma pedagogia que, fundamentada no processo científico, traduz-se pelo ato de facilitar e de criar condições para que o aluno possa aprender, considerando o seu arcabouço de conhecimentos previamente adquiridos, conforme as teorias de aprendizagem construtivista, significativa e baseada em problemas.

A competência é a capacidade de mobilizar um conjunto de recursos cognitivos (conteúdos e habilidades) para solucionar uma situação-problema (PERRENOUD, 1999). A partir da solução desses problemas, é possível exercitar o aprendizado dos conhecimentos de qualidade de arquitetura de software, os quais serão fundamentais durante a atividade profissional do engenheiro de software.

Seguem as competências consideradas no roteiro de ensino de qualidade de arquitetura de software, baseadas nos currículos propostos dos cursos de Ciência da Computação e Engenharia de Computação definidos pela The Joint Task Force on Computing Curricula e IEEE Computer Society - Association for Computing Machinery (ACM/IEEE-CS JOINT TASK FORCE ON COMPUTING CURRICULA, 2004, 2013):

- Definir a arquitetura de software a ser utilizada, de acordo com os requisitos de qualidade demandados pelas necessidades de negócio;

- Entender os impactos na qualidade do produto de software, decorrentes das decisões arquiteturais tomadas durante o desenvolvimento de um sistema de software;

- Definir os requisitos não funcionais implícitos no processo de negócio;

- Avaliar diferentes alternativas de arquitetura de software para a implementação de determinado sistema considerando os trade-offs entre os requisitos não funcionais de uma aplicação; 
- Utilizar técnicas de avaliação da qualidade de arquitetura de software para nortear as decisões arquiteturais;

- Utilizar técnicas que auxiliem na escolha e na implementação de uma arquitetura de software, tais como simulação, provas de conceitos, injeção de falha no software, etc.

O objetivo do roteiro proposto é auxiliar que o aluno submetido ao mesmo possa desenvolver as competências citadas relacionadas à qualidade de arquitetura de software, orientada pelos requisitos não funcionais, por meio de uma abordagem prática, iterativa e dirigida pelo processo de negócio, visando a aprendizagem da importância dos atributos de qualidade na definição da arquitetura de software e medição desses atributos durante a construção de um sistema, verificando-se se o nível de qualidade atingido pela arquitetura de software implementada atende aos requisitos do processo de negócio.

$O$ roteiro de ensino de qualidade de arquitetura de software guiado por requisitos não funcionais proposto neste trabalho trata-se de um método experimental composto por um conjunto de 19 princípios técnicos e pedagógicos, e 13 etapas de aplicação do mesmo, que foram baseados nas referências teóricas descritas nos Capítulos 2 e 3 , e também na aplicação prática e nos refinamentos iterativos realizados durante os 10 anos de aplicação do roteiro proposto.

Nesta seção, são descritos os princípios técnicos e pedagógicos do roteiro proposto e as etapas para a aplicação do mesmo em sistemas existentes.

4.4.1 Princípios técnicos e pedagógicos considerados na elaboração do roteiro proposto

Os 19 princípios técnicos e pedagógicos considerados na criação do roteiro proposto resultaram dos conceitos relacionados à qualidade de arquitetura de software descritos no Capítulo 2 e pedagógicos descritos no Capítulo 3. Os princípios técnicos e pedagógicos basearam-se nos seguintes itens:

- Tópicos das disciplinas dos currículos dos cursos de Engenharia de Computação e Ciência da Computação elaborados pela The Joint Task Force on Computing Curricula e IEEE Computer Society - Association for Computing 
Machinery (ACM/IEEE-CS JOINT TASK FORCE ON COMPUTING CURRICULA, 2004, 2013) que estão relacionados com arquitetura de software e qualidade de arquitetura de software. Os tópicos das disciplinas dos cursos de Engenharia de Computação e Ciência da Computação que abordam diretamente ou indiretamente conceitos relacionados com arquitetura de software e qualidade de arquitetura de software foram listados na Tabela 2 e Tabela 3, respectivamente;

- Teorias de aprendizagem descritas no Capítulo 3 e nas características pedagógicas norteadoras das disciplinas dos currículos dos cursos de Engenharia de Computação e Ciência da Computação elaborados pela The Joint Task Force on Computing Curricula e IEEE Computer Society Association for Computing Machinery (ACM/IEEE-CS Joint Task Force on Computing Curricula, 2004, 2013). Essas características foram descritas nos itens 3.3.1 e 3.3.2;

- Características resultantes da prática da aplicação do roteiro proposto desde 2005. À medida que o roteiro foi aplicado ao longo dos anos, características foram gradativamente incorporadas e avaliadas quanto aos benefícios trazidos ao processo de aprendizado de qualidade de arquitetura de software.

- Na Tabela 6, é apresentado o mapeamento entre os princípios técnicos (1 a 11) do roteiro proposto e os tópicos das disciplinas dos currículos dos cursos de Engenharia de Computação e Ciência da Computação elaborados pela The Joint Task Force on Computing Curricula e IEEE Computer Society Association for Computing Machinery (ACM/IEEE-CS Joint Task Force on Computing Curricula, 2004, 2013) relacionados com arquitetura de software e qualidade de arquitetura de software.

Os princípios foram numerados para facilitar a identificação. Assim como na Tabela 4 e Tabela 5, os tópicos mais significativos em cada disciplina foram sufixados com o símbolo [S], enquanto os tópicos que podem ser considerados pré-requisitos para o roteiro foram sufixados com o símbolo [P]. 
Tabela 6 - Mapeamento entre os princípios técnicos do roteiro e tópicos das disciplinas dos cursos de Engenharia de Computação e Ciência da Computação relacionados com arquitetura de software e qualidade de arquitetura de software

\begin{tabular}{|c|c|c|}
\hline $\begin{array}{l}\text { Princípios técnicos do roteiro } \\
\text { proposto }\end{array}$ & $\begin{array}{l}\text { Disciplinas do Curso de } \\
\text { Engenharia de Computação }\end{array}$ & $\begin{array}{l}\text { Disciplinas do Curso de Ciência } \\
\text { da Computação }\end{array}$ \\
\hline $\begin{array}{l}\text { Princípio } 1 \text { - Requisitos não } \\
\text { funcionais extraídos do processo } \\
\text { de negócio }\end{array}$ & $\begin{array}{l}\text { Engenharia de Sistemas de } \\
\text { Computação } \\
\text { - Avaliação de diversas alternativas de } \\
\text { projeto e como a escolha da estratégia } \\
\text { de projeto afeta o sistema resultante [S] } \\
\text { - Exemplos de trade-offs em sistemas } \\
\text { computacionais [S] } \\
\text { - Elicitação de requisitos funcionais e não } \\
\text { funcionais [S] } \\
\text { - Abordagens para extração de requisitos } \\
\text { funcionais e não funcionais } \\
\text { - Quantificação dos requisitos não } \\
\text { funcionais [S] } \\
\text { - Elementos qualidade em projetos de } \\
\text { software [S] } \\
\text { Engenharia de Software } \\
\text { - Construção de sistemas } \\
\text { computacionais que satisfaçam os } \\
\text { requisitos do usuário [S] } \\
\text { - Requisitos Funcionais e não funcionais } \\
\text { [S] }\end{array}$ & $\begin{array}{l}\text { Engenharia de Software } \\
\text { - Conceitos de qualidade de software [S] } \\
\text { - Elicitação de requisitos funcionais e não } \\
\text { funcionais [S] } \\
\text { - Requisitos não funcionais e seu } \\
\text { relacionamento com qualidade de } \\
\text { software [S] } \\
\text { - Aceitabilidade de certezas/incertezas } \\
\text { relacionadas a sistemas de software e } \\
\text { seu comportamento [S] } \\
\text { - Validação de requisitos [S] } \\
\text { - Trade-offs entre diferentes aspectos de } \\
\text { qualidade [S] } \\
\text { Fundamentos de Desenvolvimento de } \\
\text { Software } \\
\text { Conceitos de especificação de requisitos } \\
\text { de software [S] }\end{array}$ \\
\hline $\begin{array}{l}\text { Princípio } 2 \text { - Uso de provas de } \\
\text { conceito }\end{array}$ & $\begin{array}{l}\text { Fundamentos de Programação } \\
\text { - Análise e projeto orientados a objeto [P] } \\
\text { - Programação orientada a eventos e } \\
\text { programação concorrente [S] } \\
\text { - Tratamento de Exceções [P] } \\
\text { Engenharia de Sistemas de } \\
\text { Computação } \\
\text { - Diferentes modelos de ciclos de vida: } \\
\text { pontos fortes de cada um deles [P] } \\
\text { Engenharia de Software } \\
\text { - Avaliação de ferramentas, métodos e } \\
\text { abordagens mais adequadas para } \\
\text { determinados cenários de } \\
\text { desenvolvimento de software [P] } \\
\text { - Ciclo de vida de um sistema de } \\
\text { software [P] }\end{array}$ & $\begin{array}{l}\text { Linguagens de Programação } \\
\text { - Análise e projeto orientados a objeto [P] } \\
\text { - Programação orientada a eventos e } \\
\text { programação concorrente [S] } \\
\text { - Tratamento de Exceções [P] } \\
\text { Engenharia de Software } \\
\text { - Introdução a modelos de processos de } \\
\text { software (cascata, incremental e ágil) [P] }\end{array}$ \\
\hline $\begin{array}{l}\text { Princípio } 3 \text { - Prototipação } \\
\text { arquitetural }\end{array}$ & $\begin{array}{l}\text { Engenharia de Sistemas de } \\
\text { Computação } \\
\text { - Conceitos de prototipação e simulação } \\
\text { [S] } \\
\text { Engenharia de Software } \\
\text { - Prototipação [S] } \\
\text { Engenharia de Software } \\
\text { - Uso de técnicas de projeto de software } \\
\text { em estágios iniciais da programação [S] }\end{array}$ & $\begin{array}{l}\text { Engenharia de Software } \\
\text { - Prototipação [S] }\end{array}$ \\
\hline Princípio 4 - Inspeção & $\begin{array}{l}\text { Engenharia de Software } \\
\text { - Técnicas de Inspeção [S] }\end{array}$ & $\begin{array}{l}\text { Fundamentos de Desenvolvimento de } \\
\text { Software } \\
\text { - Revisão de código [S] } \\
\text { Engenharia de Software } \\
\text { - Inspeções [S] }\end{array}$ \\
\hline
\end{tabular}


Continuação

\begin{tabular}{|c|c|c|}
\hline $\begin{array}{l}\text { Princípios técnicos do roteiro } \\
\text { proposto }\end{array}$ & $\begin{array}{l}\text { Disciplinas do Curso de } \\
\text { Engenharia de Computação }\end{array}$ & $\begin{array}{l}\text { Disciplinas do Curso de Ciência } \\
\text { da Computação }\end{array}$ \\
\hline Princípio 5 - Uso de simuladores & $\begin{array}{l}\text { Engenharia de Sistemas de } \\
\text { Computação } \\
\text { - Conceitos de prototipação e simulação } \\
\text { [S] }\end{array}$ & $\begin{array}{l}\text { Ciência da Computação } \\
\text { - Ferramentas e técnicas de simulação } \\
\text { [S] }\end{array}$ \\
\hline $\begin{array}{l}\text { Princípio } 6 \text { - Métricas de } \\
\text { requisitos não funcionais }\end{array}$ & $\begin{array}{l}\text { Engenharia de Software } \\
\text { - Uso de técnicas para medição para } \\
\text { controle de qualidade do sistema em } \\
\text { desenvolvimento [S] } \\
\text { - Uso de métricas [S] }\end{array}$ & $\begin{array}{l}\text { Engenharia de Software } \\
\text { - Métricas de processo de } \\
\text { software [S] } \\
\text { - Medição e análise da qualidade do } \\
\text { projeto [S] }\end{array}$ \\
\hline Princípio 7 - Testes arquiteturais & $\begin{array}{l}\text { Engenharia de Sistemas de } \\
\text { Computação } \\
\text { - Testes de sistema e diagnostico de } \\
\text { falhas [P] } \\
\text { - Tipos de manutenção: corretiva e } \\
\text { evolutiva [P] } \\
\text { Engenharia de Software } \\
\text { - Verificação e validação [P] }\end{array}$ & $\begin{array}{l}\text { Fundamentos de Desenvolvimento de } \\
\text { Software } \\
\text { - Fundamentos de testes e geração de } \\
\text { testes [P] } \\
\text { Engenharia de Software } \\
\text { - Ferramentas para testes estáticos e } \\
\text { dinâmicos [P] } \\
\text { - Verificação e validação [P] }\end{array}$ \\
\hline $\begin{array}{l}\text { Princípio } 8 \text { - Utilização de táticas } \\
\text { arquiteturais }\end{array}$ & $\begin{array}{l}\text { Fundamentos de Programação } \\
\text { - Padrões de Projeto [S] } \\
\text { Engenharia de Sistemas de } \\
\text { Computação } \\
\text { - Diferentes abordagens de projetos de } \\
\text { arquitetura de software: pontos fortes e } \\
\text { fracos [S] } \\
\text { Engenharia de Software } \\
\text { - Arquitetura de Software [S] } \\
\text { - Projeto para reutilização } \\
\text { de software [S] }\end{array}$ & $\begin{array}{l}\text { Fundamentos de Desenvolvimento de } \\
\text { Software } \\
\text { - Programação defensiva [S] } \\
\text { Engenharia de Software } \\
\text { - Princípios de projeto de sistemas, } \\
\text { níveis de abstração (projeto arquitetural } \\
\text { e projeto detalhado) [S] } \\
\text { - Padrões de Projetos [S] } \\
\text { - Projeto de atributos de qualidade: } \\
\text { eficiência, desempenho, tolerância a } \\
\text { falha, funcionalidade, confiabilidade, } \\
\text { eficiência [S] } \\
\text { Mecanismos para construção de } \\
\text { sistemas de software com qualidade [S] }\end{array}$ \\
\hline Princípio 9 - Trabalho em equipe & $\begin{array}{l}\text { Engenharia de Sistemas de } \\
\text { Computação } \\
\text { - Natureza multidisciplinar associada ao } \\
\text { desenvolvimento de sistemas } \\
\text { computacionais [S] }\end{array}$ & $\begin{array}{l}\text { Engenharia de Software } \\
\text { - Papéis e responsabilidades em uma } \\
\text { equipe de desenvolvimento de software } \\
\text { - Resolução de conflitos em times }\end{array}$ \\
\hline $\begin{array}{l}\text { Princípio } 10 \text { - Uso de normas e } \\
\text { padrões reconhecidos }\end{array}$ & $\begin{array}{l}\text { Engenharia de Sistemas de } \\
\text { Computação } \\
\text { - Importância do uso de padrões e } \\
\text { referências [S] } \\
\text { - Modelos de maturidade, padrões e } \\
\text { referências [S] }\end{array}$ & $\begin{array}{l}\text { Engenharia de Software } \\
\text { - Modelos de maturidade de software [S] }\end{array}$ \\
\hline $\begin{array}{l}\text { Princípio } 11 \text { - Aspectos culturais } \\
\text { envolvidos }\end{array}$ & $\begin{array}{l}\text { Engenharia de Sistemas de } \\
\text { Computação } \\
\text { - Natureza multidisciplinar associada ao } \\
\text { desenvolvimento de sistemas } \\
\text { computacionais [S] }\end{array}$ & $\begin{array}{l}\text { Engenharia de Software } \\
\text { - Papéis e responsabilidades em uma } \\
\text { equipe de desenvolvimento de software } \\
\text { [S] } \\
\text { - Resolução de conflitos em } \\
\text { times [S] }\end{array}$ \\
\hline
\end{tabular}

Fonte: Autor e ACM/IEEE-CS Joint Task Force on Computing Curricula $(2004,2013)$ 
- $\quad \mathrm{Na}$ Tabela 7, é apresentado o mapeamento entre os princípios pedagógicos (12 a 17) do roteiro proposto e as teorias de aprendizagem descritas no Capítulo 3 ou com as características pedagógicas norteadoras das disciplinas dos currículos dos cursos de Engenharia de Computação e Ciência da Computação elaborados pela The Joint Task Force on Computing Curricula e IEEE Computer Society - Association for Computing Machinery (ACM/IEEE-CS Joint Task Force on Computing Curricula, 2004, 2013) descritas nos itens 3.3.1

e 3.3.2. A numeração iniciada na Tabela 6 foi continuada para facilitar a identificação dos princípios do roteiro:

Tabela 7 - Mapeamento entre os princípios pedagógicos do roteiro com as teorias de aprendizagem ou com tópicos das disciplinas dos cursos de Engenharia de Computação e Ciência da Computação

\begin{tabular}{|c|c|c|}
\hline $\begin{array}{l}\text { Princípios pedagógicos do roteiro } \\
\text { proposto }\end{array}$ & $\begin{array}{l}\text { Disciplinas do Curso de } \\
\text { Engenharia de Computação }\end{array}$ & $\begin{array}{l}\text { Disciplinas do Curso de Ciência } \\
\text { da Computação }\end{array}$ \\
\hline Princípio 12 - Abordagem prática & $\begin{array}{l}\text { A utilização de uma abordagem } \\
\text { prática para o processo de } \\
\text { ensino/aprendizagem é uma das } \\
\text { características pedagógicas do curso } \\
\text { de Engenharia de Computação (vide } \\
\text { item 3.3.1- Currículo de Engenharia } \\
\text { de Computação). }\end{array}$ & $\begin{array}{l}\text { A utilização de uma abordagem } \\
\text { prática para o processo de } \\
\text { ensino/aprendizagem é uma das } \\
\text { características pedagógicas do } \\
\text { curso de Ciência da Computação } \\
\text { (vide item 3.3.2 - Currículo de } \\
\text { Ciência da Computação). }\end{array}$ \\
\hline $\begin{array}{l}\text { Princípio } 13 \text { - Aprendizado } \\
\text { incremental }\end{array}$ & $\begin{array}{l}\text { O aprendizado incremental é uma } \\
\text { característica presente na teoria de } \\
\text { aprendizagem construtivista (vide } \\
\text { item 3.2.1 - Construtivismo) }\end{array}$ & $\begin{array}{l}\text { O aprendizado incremental é uma } \\
\text { característica presente na teoria de } \\
\text { aprendizagem construtivista (vide } \\
\text { item 3.2.1 - Construtivismo) }\end{array}$ \\
\hline $\begin{array}{l}\text { Princípio } 14 \text { - Aprendizagem } \\
\text { baseada em problemas (problem } \\
\text { based learning) }\end{array}$ & $\begin{array}{l}\text { A aprendizagem baseada em } \\
\text { problemas é uma abordagem de } \\
\text { ensino/aprendizagem (vide item 3.2.3 } \\
\text { - Aprendizagem baseada em } \\
\text { problemas) e também é uma das } \\
\text { características pedagógicas do curso } \\
\text { de Engenharia de Computação (vide } \\
\text { item 3.3.1- Currículo de Engenharia } \\
\text { de Computação). }\end{array}$ & $\begin{array}{l}\text { A aprendizagem baseada em } \\
\text { problemas é uma abordagem de } \\
\text { ensino/aprendizagem (vide item } \\
\text { 3.2.3 - Aprendizagem baseada em } \\
\text { problemas) e também uma das } \\
\text { características pedagógicas do } \\
\text { curso de Ciência da Computação } \\
\text { (vide item 3.3.2 - Currículo de } \\
\text { Ciência da Computação). }\end{array}$ \\
\hline $\begin{array}{l}\text { Princípio } 15 \text { - Aprendizado } \\
\text { centrado no aluno }\end{array}$ & $\begin{array}{l}\text { Aprendizado centrado no aluno é } \\
\text { uma característica presente na teoria } \\
\text { de Aprendizagem Construtivista (vide } \\
\text { item 3.2.1 - Construtivismo) e } \\
\text { também é uma das características } \\
\text { pedagógicas do curso de Engenharia } \\
\text { de Computação (vide item 3.3.1- } \\
\text { Currículo de Engenharia de } \\
\text { Computação). }\end{array}$ & $\begin{array}{l}\text { Aprendizado centrado no aluno é } \\
\text { uma característica presente na } \\
\text { teoria de Aprendizagem } \\
\text { Construtivista (vide item 3.2.1 - } \\
\text { Construtivismo) e também uma das } \\
\text { características pedagógicas do } \\
\text { curso de Ciência da Computação } \\
\text { (vide item } 3.3 .2 \text { - Currículo de } \\
\text { Ciência da Computação). }\end{array}$ \\
\hline Princípio 16 - Projetos "reais" & $\begin{array}{l}\text { A utilização de projetos "reais" para o } \\
\text { processo de ensino/aprendizagem é } \\
\text { uma das características pedagógicas } \\
\text { do curso de Engenharia de } \\
\text { Computação (vide item 3.3.1- } \\
\text { Currículo de Engenharia de } \\
\text { Computação). }\end{array}$ & $\begin{array}{l}\text { A utilização de projetos "reais" para } \\
\text { o processo de ensino/aprendizagem } \\
\text { é uma das características } \\
\text { pedagógicas do curso de Ciência da } \\
\text { Computação (vide item 3.3.2 - } \\
\text { Currículo de Ciência da } \\
\text { Computação). }\end{array}$ \\
\hline Princípio 17 - Aulas práticas & $\begin{array}{l}\text { Aulas práticas é das características } \\
\text { pedagógicas do currículo de } \\
\text { Engenharia de Computação (vide } \\
\text { item 3.3.1- Currículo de Engenharia } \\
\text { de Computação). }\end{array}$ & $\begin{array}{l}\text { Aulas práticas é das características } \\
\text { pedagógicas do currículo de Ciência } \\
\text { da Computação (vide item 3.3.2 - } \\
\text { Currículo de Ciência da } \\
\text { Computação). }\end{array}$ \\
\hline
\end{tabular}

Fonte: Autor 
Na Tabela 8, são apresentados os princípios do roteiro proposto resultantes da pratica de aplicação (18 e 19) do roteiro e refinamentos sucessivos no roteiro desde 2005. Como foram derivados da prática em sala de aula, também foram considerados princípios pedagógicos. A numeração utilizada na Tabela 6 e na Tabela 7 foi continuada para facilitar a identificação dos princípios do roteiro:

Tabela 8 - Princípios pedagógicos do roteiro baseados na prática de aplicação do mesmo desde 2005.

\begin{tabular}{|c|c|c|}
\hline Princípio pedagógicos do Roteiro & $\begin{array}{l}\text { Disciplinas do Curso de } \\
\text { Engenharia de Computação }\end{array}$ & $\begin{array}{l}\text { Disciplinas do Curso de Ciência } \\
\text { da Computação }\end{array}$ \\
\hline $\begin{array}{l}\text { Princípio } 18 \text { - Documentação } \\
\text { essencial }\end{array}$ & $\begin{array}{l}\text { Este princípio foi considerado no } \\
\text { roteiro proposto, como resultado } \\
\text { prático de aplicação do mesmo. } \\
\text { Documentando-se somente o } \\
\text { necessário para a implementação de } \\
\text { um sistema de software, foi possível } \\
\text { dedicar mais tempo para o } \\
\text { aprendizado prático dos conceitos de } \\
\text { qualidade de arquitetura de software. }\end{array}$ & $\begin{array}{l}\text { Este princípio foi considerado no } \\
\text { roteiro proposto, como resultado } \\
\text { prático de aplicação do mesmo. } \\
\text { Documentando-se somente o } \\
\text { necessário para a implementação } \\
\text { de um sistema de software, foi } \\
\text { possível dedicar mais tempo para o } \\
\text { aprendizado prático dos conceitos } \\
\text { de qualidade de arquitetura de } \\
\text { software. }\end{array}$ \\
\hline $\begin{array}{l}\text { Princípio } 19 \text { - Técnicas de } \\
\text { Engenharia Simultânea }\end{array}$ & $\begin{array}{l}\text { Este princípio foi considerado no } \\
\text { roteiro proposto, como resultado } \\
\text { prático de aplicação do mesmo. } \\
\text { O uso de técnicas de Engenharia } \\
\text { Simultânea, ou seja, múltiplas } \\
\text { equipes atuando em paralelo permite } \\
\text { exercitar conceitos importantes de } \\
\text { qualidade de arquitetura como } \\
\text { desacoplamento, programação de } \\
\text { componentes, uso de simuladores, } \\
\text { etc. }\end{array}$ & $\begin{array}{l}\text { Este princípio foi considerado no } \\
\text { roteiro proposto, como resultado } \\
\text { prático de aplicação do mesmo. } \\
\text { O uso de técnicas de Engenharia } \\
\text { Simultânea, ou seja, múltiplas } \\
\text { equipes atuando em paralelo } \\
\text { permite exercitar conceitos } \\
\text { importantes de qualidade de } \\
\text { arquitetura como desacoplamento, } \\
\text { programação de componentes, uso } \\
\text { de simuladores, etc. }\end{array}$ \\
\hline
\end{tabular}

Fonte: Autor

Segue o detalhamento dos 19 princípios técnicos e pedagógicos considerados na criação do roteiro proposto:

\section{Princípio 1 - Requisitos não funcionais extraídos do processo de negócio}

De acordo com Clements e Bass (2010), alguns objetivos de negócio derivamse em atributos de qualidade, que, para serem implementados, necessitam que decisões arquiteturais sejam tomadas, o que impactará a arquitetura do sistema resultante, sendo que também há objetivos de negócio que não demandam soluções arquiteturais, conforme representado na Figura 14. 
Figura 14 - Relação entre objetivo de negócio e arquitetura de software

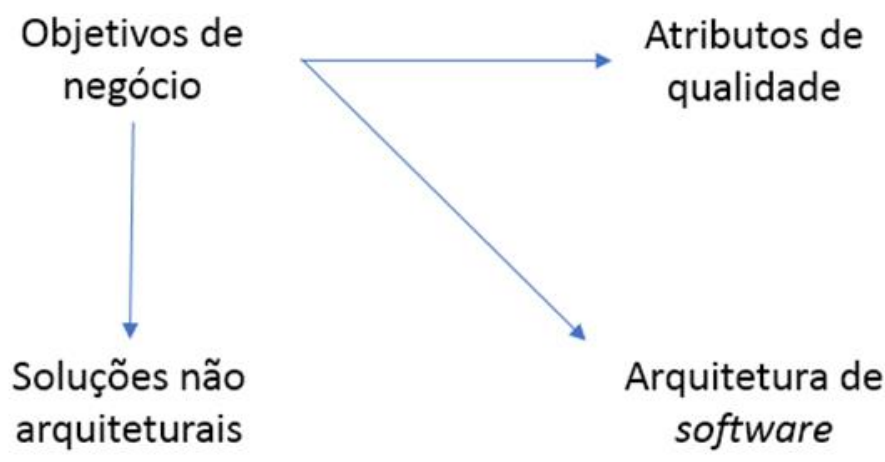

Fonte: Adaptado de Clements e Bass (2010)

Com o auxílio do RM-ODP, principalmente do ponto de vista da Empresa, o roteiro estimula que os alunos entendam o processo de negócio e sua criticidade através das relações entre os diversos atributos de qualidade, principalmente os não funcionais, que muitas vezes não são explicitamente elicitados. Dessa forma, o aluno de posse do entendimento do processo de negócio pode visualizar as táticas e mecanismos que atendam aos requisitos do negócio.

\section{Princípio 2 - Uso de provas de conceito}

Prova de conceito, do inglês, Proof of Concept (PoC) é uma técnica que permite avaliar que uma determinada ideia é tecnicamente possível, permitindo verificar a viabilidade de implementação de um sistema antes de se iniciar a construção efetiva do mesmo. Segundo Jacobson et al. (2013), a implementação mínima de requisitoschave já serve como base para avaliar a arquitetura, não sendo necessário implementar o sistema todo para essa avaliação.

Uma prova de conceito que tem como objetivo avaliar a viabilidade de implementação de um determinado sistema pode ser denominada PoC Construtiva. Esse tipo de PoC permite avaliar se determinada arquitetura atenderá os requisitos funcionais e não funcionais. Além disso, a PoC Construtiva potencialmente reduz 0 risco de fracasso, pois pode exercitar de forma evidenciada aspectos importantes no desenvolvimento de uma aplicação, como por exemplo: integração entre componentes, escalabilidade e desempenho (GUIMARÃES, 2008). 
Como complemento, também foi utilizada, a PoC Destrutiva, que explicita os pontos vulneráveis e limites do sistema, antes de sua implementação. A utilização das PoC Destrutivas foi baseada nos estudos de Petroski (1994), que afirma que o conceito de falha é crucial no processo de projeto (design), e que através do entendimento de como evitar as falhas é que projetos bem sucedidos são construídos. Embora frequentemente vista como uma parte implícita e tácita das metodologias de projeto, a consideração e análise proativa das falhas são essenciais para atingir o sucesso. E precisamente quando a consideração e análise proativa das falhas são feitas de forma incorreta ou incompleta, há maior possibilidade de introdução dos erros de projeto que podem resultar em falhas (PETROSKI, 1994).

\section{Princípio 3 - Prototipação arquitetural}

De forma análoga às provas de conceito, o uso de protótipos arquiteturais auxilia o processo de ensino/aprendizagem de arquitetura de software. Segundo Bardram et al. (2005), um protótipo arquitetural consiste em um conjunto de executáveis criados para investigar os atributos de qualidade de uma arquitetura relacionados aos requisitos de negócio de um sistema em desenvolvimento. Há dois tipos de protótipos que podem ser utilizados para facilitar a elaboração de uma arquitetura: exploratórios ou experimentais. O primeiro tipo é construído para explorar alternativas de solução arquitetural, enquanto o segundo é utilizado para aferir a adequação de uma arquitetura proposta em relação aos requisitos de qualidade.

\section{Princípio 4 - Inspeção}

De acordo com Elberzhager et al. (2012), atividades de inspeção são fundamentais para entrega de sistemas de alta qualidade, e os problemas encontrados durantes as várias inspeções realizadas durante o processo de desenvolvimento devem servir como subsídio para os testes de software. No roteiro de ensino proposto, utiliza-se a técnica de inspeção dos artefatos de software como mecanismo de avaliação de qualidade.

\section{Princípio 5 - Uso de simuladores}

Técnicas de simulação são utilizadas nas disciplinas de engenharia por muitos anos. Há várias áreas nas quais o uso de simuladores pode auxiliar na Engenharia de 
Software, como por exemplo: avaliação do custo de desenvolvimento do software, trade-offs entre atributos de qualidade, avaliação de requisitos não funcionais, educação de engenheiros de software, gerenciamento de risco, melhoria de processo e gerenciamento de aquisição (COLLOFELLO, 2000).

Simuladores também podem auxiliar a visualização dos aspectos dinâmicos de uma arquitetura. Essa visualização da arquitetura em execução é útil para se identificar falhas no projeto arquitetural, tais como, pontos de gargalos, esgotamento de recursos, vazamento de memória e baixo desempenho. Simulações feitas durante o processo de definição e projeto da arquitetura também representam uma alternativa de baixo custo em relação à implementação definitiva (BARBER; HOLT, 2001).

No roteiro, os simuladores também foram utilizados para que os alunos aprendam técnicas de desacoplamento entre os componentes de uma arquitetura, em cenários nos quais um componente, apesar de não estar pronto, já possuía sua interface definida. Alguns exemplos de técnicas para a implementação de simuladores que foram utilizadas no roteiro: loopbacks ${ }^{13} \mathrm{em}$ conexões com bancos de dados, classes provedoras de autenticação e web services de pagamento, etc.

De acordo com Naraharisetty e Vanka (2012), do ponto de vista pedagógico, técnicas de simulação permitem a experimentação mais profunda do conhecimento aprendido, dado que se trata de um ambiente sem risco, propiciando maior absorção dos conceitos.

\section{Princípio 6 - Métricas de requisitos não funcionais}

Métricas de software são reconhecidas tanto por pesquisadores e educadores em Engenharia de Software como de grande importância para melhorar o processo de desenvolvimento de software e, consequentemente, o sistema resultante. Infelizmente, a prática na indústria não dá o devido valor às métricas que, comumente, são ignoradas, e a avaliação da qualidade é trabalhada de uma forma instintiva e subjetiva (THOMAS, 1996). Como os requisitos não funcionais são determinantes para a qualidade final do sistema gerado, é de certa forma surpreendente que a

\footnotetext{
${ }^{13}$ Loopback: conexão através do protocolo Transmission Control Protocol (TCP) para a própria máquina que originou a conexão, por meio do endereço 127.0.0.1 (FAROULT; ROBSON, 2006).
} 
medição desses requisitos seja ignorada durante o desenvolvimento e/ou manutenção do software (PASTERNAK, 2003).

\section{Princípio 7 - Testes arquiteturais}

Durante a aplicação do roteiro, são realizados testes dos requisitos funcionais e não funcionais utilizando o conceito definido em Clements et al. (2011), no qual os testes são baseados nos cenários arquiteturais que mapeiam os requisitos de qualidade. Ferramentas de testes automatizados, como, por exemplo, o JMeter, criado pela The Apache Software Foundation (2013), para realização de testes de carga também são previstas no roteiro para a realização de testes arquiteturais.

\section{Princípio 8 - Utilização de táticas arquiteturais}

Uma tática arquitetural representa uma decisão de projeto que influencia a obtenção da resposta de um atributo de qualidade. Táticas afetam diretamente a resposta do sistema a alguns estímulos. Táticas são selecionadas de acordo com o requisito não funcional a ser considerado na arquitetura (KIM et al., 2008).

O foco de uma tática arquitetural está restrito à resposta de somente um atributo de qualidade, ou seja, não há trade-offs no contexto de uma tática (BASS; CLEMENTS; KAZMAN, 2012). Os trade-offs impostos pelas escolhas de diversas táticas arquiteturas devem ser feitos pelo arquiteto, baseado na criticidade dos processos de negócio. No roteiro, os alunos definem as táticas conforme o ponto de vista da Engenharia do RM-ODP e as implementam usando mecanismos conforme o ponto de vista de Tecnologia.

\section{Princípio 9 - Trabalho em equipe}

Uma organização atinge níveis mais elevados de maturidade quando atividades individuais se tornam atividades de uma equipe (FAVELA; PEÑA-MORA, 2001). Como o desenvolvimento de software tem se globalizado, a proposição de uma abordagem educacional deve considerar experiências em grupo, as quais certamente os estudantes enfrentarão em suas vidas profissionais.

\section{Princípio 10 - Uso de normas e padrões reconhecidos}


Conforme Paula Filho (2001), um processo educacional em Engenharia de Software deve expor o aluno a normas e padrões largamente reconhecidos. Como nas demais Engenharias, os estudantes devem conhecer e aplicar notações e seguir procedimentos padronizados para as atividades de Engenharia de Software. O roteiro proposto utiliza as normas ISO/IEC 10746-1, ISO/IEC 9126, ISO/IEC 14598-5, apresentadas respectivamente nos itens 2.4, 2.7.1 e 2.7.2. Além dessas normas, o método de avaliação de arquitetura de software ATAM, descrito no item 2.11, também foi utilizado no roteiro.

\section{Princípio 11 - Aspectos culturais envolvidos}

Um grande desafio educacional é a integração de várias disciplinas de forma coesa, visando uma formação multidisciplinar dos engenheiros de software. Sem abandonar o aspecto técnico e sistemático característico da engenharia, uma formação mais abrangente, que enfatize importantes aspectos como modelagem do processo de negócio, habilidades humanas de comunicação e expressão, noções de gerenciamento de pessoas e projetos poderia indubitavelmente contribuir na formação de engenheiros mais preparados para assumir cargos de liderança nas mais diversas áreas (YEH, 2002). Segundo o Currículo de Engenharia de Computação proposto pelo IEEE e pela ACM, é esperado do engenheiro de computação uma formação multidisciplinar, uma vez que a maioria dos projetos de que o aluno de Engenharia da Computação participará em sua vida profissional envolvem pessoas de várias áreas, ou seja, são multidisciplinares por natureza (ACM/IEEE-CS JOINT TASK FORCE ON COMPUTING CURRICULA, 2004). Por meio de projetos práticos realizados por uma equipe, o roteiro expõe os alunos a um ambiente de características multidisciplinares, uma vez que envolve desafios de natureza técnica, humana, cultural e organizacional.

Essa abordagem muitas vezes enfrenta resistências culturais por parte dos alunos, que segundo Callahan e Pedigo (2002), deve-se à falta de experiência prática dos estudantes. Uma das formas de se lidar com este problema é adotar uma estratégia educacional que auxilie os alunos na percepção de que a prática da Engenharia de Software deve transcender o tecnicismo puro e interagir com outras disciplinas, formando um engenheiro capaz de liderar processos, projetos e pessoas de forma harmoniosa. $O$ roteiro proposto, através de atividades relacionadas ao processo de negócio, à tomada de decisões baseadas em trade-offs, ao 
desenvolvimento de mecanismos arquiteturais para a obtenção de qualidade e ao trabalho em equipe demanda uma atitude multidisciplinar dos alunos, buscando amenizar as resistências culturais que surgem no decorrer das aulas.

\section{Princípio 12 - Abordagem prática}

Pesquisadores da área de educação, McCaslin e Lowman, (1995) e Schank e Cleary (1995) afirmam que o processo de aprender fazendo, do inglês learn by doing, é um fator muito importante para a eficácia do processo de aprendizado. Exemplos práticos, ou seja, implementações arquiteturais utilizadas na resolução de um problema real, auxiliam no melhor entendimento dos conceitos de qualidade de arquitetura de software, elucidam os trade-offs entre atributos de qualidade, além de relacionar os conceitos teóricos a uma instância concreta de uma arquitetura.

No roteiro proposto, dada a restrição da duração das disciplinas (em torno de 15 aulas de 4 horas cada), são utilizados sistemas já prontos, para que o aluno possa avaliar a qualidade da arquitetura desse sistema e implementar melhorias.

\section{Princípio 13 - Aprendizado incremental}

Conforme Vockell e Schwartz (1998), o conhecimento é organizado de forma hierárquica e, por essa razão, uma das formas de aumentar a eficácia do aprendizado é pela identificação dos pré-requisitos de aprendizado, ou seja, identificação dos conhecimentos necessários para o aprendizado de uma determinada abstração arquitetural.

Baseando-se nas considerações de Vockell e Schwartz (1998) e considerando a riqueza, a complexidade e as múltiplas dimensões dos conceitos de qualidade de arquitetura, o roteiro usa uma abordagem incremental, na qual os tópicos são apresentados em um nível de abstração crescente, o que permite que os alunos assimilem os conceitos de qualidade, qualidade de arquitetura e trade-offs entre requisitos de qualidade de forma gradual. 


\section{Princípio 14 - Aprendizagem baseada em problemas}

O currículo de engenharia tem sofrido mudanças, notavelmente no modo que as escolas de engenharia têm adotado a aprendizagem baseada em problemas para suprir as demandas da prática de engenharia (CHUNG; HARMON; BAKER, 2001).

O principal conceito da aprendizagem baseada em problemas estabelece que o processo de ensino/aprendizagem inicie-se a partir de um ou mais problemas que deverão ser resolvidos pelo alunos utilizando os conceitos aprendidos em aula (RICHARDSON; DELANEY, 2009). As seguintes atividades são desempenhadas nas disciplinas que utilizam a aprendizagem baseada em problemas na área de Engenharia de Software, segundo Koper e René (2004):

- Definir objetivos de aprendizado;

- Identificar conceitos e partes do problema que necessitam de esclarecimento;

- Definir o problema;

- Analisar o problema;

- Utilizar técnicas de brainstorming para discutir as causas do problema e possíveis soluções;

- Estruturar as soluções escolhidas;

- Implementar a solução;

- Avaliar a solução implementada de acordo com os requisitos do problema;

- Reportar aprendizado realizado.

O domínio somente dos aspectos técnicos de engenharia não é mais suficiente para as demandas da sociedade. Cada vez mais, programas de ensino de engenharia estão inserindo os alunos em projetos multidisciplinares, com requisitos incompletos ou mal especificados, nos quais os estudantes também possam aprender habilidades para desenvolver soluções considerando restrições de qualidade, custo, tempo, esforço, entre outras (CHUNG; HARMON; BAKER, 2001).

Ainda segundo Chung, Harmon e Baker (2001), no processo de ensino/aprendizagem baseado na metodologia $\mathrm{PBL}$, os estudantes são efetivamente envolvidos com os problemas, o que traz maior motivação para a aprendizagem significativa. 


\section{Princípio 15 - Aprendizado centrado no aluno}

Abordagens pedagógicas práticas são construídas sobre o pressuposto que a mente humana é um recipiente e que a responsabilidade dos professores é preenchêlo com conhecimento. Esse método de ensino é conhecido como aprendizado centrado no professor, no qual a educação é vista como um processo no qual o conhecimento é transferido do professor para o aluno (SCHÖN, 2000). Segundo essa concepção, os alunos são elementos passivos e cabe ao professor, elemento ativo do processo, inserir nos estudantes um conjunto de conhecimentos factuais e habilidades intelectuais, testando periodicamente a aquisição destes conhecimentos por meio de provas e exames. Baseado nas teorias pedagógicas descritas no Capítulo 2, o roteiro utiliza uma abordagem de ensino oposta, na qual o conhecimento é construído na mente do aluno, que participa ativamente do processo de aprendizagem, o que exige uma atitude proativa por parte dos estudantes.

Unindo o aprendizado centrado no aluno com uma forte iniciativa prática, podese explorar a habilidade inata do ser humano de explorar para descobrir, que segundo Ohlsson e Johansson (1995), fomenta a aprendizagem significativa.

Segundo a teoria construtivista, o estudante deve participar ativamente do processo de ensino/aprendizagem, exercitando a criatividade na resolução de problemas. Este ambiente, no qual o aluno participa ativamente em sua aprendizagem, cria uma motivação natural para aprender, o que certamente refletirá em sua vida profissional (MULDER; LIDTKE; STOKES, 1997).

\section{Princípio 16 - Projetos "reais"}

Segundo Mulder; Lidtke e Stokes (1997), pode-se aumentar a eficiência do aprendizado fazendo com que os alunos resolvam problemas relativamente complexos, cuja solução exija um determinado nível de estruturação arquitetural e um planejamento de engenharia, o que possibilita o trabalho em equipe e fomenta discussões e constantes avaliações do design e da qualidade da arquitetura de software do sistema e desenvolve nos estudantes habilidades práticas (ZHANG, 2013). A resolução de problemas reais de relativa magnitude e complexidade possibilita o aprendizado efetivo de conceitos e técnicas de arquiteturas de software. 
$\mathrm{Na}$ aplicação do roteiro proposto, procura-se modelar uma situação real de projeto de software, sob a qual os alunos adquirem habilidades essenciais de um engenheiro de software como trabalho em equipe, gerenciamento de projetos, aplicação de metodologia de desenvolvimento de software, avaliação de qualidade de software, uso de padrões e normas e treinamento de habilidades de comunicação e liderança. A simulação de um ambiente de um projeto centrado em arquitetura de software, em que os alunos devem entender os processos de negócio, analisar tradeoffs entre requisitos de qualidade, escolher táticas arquiteturais para promover a melhoria de qualidade e medir os atributos de qualidade auxilia na consolidação do aprendizado, permite que esse ambiente seja adaptado e replicado em diversas situações de sua vida profissional.

\section{Princípio 17 - Aulas práticas}

Sendo o roteiro de ensino de qualidade de arquitetura de software fortemente baseado em uma abordagem prática, o uso de aulas em laboratório é um dos principais recursos utilizados. O princípio de aulas práticas, juntamente com 0 princípio de "projetos reais", possibilita a simulação, em menor escala, de situações e projetos da indústria, o que é fundamental na formação dos alunos (SMOLANDER, 2002). A apresentação da teoria e de modelos arquiteturais inseridos em um contexto prático potencializa o aprendizado dos alunos, além de solidificar os conceitos aprendidos, transcendendo mudanças tecnológicas (SHAW, 2000).

\section{Princípio 18 - Documentação essencial}

O objetivo da documentação arquitetural é registrar as principais decisões e respectivos racionais, de forma suficiente, para que possa ser utilizada para construir e manter um sistema de software (CLEMENTS et al., 2010).

Segundo Fairbanks (2010), a documentação ideal de arquitetura de software deve ser clara e concisa para permitir que o desenvolvedor entenda o que deve ser feito, sem perder a conexão com os requisitos de negócio e as restrições do sistema.

A documentação também deve conter diagramas, protótipos, tabelas, trechos de código, artefatos do dia a dia do desenvolvedor, o que potencialmente diminui a possibilidade de uma interpretação incorreta dos requisitos do sistema. De acordo 
com estudo realizado por Prasad e Ojha (2012), tabelas e gráficos são entendidos de forma mais rápida e precisa pelos desenvolvedores, se comparadas a sentenças em texto livre.

\section{Princípio 19 - Técnicas de engenharia simultânea}

Os componentes da arquitetura, definidos no ponto de vista da Computação e Engenharia do RM-ODP, permitem uma separação clara do trabalho dos desenvolvedores, possibilitando o uso de técnicas de engenharia simultânea (paralelismo), o que diminui o tempo de desenvolvimento de um sistema. A engenharia simultânea pode ser definida como um método sistemático aplicado ao desenvolvimento integrado dos serviços ou produtos, enfatizando a importância da satisfação dos requisitos, o que inclui formas de cooperação, responsabilidade e compartilhamento nas equipes, de forma que as decisões de projeto sejam produto de um processo paralelo, sincronizados por um eficiente sistema de informação, até produzir um consenso. A utilização da engenharia simultânea pode trazer os seguintes benefícios ao projeto (DEWAN; RIEDL, 1993; HANDFIELD, 1994; REDDY et al., 1993; SILVA, 1996) apud (BECERRA, 1998).

- Redução do tempo de desenvolvimento do serviço ou produto, devido ao paralelismo das atividades;

- Homogeneização e melhora da qualidade, originadas pela revisão contínua de inconsistências e erros e dos requisitos do usuário. Essa revisão é realizada por diferentes especialistas, representantes de todas as fases do projeto;

- Diminuição das alterações e do retrabalho, em decorrência do trabalho cooperativo e multidisciplinar, os diferentes critérios técnicos relacionados com o produto ou serviço são analisados e incorporados desde o início do projeto;

- Redução dos custos do projeto, como consequência direta dos benefícios anteriormente descritos.

4.4.2 Etapas do roteiro de ensino para o ensino de qualidade de arquitetura de software guiado por requisitos não funcionais

O roteiro de ensino proposto é composto por 13 etapas sequenciais que podem ser aplicadas no ambiente de aula de disciplinas relacionadas à Engenharia de 
Software e arquitetura de software. Como o principal objetivo do roteiro é auxiliar no processo de ensino/aprendizagem dos conceitos de qualidade de arquitetura de software guiado por requisitos não funcionais, optou-se primeiramente pela utilização de sistemas já existente durante a aplicação do roteiro. Dessa forma, é possível aplicar os conceitos de aprendizagem baseada em problemas. Outro fator que motivou essa escolha inicial deve-se à duração média de aproximadamente 15 semanas, ou seja, um semestre letivo, nas disciplinas em que roteiro foi aplicado. A utilização de um sistema existente possibilitou maior aprofundamento no processo de ensino/aprendizagem de qualidade de arquitetura de software, avaliação dos tradeoffs entre requisitos não funcionais, implementações pontuais na arquitetura do sistema existente e medição dos atributos de qualidade.

Após 5 anos de aplicação do roteiro proposto utilizando sistemas existentes, o mesmo foi ajustado para também suportar a aplicação em disciplinas nas quais os alunos desenvolvem todo o sistema desde o início. Os ajustes realizados no roteiro estão descritos no item 4.5 .

A Figura 15 ilustra as etapas do roteiro proposto com o uso de sistemas existentes, utilizando-se a notação do diagrama de atividades da UML (Unified Modeling Language) (OBJECT MANAGEMENT GROUP, 2013). Para facilitar a referência às etapas do roteiro, as etapas foram identificadas com números colocados no canto superior direito de cada uma delas. 
Figura 15 - Etapas do Roteiro proposto de ensino de qualidade de arquitetura de software guiado por requisitos não funcionais utilizando sistemas existentes

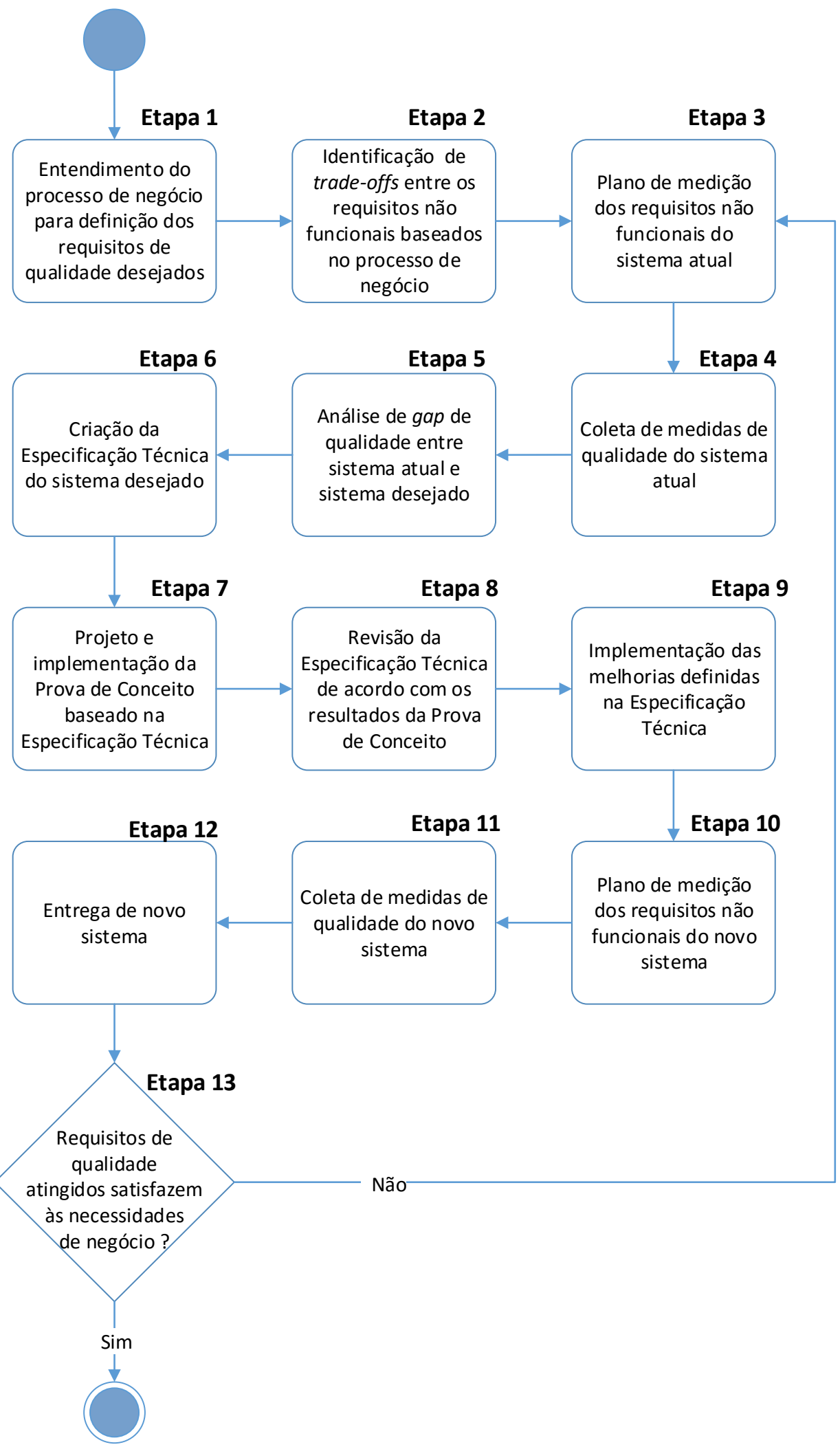

Fonte: Autor 
As etapas do descritas na Figura 15 são aplicadas em disciplinas da área de Engenharia de Software em cursos de graduação ou pós-graduação de Engenharia da Computação. Essas etapas ocorrem em paralelo com as atividades da disciplina. Como o roteiro propõe uma abordagem prática para o ensino de qualidade de arquitetura de software, os alunos das disciplinas nas quais o roteiro é aplicado são divididos em grupos de dois ou três integrantes, e cada grupo executa, como parte do trabalho da disciplina, atividades relacionadas à qualidade de arquitetura de software, principalmente as relacionadas aos requisitos não funcionais, suportados por métricas que permitem avaliar se o objetivo de negócio do sistema foi atingido ou não. As aplicações do roteiro, detalhadas no Capítulo 5 , foram realizadas em classes com aproximadamente 18 alunos, na média.

Segue a descrição de cada etapa do roteiro, de acordo com a identificação ilustrada na Figura 15:

\section{Etapa 1 - Entendimento do processo de negócio para definição dos requisitos de qualidade desejados}

Para criar um cenário de aprendizado, os alunos da disciplina na qual o roteiro é aplicado recebem um sistema de software pronto, e baseando-se no ponto de vista da Empresa do RM-ODP e no ATAM, o processo de negócio é entendido, identificando-se seus fluxos críticos e os requisitos não funcionais que suportam as funcionalidades do sistema.

Como resultado desta etapa, espera-se que os alunos compreendam a relação entre processo de negócio e atributos de qualidade, principalmente os requisitos não funcionais e como esses requisitos, mesmo implícitos, têm grande impacto na percepção da qualidade do sistema como um todo.

\section{Etapa 2 - Identificação dos trade-offs entre os requisitos não funcionais baseados no processo de negócio}

Nesta etapa, o conceito de trade-off é introduzido na disciplina. Usando a ISO/IEC 9126-1 como modelo de qualidade e a árvore de utilidade do ATAM como ferramenta para avaliar os trade-offs, os alunos são divididos em grupos de dois ou três integrantes e o trabalho da disciplina é proposto: todos os grupos trabalham no 
mesmo sistema e é solicitado a cada grupo que proponham melhorias arquiteturais que impactem positivamente nos requisitos não funcionais do sistema já existente. Os temas dos trabalhos, pré-definidos pelo professor, obrigatoriamente envolvem cenários de trade-off entre requisitos não funcionais, como por exemplo:

- Usabilidade x Manutenibilidade: trade-off entre sofisticação da camada de interface humano-computador, como por exemplo uso de interfaces web assíncronas, e impactos na manutenibilidade na arquitetura do sistema;

- Segurança (security ${ }^{14}$ ) x Desempenho: análise do trade-off entre a implementação de mecanismos de segurança e como esses mecanismos afetam o desempenho do sistema.

- Monitoração x Desempenho: trade-off entre o grau de intrusão provocado pela monitoração do sistema e impactos na monitoração;

- Concorrência x Acesso Simultâneo: trade-off entre quantidade de acessos concorrentes e quantidade de usuários que o sistema suporta atender sem apresentar mensagens de erro devido ao número excessivo de acessos concorrentes;

- Integridade x Concorrência: trade-off entre mecanismos para manter a integridade transacional de um sistema em cenários de alta concorrência;

- Disponibilidade x Portabilidade: trade-off entre a disponibilidade de recursos computacionais e portabilidade desses mesmos recursos, como por exemplo banco de dados.

Ao fim dessa etapa, espera-se que o aluno consiga compreender o conceito de trade-off do ponto de vista de negócio e consiga tomar decisões baseadas no processo de negócio de qual requisito será atendido e quais serão afetados.

\section{Etapa 3 - Plano de medição dos requisitos não funcionais do sistema existente}

Antes da implementação da melhoria, com o auxílio do professor e monitores, os alunos fazem uma análise exploratória do sistema existente, focando no tema do trabalho proposto. Os conceitos dos pontos de vista da Informação e Computação do

\footnotetext{
14 Neste trade-off, o conceito de segurança, do inglês security, refere-se à segurança da informação, preservação da confidencialidade, integridade, disponibilidade das informações, autenticidade, responsabilidade, não-repúdio e confiabilidade da informação (ISO/IEC, 2013).
} 
RM-ODP são utilizados na atividade de análise do sistema. Uma vez entendidos os componentes e a arquitetura do sistema, os alunos elaboram um planejamento para diagnosticar a qualidade do sistema existente por meio da coleta de medidas estáticas e dinâmicas. Aqui, conceitos da ISO/IEC 14598-5 são utilizados para o planejamento da avaliação do software.

O que se espera no fim desta etapa é a capacidade de o aluno diagnosticar a arquitetura de software de um sistema por meio do uso de métricas para avaliação dos requisitos não funcionais, do ponto de vista de negócio.

\section{Etapa 4 - Coleta de medidas de qualidade do sistema existente}

Nesta etapa, aplica-se o plano definido na etapa anterior para coleta de métricas do sistema existente. Ferramentas para realização automática de testes, como $\mathrm{JMeter}^{15}$, são utilizadas para a coleta de medidas do sistema.

Espera-se que o aluno saiba aplicar o plano de medição ao término desta etapa.

\section{Etapa 5 - Análise de gap de qualidade entre sistema existente e sistema desejado}

Apoiado pelas necessidades e objetivos de negócio, pela árvore de utilidade e pelo resultado da coleta das medidas de qualidade, o aluno realiza uma análise de gap entre a qualidade da arquitetura do sistema existente e o nível de qualidade proposto como melhoria para a nova implementação do sistema.

Como resultado dessa etapa, a expectativa é que o aluno aprenda a fazer uma análise de gap orientada pelos objetivos de negócio baseado nas evidências coletadas no plano de medição nos conceitos aprendidos.

\section{Etapa 6 - Criação da Especificação Técnica do sistema desejado}

Com a análise de gap finalizada, os alunos elaboram a Especificação Técnica da arquitetura do novo sistema já considerando a escolha das táticas arquiteturais que

\footnotetext{
15 JMeter: aplicação construída em Java projetada para realização de testes de carga e testes de desempenho em sistemas de software (THE APACHE SOFTWARE FOUNDATION, 2013).
} 
potencialmente podem ser utilizadas, de acordo com o ponto de vista de Engenharia do RM-ODP. A elaboração de uma especificação técnica sucinta e concisa, contendo apenas as informações necessárias para implementar as melhorias arquiteturais do novo sistema, constitui o objetivo desta etapa.

\section{Etapa 7 - Projeto e implementação da Prova de Conceito baseado na Especificação Técnica}

Baseada na Especificação Técnica, uma prova de conceito é implementada, sendo esta uma das etapas mais importantes do roteiro, dado o seu potencial pedagógico.

O objetivo da prova de conceito não é somente confirmar que a implementação arquitetural é viável e atende aos requisitos não funcionais do processo de negócio, mas também identificar os limites e pontos de vulnerabilidade da arquitetura proposta, exemplificando o conceito da PoC Destrutiva, descrito no item 4.4.1. A etapa da prova de conceito relaciona-se com o ponto de vista da Tecnologia do RM-ODP, utilizandose mecanismos para a implementação das táticas definidas na Especificação Técnica feita na Etapa 6.

\section{Etapa 8 - Revisão da Especificação Técnica de acordo com os resultados da Prova de Conceito}

Com os resultados obtidos na PoC implementada, a Especificação Técnica é revisada e atualizada pelos alunos para que se inicie a implementação das melhorias arquiteturais para o novo sistema. A PoC Construtiva permite que os alunos avaliem a viabilidade de implementação da arquitetura de software escolhida e a PoC Destrutiva fornece evidências dos pontos fracos da arquitetura de software que precisam de ajustes.

O objetivo desta etapa é fomentar a prática de revisões nos artefatos de software, buscando mitigar as falhas durante a implementação. 


\section{Etapa 9 - Implementação das melhorias definidas na Especificação Técnica}

Nesta etapa, o objetivo é implementar as melhorias arquiteturais visando atender às necessidades de negócio.

O uso de técnicas de engenharia simultânea é incentivado pelos professores para que os alunos aprendam a trabalhar em várias frentes de trabalho de forma coordenada. Dessa forma, os alunos aprendem a dividir as tarefas de implementação de forma desacoplada e a programar visando 0 atendimento de uma interface ${ }^{16}$ bem definida, o que permite a implementação por vários alunos de forma desacoplada.

\section{Etapa 10 - Plano de medição dos requisitos não funcionais do novo sistema}

Finalizada a implementação, um novo plano de medição é elaborado visando capturar as medidas de qualidade do novo sistema. Pode-se atualizar o Plano de Medição elaborado na Etapa 3, mantendo o foco da medição nos pontos críticos do negócio.

O Plano de Medição deve ser atualizado, considerando as melhorias arquiteturais potencialmente implementadas no sistema.

\section{Etapa 11 - Coleta de medidas de qualidade do novo sistema}

Utilizando-se o plano de medições definido na Etapa 10, uma nova coleta de medidas é realizada no novo sistema.

O objetivo dessa nova medição é verificar se as mudanças implementadas no sistema surtiram o efeito desejado, ou seja, a melhoria dos atributos de qualidade sob a perspectiva de negócio e considerando os trade-offs entre os requisitos não funcionais.

\footnotetext{
${ }^{16}$ Uma interface define um contrato de serviços a serem implementados. Qualquer classe que realiza uma interface deve implementar o contrato definido pela interface (OBJECT MANAGEMENT GROUP, 2013)
} 


\section{Etapa 12 - Entrega do novo sistema}

Nesta etapa, o novo sistema com as melhoras propostas implementadas é entregue pelos alunos. A entrega é formalizada durante uma apresentação, na qual os alunos detalham as implementações realizadas, o racional das decisões tomadas e o processo de medição. É realizada uma demonstração do sistema para toda a sala de aula.

\section{Etapa 13 - Requisitos de qualidade atingidos satisfazem as necessidades de negócio?}

$\mathrm{Na}$ apresentação do novo sistema pelos alunos, o professor e os monitores da disciplina executam os testes de aceitação, simulando os participantes da área de negócio em um projeto no mundo real. Caso o nível de qualidade dos requisitos não funcionais tenha sido atingido, a aplicação do roteiro é finalizada; caso contrário, podese aplicar o roteiro novamente a partir da etapa 3 . Devido às restrições de duração dos cursos, o roteiro tem sido tipicamente aplicado somente uma vez.

\subsection{AdAPTAÇÃO DO ROTEIRO DE ENSINO DE QUALIDADE DE ARQUITETURA DE SOFTWARE GUIADO POR REQUISITOS NÃO FUNCIONAIS PARA SISTEMAS NOVOS}

Para viabilizar um maior aprofundamento no processo de ensino/aprendizagem de qualidade de arquitetura de software, avaliação dos trade-offs entre requisitos não funcionais, implementação de melhorias pontuais na arquitetura de software de um sistema e medição dos atributos de qualidade, e visando ampliar as possibilidades de uso do roteiro de ensino em uma quantidade maior de cenários, o roteiro foi adaptado para também considerar o desenvolvimento de sistemas novos. A Figura 16 ilustra 0 roteiro para o ensino de qualidade de arquitetura de software guiado por requisitos não funcionais, adaptado para utilização em sistemas novos. As etapas foram identificadas com um apóstrofo, visando diferenciá-las da identificação utilizada na Figura 15. Dessa forma, na Figura 16, as etapas são identificadas como Etapa 1' (umlinha), Etapa 2' (dois-linha), e assim por diante. 
Figura 16 - Roteiro de ensino de qualidade de arquitetura de software guiado por requisitos não funcionais adaptado para o desenvolvimento de sistemas novos

Etapa 1'

Etapa 2'

Etapa 3'

Entendimento do
processo de negócio
para definição dos
requisitos de
qualidade desejados

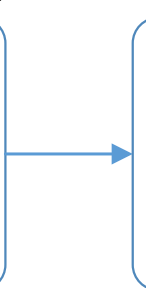
Identificação de trade-offs entre os requisitos não funcionais baseados no processo de negócio

\section{Etapa 6'}

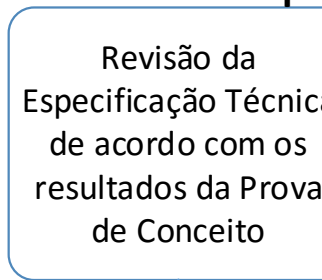

\section{Etapa 5'}

Projeto e implementação da Prova de Conceito baseado na Especificação Técnica

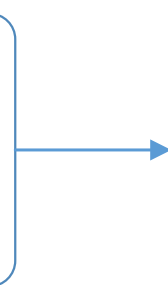

Plano de medição dos requisitos nãofuncionais a serem implementados

$\int_{1}^{2}$

Etapa 7'

Implementação do sistema conforme $\longrightarrow \begin{gathered}\text { Coleta de medidas de } \\ \text { qualidade do sistema } \\ \text { usando o Plano de } \\ \text { Medição }\end{gathered}$

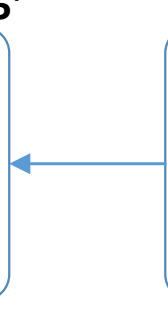

Criação da Especificação Funcional e Técnica do sistema
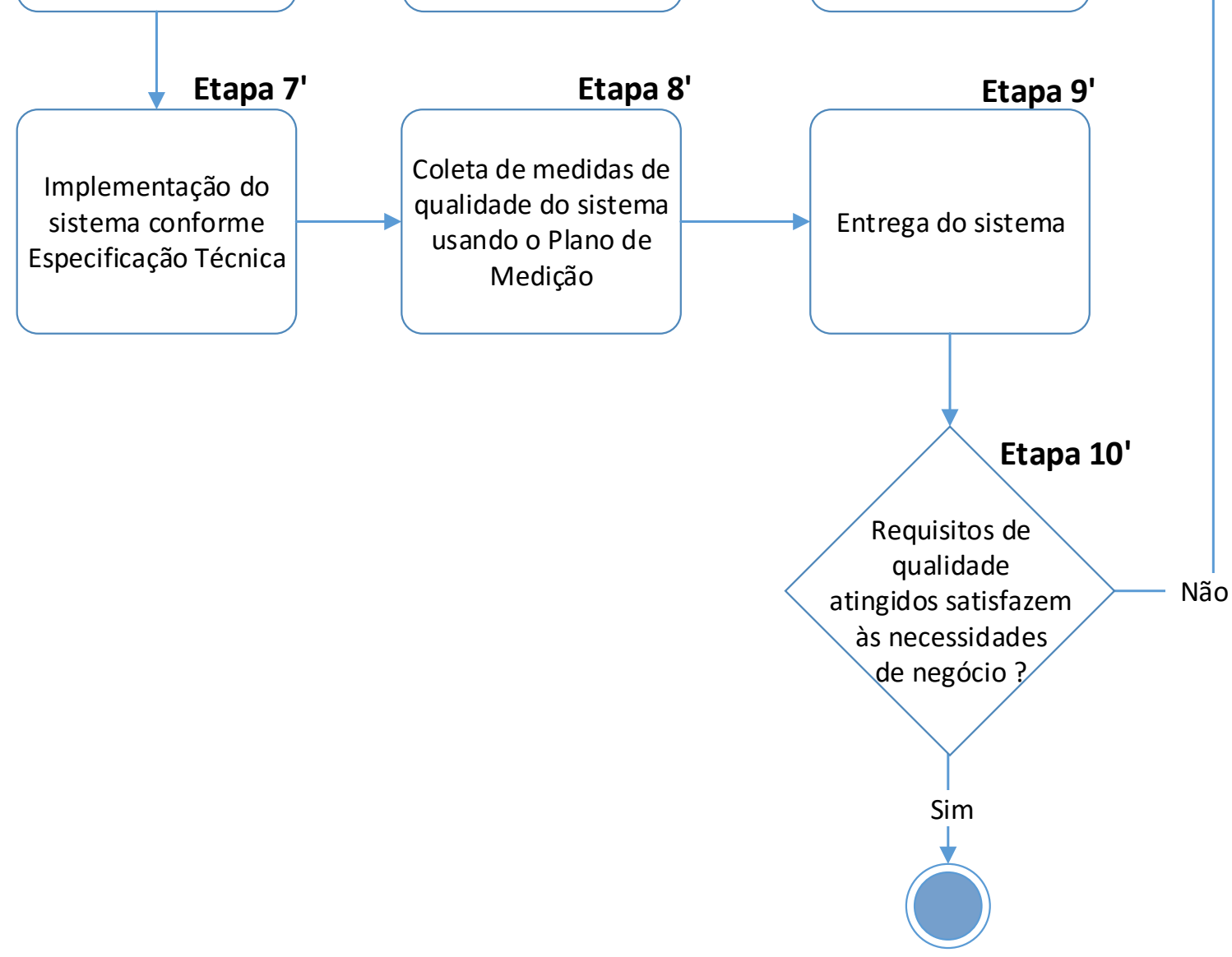


\section{A Tabela 9 detalha os pontos de ajuste para aplicação do roteiro em sistemas}

novos, por meio do mapeamento com o roteiro proposto para sistemas existentes:

\section{Tabela 9 - Mapeamento entre etapas do roteiro proposto para sistemas existentes e sistemas novos}

\begin{tabular}{|c|c|c|}
\hline $\begin{array}{l}\text { Etapas do roteiro proposto para } \\
\text { sistemas existentes - Figura } 15\end{array}$ & $\begin{array}{l}\text { Etapas do roteiro adaptado para } \\
\text { sistemas novos - Figura } 16\end{array}$ & Observação \\
\hline $\begin{array}{l}\text { Etapa } 1 \text { - Entendimento do processo de } \\
\text { negócio para definição dos requisitos de } \\
\text { qualidade desejados }\end{array}$ & $\begin{array}{l}\text { Etapa 1' - Entendimento do processo de } \\
\text { negócio para definição dos requisitos de } \\
\text { qualidade desejados }\end{array}$ & Etapa sem alteração. \\
\hline $\begin{array}{l}\text { Etapa } 2 \text { - Identificação de trade-offs entre } \\
\text { os requisitos não funcionais baseados no } \\
\text { processo de negócio }\end{array}$ & $\begin{array}{l}\text { Etapa 2' - Identificação de trade-offs } \\
\text { entre os requisitos não funcionais } \\
\text { baseados no processo de negócio }\end{array}$ & Etapa sem alteração. \\
\hline $\begin{array}{l}\text { Etapa } 3 \text { - Plano de medição dos } \\
\text { requisitos não funcionais do sistema } \\
\text { atual }\end{array}$ & $\begin{array}{l}\text { Etapa 3' - Plano de medição dos } \\
\text { requisitos não funcionais a serem } \\
\text { implementados }\end{array}$ & Etapa sem alteração. \\
\hline $\begin{array}{l}\text { Etapa } 4 \text { - Coleta de medidas de } \\
\text { qualidade do sistema atual }\end{array}$ & 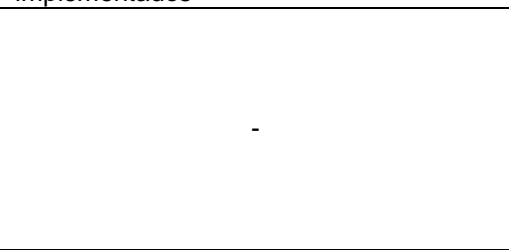 & $\begin{array}{l}\text { Etapa não aplicável no roteiro para sistemas } \\
\text { novos, dado que o sistema ainda não existe. } \\
\text { Em uma } 2^{\mathrm{a}} \text {. iteração de aplicação do roteiro } \\
\text { de ensino pode-se utilizar a versão do roteiro } \\
\text { para sistemas existentes, descrito na Figura } \\
15, \text { dado que já haveria um sistema existente } \\
\text { para a realização da coleta de medidas de } \\
\text { qualidade. }\end{array}$ \\
\hline $\begin{array}{l}\text { Etapa } 5 \text { - Análise de gap de qualidade } \\
\text { entre sistema atual e sistema desejado }\end{array}$ & - & $\begin{array}{l}\text { Etapa não aplicável no roteiro para sistemas } \\
\text { novos, dado que o sistema ainda não existe. } \\
\text { Em uma } 2^{\mathrm{a}} \text {. iteração de aplicação do roteiro } \\
\text { de ensino pode-se utilizar a versão do roteiro } \\
\text { para sistemas existentes, descrito na Figura } \\
15, \text { dado que já haveria um sistema existente } \\
\text { para a realização da coleta de medidas de } \\
\text { qualidade. }\end{array}$ \\
\hline $\begin{array}{l}\text { Etapa } 6 \text { - Criação da Especificação } \\
\text { Técnica do sistema desejado }\end{array}$ & $\begin{array}{l}\text { Etapa 4' - Criação da Especificação } \\
\text { Funcional e Técnica do sistema }\end{array}$ & $\begin{array}{l}\text { No roteiro proposto para sistemas existentes, } \\
\text { a base para a Criação de Especificação } \\
\text { Técnica deriva-se da Análise de gap e } \\
\text { qualidade entre o sistema atual e o desejado } \\
\text { (Etapa 5). Já no roteiro adaptado para } \\
\text { sistemas novos, a Especificação Funcional } \\
\text { deve ser baseada no resultado da Etapa 1' - } \\
\text { Entendimento do processo de negócio para } \\
\text { definição dos requisitos de qualidade } \\
\text { desejados. }\end{array}$ \\
\hline $\begin{array}{l}\text { Etapa } 7 \text { - Projeto e implementação da } \\
\text { Prova de Conceito baseado na } \\
\text { Especificação Técnica }\end{array}$ & $\begin{array}{l}\text { Etapa 5' - Projeto e implementação da } \\
\text { Prova de Conceito baseado na } \\
\text { Especificação Técnica }\end{array}$ & Etapa sem alteração. \\
\hline $\begin{array}{l}\text { Etapa } 8 \text { - Revisão da Especificação } \\
\text { Técnica de acordo com os resultados da } \\
\text { Prova de Conceito }\end{array}$ & $\begin{array}{l}\text { Etapa 6' - Revisão da Especificação } \\
\text { Técnica de acordo com os resultados da } \\
\text { Prova de Conceito }\end{array}$ & Etapa sem alteração. \\
\hline $\begin{array}{l}\text { Etapa } 9 \text { - Implementação das melhorias } \\
\text { definidas na Especificação Técnica }\end{array}$ & $\begin{array}{l}\text { Etapa 7' - Implementação do sistema } \\
\text { conforme Especificação Técnica }\end{array}$ & Etapa sem alteração. \\
\hline $\begin{array}{l}\text { Etapa } 10 \text { - Plano de medição dos } \\
\text { requisitos não funcionais do novo } \\
\text { sistema }\end{array}$ & - & $\begin{array}{l}\text { Para aplicação em sistemas novos, aplica-se } \\
\text { o plano de medição desenvolvido no item 3' - } \\
\text { Plano de medição dos requisitos não } \\
\text { funcionais a serem implementados. }\end{array}$ \\
\hline $\begin{array}{l}\text { Etapa } 11 \text { - Coleta de medidas de } \\
\text { qualidade do novo sistema }\end{array}$ & $\begin{array}{l}\text { Etapa 8' - Coleta de medidas de } \\
\text { qualidade do sistema usando o Plano de } \\
\text { Medição }\end{array}$ & $\begin{array}{l}\text { No roteiro proposto, a coleta de medidas de } \\
\text { qualidade utiliza-se o Plano de medição dos } \\
\text { requisitos não funcionais do novo sistema } \\
\text { (Etapa 10). Já para sistemas novos, utiliza-se } \\
\text { o Plano de medição dos requisitos não } \\
\text { funcionais a serem implementados (Etapa 3'). }\end{array}$ \\
\hline Etapa 12 - Entrega de novo sistema & Etapa 9' - Entrega do sistema & Etapa sem alteração. \\
\hline $\begin{array}{l}\text { Etapa } 13 \text { - Requisitos de qualidade } \\
\text { atingidos satisfazem as necessidades de } \\
\text { negócio? }\end{array}$ & $\begin{array}{l}\text { Etapa 10' - Requisitos de qualidade } \\
\text { atingidos satisfazem as necessidades de } \\
\text { negócio? }\end{array}$ & Etapa sem alteração. \\
\hline
\end{tabular}

Fonte: Autor 


\subsection{CONCLUSÕES DO CAPÍTULO}

Neste capítulo foi apresentada a proposta deste trabalho de pesquisa, um roteiro de ensino de qualidade de arquitetura de software guiado por requisitos não funcionais, considerando ambos os aspectos pesquisados: a dimensão técnica, referente ao domínio de arquitetura de software e a pedagógica, sobre aspectos relativos ao processo de ensino/aprendizagem. $O$ roteiro proposto foi elaborado considerando-se 19 princípios técnicos e pedagógicos que definem suas características e, em relação à aplicação do mesmo, foram definidos dois cenários: utilização do roteiro considerando sistemas existentes, por meio de um conjunto de 13 etapas, e utilização do roteiro com sistemas novos, em um conjunto de 10 etapas. Ambos os cenários podem ser aplicados em disciplinas cujo conteúdo esteja relacionado com arquitetura de software em cursos de graduação e de pós-graduação em Engenharia da Computação. A principal contribuição do roteiro é auxiliar, de forma prática e baseada em problemas "reais", no processo de aprendizagem da importância dos atributos de qualidade de arquitetura de software e medição desses atributos durante todo o ciclo de vida de um sistema, considerando o trade-off entre os atributos de qualidade por meio da análise das necessidades do processo de negócio. A aplicação do roteiro proposto é detalhada no próximo capítulo. 


\section{APLICAÇÃO DO ROTEIRO PROPOSTO PARA O ENSINO DE QUALIDADE DE ARQUITETURA DE SOFTWARE}

\subsection{OBJETIVO dO CAPÍTULO}

O objetivo deste capítulo é apresentar aplicações do roteiro de ensino proposto em cenários educacionais, mais precisamente em disciplinas de graduação e pósgraduação relacionadas à Engenharia de Software e Arquitetura de Software.

Experimentos em mais de um contexto permitem avaliar a proposta sob diferentes pontos de vista, explicitando os pontos positivos e negativos do roteiro de apresentado no Capítulo 4.

Quando utilizado em disciplinas de graduação, o roteiro é aplicado em disciplinas ministradas em laboratório, nas quais os alunos implementam um sistema ou desenvolvem melhorias em um sistema existente. Além disso, exercita-se o roteiro para uma audiência ainda com pouca ou nenhuma experiência no mercado de trabalho.

Já a aplicação do roteiro em disciplinas de pós-graduação oferece um contexto diferente. Há alunos que raramente implementam sistemas em suas empresas e que já possuem experiência profissional em projetos de software. Nesses casos, a aplicação do roteiro torna-se menos prática, porém alcançando maior profundidade nas discussões propostas.

Os resultados da avaliação em cada aplicação do roteiro e as respectivas conclusões e ajustes também são apresentados.

\subsection{PROJETO de CASOS MÚltiplos}

O roteiro de ensino proposto neste trabalho de pesquisa foi aplicado em diferentes contextos como disciplinas de graduação e pós-graduação. Neste capítulo, são apresentadas três aplicações do roteiro de ensino proposto. Segundo Yin (2005), pesquisas de abordagens educacionais são melhores analisadas por meio de projetos de casos múltiplos, pela qual uma abordagem é analisada várias vezes, o que permite 
a avaliação da proposta de forma mais ampla. Os motivos que foram considerados para a escolha do projeto de casos múltiplos, ou seja, aplicações do roteiro proposto em disciplinas de graduação e pós-graduação foram:

- Avaliação em diferentes contextos: aplicações em diferentes contextos permitem a avaliação da proposta de forma mais ampla, auxiliando na identificação de pontos positivos e negativos da proposta;

- Possibilidade de generalização ou especialização da abordagem: a partir de características comuns de diversos contextos, pode-se, de acordo com a necessidade, generalizar ou especializar o roteiro proposto para que o mesmo seja aplicável em uma quantidade maior de cenários de ensino.

\subsection{ESTRUTURA GERAL DAS APLICAÇÕES DO ROTEIRO DE ENSINO PROPOSTO}

As aplicações do roteiro foram organizadas de acordo com a seguinte estrutura:

- Contexto: descreve o cenário de aplicação do roteiro, considerando características peculiares dos alunos de cada disciplina;

- Aplicação do roteiro: descreve a aplicação do roteiro de ensino proposto neste trabalho conforme as etapas descritas no item 4.4.2;

- Avaliação da aplicação do roteiro: apresentação dos resultados da aplicação do roteiro. Os critérios de avaliação estão descritos no item 5.4 deste capítulo;

- Conclusões: apresentação das conclusões de cada aplicação do roteiro de ensino, destacando os pontos positivos e negativos de cada aplicação.

\subsection{CRITÉRIOS DE AVALIAÇÃo DO ROTEIRO PROPOSTO}

Segundo Libâneo (1994), a avaliação do aprendizado é uma tarefa complexa que não se restringe somente à realização de provas e atribuição de notas. A mensuração apenas proporciona dados que devem ser submetidos a uma apreciação qualitativa.

Para a avaliação do roteiro de ensino proposto neste trabalho, são utilizados os seguintes mecanismos na seguinte ordem de importância: 
1) Questionários aplicados aos alunos nas disciplinas em que o roteiro foi utilizado para avaliar, em diferentes momentos, o nível de conhecimento dos alunos sobre os conceitos de qualidade de arquitetura de software tratados pelo roteiro proposto;

2) Avaliação dos artefatos produzidos pelos alunos durante as disciplinas nas quais o roteiro proposto foi aplicado, como por exemplo: especificações técnicas, planos de medição, provas de conceito, planos de testes, sistemas implementados, artigos acadêmicos elaborado pelos alunos, etc.;

3) Comentários dos alunos que participaram da aplicação do roteiro proposto em disciplinas dos cursos de Engenharia de Computação tanto de graduação como de pós-graduação.

Os mecanismos utilizados para a avaliação do roteiro proposto não oferecem uma prova irrefutável de que o aluno submetido ao processo do roteiro aprendeu satisfatoriamente os conceitos de qualidade de arquitetura de software, mas procuram identificar evidências da eficácia do processo de ensino. Os mecanismos de avaliação utilizados no roteiro são detalhados nos itens 5.4.1, 5.4.2 e 5.4.3 descritos a seguir.

\subsubsection{Questionários de avaliação}

A avaliação do nível conhecimento dos alunos nos tópicos ministrados nas disciplinas em que o roteiro proposto foi utilizado é feita por meio da aplicação de um questionário, descrito no Apêndice $A$, o qual é respondido pelos alunos três vezes durante a disciplina, mais precisamente no início, no meio e ao final da disciplina.

Para a elaboração dos questionários foi utilizada a estratégia baseada em proposições teóricas, descrita por Yin (2005). Segundo esta estratégia, o conjunto de questões deve refletir as proposições teóricas e os objetivos que nortearam a pesquisa.

Como o objetivo deste trabalho é auxiliar no processo de ensino/aprendizagem de qualidade de arquitetura de software, os questionários aplicados buscam evidências do aprendizado dos conceitos relacionados à qualidade de arquitetura. 
Essas avaliações são independentes do critério de avaliação definido na ementa da disciplina, constituindo apenas mecanismos para a avaliação da abordagem proposta. Os seguintes objetivos foram considerados na elaboração dos questionários:

- Identificar o nível de conhecimento dos alunos sobre qualidade de software, atributos de qualidade, métricas, relação entre qualidade e arquitetura de software e, finalmente, qualidade de arquitetura de software;

- Identificar as expectativas dos alunos em relação à disciplina;

- Avaliar o aprendizado dos conceitos de qualidade de arquitetura de software guiado por requisitos não funcionais;

- Identificar os problemas no roteiro de ensino;

- Receber dos alunos submetidos ao roteiro proposto, a sugestão de possíveis soluções e ações para resolver ou minimizar os problemas identificados no roteiro de ensino proposto neste trabalho, visando a melhoria em futuras aplicações do roteiro.

Objetivando a tabulação dos dados, o questionário indaga o nível de conhecimento dos alunos sobre os sete conceitos descritos a seguir. Esses conceitos são sugeridos nos currículos propostos pela iniciativa em conjunto da ACM e do IEEE (ACM/IEEE-CS JOINT TASK FORCE ON COMPUTING CURRICULA, 2004, 2013) e são enfatizados durante o processo de aplicação do roteiro de ensino proposto.

1. Medidas em geral: conceito que, no contexto de Engenharia de Software, fornece um indicador quantitativo de extensão, quantidade, dimensão, capacidade, ou do tamanho de algum atributo de um produto ou processo (PRESSMAN; MAXIM, 2014);

2. Medidas de arquitetura de software: conceitos relacionadas com os atributos de qualidade de um sistema diretamente relacionados com sua arquitetura de software, como funcionalidade, robustez, disponibilidade, interoperabilidade, segurança, etc. (BASS; CLEMENTS; KAZMAN, 2012; PRESSMAN; MAXIM, 2014);

3. Medidas Estáticas: conceitos das medidas derivadas da análise do código do sistema quando o mesmo não está em execução, como por exemplo, 
complexidade ciclomática, quantidade de linhas de código, manutenibilidade, etc. (KAUR et al., 2009);

4. Medidas Dinâmicas: conceitos das medidas obtidas com a análise do código em execução, como desempenho, escalabilidade, etc. (KAUR et al., 2009);

5. Utilidade das medidas para melhoria da arquitetura de software: entendimento da utilidade e importância das medidas para avaliar se os atributos de qualidade de um sistema estão implementados de forma satisfatória pela arquitetura de software desse sistema (BASS; CLEMENTS; KAZMAN, 2012);

6. Conceitos de qualidade: conceito definido como sendo a totalidade das características de uma entidade que the confere a capacidade de satisfazer às necessidades explícitas e implícitas do cliente (ISO, 2005);

7. Relação entre arquitetura de software e qualidade: entendimento de que a definição e forma de implementação da arquitetura de software afeta os atributos de qualidade do sistema resultante e a percepção da qualidade do usuário final (BASS; CLEMENTS; KAZMAN, 2012).

Para cada um dos sete conceitos considerados na avaliação do roteiro proposto, o aluno escolhe o seu nível de conhecimento dentre as opções a seguir. $O$ objetivo de cada questionário, os conceitos avaliados e a forma de responder foram bem explicados aos alunos para mitigar possíveis problemas na avaliação dos dados devido à falta de entendimento dos alunos sobre o questionário.

- Fraco: autoavaliação do aluno de que não possui conhecimentos sobre o conceito avaliado ou possui um fraco conhecimento sobre o conceito. São alunos que desconhecem o conceito, ou possuem um conhecimento muito superficial do mesmo;

- Médio: autoavaliação do aluno de que possui conhecimento mediano sobre o conceito avaliado, porém apenas de forma teórica, ou seja, conhece o significado do conceito avaliado, porém não sabe aplicá-lo;

- Bom: autoavaliação do aluno de que possui um bom conhecimento sobre o conceito avaliado e sabe aplicá-lo, com limitações, em uma situação prática, 
ou seja, ainda não tem fluência na aplicação do conceito avaliado no que se refere à qualidade da arquitetura de software;

- Ótimo: autoavaliação do aluno de que possui ótimos conhecimentos sobre o conceito avaliado e sabe aplicá-lo em sua plenitude, ou seja, aplica os conceitos de forma plenamente consciente dos objetivos a serem alcançados na qualidade de arquitetura de software. A importância da qualidade da arquitetura de software já foi incorporada ao conjunto de conhecimentos do aluno que se avalia nessa categoria, uma vez que, neste caso, a aprendizagem significativa foi consolidada. Esse aluno já seria capaz de orientar outras pessoas na aplicação dos conceitos de qualidade de arquitetura no ambiente em que estiver atuando, seja na academia ou na indústria, atuando como vetor de disseminação desses conceitos nos projetos em que participar.

Não é definida uma medida formal para a resposta do nível de conhecimento. Dessa forma, o próprio aluno se avalia. Além disso, o nível de conhecimento é um conceito subjetivo. Foram definidos níveis de conhecimento para cada item visando medir a variação do nível de conhecimento dos alunos entre as três aplicações dos questionários. Uma variação positiva do nível de conhecimento dos conceitos questionados, produz evidências a respeito do aprendizado do aluno.

Os níveis de conhecimento definidos no questionário foram baseados na escala Likert, proposta por Rensis Likert em 1932. Essa escala, utilizada em questionários, permite medir as opiniões, atitudes e percepções dos respondentes. Esse tipo de medição é muito utilizada em pesquisas educacionais (CLASON; DORMODY, 1994).

Seguem os objetivos de cada aplicação do questionário de avaliação do roteiro de ensino proposto nesta pesquisa:

- Questionário 1: aplicado aos alunos no primeiro dia de aula com o objetivo de avaliar o conhecimento dos alunos nos conceitos questionados no início do curso. Baseado nas respostas dos alunos, o professor e os monitores podem identificar itens do curso que devem ser ministrados com maior profundidade;

- Questionário 2: esta aplicação ocorre na metade da disciplina e objetiva capturar evidências de aprendizado dos conceitos ministrados até o meio do curso. Neste momento do curso, os alunos já possuem conhecimento sobre o 
roteiro e podem contribuir com sugestões ou críticas visando melhorar o processo de ensino/aprendizagem;

- Questionário 3: esta avaliação é aplicada na última aula e tem como meta capturar o nível de conhecimento dos alunos no término do curso visando capturar as evidências finais de aprendizado de qualidade de software.

A população submetida à avaliação por meio dos questionários corresponde aos alunos das disciplinas nas quais o roteiro proposto foi utilizado. Em cada aplicação do questionário o aluno dispõe de espaço para, se quiser, escrever suas próprias considerações sobre o roteiro, como por exemplo: sugestões de melhoria, críticas, elogios ou constatação de aprendizados de novos conceitos. Os comentários dos alunos que teceram considerações sobre o roteiro estão reproduzidos no Apêndice F.

Após a realização dos questionários, as respostas dos alunos são tabuladas e analisadas quantitativamente. Espera-se que os alunos, após cursarem a disciplina cujo método de ensino baseou-se na utilização do roteiro de ensino proposto nesta tese, avaliem seu conhecimento nos sete conceitos questionados como Bom ou Ótimo no Questionário 3, aplicado no último dia de aula.

Um alto percentual de respostas de nível de conhecimento igual a Bom ou Ótimo, mesmo que avaliadas de forma quantitativa, constituem uma evidência de aprendizado e, consequentemente, da própria eficácia da utilização do roteiro como uma ferramenta para o ensino de qualidade de arquitetura de software em uma disciplina da área de Engenharia de Software.

\subsubsection{Avaliação dos artefatos produzidos pelos alunos}

Os artefatos produzidos pelos alunos como parte do trabalho da disciplina também são avaliados pelo professor e pelos monitores com o objetivo de verificar se os conceitos de qualidade de arquitetura de software explorados pelo roteiro proposto foram corretamente considerados pelos alunos.

$\mathrm{Na}$ aplicação do roteiro de ensino em disciplinas de graduação, os alunos produzem os artefatos listados a seguir: 
- Plano de medição dos requisitos não funcionais: baseados no processo de negócio, considerando o ponto de vista da Empresa da RM-ODP, os atributos de qualidade da norma ISO/IEC 9126 e na árvore de utilidade do ATAM, os alunos elaboram um plano de medição dos requisitos não funcionais com o objetivo de coletar as medidas dos atributos de qualidade relevantes para o processo de negócio e avaliar se o atendem. No roteiro de ensino que utiliza sistemas já existentes, uma atualização deste artefato é realizada após a implementação das melhorias na arquitetura de software do sistema;

- Especificação funcional: artefato criado somente na aplicação do roteiro de ensino adaptado para o desenvolvimento de sistemas novos, dado que, nesse caso todo o sistema é implementado pelos alunos. Neste artefato, os alunos descrevem as funcionalidades que o sistema deverá oferecer, já identificando também os requisitos não funcionais;

- Especificação técnica: neste artefato, os alunos, descrevem a arquitetura do de software do sistema, por meio da escolha das táticas arquiteturais que serão implementadas, e definem o que será implementado como prova de conceito;

- Implementação da prova de conceito (PoC): neste artefato, baseado na Especificação Técnica, os alunos desenvolvem, antes da implementação do sistema, a PoC Construtiva, para avaliar a viabilidade da arquitetura de software que será implementada, e a PoC Destrutiva, para encontrar pontos de vulnerabilidade e limites do sistema;

- Sistema implementado: na aplicação do roteiro de ensino proposto utilizando sistemas existentes, ilustrado na Figura 15, os alunos desenvolvem melhorias na arquitetura de software de um sistema existente. Já na aplicação do roteiro de ensino adaptado para o desenvolvimento de sistemas novos, conforme representado na Figura 16, os alunos implementam todo o sistema.

$\mathrm{Na}$ aplicação do roteiro de ensino em disciplinas de pós-graduação, os alunos utilizam o roteiro de ensino proposto utilizando sistemas existentes e, seguindo as etapas nele definidas, produzem artigos acadêmicos com temas relacionados à qualidade de arquitetura de software, avaliação e proposição de melhorias na arquitetura de software de sistemas existentes, utilizando as referências teóricas ministradas em aula, como o método ATAM, o modelo de referência RM-ODP e as 
normas de qualidade de qualidade do produto de software (ISO/IEC, 2001) e de avaliação do produto de software (ISO/IEC, 1998a).

A avaliação dos artefatos produzidos pelos alunos segue os critérios de avaliação da própria disciplina na qual o roteiro de ensino é aplicado e serve como mais uma evidência da efetividade do processo de ensino/aprendizagem. Alguns trabalhos realizados pelos alunos foram reproduzidos no Apêndice $E$.

\subsubsection{Comentários dos alunos sobre o roteiro de ensino proposto}

No questionário aplicado para avaliação do nível conhecimento dos alunos, reproduzido no Apêndice $A$, há um espaço para os alunos possam tecer seus comentários sobre o roteiro proposto.

A partir dos registros dos próprios alunos que participaram das aplicações do roteiro proposto, é possível identificar mais uma evidência de aprendizado, pois de forma geral, os alunos registram em seus comentários o que aprenderam na disciplina e como poderão utilizar esse conhecimento.

Adicionalmente, críticas e sugestões também são registradas pelos alunos, o que permite efetuar ajustes e melhorias no roteiro de ensino para futuras aplicações. Os comentários dos alunos foram reproduzidos no Apêndice $F$.

\subsection{APLICAÇÃO DO ROTEIRO DE ENSINO DE QUALIDADE DE ARQUITETURA DE SOFTWARE}

O roteiro de ensino proposto neste trabalho de pesquisa é aplicado em disciplinas da área de Engenharia de Software em cursos de graduação e pósgraduação em Engenharia de Computação. As etapas do roteiro de ensino, descritas no item 4.4.2, são aplicadas em conjunto com as atividades planejadas na ementa das disciplinas. A seguir são apresentadas as aplicações do roteiro de ensino proposto:

- Aplicação 1: disciplina de Laboratório de Engenharia de Software em curso de graduação em Engenharia Elétrica com ênfase em Computação, utilizando um sistema existente; 
- Aplicação 2: disciplina de Laboratório de Engenharia de Software em curso de graduação em Engenharia Elétrica com ênfase em Computação considerando o desenvolvimento de um sistema novo;

- Aplicação 3: disciplina de Arquitetura de Software em curso de pós-graduação em Engenharia de Computação utilizando um sistema existente.

Apesar de o roteiro proposto ter considerado as disciplinas dos cursos de Engenharia de Computação e Ciência da Computação elaborados pela The Joint Task Force on Computing Curricula e IEEE Computer Society - Association for Computing Machinery (ACM/IEEE-CS Joint Task Force on Computing Curricula, 2004, 2013), não foi possível aplicar o roteiro proposto em disciplinas do curso de Ciência da Computação.

5.5.1 Mapeamento entre princípios do roteiro de ensino e disciplinas do curso de graduação em Engenharia de Computação

Visando contextualizar a aplicação do roteiro proposto nas disciplinas de graduação, foi realizado o mapeamento entre os princípios do roteiro e em quais disciplinas os mesmos são ministrados, considerando-se o currículo do Curso de Engenharia Elétrica com ênfase em Computação da Escola Politécnica da Universidade de São Paulo (ESCOLA POLITÉCNICA DA USP, 2013a). Os cursos de engenharia de computação da Escola Politécnica da USP estão sendo reestruturados baseando-se nos currículos propostos pelo ACM e IEEE (CUGNASCA; MELNIKOFF; CAMARGO JR., 2014).

A Tabela 10 apresenta esse mapeamento. Os detalhes das disciplinas listadas, contendo os tópicos ministrados em cada disciplina encontram no Apêndice C. 
Tabela 10 - Mapeamento entre os princípios do roteiro proposto e disciplinas do curso de Engenharia Elétrica com ênfase em Computação da Escola Politécnica da USP

\begin{tabular}{|c|c|}
\hline Princípios do Roteiro & $\begin{array}{l}\text { Disciplinas do curso de graduação em Engenharia } \\
\text { Elétrica com ênfase em de Computação e tópicos da } \\
\text { ementa relacionados }\end{array}$ \\
\hline $\begin{array}{l}\text { Princípio } 1 \text { - Requisitos não funcionais extraídos do } \\
\text { processo de negócio }\end{array}$ & $\begin{array}{l}\text { PNV2100 - Introdução à Engenharia } \\
\text { - Introdução a métodos de projeto } \\
\text { - Consideração de aspectos econômicos, sociais, } \\
\text { ambientais e de segurança } \\
\text { PCS2419 - Laboratório de Engenharia de Software I } \\
\text { - Entendimento do sistema a ser desenvolvido } \\
\text { - Especificação dos requisitos de software } \\
\text { - Aplicação de uma técnica para revisão da Especificação de } \\
\text { Requisitos } \\
\text { PCS2511 - Gerência, Qualidade e Tecnologia de } \\
\text { Software } \\
\text { - Conceitos de qualidade de produto e qualidade de } \\
\text { processo }\end{array}$ \\
\hline Princípio 2 - Uso de provas de conceito & $\begin{array}{l}\text { MAC2166 - Introdução à Computação } \\
\text { - Conceitos de linguagens de programação } \\
\text { - Modularização de programas } \\
\text { MAC2301 - Laboratório de Programação } \\
\text { - Ferramentas básicas de desenvolvimento } \\
\text { - Abstração de dados } \\
\text { - Ambientes de programação: compilação, montagem e } \\
\text { utilização de bibliotecas. } \\
\text { - Elementos de estilo de programação e padrões de } \\
\text { documentação de código. } \\
\text { PCS2302 - Laboratório de Fundamentos de Engenharia } \\
\text { de Computação } \\
\text { - Padrão de documentação do código-fonte } \\
\text { - Decisões da lógica de implementação, dos algoritmos e } \\
\text { das estruturas de dados utilizados } \\
\text { PCS2309 - Engenharia de Software I } \\
\text { - Modelagem de sistemas de software } \\
\text { - Modelos de ciclos de vida de desenvolvimento de sistemas } \\
\text { - Análise e projeto orientados a objetos } \\
\text { PCS2419 - Laboratório de Engenharia de Software I } \\
\text { - Desenvolvimento dos modelos da Análise Orientada a } \\
\text { Objetos } \\
\text { PCS2420 - Laboratório de Engenharia de Software II } \\
\text { - Tratamento de erros }\end{array}$ \\
\hline Princípio 3 - Prototipação arquitetural & $\begin{array}{l}\text { PCS2419 - Laboratório de Engenharia de Software I } \\
\text { - Protótipo da interface de usuário } \\
\text { PCS2419 - Laboratório de Engenharia de Software I } \\
\text { - Desenvolvimento da arquitetura de software } \\
\text { PCS2420 - Laboratório de Engenharia de Software II } \\
\text { - Desenvolvimento de um único sistema, baseado na } \\
\text { integração de componentes }\end{array}$ \\
\hline Princípio 4 - Inspeção & $\begin{array}{l}\text { PCS2419 - Laboratório de Engenharia de Software I } \\
\text { - Especificação, projeto, implementação e teste de um } \\
\text { sistema de software, realizando as verificações } \\
\text { intermediárias dos produtos gerados. }\end{array}$ \\
\hline
\end{tabular}


Continuação

\begin{tabular}{|c|c|}
\hline Princípio 5 - Uso de simuladores & $\begin{array}{l}\text { PCS2401 - Modelagem e Simulação de Sistemas Computacionais } \\
\text { - Metodologia de análise de desempenho } \\
\text { - Métricas de desempenho } \\
\text { - Ferramentas de simulação } \\
\text { PCS2453 - Sistemas Operacionais } \\
\text { - Simulação } \\
\text { - Técnicas de simulação: determinística, estatística, dirigida por eventos. }\end{array}$ \\
\hline $\begin{array}{l}\text { Princípio } 6 \text { - Métricas de requisitos não } \\
\text { funcionais }\end{array}$ & $\begin{array}{l}\text { PCS2401 - Modelagem e Simulação de Sistemas Computacionais } \\
\text { - Metodologia de análise de desempenho } \\
\text { - Métricas de desempenho } \\
\text { - Ferramentas de simulação }\end{array}$ \\
\hline Princípio 7 - Testes arquiteturais & $\begin{array}{l}\text { PCS2302 - Laboratório de Fundamentos de Engenharia de } \\
\text { Computação } \\
\text { - Projeto e execução de plano de testes } \\
\text { PCS2309 - Engenharia de Software I } \\
\text { - Testes de sistemas } \\
\text { - Manutenção de sistemas de software } \\
\text { PCS2419 - Laboratório de Engenharia de Software I } \\
\text { - Testes do sistema } \\
\text { - Elaboração do Plano de Aceitação } \\
\text { - Processo de aceitação } \\
\text { PCS2420 - Laboratório de Engenharia de Software II } \\
\text { - Elaboração e revisão do plano de aceitação } \\
\text { - Processo de aceitação }\end{array}$ \\
\hline Princípio 8 - Utilização de táticas arquiteturais & $\begin{array}{l}\text { PCS2410 - Engenharia de Software II } \\
\text { - Conceito de transações em bases de dados } \\
\text { - Recuperação de paradas e falhas } \\
\text { - Controle de acessos concorrentes } \\
\text { - Segurança de dados } \\
\text { PCS2420 - Laboratório de Engenharia de Software II } \\
\text { - Conceitos de componentes e objetos distribuídos } \\
\text { - Conceito de web service } \\
\text { PCS2430 - Requisitos de Sistemas Computacionais } \\
\text { - Conceitos de confiabilidade, disponibilidade, manutenabilidade, } \\
\text { testabilidade, segurança e dependabilidade } \\
\text { - Conceitos de confiabilidade e segurança de software } \\
\text { PCS2582 - Segurança da Informação } \\
\text { - Segurança da Informação em sistemas de computação e comunicação }\end{array}$ \\
\hline Princípio 9 - Trabalho em equipe & $\begin{array}{l}\text { PNV2100 - Introdução à Engenharia } \\
\text { - Trabalho em equipe } \\
\text { PCS2419 - Laboratório de Engenharia de Software I } \\
\text { - Trabalho em equipe } \\
\text { PCS2420 - Laboratório de Engenharia de Software II } \\
\text { - Trabalho em equipe }\end{array}$ \\
\hline $\begin{array}{l}\text { Princípio } 10 \text { - Uso de normas e padrões } \\
\text { reconhecidos }\end{array}$ & $\begin{array}{l}\text { PCS2511 - Gerência, Qualidade e Tecnologia de Software } \\
\text { - Modelos de qualidade de software: ISO9000, CMM, CMMI, SPICE } \\
\text { - Modelos de qualidade } \\
\text { - Modelos de maturidade }\end{array}$ \\
\hline
\end{tabular}




\begin{tabular}{|c|c|}
\hline Princípio 11 - Aspectos culturais envolvidos & $\begin{array}{l}\text { PCS2420 - Laboratório de Engenharia de Software II } \\
\text { - Organização e controle das atividades de um projeto para obter um } \\
\text { único sistema integrado } \\
\text { - Exercício de conceitos avançados de Engenharia de Software: prática de } \\
\text { gestão, paralelismo, integração entre equipes e desenvolvimento usando } \\
\text { componentes } \\
\text { PCS2511 - Gerência, Qualidade e Tecnologia de Software } \\
\text { - Apresentar processos de desenvolvimento, aquisição e manutenção de } \\
\text { software } \\
\text { - Introduzir técnicas de gerência de projetos conforme Project } \\
\text { Management Body of Knowledge (PMBoK) adaptadas aos processos de } \\
\text { software } \\
\text { - Aspectos de planejamento e controle de projetos: escopo, prazos, custo, } \\
\text { recursos humanos, comunicação, risco, contratação } \\
\text { - Técnicas de estimativa de esforço de desenvolvimento } \\
\text { PCS2554 - Engenharia de Informação } \\
\text { - Sistemas de informação } \\
\text { - Sistemas distribuídos de informação } \\
\text { - Computação corporativa } \\
\text { - Sistemas de workflow e automação de negócio } \\
\text { - Sistemas de suporte à decisão }\end{array}$ \\
\hline Princípio 12 - Abordagem prática & $\begin{array}{l}\text { MAC2301 - Laboratório de Programação } \\
\text { - Ambientes de programação: compilação, montagem e utilização de } \\
\text { bibliotecas. } \\
\text { - Elementos de estilo de programação e padrões de documentação de } \\
\text { código. } \\
\text { PCS2419 - Laboratório de Engenharia de Software I } \\
\text { - Apresentação dos ambientes de desenvolvimento e seus componentes } \\
\text { - Projeto do Banco de Dados } \\
\text { - Implementação do sistema e do banco de dados, utilizando linguagens } \\
\text { adequadas } \\
\text { - Especificação, projeto, implementação e teste de um sistema de } \\
\text { software, realizando as verificações intermediárias dos produtos gerados } \\
\text { PCS2420 - Laboratório de Engenharia de Software II } \\
\text { - Desenvolvimento de um único sistema, baseado na integração de } \\
\text { componentes }\end{array}$ \\
\hline Princípio 13 - Aprendizado incremental & $\begin{array}{l}\text { O princípio de Aprendizado incremental não foi explicitamente mapeado } \\
\text { em uma disciplina, mas foi aplicado no roteiro durante as aulas da } \\
\text { disciplina PCS2420 - Laboratório de Engenharia de Software II, } \\
\text { baseando-se na teoria de aprendizagem construtivista (vide item 3.2.1 - } \\
\text { Construtivismo) }\end{array}$ \\
\hline $\begin{array}{l}\text { Princípio } 14 \text { - Aprendizagem baseada em } \\
\text { problemas (problem based learning) }\end{array}$ & $\begin{array}{l}\text { O princípio de aprendizado incremental não foi explicitamente mapeado } \\
\text { em uma disciplina, mas foi aplicado no roteiro durante as aulas da } \\
\text { disciplina PCS2420 - Laboratório de Engenharia de Software II, } \\
\text { baseando-se tanto na teoria de Aprendizagem Construtivista (vide item } \\
\text { 3.2.1 - Construtivismo) como na Aprendizagem baseada em problemas } \\
\text { (vide item 3.2.3 - Aprendizagem baseada em problemas). Além disso, } \\
\text { também é uma das características pedagógicas do curso de Engenharia } \\
\text { de Computação (vide item 3.3.1- Currículo de Engenharia de } \\
\text { Computação). }\end{array}$ \\
\hline Princípio 15 - Aprendizado centrado no aluno & $\begin{array}{l}\text { O princípio de Aprendizado incremental não foi explicitamente mapeado } \\
\text { em uma disciplina, mas foi aplicado no roteiro durante as aulas da } \\
\text { disciplina PCS2420 - Laboratório de Engenharia de Software II, } \\
\text { baseando-se na teoria de aprendizagem construtivista (vide item 3.2.1 - } \\
\text { Construtivismo). Além disso, também é uma das características } \\
\text { pedagógicas do curso de Engenharia de Computação (vide item 3.3.1- } \\
\text { Currículo de Engenharia de Computacão). }\end{array}$ \\
\hline
\end{tabular}




\begin{tabular}{|c|c|}
\hline Princípio 16 - Projetos "reais" & $\begin{array}{l}\text { PNV2100 - Introdução à Engenharia } \\
\text { - Simulação de um pequeno projeto de Engenharia. } \\
\text { - Desenvolvimento de um projeto temático, compreendendo: Definição do } \\
\text { problema e formação de alternativas de solução; estabelecimento de } \\
\text { critérios, escolha e avaliação de soluções, especificação da solução. }\end{array}$ \\
\hline Princípio 17 - Aulas práticas & $\begin{array}{l}\text { Experimentos práticos são ministrados em todas as disciplinas de } \\
\text { laboratório, dentre as quais destacam-se: } \\
\text { - MAC2301 - Laboratório de Programação } \\
\text { - PCS2302 - Laboratório de Fundamentos de Engenharia de } \\
\text { Computação } \\
\text { - PCS2419 - Laboratório de Engenharia de Software I } \\
\text { - PCS2420 - Laboratório de Engenharia de Software II }\end{array}$ \\
\hline Princípio 18 - Documentação essencial & $\begin{array}{l}\text { O princípio de Documentação Essencial não foi explicitamente mapeado } \\
\text { em uma disciplina, mas foi aplicado no roteiro durante as aulas da } \\
\text { disciplina PCS2420 - Laboratório de Engenharia de Software II, } \\
\text { produzindo-se somente a documentação necessária para o } \\
\text { desenvolvimento e/ou manutenção do sistema utilizado durantes as aulas }\end{array}$ \\
\hline $\begin{array}{l}\text { Princípio } 19 \text { - Técnicas de Engenharia } \\
\text { Simultânea }\end{array}$ & $\begin{array}{l}\text { PCS2420 - Laboratório de Engenharia de Software II } \\
\text { - Exercício de conceitos avançados de Engenharia de Software: prática de } \\
\text { gestão, paralelismo, integração entre equipes e desenvolvimento usando } \\
\text { componentes } \\
\text { PCS2420 - Laboratório de Engenharia de Software II } \\
\text { Organização das equipes para o desenvolvimento paralelo }\end{array}$ \\
\hline
\end{tabular}

Fonte: Autor

No curso de graduação em Engenharia Elétrica com ênfase em Computação, oferecido pela Escola Politécnica da USP, o roteiro de ensino proposto foi aplicado na disciplina Laboratório de Engenharia de Software II (PCS2420).

5.5.2 Aplicação 1 - Disciplina de Laboratório de Engenharia de Software em curso de graduação em Engenharia Elétrica com ênfase em Computação utilizando um sistema existente

\section{Contexto da Disciplina}

Esta aplicação do roteiro de ensino teve como cenário uma disciplina de laboratório ministrada no quarto ano do curso de Engenharia Elétrica com ênfase em Computação, da Escola Politécnica da Universidade de São Paulo, denominada Laboratório de Engenharia de Software II (PCS2420) (ESCOLA POLITÉCNICA DA USP, 2013b), que também é oferecida para o curso de Engenharia de Computação da mesma escola. Nessa disciplina, com aulas de 4 horas semanais durante um semestre letivo (aproximadamente 15 aulas), todos os alunos, estudantes desse curso foram agrupados em equipes de dois a três participantes com o objetivo de implementar melhorias arquiteturais em um sistema já existente em um cenário no qual há um trade-off entre requisitos não funcionais derivado do processo de negócio. 
O contexto da disciplina envolve a simulação de uma situação em que cada equipe recebe a tarefa de efetuar a manutenção em um sistema desconhecido, o que exige que o aluno aprenda a arquitetura do sistema e os pontos críticos do processo de negócio em um curto período de tempo. Do ponto de vista técnico, as tecnologias utilizadas na implementação do sistema não são necessariamente conhecidas pelos alunos, sendo que a realização do aprendizado suficiente de tais tecnologias para a elaboração do trabalho de curso constitui um desafio adicional para os alunos.

Além disso, também são solicitadas alterações nos objetivos de negócio, fazendo-se necessário que a melhoria arquitetural também considere tais processos.

O uso de um sistema já existente cria um cenário de aprendizado que permite que a arquitetura desse sistema seja estudada e avaliada através de medição, modificada e reavaliada, visando obter-se a melhoria arquitetural.

O professor, ao mesmo tempo que ministra os conceitos contidos na ementa da disciplina, também faz o papel de principal interessado no sistema (cliente), oferecendo aos estudantes a experiência de tomar decisões arquiteturais que afetarão a qualidade do sistema como um todo e, consequentemente, gerarão a satisfação do professor-cliente.

Nesta aplicação do roteiro proposto, destacam-se o aprendizado de qualidade de arquitetura de software, a importância da arquitetura como artefato fundamental para atingir a qualidade esperada pelos usuários, o uso de provas de conceito construtivas e destrutivas, medições estáticas e dinâmicas, trade-offs arquiteturais baseados no processo de negócio apoiados pelo uso das normas e técnicas de avaliação de arquitetura descritas no Capítulo 4.

O presente experimento foi aplicado seis vezes, nos anos letivos de 2007 a 2012, para uma população total de 85 alunos, com um acumulado de aproximadamente 360 horas de aula em laboratório. Alguns exemplos de artefatos dos projetos elaborados pelos alunos, como especificação técnica, prova de conceitos e trechos dos sistemas implementados, estão descritos no Apêndice E.

Nas aplicações, foi utilizado o sistema Java Pet Store 2.0 (ORACLE, 2007). Trata-se um portal de anúncios de animais pela internet, no qual os usuários podem 
cadastrar animais para serem anunciados, informando a espécie (cachorro, gato, lagarto, pássaro, etc.), subtipo (por exemplo, gato de pelo longo, gato de pelo curto, etc.), nome, preço, localização, etc. Usuários visitantes do site podem buscar animais para comprá-los.

Essa aplicação utilizada como referência foi desenvolvida pelo fabricante da tecnologia Java para ilustrar os conceitos de como o Java Enterprise Edition pode ser utilizado para desenvolver aplicações que utilizem o padrão arquitetural Model-ViewController (MVC), Asynchronous JavaScript and XML (AJAX), Java Persistence Application Programming Interface (API) e serviços externos como Google Maps e PayPal. As principais tecnologias e ferramentas utilizadas no roteiro, como a linguagem de programação Java, servidores web, servidores de aplicação, ferramentas de desenvolvimento e testes, etc. estão listadas no Apêndice D.

\section{Aplicação do roteiro}

Segue o detalhamento da aplicação do roteiro de ensino na disciplina de Laboratório de Engenharia de Software II em curso de graduação:

\section{Etapa 1 - Entendimento do processo de negócio para definição dos requisitos de qualidade desejados}

Nesta fase, após a apresentação da disciplina, é feita uma demonstração do Pet Store aos alunos, visto que todos o utilizaram como base para o trabalho do curso. Os objetivos de negócio do sistema foram estabelecidos destacando-se as deficiências do sistema em relação a determinados atributos de qualidade como segurança, usabilidade, manutenibilidade, etc.

O roteiro de ensino foi apresentado aos alunos, com suas atividades distribuídas ao longo do calendário do curso. Os pontos de vista do RM-ODP foram apresentados, e o ponto de vista da Empresa foi utilizado nesta etapa.

Os alunos respondem, então, o Questionário 1, para a avaliação do conhecimento dos alunos no início do curso e recebem um kit contendo ferramentas e instruções para a instalação do sistema Pet Store e o fazem com o apoio do professor e dos monitores. 


\section{Etapa 2 - Identificação de trade-offs entre os requisitos não funcionais baseados no processo de negócio}

Dado os objetivos do processo de negócio estabelecidos na etapa anterior, os próprios alunos perceberam, baseando-se nas deficiências do sistema, que a arquitetura atual não atendia aos objetivos de negócio propostos. Os alunos foram divididos em grupos de 2 a 3 participantes e cada grupo era responsável por um determinado conjunto de requisitos de negócio, que propositadamente, envolvia um trade-off arquitetural. Para cada trade-off arquitetural, o qual estava diretamente relacionado ao processo de negócio, derivavam-se um ou dois temas de trabalhos relacionados. Na Figura 17, ilustra-se um grupo de seis trade-offs arquiteturais, dos quais foram derivados oito temas de trabalho. Se necessário, mais temas podem ser adicionados em cada trade-off arquitetural. Cada grupo de alunos trabalhou com um tema.

Figura 17 - Exemplo de temas de trabalho em uma aplicação do roteiro de ensino em uma disciplina de graduação com o uso de um sistema existente (Pet Store)

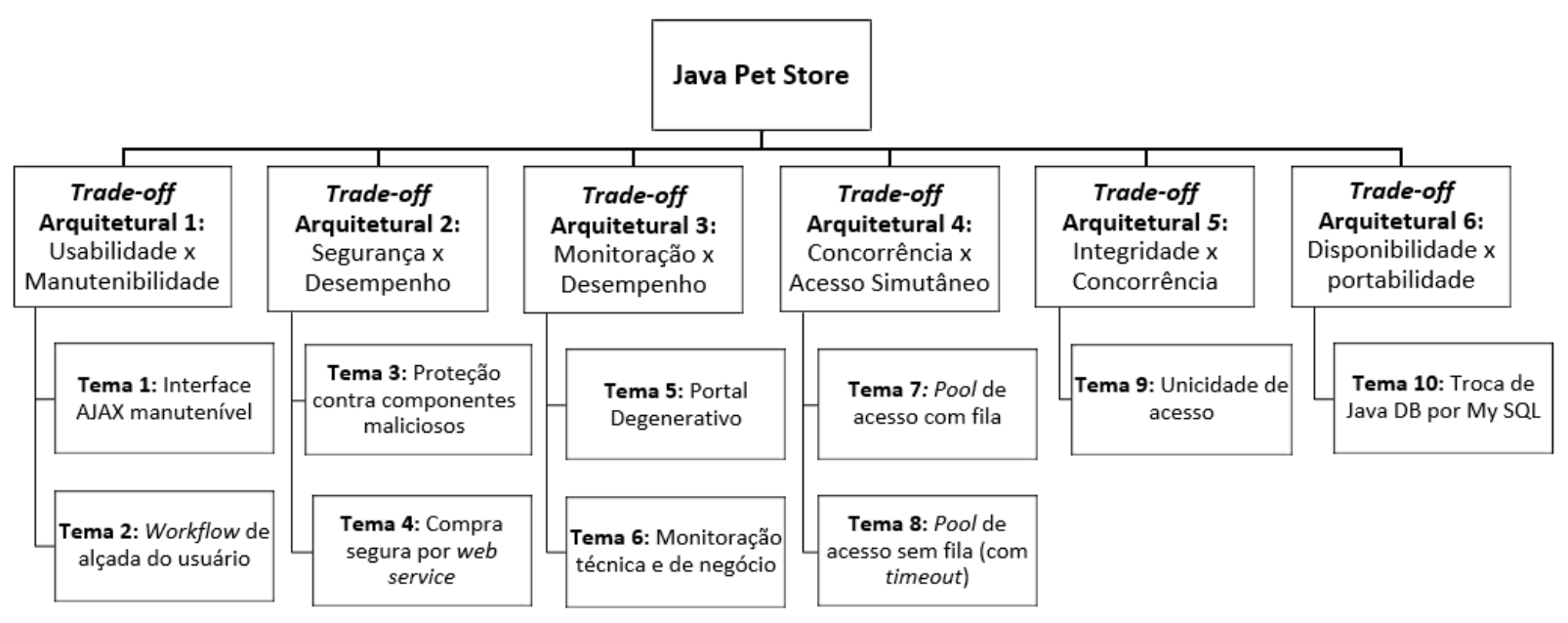

Fonte: Autor

Segue uma descrição dos temas propostos aos alunos na aplicação do roteiro proposto:

- Usabilidade x Manutenibilidade

- Interface AJAX manutenível: trade-off entre criação de interfaces web com AJAX e impactos na manutenção; 
- Workflow de alçada de usuário: implementação de mecanismos de proteção contra usuários mal-intencionados que queiram cadastrar animais inapropriados no site por meio de moderação de conteúdo por administradores do sistema e impactos na manutenção do sistema causado pela implementação desses mecanismos;

\section{- Segurança x Desempenho}

- Proteção contra componentes maliciosos: implementação contra componentes maliciosos através de mecanismo de autenticação e avaliação dos impactos causados por esses mecanismos no desempenho do sistema;

- Compra segura por web service: implementação de mecanismos de segurança por meio em módulos de pagamento e impactos decorrentes da implantação desses módulos no desempenho do sistema;

\section{- Monitoração x Desempenho}

- Portal degenerativo: implementação de sistema web com capacidade de degeneração ${ }^{17}$ controlada em cenários de alta demanda e impacto no desempenho do sistema como um todo;

- Monitoração técnica e de negócio: inserção de monitoração de características técnicas, como por exemplo: nível de utilização de processador, memória, transações no banco de dados e, de negócio, como venda de animais, margem de lucro, pagamento de fornecedores no Pet Store e avaliação da queda de desempenho devido à intrusão decorrente da monitoração implementada;

\section{- Concorrência x Acesso Simultâneo}

- Pool de acesso com fila: criação de mecanismo de fila de conexões para suportar alta demanda de acesso ao sistema;

- Pool de acesso sem fila (com timeout): criação de mecanismo de fila de conexões com recurso de timeout ${ }^{18}$ para evitar queda do sistema devido à alta demanda de acesso;

- Integridade x Concorrência

\footnotetext{
${ }^{17}$ Degeneração: queda progressiva de vitalidade, força ou qualidade para um nível pior do que em estados anteriores (MERRIAMWEBSTER, 2003). No tema de trabalho Portal degenerativo, o objetivo dos alunos é a implementação de mecanismos de monitoração que possibilite a degeneração controlada do sistema.

${ }^{18}$ Timeout: limite de tempo para que um programa de termine determinada ação (BUTTAZZO, 2011).
} 
- Unicidade de acesso: implementação de controle transacional no sistema para garantir coerência do que é mostrado ao usuário em cenários de concorrência de dois ou mais usuários tentando comprar o mesmo animal;

\section{- Disponibilidade x Portabilidade}

- Troca de banco de dados Java DB por My SQL: portabilidade entre banco de dados de diferentes fornecedores em cenários de indisponibilidade de um dos bancos de dados.

Todos os grupos atuam no mesmo sistema, porém em temas distintos. Por conseguinte, os trabalhos não têm obrigação de serem complementares ou integráveis entre si. Tomando como exemplo o trade-off "Concorrência x Acesso simultâneo", há dois temas de trabalho: um deles com foco na implementação do mecanismo de fila e outro sem fila, porém com uso de timeouts. Além disso, o objetivo de cada grupo foi bem especifico. Ainda, exemplificando com o trade-off "Concorrência x Acesso simultâneo", o objetivo da melhoria arquitetural é atender uma maior quantidade de usuários, número que seria obtido através de medições, que concorriam pelos recursos computacionais e pelos animais vendidos no site, sendo que mais de um usuário podia comprar o mesmo animal, o que não seria aceitável em um sistema real.

Para a avalição entre os diversos trade-offs, a árvore de utilidade do ATAM foi utilizada, suportada pelas definições dos atributos de qualidade da ISO/IEC 9126-1.

\section{Etapa 3 - Plano de medição dos requisitos não funcionais do sistema atual}

Um plano para coletas de medidas estáticas e dinâmicas foi elaborado pelos alunos, suportados pelos pontos de vista da Informação e Computação do RM-ODP e pelos conceitos de avaliação de produto de software da ISO/IEC 14598-5. O uso de medidas estáticas ou dinâmicas dependia do objetivo de cada grupo. Por exemplo, no tema "Interface AJAX manutenível", utilizaram-se majoritariamente métricas para coleta de medidas estáticas, como acoplamento das classes, complexidade ciclomática, etc. Já no tema de "Portal Degenerativo", métricas dinâmicas foram utilizadas para avaliação de comportamento do sistema quando submetido a alta 
carga de acesso. O JMeter foi utilizado como ferramenta de apoio para o planejamento e coleta dessas medidas.

\section{Etapa 4 - Coleta de medidas de qualidade do sistema atual}

Nesta etapa, baseados no plano de medição criado na Etapa 3, os alunos coletaram as medidas estáticas e dinâmicas do sistema atual. Para a obtenção das medidas estáticas, a própria ferramenta de desenvolvimento é utilizada. Em relação às medidas dinâmicas, como por exemplo, escalabilidade e desempenho, a ferramenta JMeter é utilizada.

Uma vez coletadas as medidas, as mesmas são tabuladas para a realização da análise de gap de qualidade entre sistema atual e sistema desejado, na próxima etapa do roteiro.

\section{Etapa 5 - Análise de gap de qualidade entre sistema atual e sistema desejado}

Os alunos realizaram uma análise do gap de qualidade alcançada pelo sistema atual e a expectativa de qualidade desejada para atender os requisitos de negócio. As medidas coletadas, a árvore de utilidade e as demandas de negócio orientaram essa análise. Exemplificando essa análise com o tema "Pool de acesso sem fila (com timeout)": após uma análise estática do código-fonte mais aprofundada, verificou-se que na arquitetura inicial, várias classes referenciavam uma determinada classe do sistema, denominada CatalogFacade, a qual, por sua vez, provia o acesso aos dados. Em testes comportamentais, simulados com o apoio do JMeter em tempo de execução, quando havia vários usuários requisitando dados simultaneamente, o Pet Store tentava atender a todos até que, em um determinado ponto, não mais respondia a tantas requisições, situação em que o usuário recebia uma tela de erro.

Do ponto de vista pedagógico, o processo de ensino/aprendizagem de qualidade de arquitetura tornou-se muito mais rico quando, em casos como esse, os alunos, por meio de medições descobriam os limites do sistema e constatavam, por intermédio de evidências que a arquitetura de software não mais atendia os requisitos do negócio. 


\section{Etapa 6 - Criação da Especificação Técnica do sistema desejado}

Nesta etapa, iniciou-se a elaboração da Especificação Técnica do sistema, na qual, de acordo com o ponto de vista da Engenharia do RM-ODP, já se definem as possíveis táticas arquiteturais que podem ser implementadas. Apoiando-se no princípio do roteiro de "Documentação essencial", a Especificação Técnica produzida pelos alunos foi sucinta, e continha apenas as informações que serviram como base para a implementação da prova de conceito.

\section{Etapa 7 - Projeto e implementação da Prova de Conceito baseado na Especificação Técnica}

Neste ponto do roteiro, apoiados pelo ponto de vista da Tecnologia do RMODP, os alunos implementaram a prova de conceito baseando-se na Especificação Técnica. Essa prova de conceito podia ser Construtiva ou Destrutiva, de acordo com a necessidade de cada grupo. Como exemplo, para atender o objetivo de negócio do grupo "Pool de acesso sem fila (com timeout)", que, no caso do Pet Store, significava responder a muitos usuários simultaneamente sem que o sistema retorne uma mensagem de erro, os alunos acabaram por decidir que seria aceitável, ao se ultrapassar a quantidade de usuários que o sistema é capaz de atender, uma mensagem de indisponibilidade temporária, exibida ao usuário através do uso adequado do mecanismo de timeout, conceito esse desconhecido por muitos alunos.

Em uma das aplicações do roteiro, após a primeira implementação da prova de conceito, após alteração dos mecanismos de acesso aos dados, os alunos constataram que a solução não era viável, pois mensagens de erros técnicas continuavam a ser exibidas quando o sistema era submetido a alta carga de acesso.

Ainda na mesma aplicação do roteiro, os alunos decidiram considerar uma segunda alternativa de solução. A Figura 18 destaca o ponto avaliado na arquitetura inicial e a modificação proposta. Na solução inicial, não havia controle da quantidade de acessos simultâneos. Na segunda solução, o controle era feito através da criação de uma classe auxiliar, denominada AccessController, que implementava o controle do pool de acessos por meio da implementação de um método chamado testAccess(). 
Figura 18 - Exemplo de solução proposta por alunos do Grupo "Pool sem filas" (com timeout)

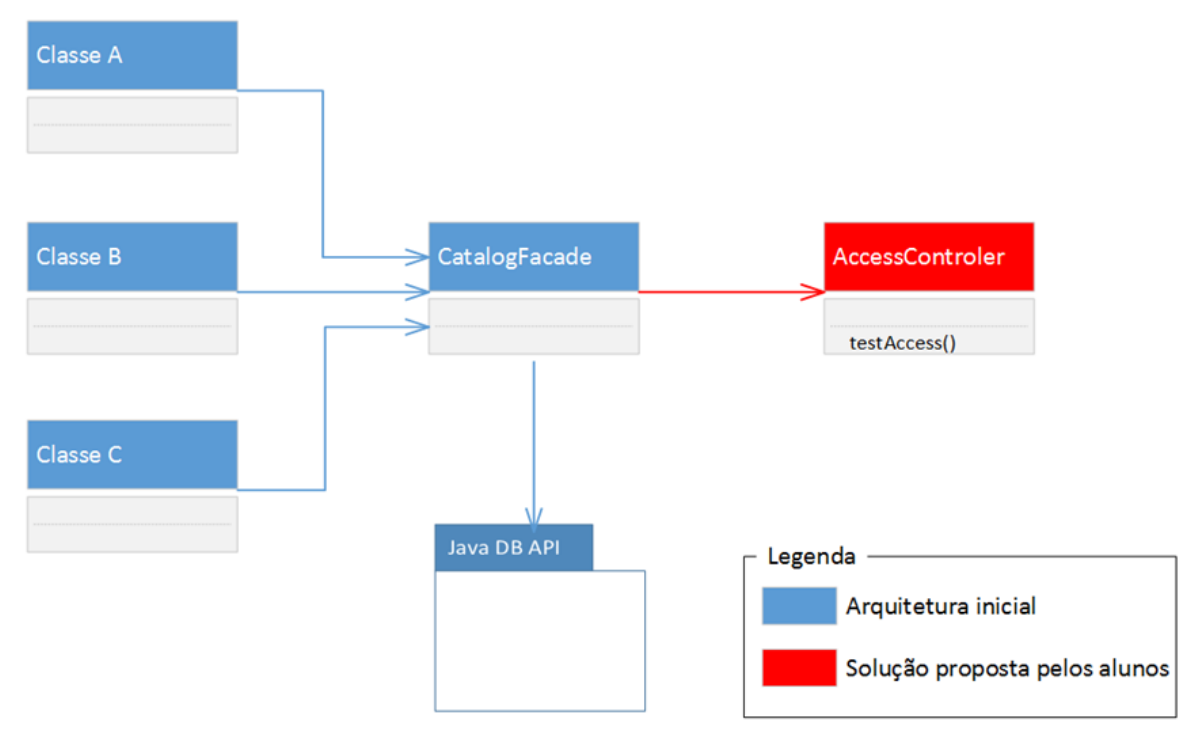

Fonte: adaptado de Guimarães (2008)

Quando uma requisição de acesso aos dados era feita à classe CatalogFacade pelas diversas classes que a referenciam, o método testAccess() da classe AccessController era invocado. Esse método verificava se o contador interno de acessos chegou ao limite, ou seja, à capacidade de atendimento do pool. Se não chegou, o contador era incrementado e retornava-se VERDADEIRO para a classe CatalogFacade, permitindo a liberação da requisição de acesso. Quando a requisição terminava de ser atendida, o contador era decrementado. Se o contador chegasse ao limite especificado pelo tamanho do pool, o método testAccess() retornava FALSO, impedindo a liberação da requisição e uma mensagem adequada ao usuário era exibida.

O aprendizado de avaliação de diversas alternativas foi rico, do ponto de vista pedagógico, para a formação do arquiteto de software, pois, com essa experiência, os alunos aprenderam a avaliar e testar alternativas arquiteturais, constatando, por meio de evidências coletadas nas medições, que a abordagem utilizada inicialmente não foi a mais adequada. Infelizmente, muitos profissionais de mercado só descobrem que a arquitetura de software implementada não atende aos requisitos quando recebem reclamações do usuário de um sistema em produção. 


\section{Etapa 8 - Revisão da Especificação Técnica de acordo com os resultados da Prova de Conceito}

Nesta fase, os alunos atualizaram a Especificação Técnica, inserindo os resultados e as alterações necessárias derivadas da implementação das provas de conceito. Nesta etapa, o Questionário 2 (intermediário) foi aplicado com o objetivo de avaliar se os conceitos ministrados até a metade do curso foram assimilados pelos alunos. A Especificação Técnica também foi avaliada pelo professor e pelos monitores do curso, buscando-se evidencias da aplicação dos conceitos lecionados.

\section{Etapa 9 - Implementação das melhorias definidas na Especificação Técnica}

Uma vez atualizada a Especificação Técnica, iniciava-se para a implementação das melhorias arquiteturais. Os alunos eram estimulados a utilizarem técnicas de engenharia simultânea, visando paralelizar, entre os integrantes de cada grupo, a implementação dos componentes da nova arquitetura de software.

\section{Etapa 10 - Plano de medição dos requisitos não funcionais do novo sistema}

Finalizada a implementação, o plano de medição elaborado na Etapa 3 era atualizado, considerando os requisitos de qualidade esperados pelo processo de negócio. Nesse novo plano, os alunos consideraram os requisitos funcionais e não funcionais, tendo como referência as melhorias arquiteturais implementadas na Etapa 9.

\section{Etapa 11 - Coleta de medidas de qualidade do novo sistema}

O plano de medição criado na Etapa 10 era executado pelos alunos. Após a execução do plano, já era possível saber quais requisitos foram atendidos pela nova arquitetura. Do ponto de vista pedagógico, essa era uma etapa importante, pois os alunos aprenderam a coletar medidas da implementação que eles mesmos fizeram e, dessa forma, podem avaliar como os requisitos de qualidade foram atendidos pela arquitetura de software escolhida por eles, o que está relacionado com o objetivo secundário deste trabalho, conforme descrito no Capítulo 1.

\section{Etapa 12 - Entrega de novo sistema}


Os alunos, de posse das evidencias colhidas na Etapa 11, elaboraram uma apresentação para comunicar os resultados atingidos com a nova arquitetura de software ao professor e aos monitores da disciplina, mostrando as evidências da melhoria da arquitetura de software do Pet Store.

\section{Etapa 13 - Requisitos de qualidade atingidos satisfazem as necessidades de negócio?}

$\mathrm{Na}$ última etapa do roteiro, o professor e os monitores avaliaram os artefatos produzidos e realizaram os testes de aceitação no novo sistema, dando feedback aos alunos dos pontos positivos e negativos da nova arquitetura de software implementada. Caso a arquitetura de software não atendesse minimamente aos requisitos de qualidade exigidos pelo processo de negócio, o grupo tinha a chance de realizar ajustes no trabalho. Aplicou-se o Questionário 3, de avaliação final do roteiro e as respostas foram tabuladas para avaliar se houve uma melhoria no nível de conhecimento dos conceitos questionados aos alunos. O sistema implementado também foi avaliado, e os comentários dos alunos nos questionários analisados, buscando-se principalmente críticas e sugestões que possam contribuir com 0 aprimoramento do roteiro de ensino proposto.

\section{Mapeamento entre as atividades do plano da disciplina e etapas do roteiro de ensino}

A Tabela 11 descreve o mapeamento entre atividades da ementa da disciplina e as etapas do roteiro de ensino aplicadas na disciplina de graduação Laboratório de Engenharia de Software II.

Nas 4 primeiras colunas da tabela estão descritas as informações relacionadas à ementa da disciplina como número da aula, etapas da disciplina, atividades planejadas e assuntos tópicos ministrados juntamente com artefatos produzidos em cada aula. Na quinta coluna, são descritas as etapas de aplicação do roteiro de ensino proposto, as quais ocorrem concomitantemente com as atividades da disciplina e suportam a ementa da disciplina. 
Tabela 11 - Aplicação 1 - Mapeamento entre as atividades do roteiro e o plano da disciplina Laboratório de Engenharia de Software em curso de graduação

\begin{tabular}{|c|c|c|c|c|}
\hline \multicolumn{4}{|c|}{ Ementa da Disciplina } & \multirow{2}{*}{$\begin{array}{l}\text { Etapas do roteiro de } \\
\text { ensino }\end{array}$} \\
\hline $\begin{array}{l}\text { Num. } \\
\text { Aula }\end{array}$ & Etapa & $\begin{array}{l}\text { Atividade da } \\
\text { disciplina }\end{array}$ & $\begin{array}{l}\text { Tópicos ministrados / Artefatos de } \\
\text { Software }\end{array}$ & \\
\hline 1 & Planejamento & Plano do Curso & $\begin{array}{l}\text { - Problematização: Exemplos de } \\
\text { Desempenho de Sistemas; } \\
\text { - Expectativas dos Alunos; } \\
\text { - Critérios de avaliação, Auto avaliação; } \\
\text { - Organização das Equipes e Trade-offs; } \\
\text { - CD por equipes; } \\
\text { - Java Pet Store (1/2); }\end{array}$ & $\begin{array}{l}\text { Etapa } 1 \text { - Entendimento } \\
\text { do processo de negócio } \\
\text { para definição dos } \\
\text { requisitos de qualidade } \\
\text { desejados. } \\
\text { Aplicação do questionário } \\
\text { inicial de avaliação do } \\
\text { roteiro (Questionário 1). }\end{array}$ \\
\hline 2 & \multirow{4}{*}{$\begin{array}{l}\text { Diagnóstico e } \\
\text { Análise de } \\
\text { Gaps }\end{array}$} & $\begin{array}{l}\text { Planejamento } \\
\text { (Diagnóstico) }\end{array}$ & $\begin{array}{l}\text { - Método de Medição (Ex. ATAM); } \\
\text { - Técnicas de Medidas Estáticas e } \\
\text { Dinâmicas; } \\
\text { - Java Pet Store (2/2) e JMeter, } \\
\text { - Mapeamento de Objetivos de Negócio } \\
\text { e atributos de qualidade } \\
\text { - Planejamento; }\end{array}$ & $\begin{array}{l}\text { Etapa } 2 \text { - Identificação de } \\
\text { trade-offs entre os } \\
\text { requisitos não funcionais } \\
\text { baseados no processo de } \\
\text { negócio. }\end{array}$ \\
\hline 3 & & Coleta / Análise & $\begin{array}{l}\text { - Plano de medição (Preparação de } \\
\text { Cenários de Coleta de dados); } \\
\text { - Uso do JMeter, }\end{array}$ & $\begin{array}{l}\text { Etapa } 3 \text { - Plano de } \\
\text { medição dos requisitos } \\
\text { não funcionais do sistema } \\
\text { atual. }\end{array}$ \\
\hline 4 & & Coleta / Análise & $\begin{array}{l}\text { - Coleta, Registro e Validação; } \\
\text { - Análise dos Dados; }\end{array}$ & $\begin{array}{l}\text { Etapa } 4 \text { - Coleta de } \\
\text { medidas de qualidade do } \\
\text { sistema atual. }\end{array}$ \\
\hline 5 & & $\begin{array}{l}\text { Análise de GAPS } \\
\text { (Meta } \times \text { Atual) }\end{array}$ & $\begin{array}{l}\text { - Diagnóstico de Arquitetura com foco no } \\
\text { requisito não funcional; } \\
\text { - Requisitos de Arquitetura (atendendo } \\
\text { GAPs de qualidade). }\end{array}$ & $\begin{array}{l}\text { Etapa } 5 \text { - Análise de gap } \\
\text { de qualidade entre } \\
\text { sistema atual e sistema } \\
\text { desejado. }\end{array}$ \\
\hline 6 & \multirow{7}{*}{$\begin{array}{l}\text { Implementação } \\
\text { da melhoria de } \\
\text { arquitetura }\end{array}$} & Projeto & $\begin{array}{l}\text { - Especificação Técnica (Evolução, } \\
\text { melhoria); } \\
\text { - Especificação da PoC; }\end{array}$ & $\begin{array}{l}\text { Etapa } 6 \text { - Criação da } \\
\text { Especificação Técnica do } \\
\text { sistema desejado. }\end{array}$ \\
\hline 7 & & $\begin{array}{l}\text { Implementação de } \\
\text { PoC }\end{array}$ & - Parâmetros de Arquitetura & \multirow{2}{*}{$\begin{array}{l}\text { Etapa } 7 \text { - Projeto e } \\
\text { implementação da Prova } \\
\text { de Conceito baseado na } \\
\text { Especificação Técnica. }\end{array}$} \\
\hline 8 & & $\begin{array}{l}\text { Implementação de } \\
\text { PoC }\end{array}$ & - Parâmetros de Arquitetura & \\
\hline 9 & & $\begin{array}{l}\text { Revisão da } \\
\text { Especificação Técnica }\end{array}$ & - Especificação da Arquitetura & $\begin{array}{l}\text { Etapa } 8 \text { - Revisão da } \\
\text { Especificação Técnica de } \\
\text { acordo com os resultados } \\
\text { da Prova de Conceito } \\
\text { Aplicação do questionário } \\
\text { intermediário de avaliação } \\
\text { do roteiro (Questionário } \\
\text { 2). }\end{array}$ \\
\hline 10 & & Implementação & - Código-fonte e executável & \multirow{3}{*}{$\begin{array}{l}\text { Etapa } 9 \text { - Implementação } \\
\text { das melhorias definidas na } \\
\text { Especificação Técnica. }\end{array}$} \\
\hline 11 & & Implementação & - Código-fonte e executável & \\
\hline 12 & & Implementação & - Código-fonte e executável & \\
\hline 13 & \multirow[t]{2}{*}{ Validação } & $\begin{array}{l}\text { Planejamento do } \\
\text { Diagnóstico }\end{array}$ & - Plano de Medição & $\begin{array}{l}\text { Etapa } 10 \text { - Plano de } \\
\text { medição dos requisitos } \\
\text { não funcionais do novo } \\
\text { sistema. }\end{array}$ \\
\hline 14 & & Coleta / Análise & - Medidas - Constatação da melhoria & $\begin{array}{l}\text { Etapa } 11 \text { - Coleta de } \\
\text { medidas de qualidade do } \\
\text { novo sistema. }\end{array}$ \\
\hline 15 & Aceite Técnico & $\begin{array}{l}\text { Entrega da } \\
\text { Arquitetura Nova }\end{array}$ & - Documentação Final & $\begin{array}{l}\text { Etapa } 12 \text { - Entrega de } \\
\text { novo sistema. } \\
\text { Etapa } 13 \text { - Requisitos de } \\
\text { qualidade atingidos } \\
\text { satisfazem as } \\
\text { necessidades de negócio? } \\
\text { Aplicação do questionário } \\
\text { final de avaliação do } \\
\text { roteiro (Questionário 3). }\end{array}$ \\
\hline
\end{tabular}

Fonte: Autor 


\section{Avaliação da aplicação do roteiro}

Conforme definido no item 5.4, a avaliação do roteiro é feita por meio de questionários aplicados durante a disciplina, da avaliação dos artefatos produzidos pelos alunos como parte do trabalho da disciplina e dos comentários dos alunos sobre o roteiro. As figuras 19 a 25 ilustram os gráficos com as respostas tabuladas e consolidadas consolidados dos 3 questionários aplicados durante a disciplina, aplicados na aula 1 (início do curso), aula 9 (meio do curso) e aula 15 (fim do curso), com as respostas dos 85 alunos das seis turmas de graduação de 2007 a 2012 , relacionadas a cada um dos seguintes conceitos avaliados:

1. Nível de conhecimento de medidas em geral;

2. Nível de conhecimento de medidas de arquitetura de software;

3. Nível de conhecimento de medidas estáticas;

4. Nível de conhecimento de medidas dinâmicas;

5. Nível de conhecimento de utilidade das medidas para melhoria da arquitetura de software;

6. Nível de conhecimento de conceitos de qualidade;

7. Nível de conhecimento da relação entre arquitetura de software e qualidade.

Os gráficos considerando as respostas dos alunos para os conceitos avaliados para cada uma das seis turmas, encontram-se no Apêndice B. 
1) Nível de conhecimento de medidas em geral

Figura 19 - Aplicação 1 - Respostas dos alunos sobre o nível de conhecimento de medidas em geral

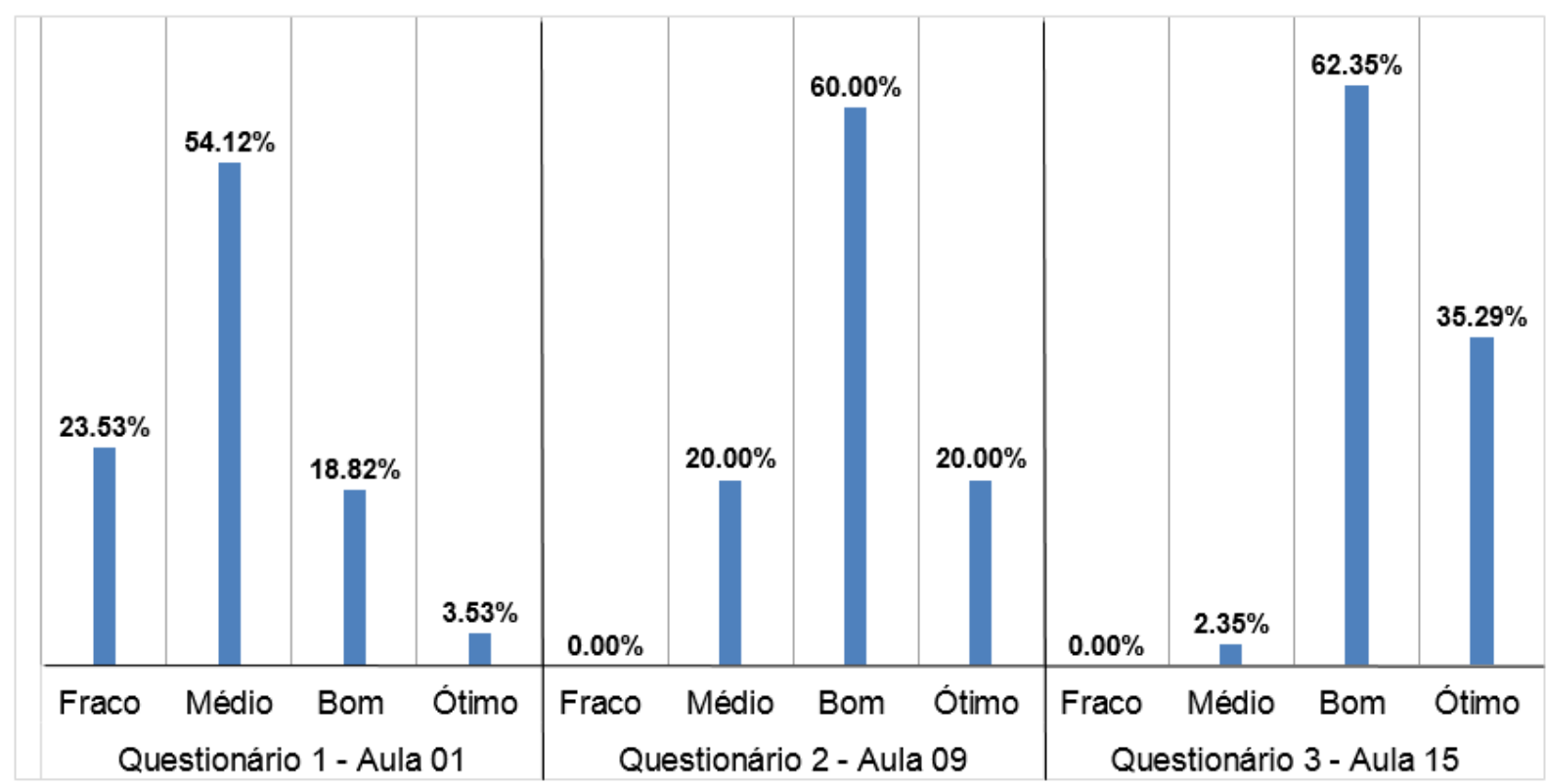

Fonte: Autor

2) Nível de conhecimento de medidas de arquitetura

Figura 20 - Aplicação 1 - Respostas dos alunos sobre o nível de conhecimento de medidas de arquitetura de software

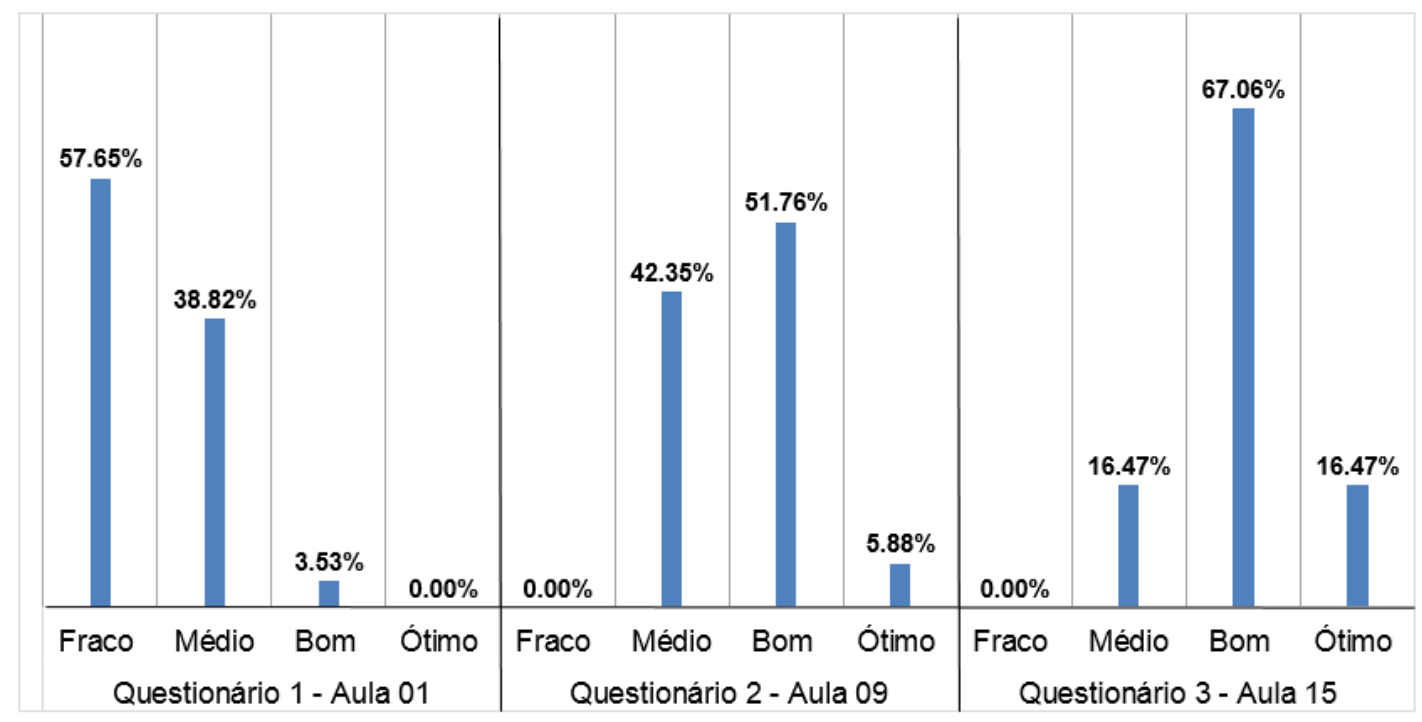

Fonte: Autor 
3) Nível de conhecimento de medidas estáticas

Figura 21 - Aplicação 1 - Respostas dos alunos sobre o nível de conhecimento de medidas estáticas

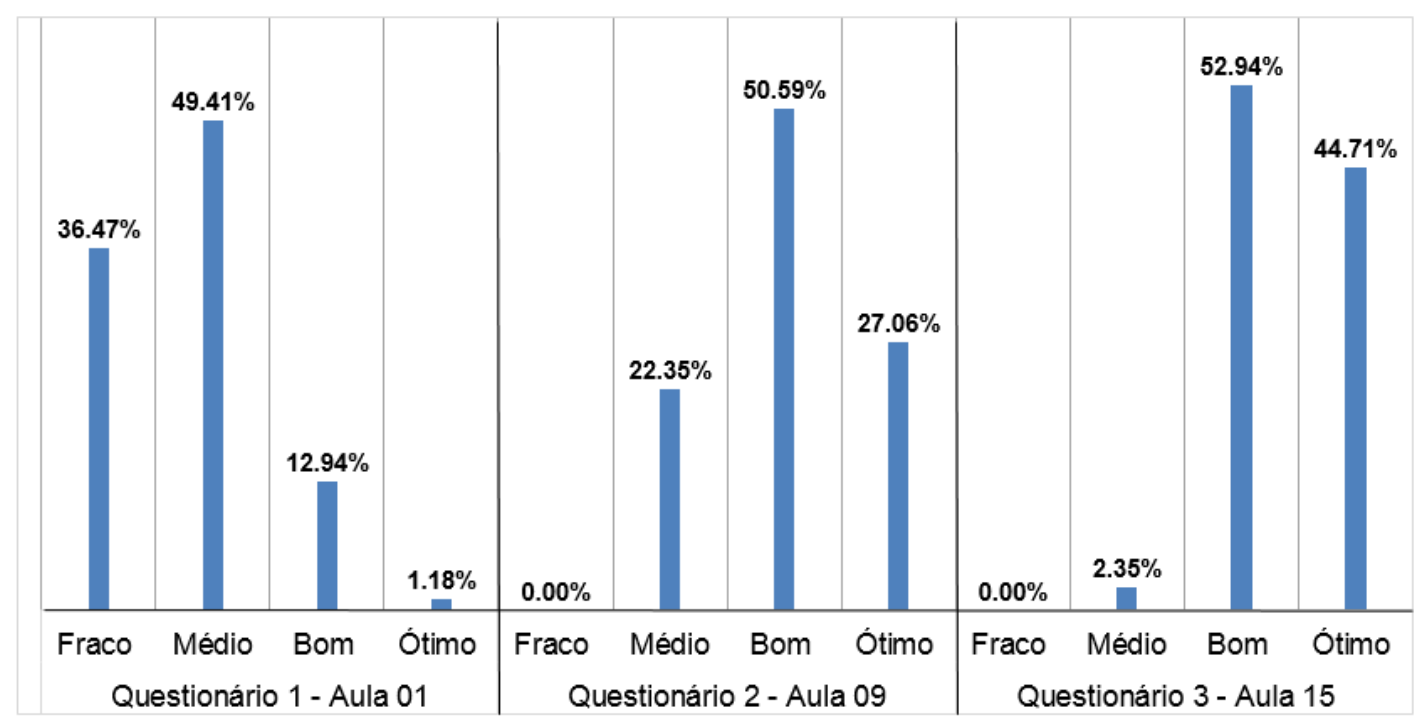

Fonte: Autor

4) Nível de conhecimento de medidas dinâmicas

Figura 22 - Aplicação 1 - Respostas dos alunos sobre o nível de conhecimento de medidas dinâmicas

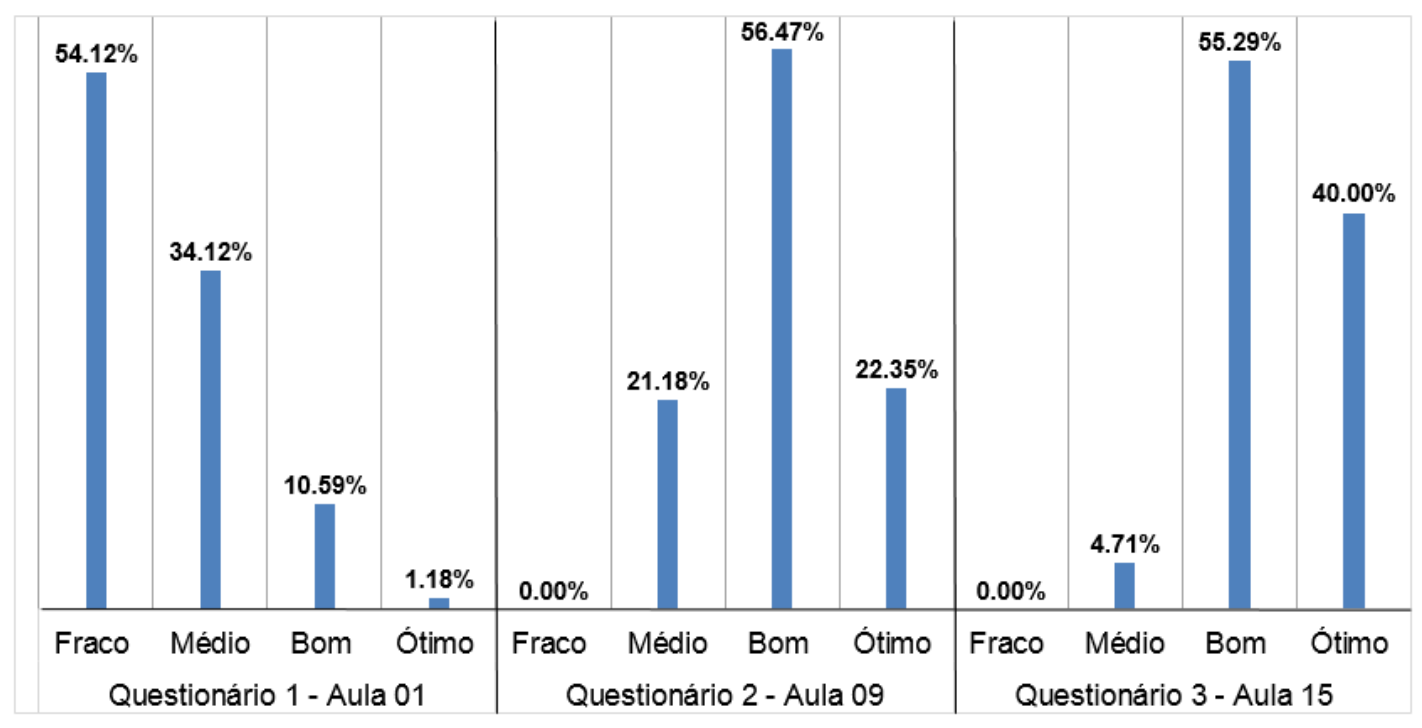

Fonte: Autor 
5) Nível de conhecimento de utilidade das medidas para melhoria da arquitetura de software

Figura 23 - Aplicação 1 - Respostas dos alunos sobre o nível de conhecimento de medidas para melhoria da arquitetura de software

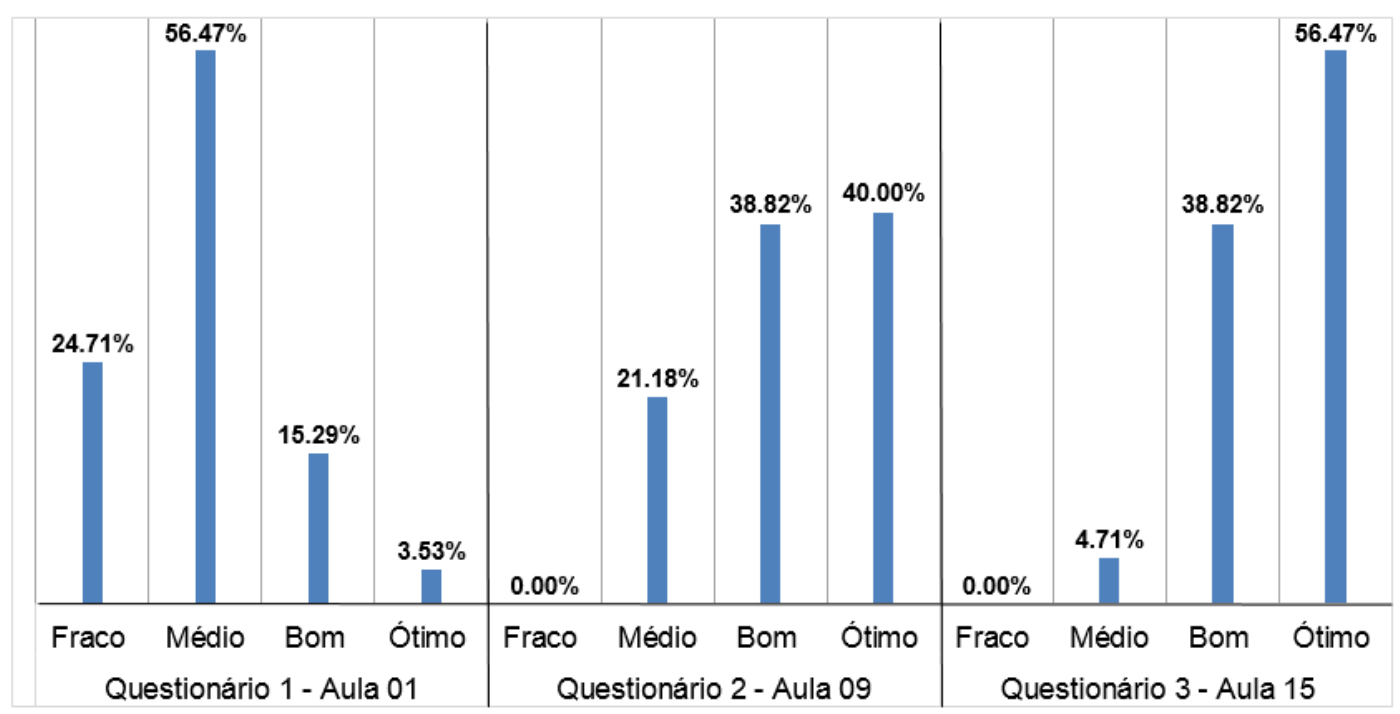

Fonte: Autor

6) Nível de conhecimento de conceitos de qualidade

Figura 24 - Aplicação 1 - Respostas dos alunos sobre o nível de conhecimento de conceitos de qualidade

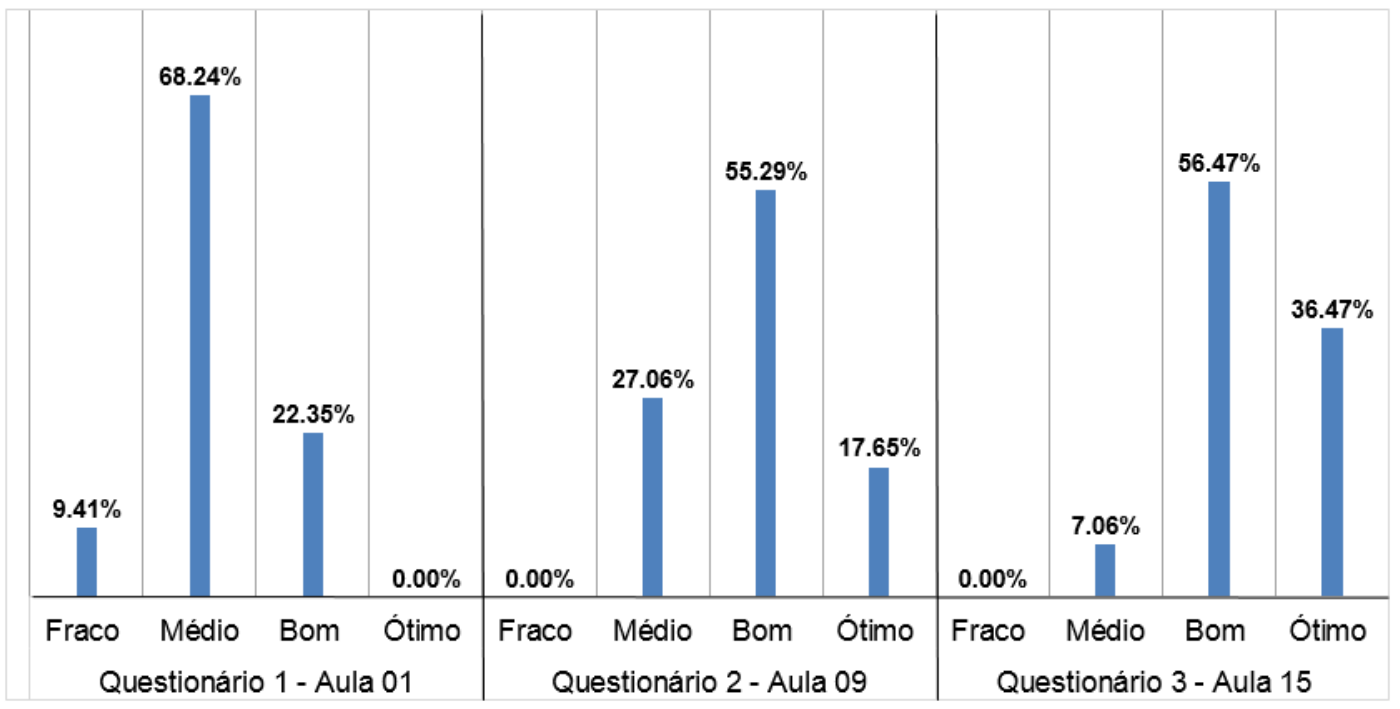

Fonte: Autor 


\section{7) Nível de conhecimento da relação entre arquitetura de software e qualidade}

Figura 25 - Aplicação 1 - Respostas dos alunos sobre o nível de conhecimento da relação entre arquitetura de software e qualidade

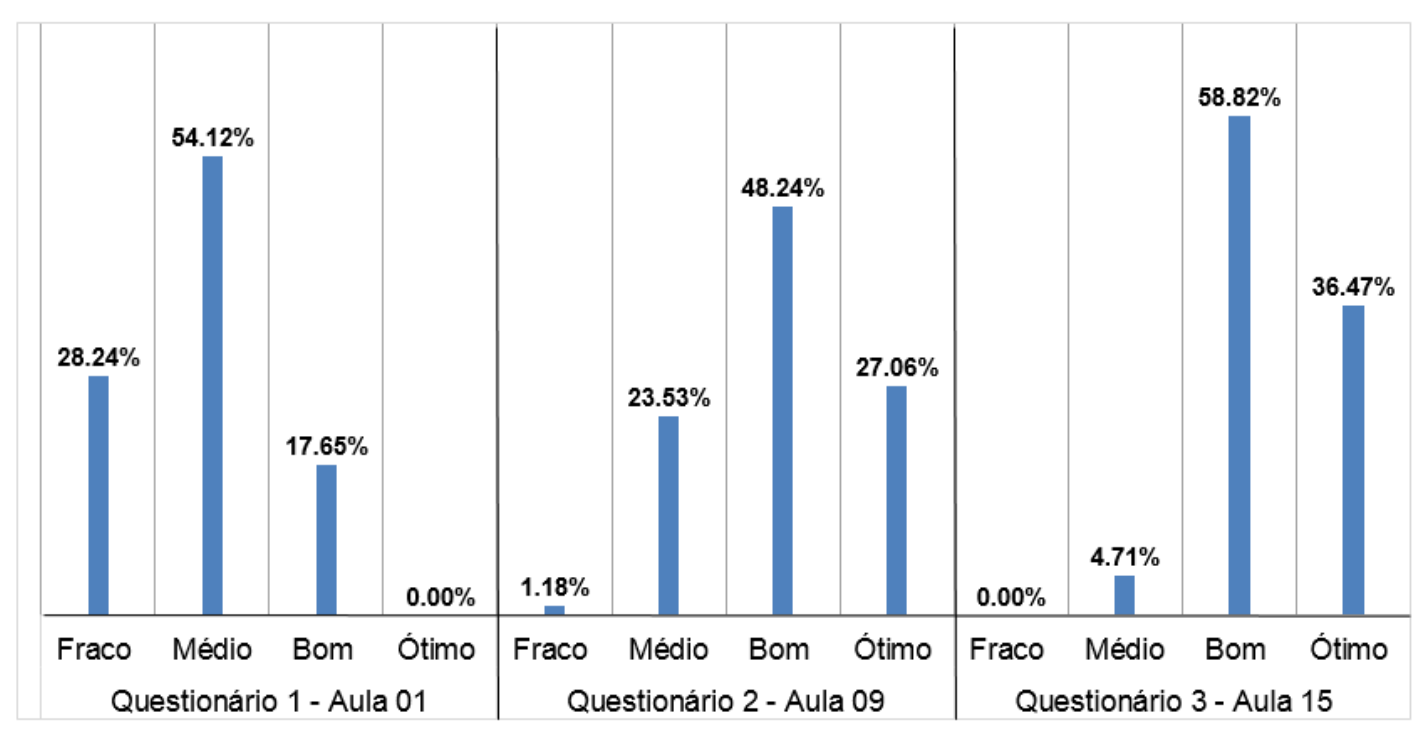

Fonte: Autor

$\mathrm{Na}$ disciplina Laboratório de Engenharia de Software II (PCS-2420), os principais artefatos entregues pelos alunos como parte do trabalho da disciplina são: plano de medição dos atributos de qualidade, especificação técnica das alterações a serem implementadas, provas de conceito e o sistema Pet Store com as alterações arquiteturais implementadas pelos alunos.

Nas aplicações do roteiro, os alunos inicialmente sentiram dificuldade tanto em trabalhar com um sistema pronto que não possui a documentação adequada, quanto com a necessidade de entender a arquitetura de software desse sistema para fazer as medições dos atributos de qualidade, identificar os pontos de melhoria e implementá-las, sempre orientados pelas necessidades do processo de negócio. A maior parte dos alunos estava acostumada a fazer toda a documentação do sistema e, uma vez que a mesma estivesse completa, iniciar a implementação, ou seja, trabalhar usando um modelo de desenvolvimento em cascata ${ }^{19}$.

\footnotetext{
${ }^{19}$ Modelo de desenvolvimento em cascata: modelo de processo de desenvolvimento de software em que as atividades ocorrem de forma sistemática e sequencial, inicializando-se com a especificação de requisitos junto ao cliente e progredindo
} 
Dois dos artefatos produzidos eram desconhecidos da maioria dos alunos: o plano de medição dos atributos de qualidade e a implementação da prova de conceito. O processo de elaboração do plano de medição foi rico do ponto de vista pedagógico, uma vez que mostrou aos alunos que os atributos de qualidade eram passiveis de serem mensurados de forma objetiva, substituindo os "achismos" relacionados aos atributos de qualidade de um sistema, como por exemplo: "o sistema deve ser rápido", por elementos quantificáveis como "o sistema deve ser capaz de suportar 200 transações por segundo em horário de pico". A utilização da árvore de qualidade do ATAM auxiliou na elaboração no plano de medição, dado que nas folhas da árvore devem ser colocados valores mensuráveis para os atributos de qualidade implementados em um sistema de software. A Figura 26 exibe um diagrama com as filas e threads do sistema, juntamente com as medições dinâmicas feitas por um grupo de alunos que trabalhou no tema Concorrência x Acesso Simultâneo com o propósito de implementar um pool de acesso com fila. 
Figura 26 - Aplicação 1 - Diagrama das filas e threads do sistema e medições dinâmicas

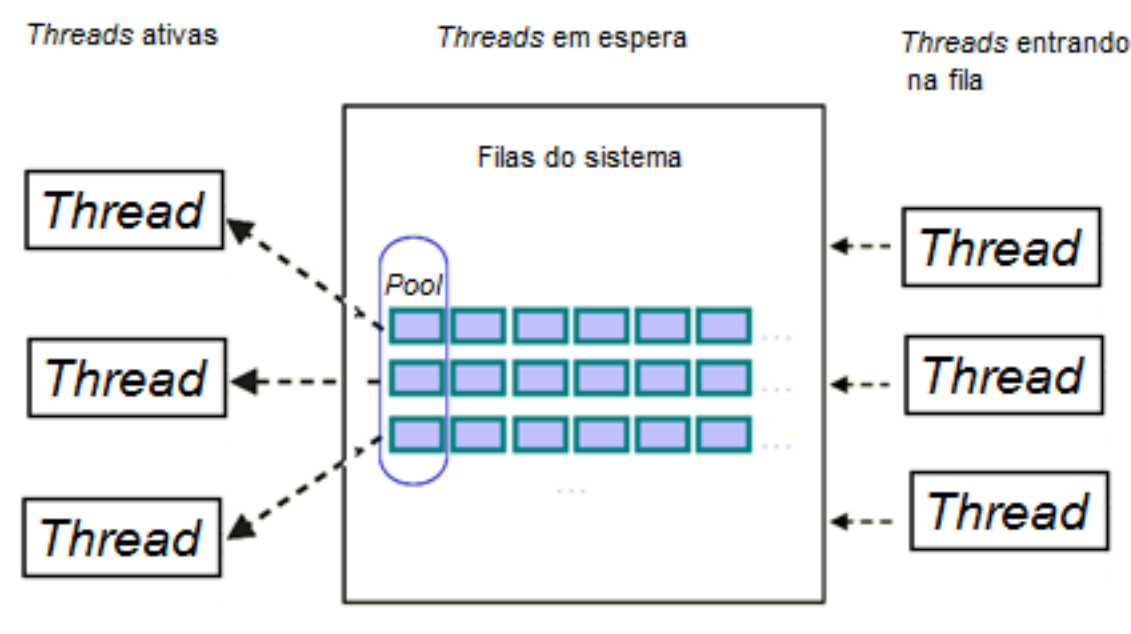

Thread 17 entrando na fila em 09:50:06

Thread chegou na primeira posição da fila em 09:50:06

Tempo em fila: $142 \mathrm{~ms}$

Tempo total da consulta ao banco de dados: $2005 \mathrm{~ms}$

Tempo total da operação: $2147 \mathrm{~ms}$

Fonte: trabalhos dos alunos que cursaram as disciplinas em que o roteiro proposto foi aplicado

A implementação da prova de conceito foi outro ponto importante do ponto de vista pedagógico. Muitos alunos reconsideram a estratégia arquitetural inicialmente adotada após os resultados da prova de conceito, ou seja, alteraram a estratégia adotada para implementar a arquitetura de software visando atingir os resultados de qualidade esperados.

Dada a natureza prática do roteiro, a especificação técnica entregue pelos alunos foi sucinta, mas já continha várias percepções práticas, como trechos de código, resultado das medições realizadas e diagramas das táticas arquiteturais utilizadas. A elaboração dessa especificação ocorreu praticamente durante toda a disciplina em um processo pendular entre documentação e implementação/medição dos atributos de qualidade.

Pela análise realizada pelo professor e pelos monitores, constatou-se que maioria dos artefatos produzidos pelos alunos considerava, em seu conteúdo, os conceitos de qualidade de arquitetura de software explorados pelo roteiro. 
O aspecto prático do roteiro, com foco nos requisitos não funcionais apresentados por meio de medições foram aspectos positivos de acordo com os comentários dos alunos, descritos no Apêndice F.

Conclusões da aplicação do roteiro proposto na disciplina de Laboratório de Engenharia de Software II (PCS2420) em curso de graduação utilizando um sistema existente

Notou-se que houve uma evolução do nível de abstração do modelo mental dos alunos submetidos ao roteiro, os quais iniciavam o curso como uma visão excessivamente centrada na linguagem de programação e, com o decorrer das aulas, adquiriam, aos poucos, uma visão mais centrada em arquitetura de software.

A Tabela 12 apresenta as respostas consolidadas dos 85 alunos aos 3 questionários de avaliação do roteiro proposto para este estudo de caso.

Tabela 12 - Aplicação 1 - Respostas consolidadas dos alunos aos 3 questionários de avaliação do roteiro proposto

\begin{tabular}{|l|c|c|c|c|c|c|c|c|c|c|c|c|}
\hline \multirow{2}{*}{$\begin{array}{l}\text { Conceito } \\
\text { Avaliado }\end{array}$} & \multicolumn{3}{|c|}{ Questionário 1 - Aula 01 } & \multicolumn{3}{c|}{ Questionário 2 - Aula 09 } & \multicolumn{3}{c|}{ Questionário 3 - Aula 15 } \\
\cline { 2 - 13 } & Fraco & Médio & Bom & Ótimo & Fraco & Médio & Bom & Ótimo & Fraco & Médio & Bom & Ótimo \\
\hline $\begin{array}{l}\text { Medidas em } \\
\text { geral }\end{array}$ & $23.53 \%$ & $54.12 \%$ & $18.82 \%$ & $3.53 \%$ & $0.00 \%$ & $20.00 \%$ & $60.00 \%$ & $20.00 \%$ & $0.00 \%$ & $2.35 \%$ & $62.35 \%$ & $35.29 \%$ \\
\hline $\begin{array}{l}\text { Medidas de } \\
\text { arquitetura de } \\
\text { software }\end{array}$ & $57.65 \%$ & $38.82 \%$ & $3.53 \%$ & $0.00 \%$ & $0.00 \%$ & $42.35 \%$ & $51.76 \%$ & $5.88 \%$ & $0.00 \%$ & $16.47 \%$ & $67.06 \%$ & $16.47 \%$ \\
\hline $\begin{array}{l}\text { Medidas } \\
\text { estáticas }\end{array}$ & $36.47 \%$ & $49.41 \%$ & $12.94 \%$ & $1.18 \%$ & $0.00 \%$ & $22.35 \%$ & $50.59 \%$ & $27.06 \%$ & $0.00 \%$ & $2.35 \%$ & $52.94 \%$ & $44.71 \%$ \\
\hline $\begin{array}{l}\text { Medidas } \\
\text { dinâmicas }\end{array}$ & $54.12 \%$ & $34.12 \%$ & $10.59 \%$ & $1.18 \%$ & $0.00 \%$ & $21.18 \%$ & $56.47 \%$ & $22.35 \%$ & $0.00 \%$ & $4.71 \%$ & $55.29 \%$ & $40.00 \%$ \\
\hline $\begin{array}{l}\text { Utilidade das } \\
\text { medidas para } \\
\text { melhoria da } \\
\text { arquitetura de } \\
\text { software }\end{array}$ & $24.71 \%$ & $56.47 \%$ & $15.29 \%$ & $3.53 \%$ & $0.00 \%$ & $21.18 \%$ & $38.82 \%$ & $40.00 \%$ & $0.00 \%$ & $4.71 \%$ & $38.82 \%$ & $56.47 \%$ \\
\hline $\begin{array}{l}\text { Conceitos de } \\
\text { qualidade }\end{array}$ & $9.41 \%$ & $68.24 \%$ & $22.35 \%$ & $0.00 \%$ & $0.00 \%$ & $27.06 \%$ & $55.29 \%$ & $17.65 \%$ & $0.00 \%$ & $7.06 \%$ & $56.47 \%$ & $36.47 \%$ \\
\hline $\begin{array}{l}\text { Relação entre } \\
\text { arquitetura de } \\
\text { software } e \\
\text { qualidade }\end{array}$ & $28.24 \%$ & $54.12 \%$ & $17.65 \%$ & $0.00 \%$ & $1.18 \%$ & $23.53 \%$ & $48.24 \%$ & $27.06 \%$ & $0.00 \%$ & $4.71 \%$ & $58.82 \%$ & $36.47 \%$ \\
\hline $\begin{array}{l}\text { Percentual } \\
\text { Médio }\end{array}$ & $\mathbf{3 3 . 4 5 \%}$ & $\mathbf{5 0 . 7 6} \%$ & $\mathbf{1 4 . 4 5 \%}$ & $\mathbf{1 . 3 4} \%$ & $\mathbf{0 . 1 7} \%$ & $\mathbf{2 5 . 3 8} \%$ & $\mathbf{5 1 . 6 0} \%$ & $\mathbf{2 2 . 8 6 \%}$ & $\mathbf{0 . 0 0 \%}$ & $\mathbf{6 . 0 5 \%}$ & $\mathbf{5 5 . 9 7 \%}$ & $\mathbf{3 7 . 9 8 \%}$ \\
\hline
\end{tabular}

Fonte: Autor

Analisando-se as respostas dos alunos, obtidas a partir da autoavaliação, é possível evidenciar a melhoria do nível de conhecimento nos conceitos questionados. 
Alguns exemplos: considerando-se o conceito avaliado "Medidas de arquitetura de software", 57,65 \% dos alunos tinham um conhecimento considerado Fraco na Aula $1 \mathrm{e}$, ao término de 15 aulas, $16,47 \%$ dos alunos avaliaram seu conhecimento como Médio, 67,06\% como Bom e 16,47\% como Ótimo. Fazendo-se a mesma análise para o conceito avaliado "Utilidade das medidas para melhoria da arquitetura de software", $24,71 \%$ dos alunos conheciam esse conceito de forma Fraca no início do curso e, ao final do mesmo, 4,71\% avaliaram seu próprio conhecimento como Médio, 38,82\% como Bom e 56,47\% como Ótimo. Finalmente, para o conceito "Relação entre arquitetura de software e qualidade", $28,24 \%$ dos alunos declararam Fraco conhecimento na aula $1,4,71 \%$ dos alunos se reavaliaram com nível conhecimento Médio, 58,82\% como Bom e 36,47\% como Ótimo na última aula.

Analisando-se a média das respostas dos alunos para todos os conceitos avaliados, aproximadamente $33,45 \%$ deles responderam que possuíam fracos conhecimentos na aula 1. Esse percentual caiu para $0,17 \%$ no questionário intermediário, aplicado na aula 9, e chegou a zero na aula 15. Ainda analisando-se a média, $1,34 \%$ dos alunos responderam que possuíam ótimos conhecimentos nos conceitos questionados na primeira aula. Essa média subiu para $22,86 \%$ no questionário intermediário e para $37,98 \%$ no questionário final.

Conceitos que eram desconhecidos ou não compreendidos pelos estudantes, como por exemplo: relação entre arquitetura de software e processo de negócio, tradeoffs entre atributos de qualidade e uso de provas de conceito construtivas e destrutivas foram absorvidos gradativamente durante as aulas, o que é uma evidência da aprendizagem.

O nível dos trabalhos apresentados e a importância dada à qualidade de arquitetura de software nas etapas de medição e durante a implementação da prova de conceito são, também, evidências de que os alunos conseguiram assimilar os principais conceitos definidos como objetivos de aprendizado.

Obstáculos técnicos surgiram durante a aplicação do roteiro, mais precisamente no que se refere ao conhecimento das tecnologias envolvidas no Java Pet Store, descritas no Apêndice D. Porém com o uso de provas de conceito que 
permite a avaliação de arquiteturas em um contexto mais simples do que o sistema todo, as dificuldades tecnologias foram superadas gradativamente.

Algumas modificações arquiteturais foram bastante localizadas, permitindo que soluções de grupos distintos pudessem ser facilmente integradas. Entretanto, havia soluções em que a integração era extremamente difícil, ou mesmo inviável. Essas soluções refletiam justamente requisitos de qualidade conflitantes, ou, ainda, que a solução adotada por um dos grupos poderia impactar negativamente os atributos de qualidade considerados por outro grupo. Apesar de a integração das soluções geradas não ser uma das etapas do roteiro, os alunos perceberam o conceito do tradeoff geral do sistema, o que contribuiu para o aprendizado.

5.5.3 Aplicação 2 - Disciplina de Laboratório de Engenharia de Software em curso de graduação em Engenharia Elétrica com ênfase em Computação considerando o desenvolvimento de um sistema novo

\section{Contexto da Disciplina}

Esta aplicação do roteiro de ensino teve como cenário a mesma disciplina utilizada no item 5.5.2, ou seja, a disciplina Laboratório de Engenharia de Software II (PCS 2420) (ESCOLA POLITÉCNICA DA USP, 2013b), porém, nesta aplicação do roteiro proposto, os alunos, agrupados em equipes de 3 a 4 participantes, desenvolveram um sistema novo baseados em conceitos de Internet das Coisas, do inglês, Internet of Things (loT). Esse experimento foi aplicado duas vezes, nas turmas de 2013 e 2014, para uma população de 36 alunos com um acumulado de aproximadamente $120 \mathrm{~h}$ de aula em laboratório.

A empresa Gartner ${ }^{20}$, em seu glossário de termos de TI, define a Internet das Coisas como "uma rede de objetos físicos que contém tecnologia embarcada para se comunicar e interagir com seus estados internos ou com o ambiente externo (GARTNER, 2014). A Internet das Coisas é um elemento-chave para a criação de aplicações inteligentes que pode provocar mudanças tecnológicas em diversos mercados de tecnologia, desde conexão com o consumidor, casas e edifícios

\footnotetext{
20 Gartner: empresa de pesquisa e consultoria em Tecnologia de Informação. Fundada em 1979, o Gartner tem sede em Stamford, Connecticut, EUA, e possui 6.600 associados, incluindo mais de 1.500 analistas de pesquisa e consultores e clientes em 85 países (GARTNER, 2015).
} 
inteligentes, saúde, indústrias e cidades inteligentes (IEEE, 2014). Do ponto de vista pedagógico, projetos de Internet das Coisas oferecem cenários de aprendizado ricos, uma vez que abrangem conceitos de arquitetura de software importantes como segurança, privacidade, desempenho, escalabilidade, disponibilidade, interoperabilidade e robustez (WALEWSKI, 2013). Além da possibilidade de exercitar todos esses conceitos, projetos de Internet das Coisas possibilitam abordagens práticas de aprendizado, de forma muito semelhante a projetos reais (ZHANG, 2012).

Da mesma forma que na Aplicação 1 do roteiro de ensino, o professor, ao mesmo tempo que ministra os conceitos contidos na ementa da disciplina, também faz o papel de "cliente" do sistema novo a ser concebido.

Nesta aplicação do roteiro, destacaram-se o aprendizado de conceitos sobre componentes e objetos distribuídos; arquitetura de software e de qualidade de arquitetura de software; desenvolvimento de software em plataformas integradas de mobilidade, geolocalização e orientação a serviços; e organização das equipes para o desenvolvimento em paralelo em projetos de aplicação prática em cenários de cunho social, econômico, industrial, comércio, educação e entretenimento.

Cada grupo de alunos recebeu um tema já previamente definido, o qual demandou a consideração de trade-offs entre requisitos não funcionais em projetos de Internet das Coisas.

Durante essa aplicação do roteiro, os alunos utilizaram microcomputadores programáveis como o Raspberry $\mathrm{Pl}$ ou microcontroladores como o Arduino Uno, sensores e placas de ensaio (protoboards). As principais tecnologias, componentes e ferramentas utilizadas no roteiro como detectores de fumaça, sensores de fumaça, Sistema de Posicionamento Global, do inglês Global Positioning System (GPS), entre outros estão listadas no Apêndice D. A Figura 27 exibe o microcomputador programável Arduino Uno, utilizado na disciplina. Alguns exemplos de artefatos do projeto produzidos pelos alunos, como especificação funcional, especificação técnica e prova de conceitos, estão descritos no Apêndice E. 
Figura 27 - Arduino Uno utilizado durante as aulas da disciplina PCS2420

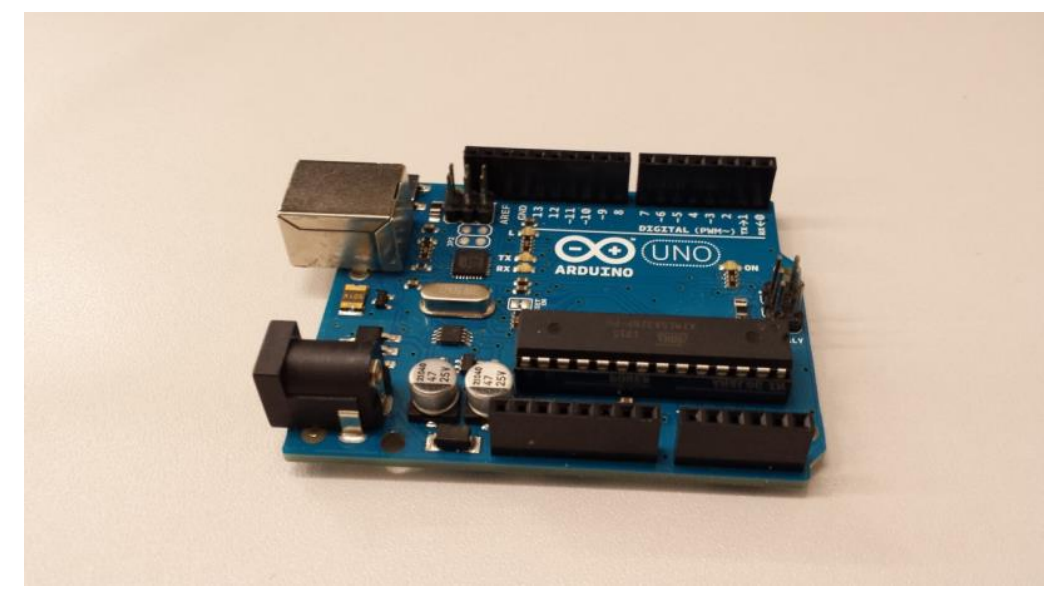

Fonte: trabalhos dos alunos que cursaram as disciplinas em que o roteiro proposto foi aplicado

\section{Aplicação do roteiro}

Dado que este exemplo de aplicação considerou o desenvolvimento de sistemas novos, utilizou-se o Roteiro de ensino de qualidade de arquitetura de software guiado por requisitos não funcionais adaptado para o desenvolvimento de sistemas novos, ilustrado na Figura 16.

Etapa 1' - Entendimento do processo de negócio para definição dos requisitos de qualidade desejados

Nesta fase, após a apresentação da disciplina, são discutidos os principais conceitos sobre Internet das Coisas, processo de negócio, arquitetura de software, qualidade de arquitetura de software e requisitos de qualidade.

O roteiro de ensino foi apresentado aos alunos, com suas atividades distribuídas ao longo do calendário do curso. Os pontos de vista do RM-ODP também foram apresentados, e o ponto de vista da Empresa utilizado nesta etapa. Os temas de trabalho listados a seguir foram propostos aos alunos:

- Conveniência para pessoas da 3a . idade: envolvia aspectos de geolocalização, sensores de presença residenciais, monitoração de sinais vitais a distância e mobilidade; 
- Localização e cuidado com animais de estimação: abordava aspectos relacionados à segurança, monitoração remota e localização de animais;

- Segurança de automóveis e do proprietário: relacionado com conceitos de segurança de automóveis e respectivos proprietários em cenários de roubo, furto e sequestro relâmpago do proprietário do veículo;

- Automação residencial: considerava a monitoração residencial de incidentes de falta de energia, invasão e incêndio através da internet/dispositivos móveis.

Os alunos responderam o Questionário 1 para avaliação do nível de conhecimento no início das aulas da disciplina e receberam um kit contendo os microcomputadores programáveis e instruções de utilização.

\section{Etapa 2' - Identificação de trade-offs entre os requisitos não funcionais baseados no processo de negócio}

Nesta etapa, os conceitos de qualidade de arquitetura de software e os tradeoffs entre atributos de qualidade foram apresentados aos alunos e, com o uso da árvore de utilidade do ATAM, os possíveis trade-offs dos temas de trabalho propostos foram mapeados. Os alunos foram divididos em grupos de 2 a 3 participantes, e cada grupo desenvolveu um sistema relacionado com os temas de trabalho descritos na etapa anterior, considerando os requisitos não funcionais inerentes à solução. A Tabela 13 lista todos os cenários extraídos de requisitos não funcionais elencados pelos alunos que trabalharam no tema "Conveniência para pessoas da $3^{\text {a }}$. idade": 
Tabela 13 - Cenários considerados pelos alunos que trabalharam no tema Cenários de conveniência para pessoas da $3^{a}$. idade

\begin{tabular}{|l|l|}
\hline \multicolumn{1}{|c|}{ Atributos de qualidade } & Cenários baseados em requisitos não funcionais \\
\hline Segurança & Apenas usuários com permissão podem acessar o painel de controle \\
\hline Segurança & Apenas usuários com permissão podem alterar parâmetros do sistema \\
\hline Usabilidade & Botões de pânico chamativos para o usuário \\
\hline Desempenho & Resposta dos botões de pânico em menos de 5 segundos \\
\hline Desempenho & Atualização do painel de controle em menos de 15 segundos \\
\hline Confiabilidade & O sistema deve enviar os dados com 95\% de precisão \\
\hline Disponibilidade & O sistema deve operar no mínimo 23 horas/dia \\
\hline Disponibilidade & Utilização de nobreak para evitar desligamento inesperado do sistema \\
\hline
\end{tabular}

Fonte: trabalhos dos alunos que cursaram as disciplinas em que o roteiro proposto foi aplicado

\section{Etapa 3' - Plano de medição dos requisitos não funcionais a serem implementados}

Nesta etapa, os alunos elaboraram um plano para a medição dos requisitos não funcionais do sistema a ser implementado, considerando medidas estáticas e dinâmicas, suportados pelos pontos de vista da Informação e Computação do RMODP e pelos conceitos de avaliação de produto de software da ISO/IEC 14598-5.

A título de exemplo, no grupo de alunos responsável pelo tema "Localização e cuidado com animais de estimação", uma das medidas consideradas no plano de medição foi o fator do erro do posicionamento ${ }^{21}$ calculado pelo módulo de GPS. A Figura 28 ilustra o recebimento de informações do módulo de GPS por 7 satélites, mas utilizando os dados de apenas 5 deles, o que já era suficiente para fornecer latitude, longitude e altitude e seus intervalos de erros, conforme destacado no quadro direito da figura.

\footnotetext{
${ }^{21}$ Fator do erro do posicionamento: os resultados de um sistema GPS são afetados por erros são afetadas por erros provenientes dos componentes do sistema, como satélite (erros orbital e de relógio), propagação (erros da ionosfera e troposfera) e do receptor (multicaminho e ruído interno) (BARONI, 2009).
} 
Figura 28 - Dados exibidos pelo módulo de GPS

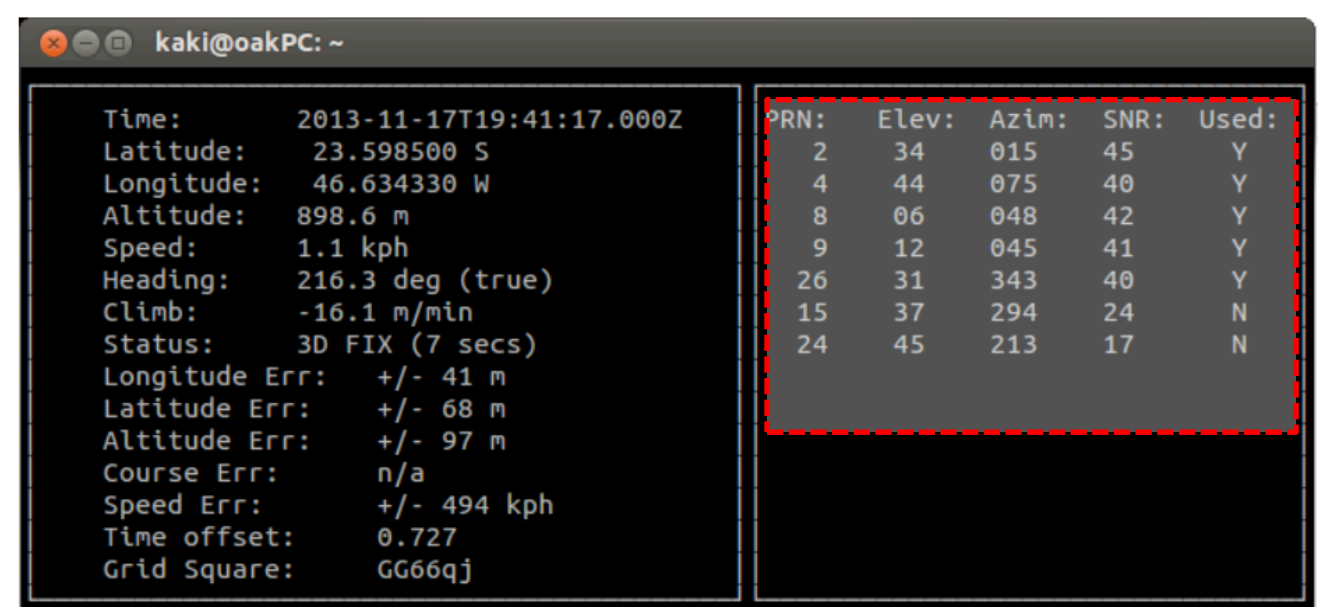

Fonte: trabalhos dos alunos que cursaram as disciplinas em que 0 roteiro proposto foi aplicado

\section{Etapa 4' - Criação da Especificação Técnica do sistema}

Nesta etapa, os alunos elaboraram a Especificação Técnica, artefato no qual as decisões e táticas arquiteturais são documentadas. Os conceitos da RM-ODP foram detalhados para auxiliar na criação da Especificação Técnica. A Figura 29 ilustra a interligação física dos componentes do trabalho "Segurança de automóveis e do proprietário". Neste trabalho foram utilizados os seguintes componentes: microcontrolador Arduino Uno, leitor Radio-frequency identification (RFID), módulo bluetooth e resistores de $10 \mathrm{k} \Omega$ e $20 \mathrm{k} \Omega$. O microcontrolador executava, a cada segundo, uma leitura do componente de RFID e enviava os dados por meio de Bluetooth para um celular previamente pareado, que exibia, por meio de um aplicativo, a localização do sensor na tela do celular. Os testes de integração entre os componentes citados foram realizados pelos alunos e documentados na especificação técnica. 
Figura 29 - Interligação física dos componentes do trabalho "Segurança de automóveis e do proprietário"

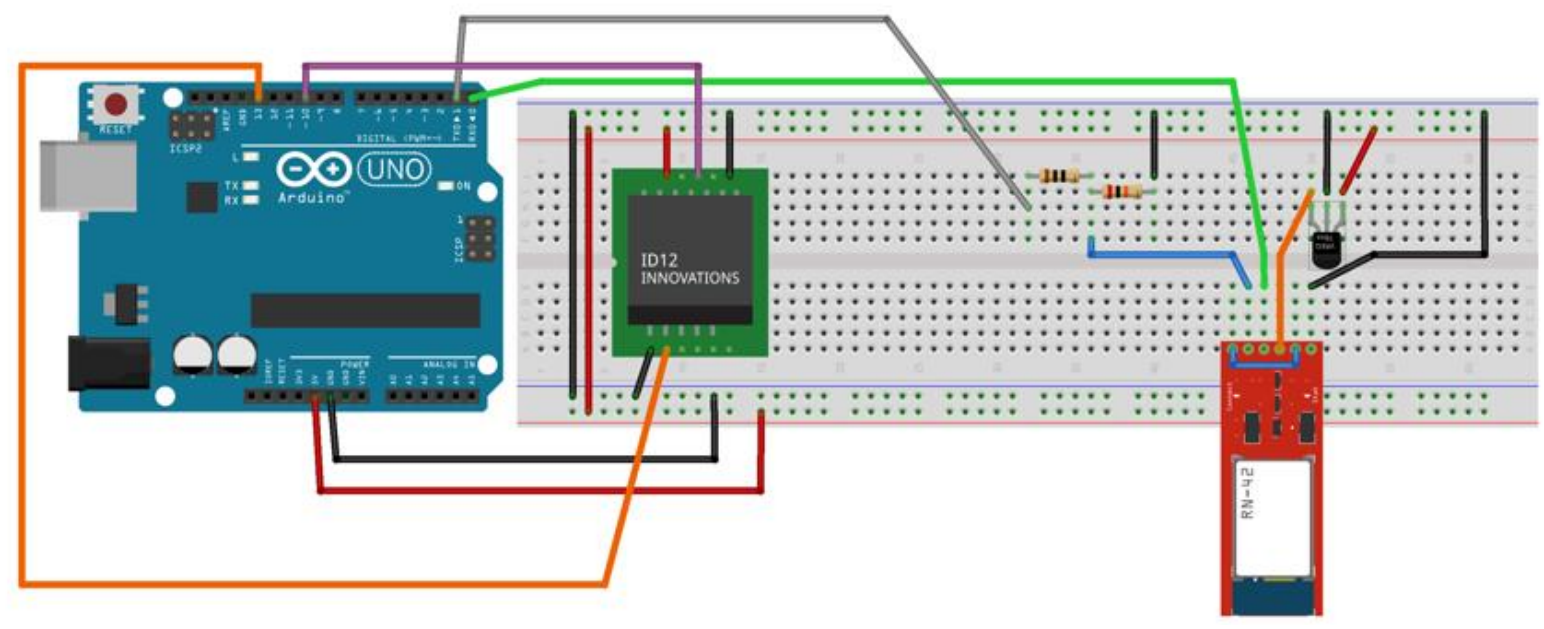

Fonte: trabalhos dos alunos que cursaram as disciplinas em que o roteiro proposto foi aplicado

Assim como no exemplo de aplicação do roteiro de ensino descrito anteriormente, a Especificação Técnica foi elaborada de forma sucinta e serviu como base para a implementação da prova de conceito.

\section{Etapa 5' - Projeto e implementação da Prova de Conceito baseado na Especificação Técnica}

Nesta etapa, foi implementada a prova de conceito baseada na Especificação Técnica para verificar a viabilidade de implementação da arquitetura de software proposta para a solução. O grupo de alunos responsáveis pelo tema "Automação residencial" implementou a prova de conceito utilizado o padrão de projeto Delegate, no qual um objeto delega para outro a execução de um método. Esse padrão permite composição de comportamentos que podem ser alterados em tempo de execução (GAMMA et al., 1994). A escolha desse padrão de projeto mostrou-se efetiva, uma vez que os requisitos de negócio foram atendidos. A Figura 30 a seguir representa 0 diagrama de componentes utilizado na prova de conceito do grupo que atuou no tema "Automação residencial", no qual se verifica a implementação do padrão Delegate nos componentes de Log (Logger Delegate), Notificação (Notification Delegate), Armazenamento (Storage Delegate), Conexão (Connection Delegate) e Segurança 
(Security Delegate). O uso desse padrão permite, por meio do desacoplamento, aumentar a modularização dos componentes lógicos do sistema.

Figura 30 - Diagrama de componentes elaborado na prova de conceito do trabalho "Automação residencial"

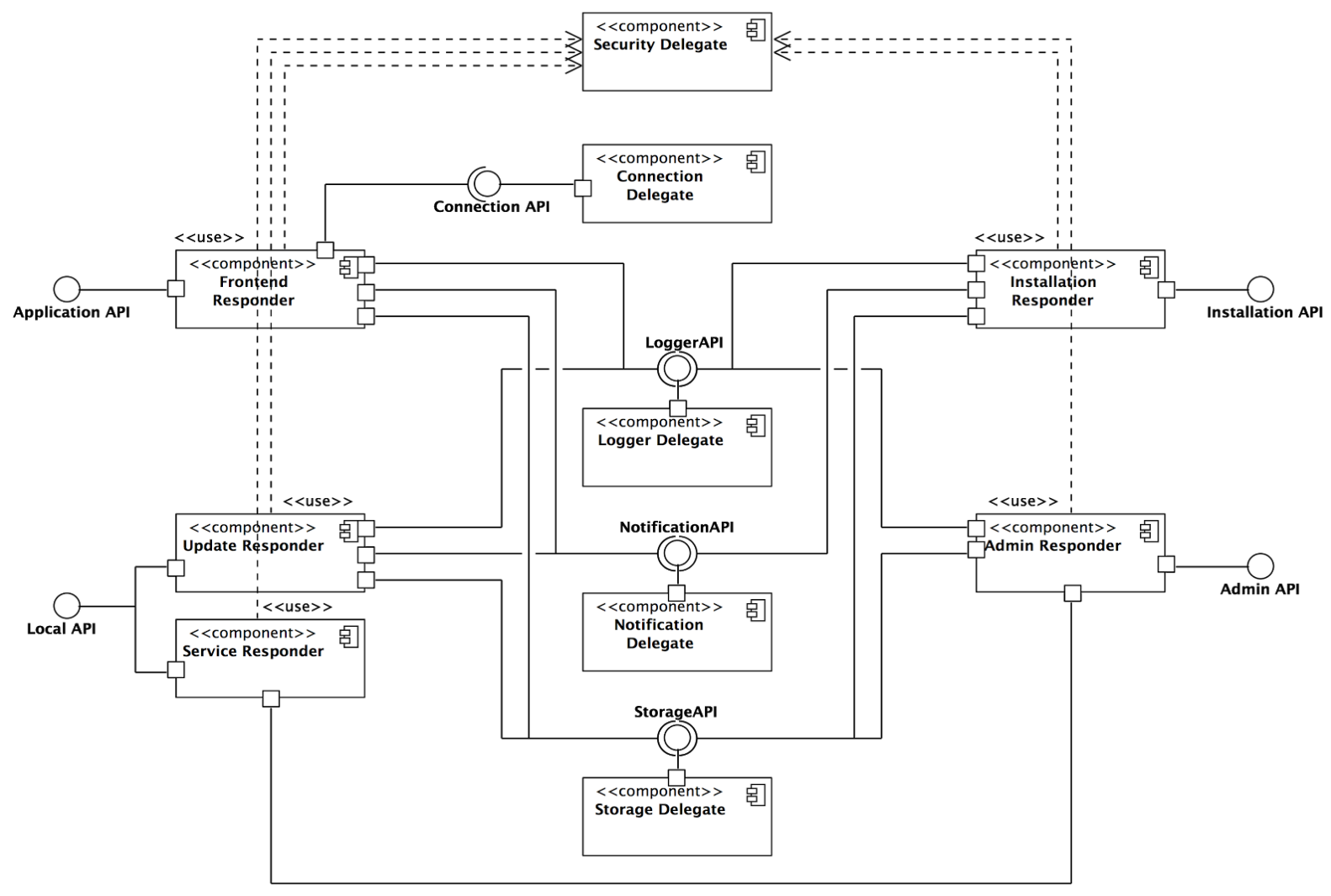

Fonte: trabalhos dos alunos que cursaram as disciplinas em que o roteiro proposto foi aplicado

Etapa 6' - Revisão da Especificação Técnica de acordo com os resultados da Prova de Conceito

Uma vez finalizada a prova de conceito, a Especificação Técnica foi atualizada com os ajustes mapeados durante a prova de conceito. O Questionário 2 visando capturar as evidências de aprendizado dos conceitos ministrados até a metade de curso foi aplicado. 


\section{Etapa 7’ - Implementação das melhorias definidas na Especificação Técnica}

Nesta etapa, o objetivo foi implementar o sistema descrito na especificação técnica e avaliado na implementação da prova de conceito. $O$ uso de técnicas de engenharia simultânea foi incentivado para que os alunos aprendam a trabalhar em várias frentes de trabalho de forma coordenada.

\section{Etapa 8' - Plano de medição dos requisitos não funcionais do novo sistema}

Nesta etapa, foram feitas as medições dos atributos de qualidade utilizando o plano de medição definido na Etapa 3'. Para esta aplicação do roteiro proposto, além da medição dos requisitos não funcionais, os requisitos funcionais também foram avaliados, por se tratar de um sistema novo desenvolvido pelos alunos. Por meio das medições, os alunos verificavam se a qualidade atingida pelo sistema de software implementado atendia aos requisitos do processo de negócio, o que representa o objetivo secundário desta tese.

\section{Etapa 9' - Entrega de novo sistema}

Finalizadas as medições dos atributos de qualidade, os sistemas implementados foram apresentados pelos alunos ao professor e aos monitores da disciplina. Durante a apresentação, os alunos utilizaram o sistema, demonstrando suas funcionalidades e as medidas coletadas, objetivando mostrar se os atributos de qualidade necessários para o processo de negócio foram atendidos.

\section{Etapa 10' - Requisitos de qualidade atingidos satisfazem as necessidades de negócio?}

$\mathrm{Na}$ apresentação do sistema pelos alunos, o professor e os monitores da disciplina executaram os testes de aceitação, fazendo o papel dos participantes (stakeholders) da área de negócio em um projeto no mundo real. No caso de não atendimento às necessidades do processo de negócio pelo sistema implementado, o grupo de alunos realizava ajustes no trabalho.

Nesta Etapa, o Questionário 3, correspondente à avaliação final de conhecimentos, foi respondido pelos alunos. Os resultados dos três questionários 
foram analisados pelo professor e pelos monitores da disciplina objetivando verificar se houve um aumento do percentual de respostas "Bom" ou "Ótimo" em comparação com as respostas dos Questionários 1 e 2. O código dos sistemas implementados também foi analisado para verificar como os padrões e táticas arquiteturais foram considerados e implementados corretamente pelos alunos. Por fim, os comentários registrados pelos alunos nos questionários também foram analisados, em busca de sugestões e críticas que pudessem ser implementadas como pontos de melhoria no roteiro de ensino proposto.

\section{Mapeamento entre as atividades do plano da disciplina e etapas do roteiro de ensino}

A Tabela 14 descreve o mapeamento entre atividades do plano da disciplina e as etapas do roteiro de ensino aplicadas na disciplina de graduação Laboratório de Engenharia de Software II.

A primeira coluna da tabela contém o número da aula da disciplina, na segunda coluna estão listadas as atividades da ementa detalhando os tópicos abordados em cada aula e, por fim, na terceira coluna são descritas as etapas de aplicação do roteiro de ensino proposto.

Tabela 14 - Aplicação 2 - Mapeamento entre as atividades do roteiro e o plano da disciplina Laboratório de Engenharia de Software em curso de graduação

\begin{tabular}{|c|c|c|}
\hline $\begin{array}{l}\text { Num. } \\
\text { Aula }\end{array}$ & Ementa da Disciplina & Etapas do roteiro de ensino proposto \\
\hline 1 & \multirow{2}{*}{$\begin{array}{l}\text { - Processo de negócio; } \\
\text { - Conceitos de loT; } \\
\text { - ATAM; } \\
\text { - ISO/IEC 9126; } \\
\text { - RM-ODP. }\end{array}$} & $\begin{array}{l}\text { Etapa 1' - Entendimento do processo de negócio para definição dos requisitos } \\
\text { de qualidade desejados; } \\
\text { Aplicação do questionário de avaliação inicial (Questionário 1). }\end{array}$ \\
\hline 2 & & $\begin{array}{l}\text { Etapa 2' - Identificação de trade-offs entre os requisitos não funcionais } \\
\text { baseados no processo de negócio; }\end{array}$ \\
\hline 3 & \multirow{2}{*}{$\begin{array}{l}\text { - Medidas de atributos de } \\
\text { qualidade; } \\
\text { - Características de uma } \\
\text { solução arquitetural: } \\
\text { hardware, software, } \\
\text { sensores, alertas e } \\
\text { componentes. }\end{array}$} & \multirow{2}{*}{$\begin{array}{l}\text { Etapa 3' - Plano de medição dos requisitos não funcionais a serem } \\
\text { implementados; } \\
\text { Etapa 4' - Criação da Especificação Técnica do sistema. }\end{array}$} \\
\hline 4 & & \\
\hline
\end{tabular}




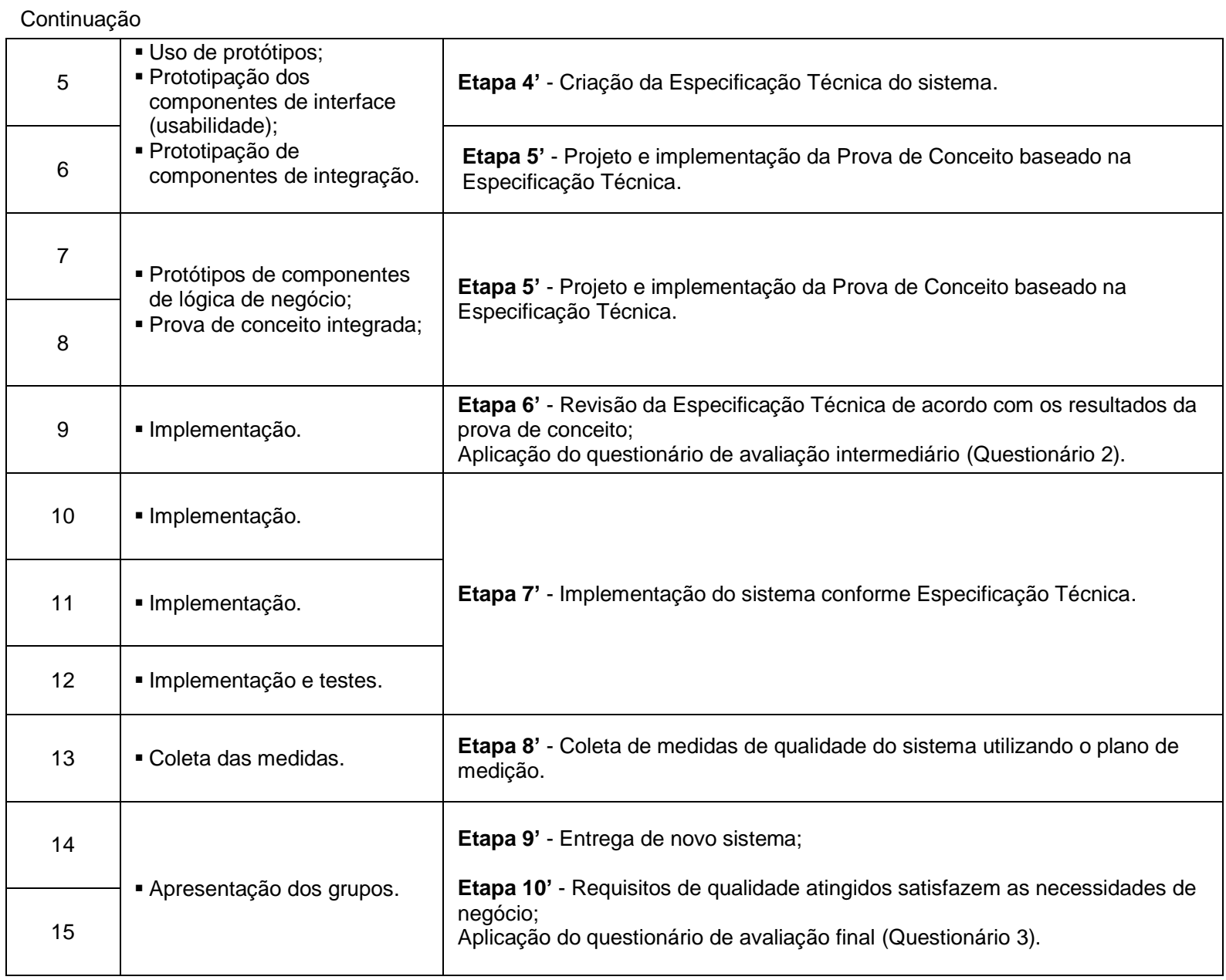

Fonte: Autor

\section{Avaliação da aplicação do roteiro}

No que tange à avaliação da aplicação do roteiro por meio de questionários, as figuras 31 a 37 ilustram os gráficos consolidados dos 3 questionários aplicados durante a disciplina, com as respostas dos 36 alunos das 2 turmas de graduação de 2013 e 2014 para os sete conceitos avaliados descritos no item 5.4. Nessas turmas, o roteiro proposto foi aplicado considerando o desenvolvimento de sistemas novos.

Os gráficos considerando as respostas dos alunos para os conceitos avaliados para cada uma das turmas, encontram-se no Apêndice B. 
1) Nível de conhecimento de medidas em geral

Figura 31 - Aplicação 2 - Respostas dos alunos sobre o nível de conhecimento de medidas em geral

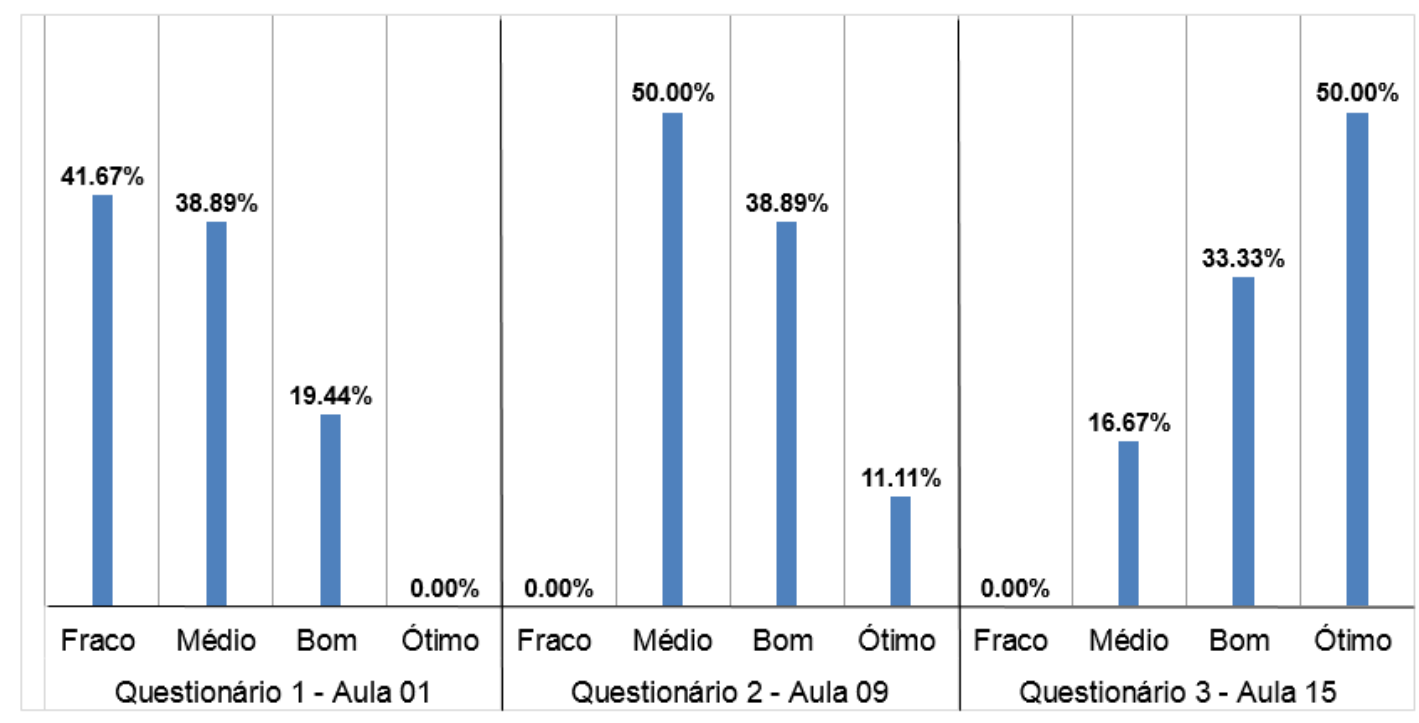

Fonte: Autor

2) Nível de conhecimento de medidas de arquitetura

Figura 32 - Aplicação 2 - Respostas dos alunos sobre o nível de conhecimento de medidas de arquitetura de software

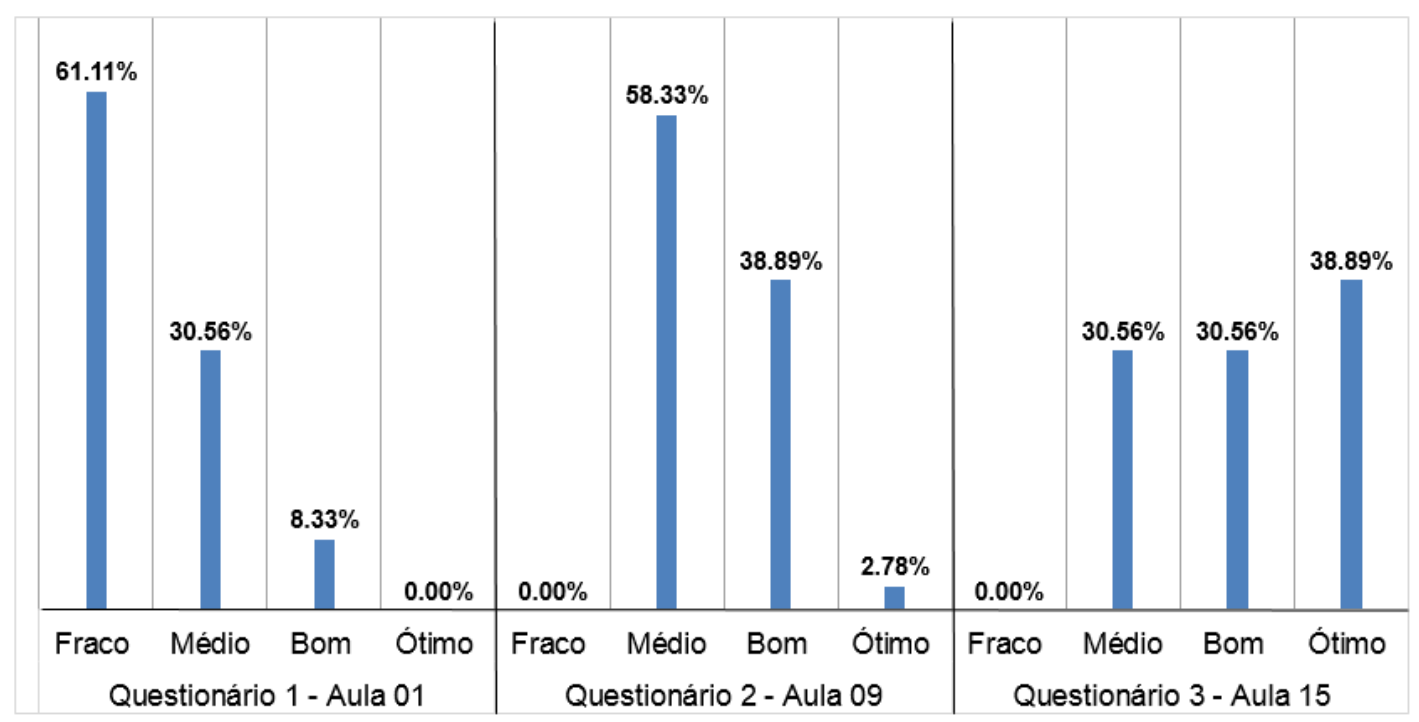

Fonte: Autor 
3) Nível de conhecimento de medidas estáticas

Figura 33 - Aplicação 2 - Respostas dos alunos sobre o nível de conhecimento de medidas estáticas

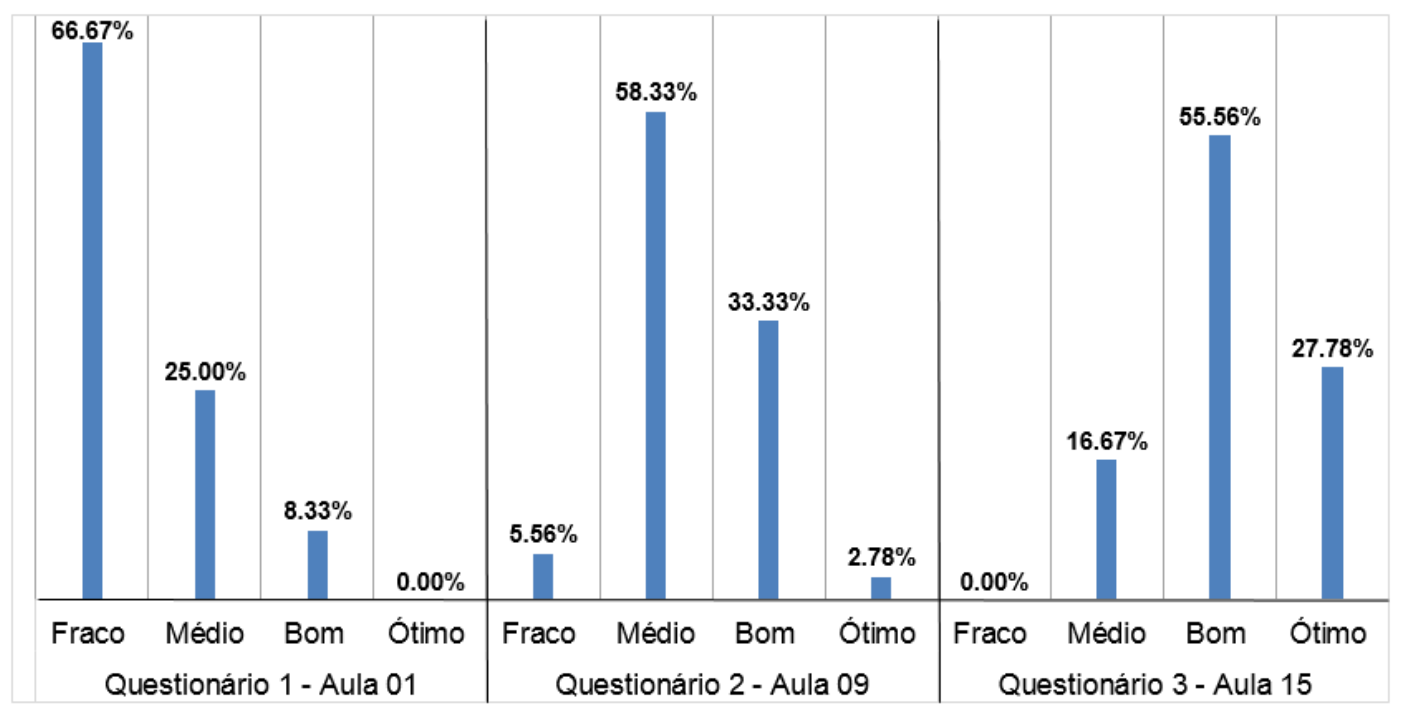

Fonte: Autor

4) Nível de conhecimento de medidas dinâmicas

Figura 34 - Aplicação 2 - Respostas dos alunos sobre o nível de conhecimento de medidas dinâmicas

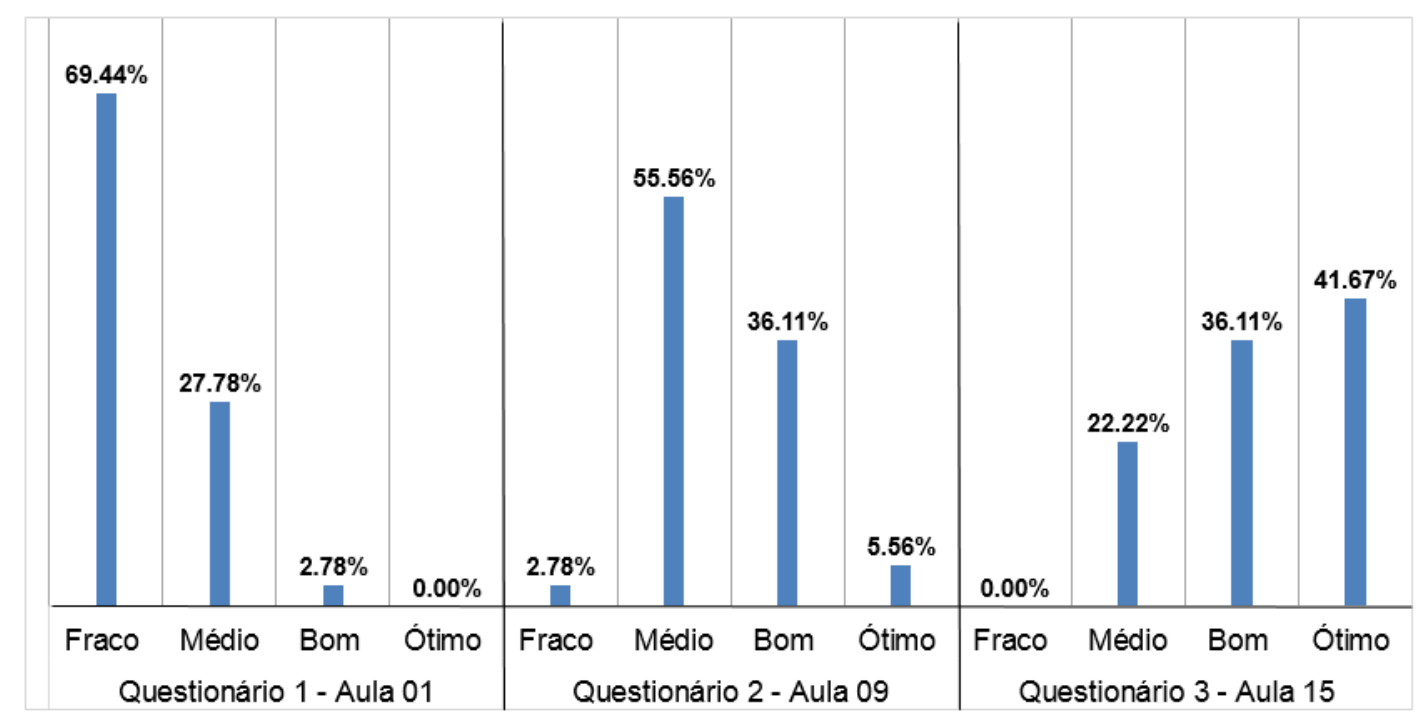

Fonte: Autor 
5) Nível de conhecimento de utilidade das medidas para melhoria da arquitetura de software

Figura 35 - Aplicação 2 - Respostas dos alunos sobre o nível de conhecimento de medidas para melhoria da arquitetura de software

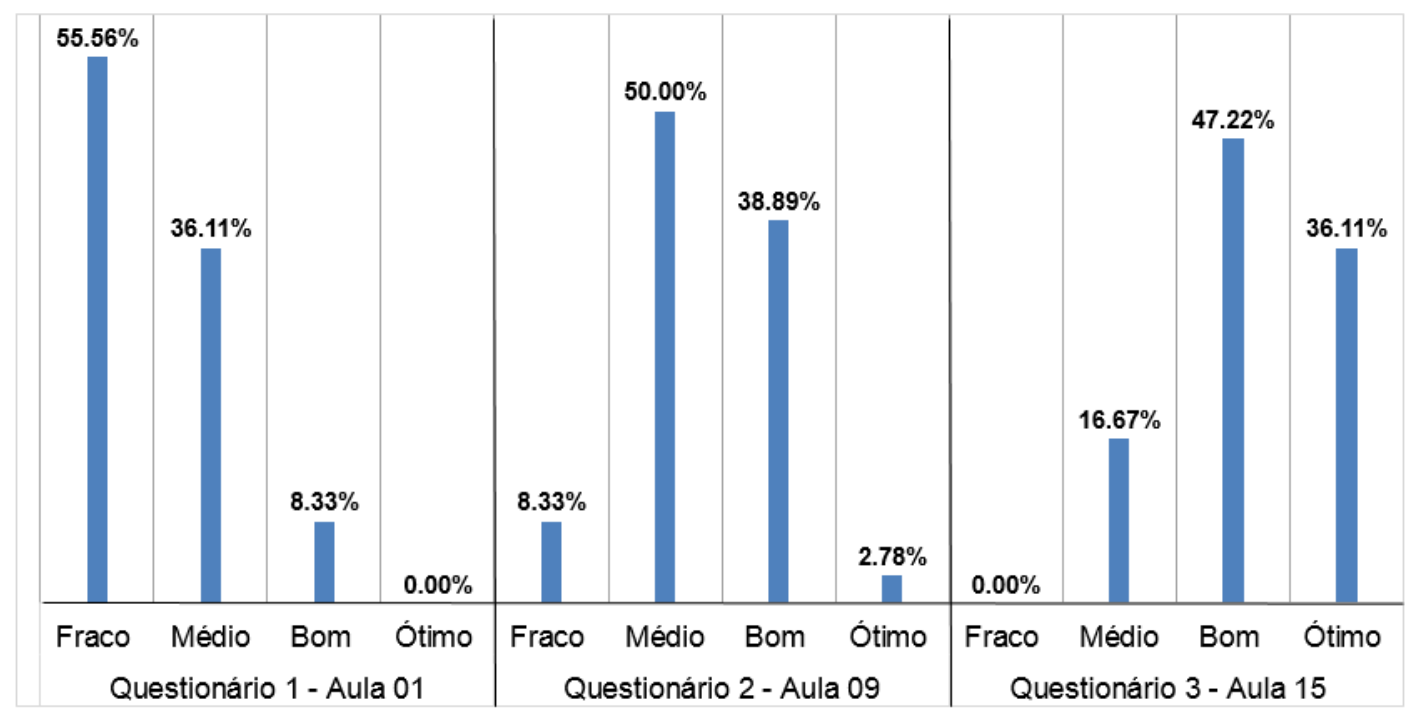

Fonte: Autor

6) Nível de conhecimento de conceitos de qualidade

Figura 36 - Aplicação 2 - Respostas dos alunos sobre o nível de conhecimento de conceitos de qualidade

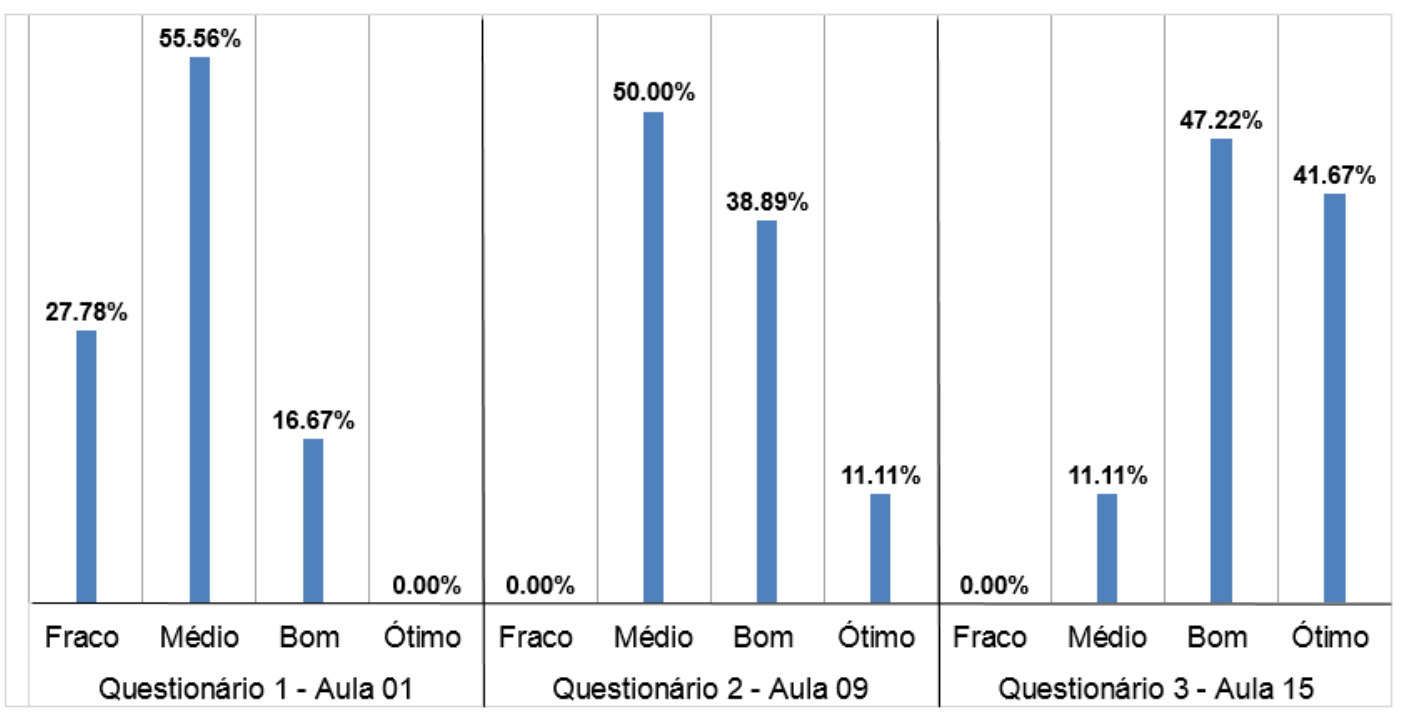

Fonte: Autor 


\section{7) Nível de conhecimento da relação entre arquitetura de software e qualidade}

Figura 37 - Aplicação 2 - Respostas dos alunos sobre o nível de conhecimento da relação entre arquitetura de software e qualidade

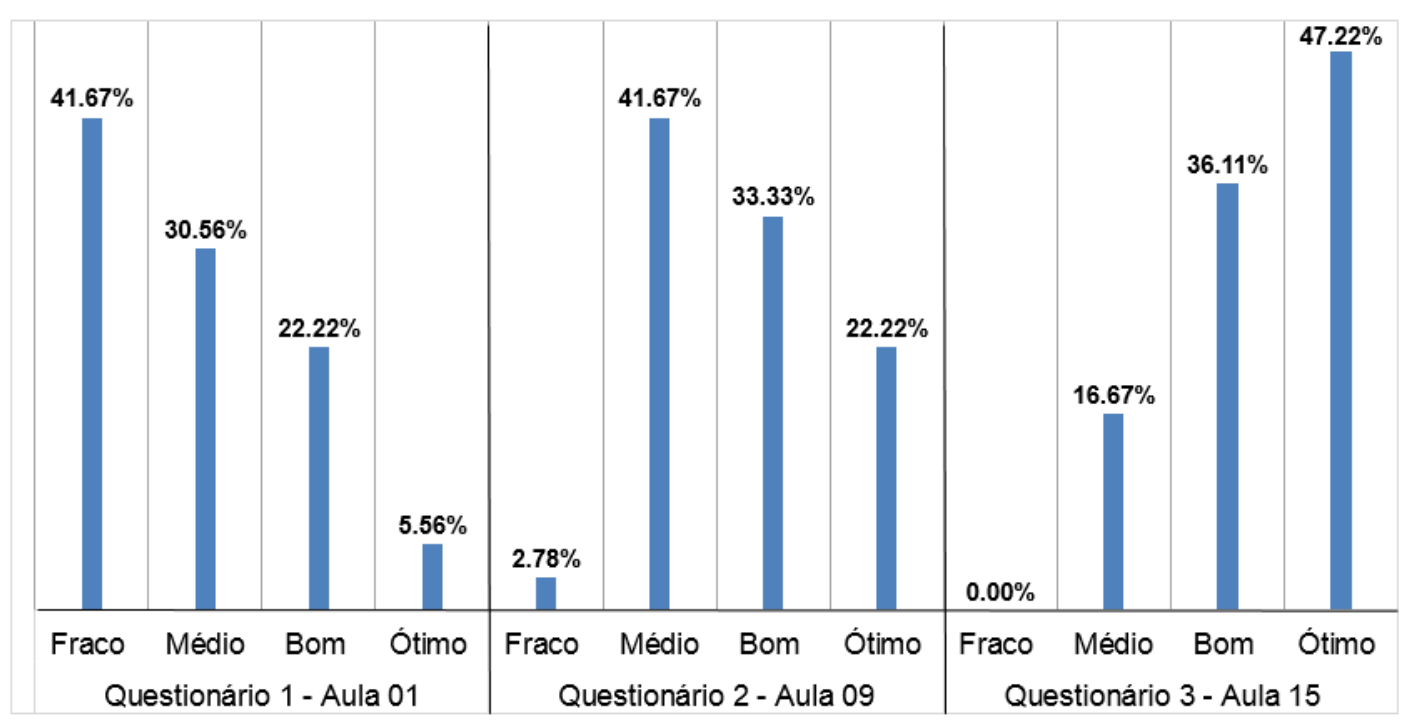

Fonte: Autor

Analisando-se os artefatos produzidos neste exemplo de aplicação do roteiro, como, por exemplo, especificação funcional e técnica, provas de conceito, protótipos, plano de medição e sistema implementado, constata-se que foram considerados vários aspectos relacionados aos requisitos funcionais, o que não ocorreu na Aplicação 1 do roteiro de ensino. Isso já era esperado, pois nesta aplicação os alunos desenvolveram todo o sistema, o que os obriga a definirem todos os requisitos funcionais.

Adicionalmente à modelagem funcional feita pelos alunos, os requisitos não funcionais também foram considerados, conforme exemplos listados na Tabela 13, para uma solução para suporte para pessoas da $3^{\text {an. }}$. idade.

Uma vez que a temática desta aplicação do roteiro envolvia obrigatoriamente a implementação de projetos de loT, as provas de conceito e as diversas etapas de integração entre os componentes de hardware e software das soluções implementadas proporcionaram um aprendizado rico, principalmente devido ao grau de integração desse tipo de solução. Além dos microcomputadores e 
microcontroladores, a maioria dos alunos trabalhou com componentes específicos como GPS, sensores de fumaça, joysticks, etc., e implementou a camada de Interação Humano-Computador $(\mathrm{IHC})$ em celulares e páginas Web. A Figura 38 ilustra telas elaboradas para celular e navegadores web de um sistema de gerenciamento de segurança de veículos implementado pelos alunos.

Figura 38 - Aplicação 2 - Telas para celular e navegadores web de um sistema de segurança de veículos

..... vivo $=\quad$ 17:15
Motor
Portas
Alarme
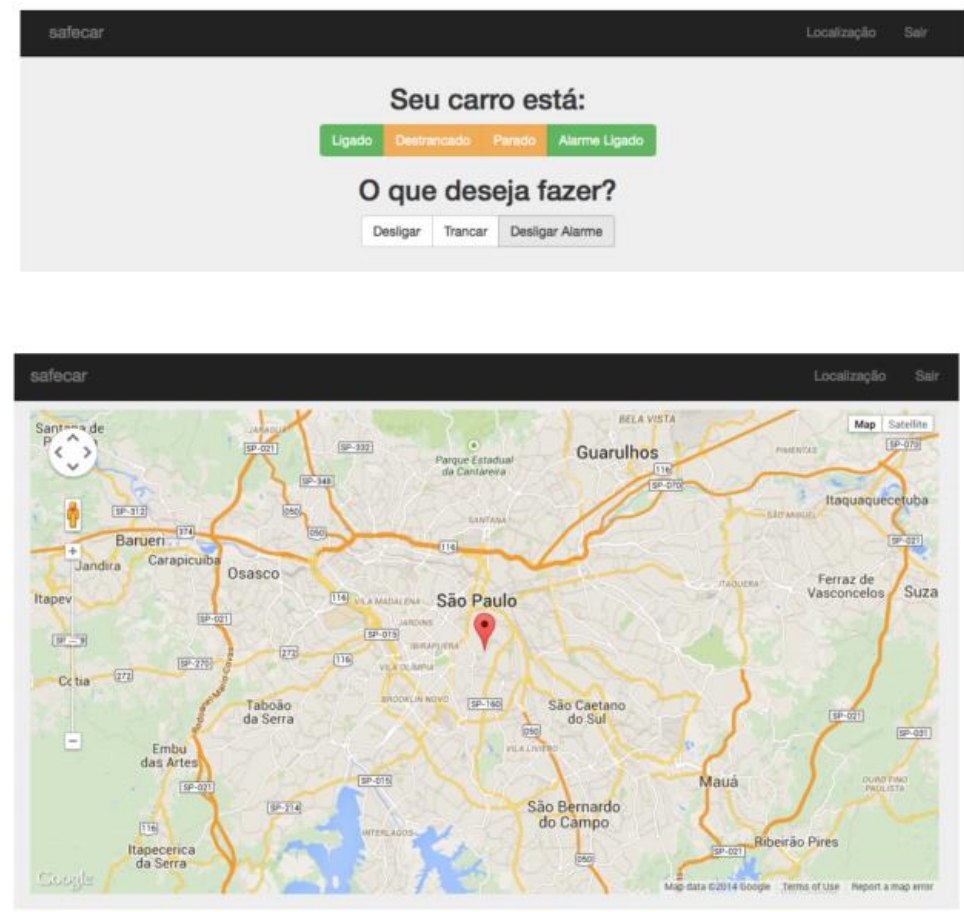

Fonte: trabalhos dos alunos que cursaram as disciplinas em que o roteiro proposto foi aplicado

A análise do trade-offs por meio do método ATAM e a forma de estruturar o processo através dos pontos de vista do RM-ODP foram pontos positivos destacados pelos alunos que foram submetidos ao roteiro de ensino proposto.

Como ponto de melhoria, alguns alunos sugeriram um detalhamento maior sobre os conceitos relacionados às medidas estáticas e dinâmicas, pois inicialmente não entenderam como aplicar as medidas para aferir os atributos de qualidade da arquitetura de software sob a perspectiva de negócio. 


\section{Conclusões da aplicação do roteiro proposto em disciplina de graduação com} o uso de sistemas novos

Assim como na primeira aplicação, constatou-se uma evolução no entendimento dos conceitos de arquitetura analisando-se as respostas dos alunos nos 3 questionários de avaliação aplicados durante o processo de aplicação do roteiro de ensino.

$\mathrm{Na}$ aplicação do roteiro para sistemas novos, houve menor foco dos alunos na implementação e medição dos requisitos não funcionais, pois nesse caso, todos os requisitos funcionais também deveriam ser implementados, visto que o sistema todo era construído pelos alunos.

A Tabela 15, utilizada para criar os gráficos apresentados neste estudo de caso, apresenta as respostas consolidadas dos 36 alunos aos 3 questionários de avaliação do roteiro proposto.

Tabela 15 - Aplicação 2 - Respostas consolidadas dos alunos aos 3 questionários de avaliação do roteiro proposto

\begin{tabular}{|l|c|c|c|c|c|c|c|c|c|c|c|c|}
\hline \multirow{2}{*}{$\begin{array}{l}\text { Conceito } \\
\text { Avaliado }\end{array}$} & \multicolumn{4}{|c|}{ Questionário 1 } & \multicolumn{3}{c|}{ Questionário 2 } & \multicolumn{3}{c|}{ Questionário 3 } \\
\cline { 2 - 12 } & Fraco & Médio & Bom & Ótimo & Fraco & Médio & Bom & Ótimo & Fraco & Médio & Bom & Ótimo \\
\hline $\begin{array}{l}\text { Medidas em } \\
\text { geral }\end{array}$ & $41.67 \%$ & $38.89 \%$ & $19.44 \%$ & $0.00 \%$ & $0.00 \%$ & $50.00 \%$ & $38.89 \%$ & $11.11 \%$ & $0.00 \%$ & $16.67 \%$ & $33.33 \%$ & $50.00 \%$ \\
\hline $\begin{array}{l}\text { Medidas de } \\
\text { arquitetura de } \\
\text { software }\end{array}$ & $61.11 \%$ & $30.56 \%$ & $8.33 \%$ & $0.00 \%$ & $0.00 \%$ & $58.33 \%$ & $38.89 \%$ & $2.78 \%$ & $0.00 \%$ & $30.56 \%$ & $30.56 \%$ & $38.89 \%$ \\
\hline $\begin{array}{l}\text { Medidas } \\
\text { estáticas }\end{array}$ & $66.67 \%$ & $25.00 \%$ & $8.33 \%$ & $0.00 \%$ & $5.56 \%$ & $58.33 \%$ & $33.33 \%$ & $2.78 \%$ & $0.00 \%$ & $16.67 \%$ & $55.56 \%$ & $27.78 \%$ \\
\hline $\begin{array}{l}\text { Medidas } \\
\text { dinâmicas }\end{array}$ & $69.44 \%$ & $27.78 \%$ & $2.78 \%$ & $0.00 \%$ & $2.78 \%$ & $55.56 \%$ & $36.11 \%$ & $5.56 \%$ & $0.00 \%$ & $22.22 \%$ & $36.11 \%$ & $41.67 \%$ \\
\hline $\begin{array}{l}\text { Utilidade das } \\
\text { medidas para } \\
\text { melhoria da } \\
\text { arquitetura de } \\
\text { software }\end{array}$ & $55.56 \%$ & $36.11 \%$ & $8.33 \%$ & $0.00 \%$ & $8.33 \%$ & $50.00 \%$ & $38.89 \%$ & $2.78 \%$ & $0.00 \%$ & $16.67 \%$ & $47.22 \%$ & $36.11 \%$ \\
\hline $\begin{array}{l}\text { Conceitos de } \\
\text { qualidade }\end{array}$ & $27.78 \%$ & $55.56 \%$ & $16.67 \%$ & $0.00 \%$ & $0.00 \%$ & $50.00 \%$ & $38.89 \%$ & $11.11 \%$ & $0.00 \%$ & $11.11 \%$ & $47.22 \%$ & $41.67 \%$ \\
\hline $\begin{array}{l}\text { Relação } \\
\text { entre } \\
\text { arquitetura de } \\
\begin{array}{l}\text { software e } \\
\text { qualidade }\end{array}\end{array}$ & $41.67 \%$ & $30.56 \%$ & $22.22 \%$ & $5.56 \%$ & $2.78 \%$ & $41.67 \%$ & $33.33 \%$ & $22.22 \%$ & $0.00 \%$ & $16.67 \%$ & $36.11 \%$ & $47.22 \%$ \\
\hline $\begin{array}{l}\text { Percentual } \\
\text { Médio }\end{array}$ & $\mathbf{5 1 . 9 8 \%}$ & $\mathbf{3 4 . 9 2 \%}$ & $\mathbf{1 2 . 3 0 \%}$ & $\mathbf{0 . 7 9 \%}$ & $\mathbf{2 . 7 8 \%}$ & $\mathbf{5 1 . 9 8 \%}$ & $\mathbf{3 6 . 9 0 \%}$ & $\mathbf{8 . 3 3 \%}$ & $\mathbf{0 . 0 0 \%}$ & $\mathbf{1 8 . 6 5 \%}$ & $\mathbf{4 0 . 8 7 \%}$ & $\mathbf{4 0 . 4 8 \%}$ \\
\hline
\end{tabular}

Fonte: Autor

Nesta aplicação do roteiro, constatou-se, no início da disciplina, elevado percentual de alunos com fraco conhecimento em "Medidas de arquitetura de 
software", "Medidas estáticas" e "Medidas dinâmicas", respectivamente iguais a $61,11 \%, 66,67 \%$ e 69,44\%. Na avaliação intermediária esses percentuais caem, respectivamente, para 0\%,5,56\% e 2,78\%. Já na avaliação final, todos caem para zero. O aumento do percentual entre os três questionários também se reflete no percentual de alunos que se avaliaram como detentores de ótimos conhecimentos sobre "Utilidade das medidas para melhoria da arquitetura de software", que, no Questionário 3 foi de $36,11 \%$.

Sobre a média das respostas dos alunos para todos os conceitos avaliados, aproximadamente $51,98 \%$ deles responderam que tinham um conhecimento conceitual fraco no início do curso. Esse percentual caiu para 2,78\% no questionário intermediário e chegou a zero no término do curso.

A média de alunos que se avaliaram com ótimos conhecimentos dos conceitos avaliados era de $0.79 \%$ no início do curso, subindo para $8,33 \%$ no questionário intermediário e para $40,48 \%$ no questionário final.

Nesta aplicação do roteiro proposto, os trade-offs entre atributos de qualidade não estavam tão explícitos como na Aplicação 1. Dessa forma, para alguns grupos, o processo de definição dos trade-offs foi relativamente difícil, se comparado à Aplicação 1, no qual os trade-offs eram definidos pelos professores e monitores da disciplina. O uso de técnicas de prototipação e provas de conceito acelerou a curva de aprendizado dos conceitos de programação para microcomputadores e microcontroladores, com os quais os alunos nunca haviam trabalhado antes.

Pelas respostas dos questionários e trabalhos entregues, há evidências de que o conceito de trade-off foi entendido pelos alunos, apesar da dificuldade inicial. Pela avaliação dos artefatos produzidos, como, por exemplo, especificações técnicas, foi notado que os alunos foram capazes de elencar os requisitos não funcionais e considerá-los na elaboração da arquitetura de software proposta para a solução.

5.5.4 Mapeamento entre princípios do roteiro de ensino e disciplinas do curso de pósgraduação em Engenharia de Computação

Para contextualizar a aplicação do roteiro proposto na disciplina de Arquitetura de Software do curso de pós-graduação do Mestrado profissionalizante do IPT, foi 
realizado o mapeamento entre os princípios do roteiro e as disciplinas nas quais tais princípios são ministrados.

A Tabela 16 apresenta o resultado desse mapeamento. Os detalhes das disciplinas listadas, contendo os itens ministrados em cada disciplina, encontram no Apêndice C.

Tabela 16 - Mapeamento entre os princípios do roteiro proposto e disciplinas do curso de Mestrado profissionalizante em Engenharia de Software do IPT

\begin{tabular}{|c|c|}
\hline Princípios do Roteiro & $\begin{array}{l}\text { Disciplinas do curso de pós-graduação em Engenharia de } \\
\text { Computação e tópicos da ementa relacionados }\end{array}$ \\
\hline $\begin{array}{l}\text { Princípio } 1 \text { - Requisitos não funcionais } \\
\text { extraídos do processo de negócio }\end{array}$ & $\begin{array}{l}\text { Tecnologias de Informação e Organizações } \\
\text { - Tecnologia de Informação e estratégia de negócios } \\
\text { - Tecnologia de Informação e mudanças em modelos de negócios: } \\
\text { Indústria Financeira, Entretenimento, Software, etc. } \\
\text { Arquitetura de Software } \\
\text { - Conceitos de arquitetura de software processo de desenvolvimento } \\
\text { centrado em arquitetura; atributos de qualidade no contexto de arquitetura } \\
\text { de software } \\
\text { - Perspectivas arquiteturais: atributos de qualidade, perspectiva de } \\
\text { desempenho, segurança e escalabilidade, ATAM } \\
\text { Engenharia de Requisitos de Software } \\
\text { - Elicitação e validação dos requisitos de software } \\
\text { - Introdução aos requisitos não funcionais do software } \\
\text { - Requisitos funcionais e especificação dos requisitos de software } \\
\text { - Requisitos de software e arquitetura corporativa } \\
\text { - Requisitos e regras de negócio } \\
\text { - Requisitos e modelo de domínio } \\
\text { Qualidade e melhoria do processo de geração de software } \\
\text { - Conceitos de qualidade de processo e produto de software } \\
\text { Tópicos Especiais da Engenharia de Requisitos de Software } \\
\text { - Modelagem conceitual de requisitos } \\
\text { - Requisitos e restrições à arquitetura de software }\end{array}$ \\
\hline Princípio 2 - Uso de provas de conceito & $\begin{array}{l}\text { Arquitetura de Software } \\
\text { - Arquitetura como elemento central do ambiente de produção de software } \\
\text { - Conceitos sobre evolução da arquitetura e decisões arquiteturais. } \\
\text { Banco de Dados } \\
\text { - Orientação a objetos e bancos de dados } \\
\text { - Modelagem UML } \\
\text { Sistemas Web } \\
\text { - Engenharia de Software para Sistemas Web }\end{array}$ \\
\hline Princípio 3 - Prototipação arquitetural & $\begin{array}{l}\text { Interação Homem - Computador e Usabilidade } \\
\text { - Projeto e prototipação }\end{array}$ \\
\hline Princípio 4 - Inspeção & $\begin{array}{l}\text { Qualidade e melhoria do processo de geração de software } \\
\text { - Inspeções de software e Testes }\end{array}$ \\
\hline Princípio 5 - Uso de simuladores & $\begin{array}{l}\text { Arquitetura de Software } \\
\text { - Uso de simuladores para avaliação de arquitetura de software }\end{array}$ \\
\hline $\begin{array}{l}\text { Princípio } 6 \text { - Métricas de requisitos não } \\
\text { funcionais }\end{array}$ & $\begin{array}{l}\text { Interação Homem - Computador e Usabilidade } \\
\text { - Avaliação de usabilidade } \\
\text { Qualidade e melhoria do processo de geração de software } \\
\text { - Métricas de qualidade do produto e do processo de software }\end{array}$ \\
\hline
\end{tabular}


Continuação

\begin{tabular}{|c|c|}
\hline Princípio 7 - Testes arquiteturais & $\begin{array}{l}\text { Processos de desenvolvimento de software com ênfase em UP } \\
\text { e modelos ágeis } \\
\text { - Desenvolvimento Orientado a Testes } \\
\text { Qualidade e melhoria do processo de geração de software } \\
\text { - Garantia de qualidade e Gerência de configuração de software } \\
\text { - Testes de Software } \\
\text { Testes de Software } \\
\text { - Introdução à disciplina de Testes de Software } \\
\text { - Descrição do Processo de Teste de Software } \\
\text { - Tipos de teste, teste funcional. } \\
\text { - Teste estrutural estático } \\
\text { - Teste estrutural dinâmico (laboratório) } \\
\text { - Teste estrutural dinâmico de sistemas orientados a objeto (laboratório) } \\
\text { - Avaliação da cobertura de testes (laboratório) } \\
\text { - Planejamento de Testes, e elaboração de Casos de Teste } \\
\text { - Testes de Usabilidade } \\
\text { - Testes em Sistemas Distribuídos e ambientes web (laboratório) } \\
\text { - Medidas da Confiabilidade de Sistemas }\end{array}$ \\
\hline Princípio 8 - Utilização de táticas arquiteturais & $\begin{array}{l}\text { Arquitetura de Software } \\
\text { - Aplicação de padrões de arquitetura (patterns): definição, categorias } \\
\text { tipo: camadas, broker, microkernel, etc. } \\
\text { Arquitetura de Software } \\
\text { - Princípios de Orientação a Serviços } \\
\text { Sistemas Web } \\
\text { - Arquitetura de software de Sistemas Web }\end{array}$ \\
\hline Princípio 9 - Trabalho em equipe & $\begin{array}{l}\text { Processos de desenvolvimento de software com ênfase em UP } \\
\text { e modelos ágeis } \\
\text { - Coordenação de Equipes }\end{array}$ \\
\hline $\begin{array}{l}\text { Princípio } 10 \text { - Uso de normas e padrões } \\
\text { reconhecidos }\end{array}$ & $\begin{array}{l}\text { Arquitetura de software } \\
\text { - ISO/IEC/IEEE } 42010 \text { - Systems and software engineering - Architecture } \\
\text { description } \\
\text { - ISO/IEC 10746-1 - Reference Model of Open Distributed Processing } \\
\text { (RM-ODP) } \\
\text { Qualidade e melhoria do processo de geração de software } \\
\text { - ISO/IEC } 12207 \text { - Systems and software engineering - Software life cycle } \\
\text { processes } \\
\text { - ISO/IEC 15504-5 - Information technology -- Process assessment } \\
\text { - Capability Maturity Model Integration for Acquisition (CMMI-ACQ) }\end{array}$ \\
\hline Princípio 11 - Aspectos culturais envolvidos & $\begin{array}{l}\text { Processos de Desenvolvimento de Software com Ênfase em Unified } \\
\text { Process (UP) e Métodos Ágeis } \\
\text { - Organização e controle das atividades de um projeto para obter um } \\
\text { único sistema integrado } \\
\text { - Prática de gestão, paralelismo, integração entre equipes e } \\
\text { desenvolvimento usando componentes } \\
\text { - Estudo de Problemas relativos à aplicação dos Métodos baseados em } \\
\text { planejamento aplicado em projetos de software } \\
\text { - Estudo de Problemas relativos a aplicação dos Métodos ágeis em } \\
\text { projetos de software } \\
\text { Gestão de Projetos de Tecnologias da Informação e Comunicação } \\
\text { - Técnicas de gerência de projetos } \\
\text { - Aspectos de planejamento e controle de projetos: escopo, prazos, custo, } \\
\text { recursos humanos, comunicação, risco, contratação } \\
\text { - Técnicas de estimativa de esforço de desenvolvimento }\end{array}$ \\
\hline Princípio 12 - Abordagem prática & $\begin{array}{l}\text { Arquitetura orientada a serviços } \\
\text { - Projeto - Software Oriented Architecture (SOA) } \\
\text { - Plataformas usuais para SOA e exemplos de casos reais } \\
\\
\text { Engenharia de Requisitos de software } \\
\text { - Visão pragmática do produto de software }\end{array}$ \\
\hline Princípio 13 - Aprendizado incremental & $\begin{array}{l}\text { O princípio de Aprendizado incremental não foi explicitamente mapeado } \\
\text { em uma disciplina, mas foi aplicado no roteiro durante as aulas da } \\
\text { disciplina Arquitetura de software, baseando-se na teoria de } \\
\text { aprendizagem construtivista (vide item 3.2.1 - Construtivismo) }\end{array}$ \\
\hline
\end{tabular}


Continuação

\begin{tabular}{|c|c|}
\hline $\begin{array}{l}\text { Princípio } 14 \text { - Aprendizagem baseada em } \\
\text { problemas (problem based learning) }\end{array}$ & $\begin{array}{l}\text { O princípio de Aprendizado incremental não foi explicitamente mapeado } \\
\text { em uma disciplina, mas foi aplicado no roteiro durante as aulas da } \\
\text { disciplina Arquitetura de software, baseando-se tanto na teoria de } \\
\text { Aprendizagem Construtivista (vide item 3.2.1 - Construtivismo) como na } \\
\text { Aprendizagem baseada em problemas (vide item 3.2.3 - Aprendizagem } \\
\text { baseada em problemas). Além disso, também é uma das características } \\
\text { pedagógicas do curso de Engenharia de Computação (vide item 3.3.1- } \\
\text { Currículo de Engenharia de Computação). }\end{array}$ \\
\hline Princípio 15 - Aprendizado centrado no aluno & $\begin{array}{l}\text { O princípio de Aprendizado incremental não foi explicitamente mapeado } \\
\text { em uma disciplina, mas foi aplicado no roteiro durante as aulas da } \\
\text { disciplina Arquitetura de software, baseando-se na teoria de } \\
\text { aprendizagem construtivista (vide item 3.2.1 - Construtivismo). Além } \\
\text { disso, também é uma das características pedagógicas do curso de } \\
\text { Engenharia de Computação (vide item 3.3.1- Currículo de Engenharia de } \\
\text { Computação). }\end{array}$ \\
\hline Princípio 16 - Projetos "reais" & $\begin{array}{l}\text { Arquitetura de Software } \\
\text { - Laboratório 1: engenharia do produto } \\
\text { - Laboratório 2: modelos arquiteturais } \\
\text { Engenharia de Requisitos de software } \\
\text { - Visão pragmática do produto de software } \\
\text { Projetos realizados em diversas disciplinas }\end{array}$ \\
\hline & $\begin{array}{l}\text { Arquitetura de Software } \\
\text { - Laboratório 1: engenharia do produto } \\
\text { - Laboratório 2: modelos arquiteturais } \\
\text { Projetos realizados em diversas disciplinas }\end{array}$ \\
\hline Princípio 18 - Documentação essencial & $\begin{array}{l}\text { O princípio de Documentação Essencial não foi explicitamente mapeado } \\
\text { em uma disciplina, mas foi aplicado no roteiro durante as aulas da } \\
\text { disciplina Arquitetura de software, produzindo-se somente a } \\
\text { documentação necessária para a produção do trabalho de aula }\end{array}$ \\
\hline $\begin{array}{l}\text { Princípio } 19 \text { - Técnicas de Engenharia } \\
\text { Simultânea }\end{array}$ & $\begin{array}{l}\text { O princípio de Documentação Essencial não foi explicitamente mapeado } \\
\text { em uma disciplina, mas foi aplicado no roteiro durante as aulas da } \\
\text { disciplina Arquitetura de software, produzindo-se somente a } \\
\text { documentação necessária para a produção do trabalho de aula }\end{array}$ \\
\hline
\end{tabular}

Fonte: Autor

No curso de pós-graduação em Engenharia de Computação oferecido pelo IPT, o roteiro de ensino proposto nesta tese foi aplicado na disciplina Arquitetura de software.

5.5.5 Aplicação 3 - Disciplina de Arquitetura de Software em curso de pós-graduação em Engenharia de Computação utilizando um sistema existente

\section{Contexto da Disciplina}

Neste exemplo, o roteiro de ensino foi aplicado na disciplina Arquitetura de Software do Curso de Mestrado profissionalizante em Engenharia de Computação do Instituto de Pesquisas Tecnológicas (IPT) do Estado de São Paulo. O roteiro proposto foi aplicado em duas turmas no ano de 2013 para um total de 46 alunos, que mapearam os processos de negócio de um sistema já existente e, com o apoio das referências ISO/IEC 9126-1, ISO/IEC 14598-5, RM-ODP e do método ATAM, fizeram 
uma avaliação de requisitos não funcionais e proposição de melhorias na arquitetura de software de um sistema escolhido pelo próprio grupo de alunos. Geralmente, o grupo escolhia um sistema no qual pelo menos um dos integrantes do grupo tinha familiaridade ou que fosse de interesse de pesquisa do grupo.

Diferentemente da aplicação do roteiro em disciplinas de graduação, que envolvia a implementação de melhorias na arquitetura do software de um sistema ou existente ou o desenvolvimento de um sistema novo, o uso do roteiro na pósgraduação auxiliou os alunos na elaboração de artigos acadêmicos relacionados com a avaliação dos atributos de qualidade e proposição de melhorias em uma determinada arquitetura de software. A razão pela aplicação do roteiro de forma que não fosse necessária a implementação de código baseia-se na enorme diversidade dos perfis alunos. Enquanto alguns alunos tinham a expectativa de aprender padrões arquiteturais implementados em Java, com ênfase em codificação, outros não tinham uma formação técnica e esperavam aprender os fundamentos de arquitetura de software.

É importante frisar que o curso de Arquitetura de Software da pós-graduação não possui a mesma quantidade de atividades práticas da disciplina de Laboratório de Engenharia de Software II do curso de graduação em Engenharia Elétrica com ênfase em Computação, ou seja, não é feita manutenção evolutiva em sistemas existentes ou implementação de novos sistemas, como apresentado, respectivamente, na Aplicação 1 (item 5.5.2) e Aplicação 2 (item 5.5.3) do roteiro de ensino. Dessa forma, como trabalho da disciplina Arquitetura de Software do curso de pós-graduação, os alunos, apoiados pelo roteiro proposto, elaboram um artigo acadêmico relacionado à avaliação de qualidade e melhorias da arquitetura de um sistema existente. Os artigos produzidos são entregues no fim do curso e, caso seja da vontade dos alunos, são submetidos para publicação em congressos da área.

\section{Aplicação do roteiro}

Segue o detalhamento da aplicação do roteiro para sistemas já existentes na disciplina de Arquitetura de Software em curso de pós-graduação. 


\section{Etapa 1 - Entendimento do processo de negócio para definição dos requisitos de qualidade desejados}

Nesta fase, os alunos, reunidos em grupos de 3 ou 4 integrantes, definiram alguns possíveis temas de artigo, os quais foram discutidos com os professores, para, a partir das opções possíveis, chegar-se à definição de um tema definitivo.

Visando atingir os objetivos pedagógicos da disciplina, todos os temas propostos pelos alunos estavam relacionados com o estudo, avaliação ou manutenção (corretiva ou evolutiva) da arquitetura de software de um sistema existente.

Uma vez definido o tema do artigo, os alunos iniciaram o entendimento do processo de negócio utilizando a o modelo de referência RM-ODP, mais precisamente o ponto de vista da Empresa. O Questionário 1 foi aplicado para capturar o nível de conhecimento dos alunos na primeira aula.

\section{Etapa 2 - Identificação de trade-offs entre os requisitos não funcionais baseados no processo de negócio}

Com o apoio das normas ISO/IEC 9126 (Qualidade do produto de software), ISO/IEC 14598-5 (Avaliação do produto de software) e da árvore de utilidade do método ATAM, os alunos analisaram como os atributos de qualidade são implementados pela arquitetura de software do sistema escolhido, considerando a perspectiva de negócio. O objetivo dessa análise foi identificar tanto deficiências de qualidade e potenciais pontos de melhoria na arquitetura de software do sistema existente.

Do ponto de vista pedagógico, a criação da árvore de utilidade trouxe um aprendizado significativo para os alunos, visto que parte deles desconhecia o conceito de trade-offs entre atributos de qualidade. Muitos relataram experiências profissionais fracassadas de sistemas que construíram que deveriam atender a todos os requisitos simultaneamente, mesmo que tais requisitos fossem conflitantes.

Um dos grupos trabalhou em um artigo cujo objetivo era a avaliação de arquiteturas de software para sistemas críticos de usinas utilizando o ATAM e a 
arquitetura corporativa de referência Purdue Enterprise Reference Architecture (PERA) (WILLIAMS, 1993). Uma versão do artigo produzidos pelos alunos foi publicada na $1^{\underline{a}}$ Conferência Latino-Americana de Segurança em SCADA (Supervisory Control And Data Acquisition), realizada entre os dias 5 e 7 de novembro de 2014 na cidade do Rio de Janeiro (TI SAFE, 2014). A Figura 39 ilustra a criticidade do atributo de qualidade disponibilidade em sistemas comercias e industriais segundo a arquitetura corporativa PERA.

Figura 39 - Criticidade do atributo de qualidade disponibilidade em sistemas comercias e industriais segundo a arquitetura corporativa PERA (WILLIAMS, 1993)

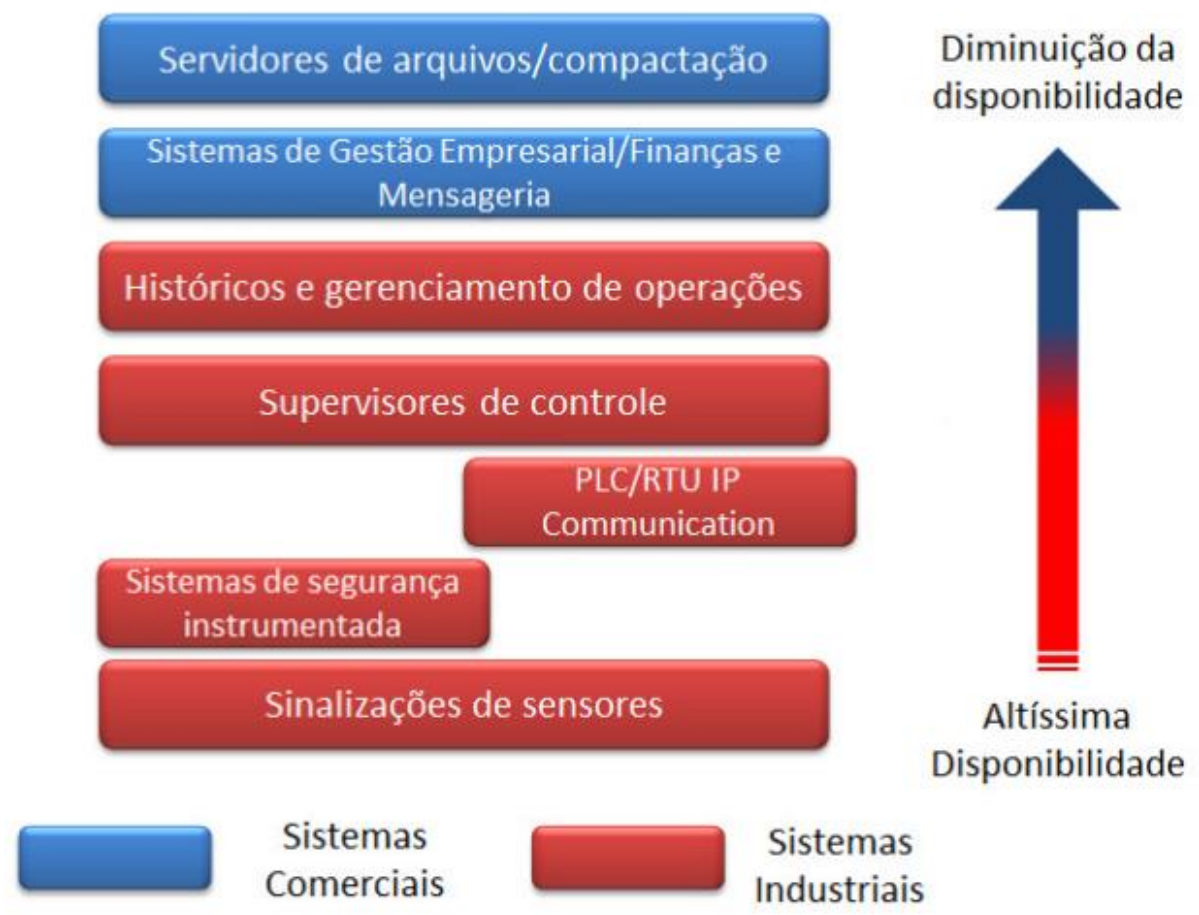

Fonte: trabalhos dos alunos que cursaram as disciplinas em que o roteiro proposto foi aplicado

\section{Etapa 3 - Plano de medição dos requisitos não funcionais do sistema atual}

Nesta etapa, os alunos elaboraram um plano de medição para apoiar o diagnóstico de qualidade da arquitetura de software do sistema existente. Os pontos de vista da Informação e Computação do RM-ODP e conceitos de avaliação de produto de software da ISO/IEC 14598-5 auxiliaram os alunos na elaboração do plano. Por ser uma disciplina mais teórica, a princípio, as medições não foram feitas nos 
sistemas existentes, mas houve exemplos de alunos que aplicaram o plano de medição nas empresas em que trabalhavam. Mesmo não sendo formalmente aplicado no sistema existente, o aprendizado trazido pela simples elaboração do plano de medição foi importante, visto que muitos alunos não conheciam técnicas para medir requisitos como desempenho, escalabilidade, manutenibilidade, entre outros.

\section{Etapa 4 - Coleta de medidas de qualidade do sistema atual}

Esta etapa não foi formalmente aplicada em sala de aula. Alguns alunos coletaram as medidas nas empresas em que trabalhavam. Por motivos de confidencialidade da informação, os professores orientaram os alunos que, se desejassem utilizar nos artigos as informações coletadas nas empresas, tais informações deveriam ser apresentadas de forma descaracterizada.

\section{Etapa 5 - Análise de gap de qualidade entre sistema atual e sistema desejado}

Como a maioria dos alunos não executou o plano de medidas criado na Etapa 3 (Plano de medição dos requisitos não funcionais do sistema atual), para que fosse possível executar a análise de gap de qualidade entre sistema atual e sistema desejado, os alunos utilizaram as informações levantadas na Etapa 1 do roteiro (Entendimento do processo de negócio para definição dos requisitos de qualidade desejados), ou seja, o gap de qualidade entre o sistema atual e desejado foi identificado a partir das demandas do processo de negócio.

Por exemplo: se, em uma determinada empresa, a vazão de processamento esperada é de 1.000 registros por segundo sob certas condições, e o sistema que suporta esse processo de negócio excuta apenas 600 registros por segundo sob as mesmas condições, conclui-se que há um gap 400 registros por segundo, o que significa que do ponto de vista de desempenho, é necessário implementar melhorias na arquitetura do software desse sistema para que o mesmo atende às necessidades de negócio, o que está relacionado com o objetivo secundário do roteiro de ensino.

Durante as aulas, cenários similares ao exemplo descrito anteriormente ocorreram várias vezes, o que possibilitou a realização da análise de gap de qualidade entre sistema atual e sistema desejado, mesmo sem a coleta das medidas do sistema existente. 


\section{Etapa 6 - Criação da Especificação Técnica do sistema desejado}

Nesta etapa, com o apoio do ponto de vista da Engenharia do RM-ODP, os alunos estudaram o conceito de táticas arquiteturais e como seria possível implementá-las. A especificação técnica não era detalhada o suficiente para que fosse implementada dada a limitação de tempo do curso, mas já continha o direcionamento arquitetural do que poderia ser feito no sistema existente para a melhoria de sua qualidade.

\section{Etapa 7 - Projeto e implementação da Prova de Conceito baseado na Especificação Técnica}

Alguns alunos da disciplina implementaram provas de conceito das táticas arquiteturais escolhidas na Etapa 6 (Criação da Especificação Técnica do sistema desejado), mas essa etapa não foi formalmente aplicada em sala, dado que a maioria dos alunos não tinha familiaridade com ferramentas de programação.

\section{Etapa 8 - Revisão da Especificação Técnica de acordo com os resultados da Prova de Conceito}

Nesta etapa, as táticas arquiteturais definidas pelos alunos na Especificação Técnica elaborada na Etapa 6 (Criação da Especificação Técnica do sistema desejado) foram revisadas juntamente com os professores. O Questionário 2 foi aplicado com o objetivo de avaliar se alunos aprenderam os conceitos ministrados na disciplina de forma satisfatória até o meio do curso.

\section{Etapa 9 - Implementação das melhorias definidas na Especificação Técnica}

Essa etapa não foi formalmente aplicada em sala. Alguns alunos relataram que propuseram as mudanças arquiteturais estudadas na disciplina nos sistemas das empresas em que trabalhavam e alguns deles já estavam planejando implementar essas mudanças em novas versões do sistema de suas empresas. 


\section{Etapa 10 - Plano de medição dos requisitos não funcionais do novo sistema}

Como não foi realizada a implementação das mudanças arquiteturais propostas nos sistemas existentes das empresas, essa etapa não foi formalmente aplicada em sala.

\section{Etapa 11 - Coleta de medidas de qualidade do novo sistema}

Esta etapa não foi formalmente aplicada em sala de aula pela mesma razão descrita no item 10 (Plano de medição dos requisitos não funcionais do novo sistema).

\section{Etapa 12 - Entrega de novo sistema e Etapa 13 - Requisitos de qualidade atingidos satisfazem as necessidades de negócio?}

$\mathrm{Na}$ aplicação do roteiro para a disciplina de Arquitetura de Software, as duas últimas etapas foram agrupadas, pois representam a entrega do artigo pelos alunos e a apresentação do mesmo para a sala de aula. Durante a apresentação, os professores avaliaram a proposta descrita no artigo e incentivaram a participação dos demais grupos na discussão sobre o trabalho apresentado. Baseado nos feedbacks dos professores e demais alunos, os autores do artigo realizaram ajustes antes de entregar a versão final para os professores.

\section{Mapeamento entre as atividades do plano da disciplina e etapas do roteiro de ensino}

A Tabela 17 descreve o mapeamento entre atividades do plano da disciplina e as etapas do roteiro de ensino aplicado em disciplina de pós-graduação. As três primeiras colunas da tabela estão relacionadas com a ementa da disciplina, como número da aula, atividades planejadas, conceitos e artefatos a serem entregues pelos alunos em cada aula. A quarta coluna descreve as etapas do roteiro que ensino que foram aplicadas na disciplina Arquitetura de Software do Mestrado profissionalizante em Engenharia da Computação. As etapas listadas não seguem uma ordem sequencial, dado que algumas delas não se aplicam. 
Tabela 17 - Mapeamento entre as atividades do roteiro e o plano da disciplina de Arquitetura de Software do curso de pós-graduação

\begin{tabular}{|c|c|c|c|}
\hline \multicolumn{3}{|c|}{ Ementa da Disciplina } & \multirow[b]{2}{*}{ Etapas do roteiro de ensino } \\
\hline $\begin{array}{l}\text { Num. } \\
\text { Aula }\end{array}$ & Atividades & Conceitos/Resultados & \\
\hline 1 & $\begin{array}{l}\text { Conceitos de Engenharia de } \\
\text { Software; } \\
\text { Conceitos de Arquitetura de } \\
\text { Software; } \\
\text { Terminologia; } \\
\text { Estabelecer metas do artigo: estudo, } \\
\text { manutenção ou avaliação } \\
\text { arquitetural. }\end{array}$ & $\begin{array}{l}\text { Alinhamento de Terminologia, } \\
\text { Normas e Modelos de arquitetura. } \\
\text { Identificação das Metas } \\
\text { Arquiteturais, caracterizadas por } \\
\text { atributos de qualidade. }\end{array}$ & $\begin{array}{l}\text { Aplicação do questionário de } \\
\text { avaliação inicial (Questionário 1) }\end{array}$ \\
\hline 2 & $\begin{array}{l}\text { Estrutura de um Artigo; } \\
\text { Requisitos Preliminares de } \\
\text { Manutenção Corretiva; } \\
\text { Requisitos Preliminares de } \\
\text { Manutenção Evolutiva; } \\
\text { Metodologia para o Diagnóstico da } \\
\text { Arquitetura; } \\
\text { Roteiro para o Diagnostico; } \\
\text { Organização dos projetos e equipes. } \\
\text { RM-ODP. }\end{array}$ & $\begin{array}{l}\text { Ciclo de negócio da arquitetura de } \\
\text { software (ABC - Architectural } \\
\text { Business Cycle); RM-ODP } \\
\text { Documentação de arquitetura (1/2): } \\
\text { Como considerar as visões, } \\
\text { stakeholders e a utilidade dos } \\
\text { documentos? }\end{array}$ & $\begin{array}{l}\text { Etapa } 1 \text { - Entendimento do processo } \\
\text { de negócio para definição dos } \\
\text { requisitos de qualidade desejados }\end{array}$ \\
\hline 3 & $\begin{array}{l}\text { Coleta das informações pelas } \\
\text { equipes (documentos e sistemas); } \\
\text { Estruturação do Artigo; } \\
\text { ATAM; } \\
\text { ISO/IEC } 9126 \text { (ISO 25010); } \\
\text { ISO/IEC 14598-5; } \\
\text { IEEE 1471; } \\
\text { Visões 4+1. }\end{array}$ & $\begin{array}{l}\text { Avaliação de Arquitetura ATAM } \\
(1 / 2) ; \\
\text { Aplicação da avaliação na criação } \\
\text { de arquitetura de software. }\end{array}$ & $\begin{array}{l}\text { Etapa } 2 \text { - Identificação de trade-offs } \\
\text { entre os requisitos não funcionais } \\
\text { baseados no processo de negócio } \\
\text { Etapa } 3 \text { - Plano de medição dos } \\
\text { requisitos não funcionais do sistema } \\
\text { atual }\end{array}$ \\
\hline 4 & Estruturação do artigo. & $\begin{array}{l}\text { Criação de arquitetura de software: } \\
\text { metas de qualidade, táticas } \\
\text { arquiteturais, mecanismos e } \\
\text { padrões. }\end{array}$ & $\begin{array}{l}\text { Etapa } 5 \text { - Análise de gap de qualidade } \\
\text { entre sistema atual e sistema } \\
\text { desejado (baseado no processo de } \\
\text { negócio) } \\
\text { Etapa } 6 \text { - Criação da Especificação } \\
\text { Técnica do sistema desejado }\end{array}$ \\
\hline 5 & $\begin{array}{l}\text { Modelagem e Especificação de } \\
\text { Projetos; } \\
\text { Validação da Estrutura do Artigo; } \\
\text { Entrega Crítica: Estrutura do artigo } \\
\text { que será produzido em itens e } \\
\text { tópicos que demonstrem o conteúdo } \\
\text { do artigo; } \\
\text { Modelo IEEE - América Latina. }\end{array}$ & $\begin{array}{l}\text { Apresentação } 1 \text { - Artigo versão } \\
\text { draft. }\end{array}$ & $\begin{array}{l}\text { Etapa } 8 \text { - Revisão da Especificação } \\
\text { Técnica de acordo com os resultados } \\
\text { da Prova de Conceito } \\
\text { Aplicação do questionário de } \\
\text { avaliação intermediário (Questionário } \\
\text { 2) }\end{array}$ \\
\hline 6 & $\begin{array}{l}\text { Detalhamento do Plano de } \\
\text { Implementação. }\end{array}$ & $\begin{array}{l}\text { Documentação arquitetural (2/2): } \\
\text { Estrutura, elaboração, notação e } \\
\text { normas. }\end{array}$ & $\begin{array}{l}\text { Etapa } 8 \text { - Revisão da Especificação } \\
\text { Técnica de acordo com os resultados } \\
\text { da Prova de Conceito }\end{array}$ \\
\hline 7 & $\begin{array}{l}\text { Execução/Medição e escrita do } \\
\text { artigo. }\end{array}$ & $\begin{array}{l}\text { Projeto arquitetural - Exemplos de } \\
\text { táticas arquiteturais. }\end{array}$ & - \\
\hline 8 & $\begin{array}{l}\text { Execução/Medição e escrita do } \\
\text { artigo. }\end{array}$ & $\begin{array}{l}\text { Projeto arquitetural - Exemplos de } \\
\text { Architectural patterns. }\end{array}$ & - \\
\hline 9 & $\begin{array}{l}\text { Execução/Medição e escrita do } \\
\text { artigo. }\end{array}$ & $\begin{array}{l}\text { Avaliação de arquitetura ATAM } \\
(2 / 2) \text {. }\end{array}$ & - \\
\hline 10 & $\begin{array}{l}\text { Execução/Medição e escrita do } \\
\text { artigo (Plantão Dúvidas). }\end{array}$ & $\begin{array}{l}\text { Avaliação de arquitetura do projeto } \\
\text { da disciplina. }\end{array}$ & - \\
\hline
\end{tabular}


Continuação

\begin{tabular}{|c|l|l|l|}
\hline \multicolumn{2}{|c|}{ Ementa da Disciplina } & \multirow{2}{*}{ Etapas do roteiro de ensino } \\
\hline$\#$ & \multicolumn{1}{|c|}{ Atividades } & \multicolumn{1}{|c|}{ Conceitos/Resultados } & $\begin{array}{l}\text { Etapa 12 - Entrega de novo } \\
\text { sistema } \\
\text { Etapa 13 - Requisitos de } \\
\text { qualidade atingidos satisfazem } \\
\text { as necessidades de negócio? }\end{array}$ \\
\hline 11 & Apresentação dos resultados obtidos & $\begin{array}{l}\text { Apresentação Final - Entrega dos } \\
\text { artigos }\end{array}$ & $\begin{array}{l}\text { Aplicação do questionário de } \\
\text { avaliação final (Questionário 3) }\end{array}$ \\
\hline 13 & Apresentação dos resultados obtidos & $\begin{array}{l}\text { Apresentação 2/2 } \\
\text { Rescaldo da Disciplina }\end{array}$ & $\begin{array}{l}\text { Entrega Final dos artigos na secretaria } \\
\text { do curso }\end{array}$ \\
\hline
\end{tabular}

Fonte: Autor

\section{Avaliação da aplicação do roteiro}

As figuras 40 a 46 contêm os gráficos das respostas dos alunos aos 7 conceitos avaliados por meio dos 3 questionários respondidos durante a aplicação do roteiro. Os dados apresentados em tais gráficos já consolidam as respostas dos 46 alunos das duas turmas da disciplina de Arquitetura de Software ministradas em 2013. Os resultados considerando as respostas dos alunos separadas por turma, encontram-se no Apêndice B.

\section{1) Nível de conhecimento de medidas em geral}

Figura 40 - Aplicação 3 - Respostas dos alunos sobre o nível de conhecimento de medidas em geral

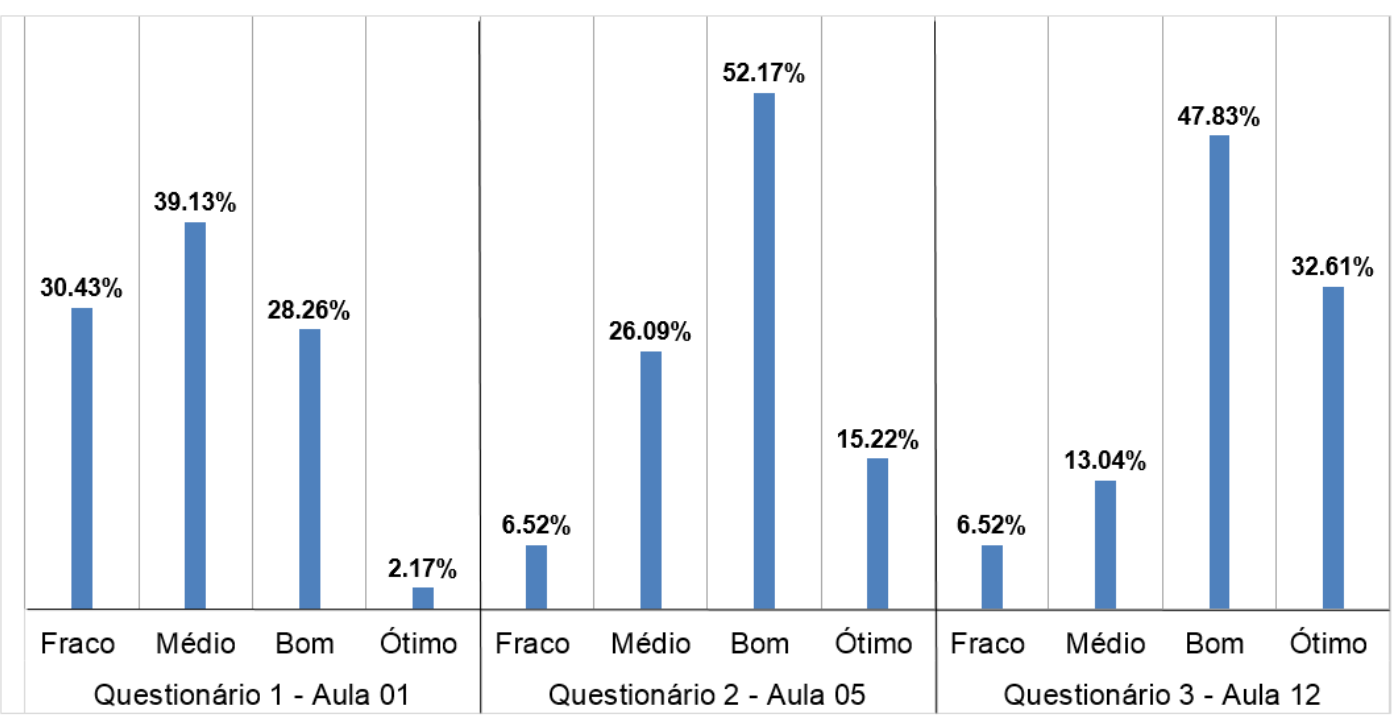

Fonte: Autor 
2) Nível de conhecimento de medidas de arquitetura de software

Figura 41 - Aplicação 3 - Respostas dos alunos sobre o nível de conhecimento de medidas de arquitetura de software

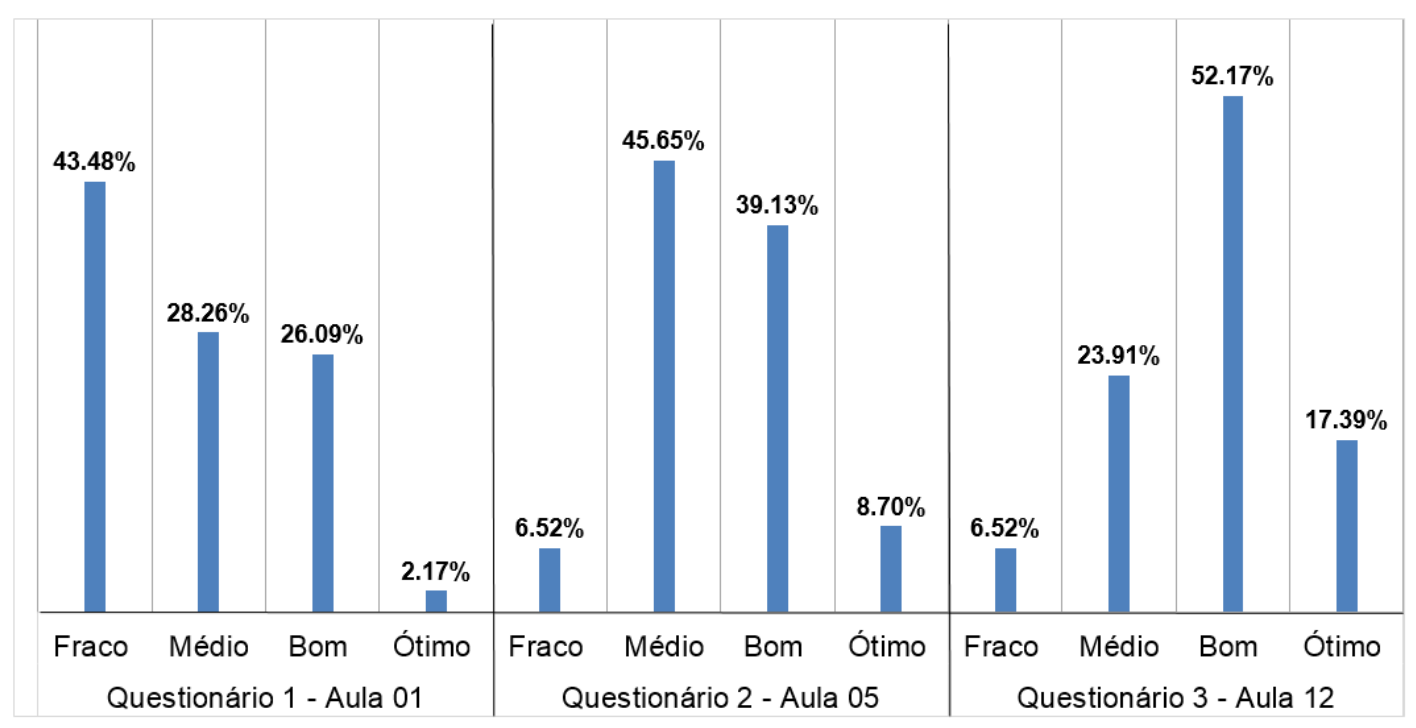

Fonte: Autor

3) Nível de conhecimento de medidas estáticas

Figura 42 - Aplicação 3 - Respostas dos alunos sobre o nível de conhecimento de medidas estáticas

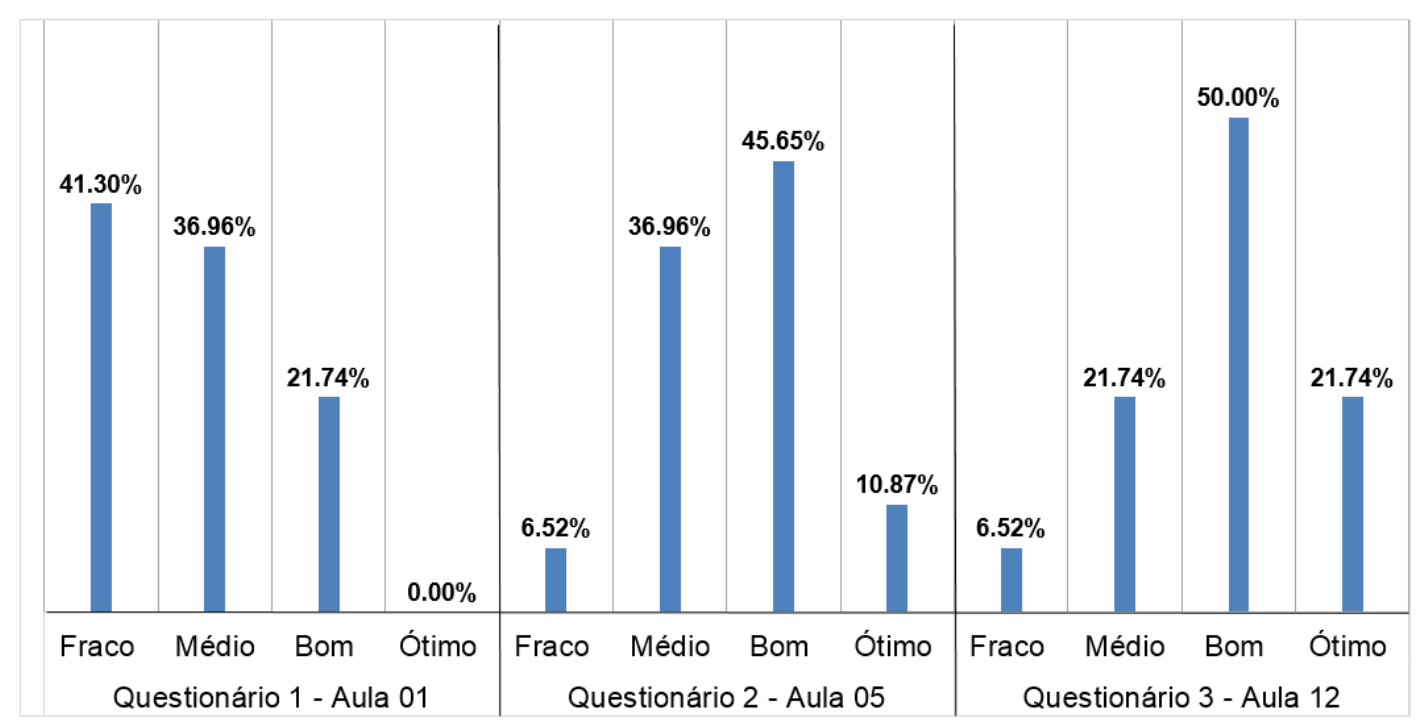

Fonte: Autor 


\section{4) Nível de conhecimento de medidas dinâmicas}

Figura 43 - Aplicação 3 - Respostas dos alunos sobre o nível de conhecimento de medidas dinâmicas

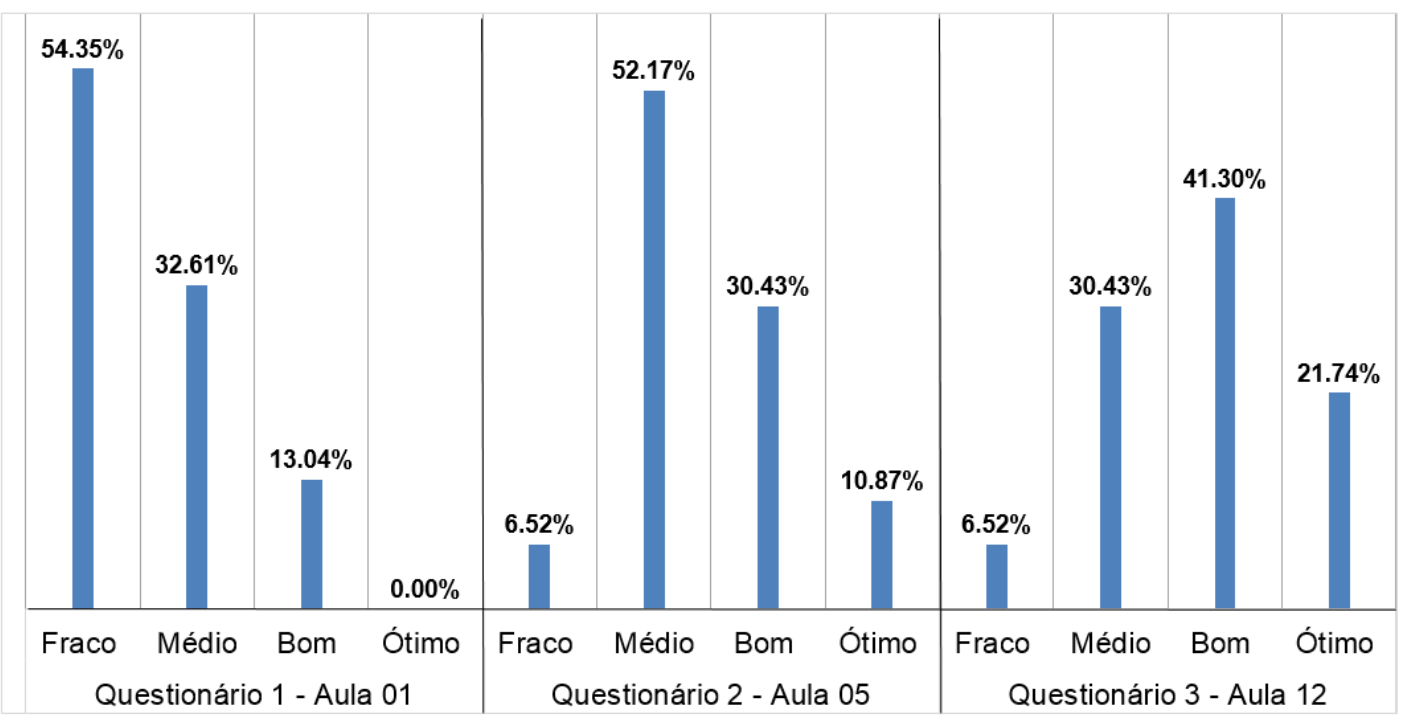

Fonte: Autor

5) Nível de conhecimento de utilidade das medidas para melhoria da arquitetura de software

Figura 44 - Aplicação 3 - Respostas dos alunos sobre o nível de conhecimento de medidas para melhoria da arquitetura de software

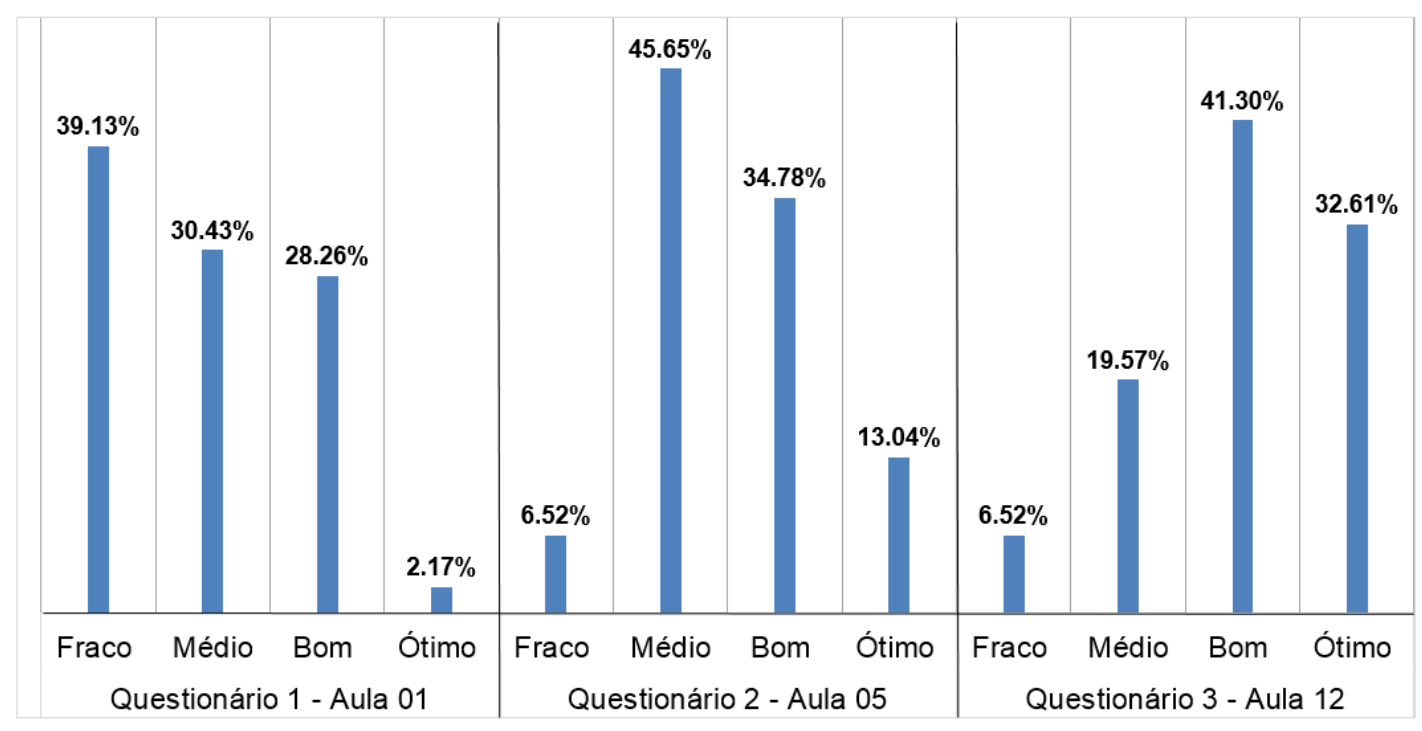

Fonte: Autor 
6) Nível de conhecimento de conceitos de qualidade

Figura 45 - Aplicação 3 - Respostas dos alunos sobre o nível de conhecimento de conceitos de qualidade

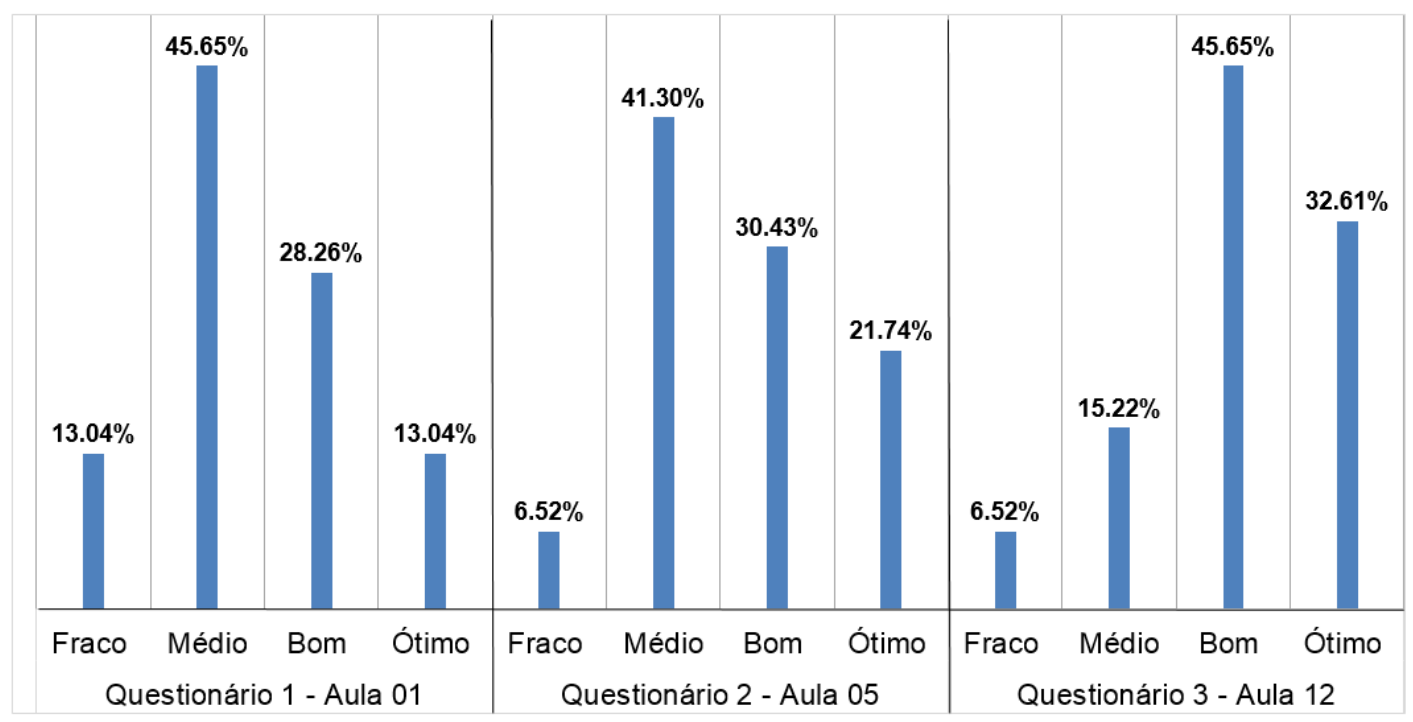

Fonte: Autor

7) Nível de conhecimento da relação entre arquitetura de software e qualidade

Figura 46 - Aplicação 3 - Respostas dos alunos sobre o nível de conhecimento da relação entre arquitetura e qualidade

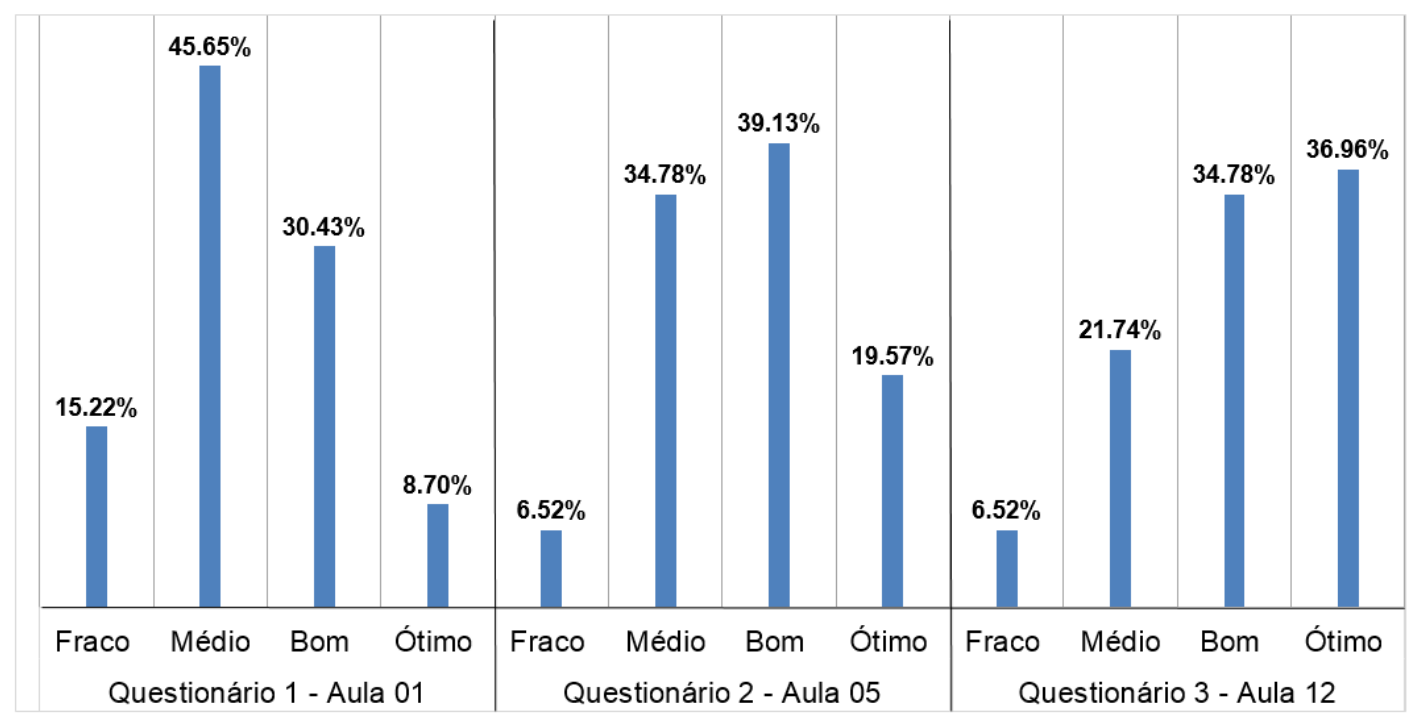

Fonte: Autor 
No curso de Mestrado profissionalizante, um artigo foi elaborado por cada grupo de alunos da disciplina Arquitetura de Software. Notou-se, pela leitura dos artigos, que grande parte dos alunos utilizou os conceitos aprendidos considerando uma visão mais focada no processo de negócio do que na implementação propriamente dita.

Tanto o modelo de referência RM-ODP como o ATAM serviram como base teórica para a maioria dos artigos produzidos. A Figura 47, por exemplo, exibe um diagrama de classes de um sistema de geolocalização com dispositivos de Internet das Coisas baseada no modelo de referência RM-ODP e no método ATAM para avaliação de atributos de disponibilidade, segurança e desempenho. Interessante notar que conceitos referentes ao processo de negócio e qualidade foram modelados pelos alunos, por meio das classes BusinessDrivers e Subscriber.

Figura 47 - Aplicação 3 - Diagrama de classes de um sistema de geolocalização baseado no RM-ODP

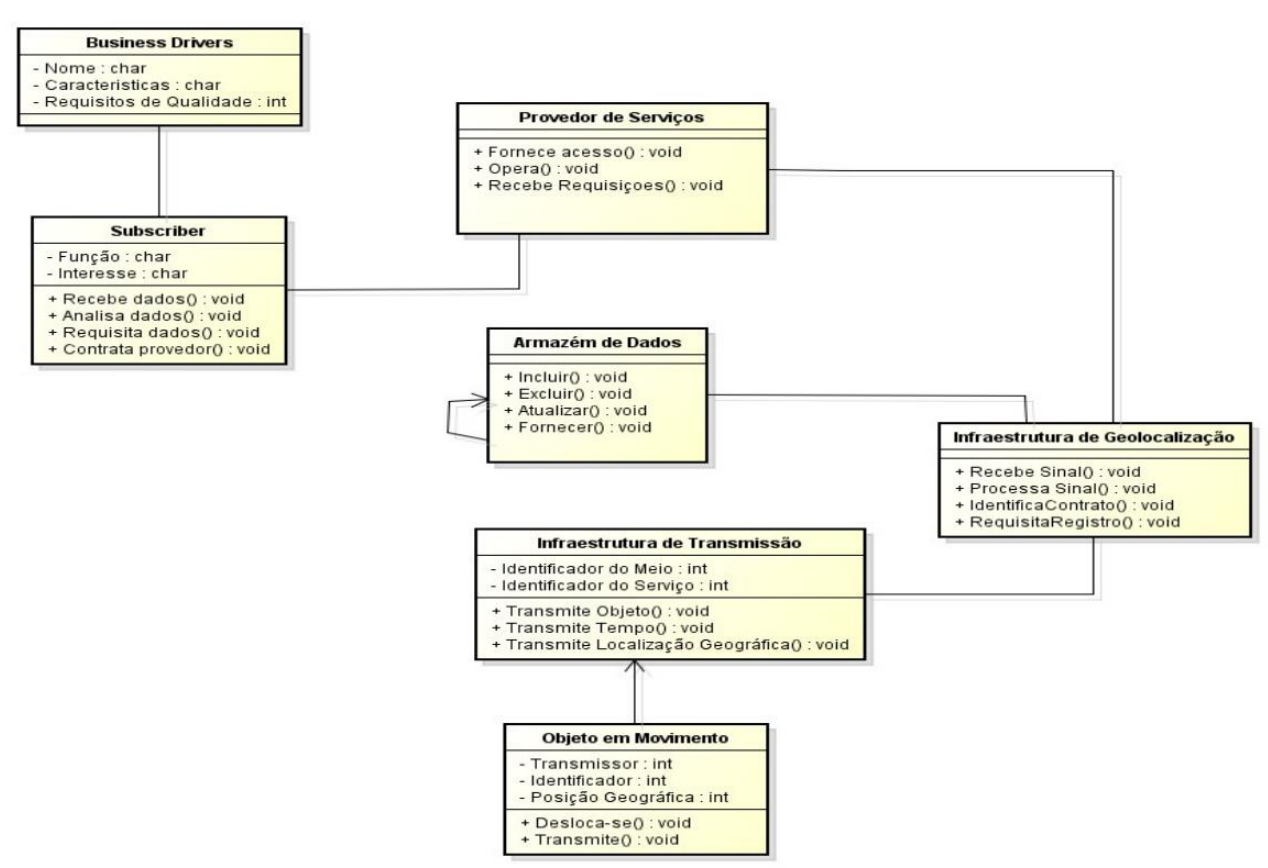

Fonte: trabalhos dos alunos que cursaram as disciplinas em que o roteiro proposto foi aplicado

Os sistemas das empresas em que os alunos trabalhavam serviram como estudo de caso para os artigos, o que trouxe um aspecto prático para as discussões 
ocorridas em sala de aula. Alguns alunos conseguiram efetivamente implementar, em suas empresas, as melhorias arquiteturais propostas no artigo elaborado por eles. A título de exemplo, a Tabela 18 descreve o resultado da avaliação dos atributos de qualidade da arquitetura de software de um sistema de cálculo de seguros, da empresa em um dos alunos trabalhava. Como resultado dessa análise, realizada com o uso do ATAM, os alunos concluíram que a arquitetura de software desse sistema não mais atendia aos requisitos demandados pelo processo de negócio, o que já estava trazendo prejuízos financeiros para a empresa, segundo o aluno que trabalhava na empresa.

Tabela 18 - Resultado da avaliação arquitetural dos atributos de qualidade de um sistema de seguros

\begin{tabular}{|l|l|}
\hline Atributo de qualidade / Cenário & $\begin{array}{l}\text { Atendimento do atributo de } \\
\text { qualidade no sistema existente }\end{array}$ \\
\hline $\begin{array}{l}\text { Atributo de qualidade: Desempenho } \\
\text { Cenário: O tempo de resposta dos três cálculos não pode ser } \\
\text { superior a } 30 \text { segundos e o tempo médio total de carregamento } \\
\text { das } 4 \text { etapas não pode ser superior a 25 segundos }\end{array}$ & NÃO ATENDE \\
\hline $\begin{array}{l}\text { Atributo de qualidade: Desempenho } \\
\text { Cenário considerado: As aplicações devem suportar até 5000 } \\
\text { acessos simultâneos }\end{array}$ & NÃO ATENDE \\
\hline $\begin{array}{l}\text { Atributo de qualidade: Escalabilidade } \\
\text { Cenário considerado: A solução deve estar pronta para } \\
\text { suportar aumento de 50\% no volume de cálculos }\end{array}$ & NÃO ATENDE \\
\hline $\begin{array}{l}\text { Atributo de qualidade: Usabilidade } \\
\text { Cenário considerado: A aplicação deve ser intuitiva e de fácil } \\
\text { aprendizado. Os clientes devem ser capazes de aprender } \\
\text { utilizar a aplicação em no máximo 8 horas }\end{array}$ & ATENDE PARCIALMENTE \\
\hline $\begin{array}{l}\text { Atributo de qualidade: Disponibilidade } \\
\text { Cenário considerado: As aplicações devem estar disponíveis } \\
24 \text { horas por dia, 7 dias por semana 99,5\% do tempo }\end{array}$ & ATENDE PARCIALMENTE \\
\hline $\begin{array}{l}\text { Atributo de qualidade: Segurança (Security) } \\
\text { cenário considerado: Todas as transações realizadas pelo } \\
\text { dados para consulta posterior }\end{array}$ & ATENDE ser registrados na base de \\
\hline $\begin{array}{l}\text { Atributo de qualidade: Compatibilidade } \\
\text { senários compatível com todos os navegadores mais populares } \\
\text { (Internet Explorer, Google Chorme e Mozilla Firefox) }\end{array}$ & NÃO ATENDE \\
\hline
\end{tabular}

Fonte: adaptado dos trabalhos dos alunos que cursaram as disciplinas em que o roteiro proposto foi aplicado 
Alguns alunos já publicaram o artigo elaborado na disciplina Arquitetura de Software em congressos e outros ainda desejam publicá-lo. Como alguns artigos produzidos na disciplina podem estar em processo de avaliados para publicação em congressos, os trabalhos dos alunos do curso de pós-graduação não foram reproduzidos no Apêndice $E$ desta tese.

Sobre os comentários registrados nos questionários, os alunos destacaram a utilização das referências conceituais do roteiro como ATAM, RM-ODP e normas de qualidade para extração dos atributos de qualidade derivados do processo de negócio. A importância da medição dos atributos de qualidade de forma qualitativa também foi destacada pelos alunos com um dos pontos positivos do roteiro proposto.

\section{Conclusões da aplicação do roteiro em disciplina de pós-graduação}

No cenário de aplicação do roteiro em disciplinas de pós-graduação (Mestrado profissionalizante), a avaliação da efetividade do roteiro foi mais complexa do que nas disciplinas de graduação. A razão da maior complexidade de avaliação reside no fato de que, nas disciplinas de graduação, foi possível avaliar um sistema desenvolvido ou mantido e alterado pelos alunos, enquanto que, nas disciplinas de pós-graduação, o artefato produzido era um artigo acadêmico.

Dessa forma, no artigo produzido, além do objetivo, estruturação e fundamentos teóricos utilizados, avaliou-se principalmente o estudo de caso proposto pelos alunos, por meio do qual foi possível verificar se os conceitos de qualidade de arquitetura de software, trade-off e medição de atributos de qualidade, tendo como referência o processo de negócio, foram corretamente aplicados.

Em um curso de Mestrado profissionalizante, o nível de abstração das discussões é maior do que em um curso de graduação. Por essa razão, outro ponto avaliado, de forma qualitativa, foi o nível das discussões fomentadas pelos próprios alunos em sala de aula sobre os temas ministrados. Pela interação com os alunos e discussões ocorridas durante as aulas, os professores e os monitores notaram que os conceitos ministrados na disciplina foram assimilados, pois os alunos conseguiram, durante as discussões, aplicar os conceitos da disciplina nos problemas relacionados à qualidade de arquitetura que enfrentavam em sua vida profissional. 
A Tabela 19, utilizada para criar os gráficos apresentados neste estudo de caso nas figuras 40 a 46, apresenta as respostas consolidadas dos 36 alunos aos três questionários de avaliação do roteiro proposto para este estudo de caso.

\section{Tabela 19 - Aplicação 3 - Respostas consolidadas dos alunos aos três questionários de avaliação do roteiro proposto}

\begin{tabular}{|l|c|c|c|c|c|c|c|c|c|c|c|c|}
\hline \multirow{2}{*}{$\begin{array}{l}\text { Conceito } \\
\text { Avaliado }\end{array}$} & \multicolumn{3}{|c|}{ Questionário 1-Aula 01 } & \multicolumn{3}{c|}{ Questionário 2 - Aula 05 } & \multicolumn{3}{c|}{ Questionário 3 - Aula 12 } \\
\cline { 2 - 13 } & Fraco & Médio & Bom & Otimo & Fraco & Médio & Bom & Ótimo & Fraco & Médio & Bom & Ótimo \\
\hline $\begin{array}{l}\text { Medidas em } \\
\text { geral }\end{array}$ & $30.43 \%$ & $39.13 \%$ & $28.26 \%$ & $2.17 \%$ & $6.52 \%$ & $26.09 \%$ & $52.17 \%$ & $15.22 \%$ & $6.52 \%$ & $13.04 \%$ & $47.83 \%$ & $32.61 \%$ \\
\hline $\begin{array}{l}\text { Medidas de } \\
\text { arquitetura de } \\
\text { software }\end{array}$ & $43.48 \%$ & $28.26 \%$ & $26.09 \%$ & $2.17 \%$ & $6.52 \%$ & $45.65 \%$ & $39.13 \%$ & $8.70 \%$ & $6.52 \%$ & $23.91 \%$ & $52.17 \%$ & $17.39 \%$ \\
\hline $\begin{array}{l}\text { Medidas } \\
\text { estáticas }\end{array}$ & $41.30 \%$ & $36.96 \%$ & $21.74 \%$ & $0.00 \%$ & $6.52 \%$ & $36.96 \%$ & $45.65 \%$ & $10.87 \%$ & $6.52 \%$ & $21.74 \%$ & $50.00 \%$ & $21.74 \%$ \\
\hline $\begin{array}{l}\text { Medidas } \\
\text { dinâmicas }\end{array}$ & $54.35 \%$ & $32.61 \%$ & $13.04 \%$ & $0.00 \%$ & $6.52 \%$ & $52.17 \%$ & $30.43 \%$ & $10.87 \%$ & $6.52 \%$ & $30.43 \%$ & $41.30 \%$ & $21.74 \%$ \\
\hline $\begin{array}{l}\text { Utilidade das } \\
\text { medidas para } \\
\text { melhoria da } \\
\text { arquitetura de } \\
\text { software }\end{array}$ & $39.13 \%$ & $30.43 \%$ & $28.26 \%$ & $2.17 \%$ & $6.52 \%$ & $45.65 \%$ & $34.78 \%$ & $13.04 \%$ & $6.52 \%$ & $19.57 \%$ & $41.30 \%$ & $32.61 \%$ \\
\hline $\begin{array}{l}\text { Conceitos de } \\
\text { qualidade }\end{array}$ & $13.04 \%$ & $45.65 \%$ & $28.26 \%$ & $13.04 \%$ & $6.52 \%$ & $41.30 \%$ & $30.43 \%$ & $21.74 \%$ & $6.52 \%$ & $15.22 \%$ & $45.65 \%$ & $32.61 \%$ \\
\hline $\begin{array}{l}\text { Relação entre } \\
\text { arquitetura de } \\
\text { software e } \\
\text { qualidade }\end{array}$ & $15.22 \%$ & $45.65 \%$ & $30.43 \%$ & $8.70 \%$ & $6.52 \%$ & $34.78 \%$ & $39.13 \%$ & $19.57 \%$ & $6.52 \%$ & $21.74 \%$ & $34.78 \%$ & $36.96 \%$ \\
\hline $\begin{array}{l}\text { Percentual } \\
\text { Médio }\end{array}$ & $\mathbf{3 3 . 8 5 \%}$ & $\mathbf{3 6 . 9 6 \%}$ & $\mathbf{2 5 . 1 6 \%}$ & $\mathbf{4 . 0 4 \%}$ & $\mathbf{6 . 5 2} \%$ & $\mathbf{4 0 . 3 7 \%}$ & $\mathbf{3 8 . 8 2} \%$ & $\mathbf{1 4 . 2 9} \%$ & $\mathbf{6 . 5 2} \%$ & $\mathbf{2 0 . 8 1 \%}$ & $\mathbf{4 4 . 7 2 \%}$ & $\mathbf{2 7 . 9 5 \%}$ \\
\hline
\end{tabular}

Fonte: Autor

Neste exemplo de aplicação do roteiro, todos os alunos já eram formados em nível superior e grande parte deles já tinha experiência na indústria. Dessa forma, era esperado que os temas ministrados na disciplina fossem, de alguma forma, familiares aos alunos.

Vale frisar, que no programa de Mestrado profissionalizante em Engenharia de Computação, a disciplina optativa Arquitetura de Software tem como requisito a disciplina obrigatória Engenharia de Software. Como exemplo, no conceito "Relação entre arquitetura de software e qualidade", apenas $15,22 \%$ dos alunos alegou fraco conhecimento como resposta ao Questionário 1. Para o mesmo conceito, os alunos de graduação tiveram percentuais bem maiores: $28,24 \%$ dos alunos da Aplicação $1 \mathrm{e}$ $41,67 \%$ da Aplicação 2 se avaliaram com fraco conhecimento no Questionário 1.

Como resultado da catalogação das respostas do Questionário 1, aplicado na primeira aula, o professor e os monitores da disciplina diagnosticaram um alto 
percentual de desconhecimento ou conhecimento fraco dos alunos nos conceitos relacionados às medidas. Dos 46 alunos, 43,48\% tinha um nível de conhecimento fraco no conceito de "Medidas de arquitetura de software", em "Medidas Estáticas" o mesmo nível foi relatado por 41,30\% dos alunos, 54,35\% em "Medidas Dinâmicas" e "Utilidade das Medidas para melhoria da arquitetura de software" era um conhecido de forma fraca por $39,13 \%$ dos alunos.

De posse dessa informação, os conceitos de medidas foram ministrados de forma mais detalhada, assim como o método ATAM, no que se refere à medição para avaliação dos trade-offs entre os atributos de qualidade. Ao término do curso, através da aplicação do Questionário 3, na 12ª . aula, 6,52\%, ou seja, três alunos do total de 46 responderam que não tinham conhecimentos dos quatro conceitos avaliados relacionados às medidas ("Medidas de arquitetura de software", "Medidas estáticas", "Medidas dinâmicas" e "Utilidade das medidas para melhoria da arquitetura de software"). Esse percentual é o mesmo registrado para esses conceitos no Questionário 2.

Também foi constatado que os alunos de pós-graduação, a princípio, seriam mais criteriosos no processo de autoavaliação. Enquanto o percentual médio dos alunos que se consideram detentores de ótimos conhecimentos dos conceitos avaliados no curso de pós-graduação é de $27,95 \%$, nos cursos de graduação esse valor é maior: 37,98\% na Aplicação 1 do roteiro e 40,48\% na Aplicação 2 do roteiro.

\subsection{ANÁLISE COMPARATIVA DAS APLICAÇÕES DO ROTEIRO DE ENSINO}

Com o objetivo de analisar as características de cada aplicação do roteiro de ensino, a Tabela 20 lista os percentuais médios das respostas dos alunos de forma consolidada por aplicação do roteiro proposto, e também o percentual médio das respostas nas três aplicações. 
Tabela 20 - Percentual médio das respostas dos alunos em cada aplicação do roteiro proposto

\begin{tabular}{|l|c|c|c|c|c|c|c|c|c|c|c|c|}
\hline \multirow{2}{*}{$\begin{array}{l}\text { Aplicação do } \\
\text { Roteiro }\end{array}$} & \multicolumn{4}{|c|}{ Questionário 1 } & \multicolumn{4}{c|}{ Questionário 2 } & \multicolumn{4}{c|}{ Questionário 3 } \\
\cline { 2 - 6 } & Fraco & Médio & Bom & Ótimo & Fraco & Médio & Bom & Ótimo & Fraco & Médio & Bom & Ótimo \\
\hline Aplicação 1 & $33.45 \%$ & $50.76 \%$ & $14.45 \%$ & $1.34 \%$ & $0.17 \%$ & $25.38 \%$ & $51.60 \%$ & $22.86 \%$ & $0.00 \%$ & $6.05 \%$ & $55.97 \%$ & $37.98 \%$ \\
\hline Aplicação 2 & $51.98 \%$ & $34.92 \%$ & $12.30 \%$ & $0.79 \%$ & $2.78 \%$ & $51.98 \%$ & $36.90 \%$ & $8.33 \%$ & $0.00 \%$ & $18.65 \%$ & $40.87 \%$ & $40.48 \%$ \\
\hline Aplicação 3 & $33.85 \%$ & $36.96 \%$ & $25.16 \%$ & $4.04 \%$ & $6.52 \%$ & $40.37 \%$ & $38.82 \%$ & $14.29 \%$ & $6.52 \%$ & $20.81 \%$ & $44.72 \%$ & $27.95 \%$ \\
\hline $\begin{array}{l}\text { Percentual } \\
\text { Médio }\end{array}$ & $\mathbf{3 9 . 7 6} \%$ & $\mathbf{4 0 . 8 8} \%$ & $\mathbf{1 7 . 3 0} \%$ & $\mathbf{2 . 0 6} \%$ & $\mathbf{3 . 1 6} \%$ & $\mathbf{3 9 . 2 4} \%$ & $\mathbf{4 2 . 4 4} \%$ & $\mathbf{1 5 . 1 6 \%}$ & $\mathbf{2 . 1 7} \%$ & $\mathbf{1 5 . 1 7 \%}$ & $\mathbf{4 7 . 1 9} \%$ & $\mathbf{3 5 . 4 7 \%}$ \\
\hline
\end{tabular}

Fonte: Autor

Analisando-se os percentuais da tabela, constata-se que em todas as aplicações do roteiro de ensino proposto, houve a migração das respostas dos níveis mais baixos de conhecimento (Fraco e Médio) para os níveis mais altos (Bom e Ótimo).

Os percentuais das respostas dos alunos que se avaliaram com nível de conhecimento Fraco no Questionário 1 são muito similares entre os alunos que participaram da Aplicação 1 (curso de graduação usando sistema existente) com os alunos envolvidos na Aplicação 3 (curso de pós-graduação usando sistema existente), respectivamente 33,45\% e 33,85\%. Já 51.98\% dos alunos da Aplicação 2 se avaliaram como detentores de conhecimento Fraco no primeiro questionário.

Em contrapartida, os alunos que participaram da Aplicação 2 foram os que mais bem se avaliaram no fim da disciplina (Questionário 3), com um percentual de respostas de nível de conhecimento Ótimo igual a 40,48\%, enquanto os alunos da Aplicação 1 e Aplicação 3, atingiram, respectivamente, 37,98\% e 27,95\% de respostas iguais a Bom no último questionário.

O desenvolvimento de um sistema a partir de seu início, como foi realizado pelos alunos da Aplicação 2, poderia ser um fator que explicasse tanto 0 alto percentual de respostas de conhecimento Fraco no Questionário 1, como também um alto percentual de respostas iguais a Ótimo no Questionário 3. Na Aplicação 2, dado que o sistema foi desenvolvido em sua totalidade pelos próprios alunos, os mesmos adquiriram um conhecimento mais profundo de todo o sistema e consequentemente de sua arquitetura de software. 
Nas Aplicações 1 e 3 do roteiro proposto, sistemas existentes foram utilizados, o que pode ter impactado a curva de aprendizado dos conceitos de qualidade de arquitetura, uma vez que os alunos dispenderam um esforço significativo para entender minimamente o sistema existente.

No caso da Aplicação 1, não havia documentação do sistema Pet Store, além do código ser de baixa qualidade. Já na Aplicação 3, geralmente o sistema escolhido para a elaboração do artigo acadêmico era de conhecimento de apenas um dos membros do grupo, pois tratava-se do sistema utilizado na empresa em que um dos trabalhava.

\subsection{CONCLUSÕES DO CAPÍTULO}

Neste capítulo, foram apresentadas três aplicações do roteiro de ensino proposto, tanto em disciplinas de graduação como de pós-graduação em Engenharia de Computação, visando avaliar o roteiro em diferentes contextos pedagógicos.

Em disciplinas de graduação, o roteiro de ensino foi aplicado oito vezes, no período de 2007 a 2014 para uma população de 121 alunos, sendo seis vezes com a utilização de sistemas existentes e duas vezes considerando o desenvolvimento de sistemas novos. As oito aplicações foram realizadas na disciplina Laboratório de Engenharia de Software II do curso de graduação em Engenharia Elétrica com ênfase em Computação da Escola Politécnica da USP.

Em disciplinas de pós-graduação, o roteiro foi aplicado duas vezes no ano de 2013, para 46 alunos da disciplina Arquitetura de Software do curso de pós-graduação (Mestrado profissionalizante) em Engenharia de Computação do IPT.

Nas aplicações apresentadas, o roteiro proposto nesta tese foi avaliado por meio de questionários aplicados no decorrer das disciplinas, pela análise dos artefatos produzidos pelos alunos e pelos comentários registrados pelos alunos nos questionários de avaliação. 
214 


\section{CONCLUSÕES}

\subsection{OBJETIVO do CAPÍTULO}

O objetivo deste capítulo é apresentar as conclusões desta tese, ressaltando a importância do ensino de qualidade em arquitetura de software na formação de engenheiros de computação. Também serão apresentadas as contribuições desta pesquisa, sugestões de melhorias e possíveis trabalhos correlatos que podem ser derivados desta pesquisa.

\subsection{CONCLUSÃO}

Com base nos resultados das aplicações do roteiro proposto descritos no Capítulo 5, é possível considerar que ele pode ser utilizado para auxiliar na aprendizagem da importância dos atributos de qualidade de arquitetura e medição desses atributos durante o todo o ciclo de vida de um sistema, conforme descrito no objetivo principal no Capítulo 1. Seguem as conclusões da pesquisa para cada um dos critérios de avaliação do roteiro proposto.

\subsubsection{Questionários de avaliação}

Analisando-se as respostas dos alunos aos questionários das aplicações do roteiro de ensino apresentados no Capítulo 5, evidencia-se que houve um processo de aprendizado de qualidade de arquitetura de software por parte dos alunos. A Tabela 21 apresenta o percentual de respostas aos conceitos avaliados dos 167 alunos dos cursos de graduação e pós-graduação que participaram da aplicação do roteiro. 
Tabela 21 - Percentual das respostas aos questionários de avaliação dos 167 alunos que participaram da aplicação do roteiro em disciplinas de graduação e pós-graduação

\begin{tabular}{|l|c|c|c|c|c|c|c|c|c|c|c|c|}
\hline \multirow{2}{*}{$\begin{array}{l}\text { Conceito } \\
\text { Avaliado }\end{array}$} & \multicolumn{4}{|c|}{ Questionário 1 } & \multicolumn{3}{c|}{ Questionário 2 } & \multicolumn{3}{c|}{ Questionário 3 } \\
\cline { 2 - 12 } & Fraco & Médio & Bom & Ótimo & Fraco & Médio & Bom & Ótimo & Fraco & Médio & Bom & Ótimo \\
\hline $\begin{array}{l}\text { Medidas em } \\
\text { geral }\end{array}$ & $29.34 \%$ & $46.71 \%$ & $21.56 \%$ & $2.40 \%$ & $1.80 \%$ & $28.14 \%$ & $53.29 \%$ & $16.77 \%$ & $1.80 \%$ & $8.38 \%$ & $52.10 \%$ & $37.72 \%$ \\
\hline $\begin{array}{l}\text { Medidas de } \\
\text { arquitetura de } \\
\text { software }\end{array}$ & $54.49 \%$ & $34.13 \%$ & $10.78 \%$ & $0.60 \%$ & $1.80 \%$ & $46.71 \%$ & $45.51 \%$ & $5.99 \%$ & $1.80 \%$ & $21.56 \%$ & $55.09 \%$ & $21.56 \%$ \\
\hline $\begin{array}{l}\text { Medidas } \\
\text { estáticas }\end{array}$ & $44.31 \%$ & $40.72 \%$ & $14.37 \%$ & $0.60 \%$ & $2.99 \%$ & $34.13 \%$ & $45.51 \%$ & $17.37 \%$ & $1.80 \%$ & $10.78 \%$ & $52.69 \%$ & $34.73 \%$ \\
\hline $\begin{array}{l}\text { Medidas } \\
\text { dinâmicas }\end{array}$ & $57.49 \%$ & $32.34 \%$ & $9.58 \%$ & $0.60 \%$ & $2.40 \%$ & $37.13 \%$ & $44.91 \%$ & $15.57 \%$ & $1.80 \%$ & $15.57 \%$ & $47.31 \%$ & $35.33 \%$ \\
\hline $\begin{array}{l}\text { Utilidade das } \\
\text { medidas para } \\
\text { melhoria da } \\
\text { arquitetura de } \\
\text { software }\end{array}$ & $35.33 \%$ & $44.91 \%$ & $17.37 \%$ & $2.40 \%$ & $3.59 \%$ & $34.13 \%$ & $37.72 \%$ & $24.55 \%$ & $1.80 \%$ & $11.38 \%$ & $41.32 \%$ & $45.51 \%$ \\
\hline $\begin{array}{l}\text { Conceitos de } \\
\text { qualidade }\end{array}$ & $14.37 \%$ & $59.28 \%$ & $22.75 \%$ & $3.59 \%$ & $1.80 \%$ & $35.93 \%$ & $44.91 \%$ & $17.37 \%$ & $1.80 \%$ & $10.18 \%$ & $51.50 \%$ & $36.53 \%$ \\
\hline $\begin{array}{l}\text { Relação entre } \\
\text { arquitetura de } \\
\text { software e } \\
\text { qualidade }\end{array}$ & $27.54 \%$ & $46.71 \%$ & $22.16 \%$ & $3.59 \%$ & $2.99 \%$ & $30.54 \%$ & $42.51 \%$ & $23.95 \%$ & $1.80 \%$ & $11.98 \%$ & $47.31 \%$ & $38.92 \%$ \\
\hline $\begin{array}{l}\text { Percentual } \\
\text { Médio }\end{array}$ & $\mathbf{3 7 . 5 5 \%}$ & $\mathbf{4 3 . 5 4 \%}$ & $\mathbf{1 6 . 9 4 \%}$ & $\mathbf{1 . 9 7 \%}$ & $\mathbf{2 . 4 8} \%$ & $\mathbf{3 5 . 2 4 \%}$ & $\mathbf{4 4 . 9 1 \%}$ & $\mathbf{1 7 . 3 7 \%}$ & $\mathbf{1 . 8 0} \%$ & $\mathbf{1 2 . 8 3} \%$ & $\mathbf{4 9 . 6 2 \%}$ & $\mathbf{3 5 . 7 6 \%}$ \\
\hline
\end{tabular}

Fonte: Autor

Observa-se, por meio dos valores apresentados na Tabela 21 que, à medida que os questionários foram aplicados durante o decorrer da disciplina, diminuiu-se o percentual de alunos que se avaliavam com conhecimento Fraco ou Médio sobre determinado conceito avaliado. Em contrapartida, elevou-se o número de respostas Bom e Ótimo.

Conforme descrito no item 5.4 - Critérios de avaliação do roteiro proposto, espera-se que os alunos, após participarem do roteiro, avaliem seu conhecimento sobre os itens questionados como Bom ou Ótimo no Questionário 3, aplicado no último dia de aula. Um aluno egresso de uma disciplina que tenha se autoavaliado como Bom ou Ótimo provavelmente conseguiu incorporar os conceitos ministrados e já tem o conhecimento da importância doa atributos de qualidade de arquitetura de software.

Somando-se a quantidade de alunos que se avaliaram com conhecimento "Fraco" ou "Médio", e de alunos com conhecimentos Bom ou Ótimo, os seguintes percentuais são obtidos, conforme mostrado na Tabela 22: 
Tabela 22 - Percentual das respostas somando-se as respostas de nível de conhecimento Fraco + Médio e Bom + Ótimo

\begin{tabular}{|l|c|c|c|c|c|c|}
\hline \multirow{2}{*}{ Conceito avaliado } & \multicolumn{2}{|c|}{ Questionário 1 de 3 } & \multicolumn{2}{c|}{ Questionário 2 de 3 } & \multicolumn{2}{c|}{ Questionário 3 de 3 } \\
\cline { 2 - 8 } & Fraco + Médio & Bom + Ótimo & Fraco + Médio & Bom + Ótimo & Fraco + Médio & Bom + Ótimo \\
\hline Medidas em geral & $76.05 \%$ & $23.95 \%$ & $29.94 \%$ & $70.06 \%$ & $10.18 \%$ & $89.82 \%$ \\
\hline $\begin{array}{l}\text { Medidas de arquitetura de } \\
\text { software }\end{array}$ & $88.62 \%$ & $11.38 \%$ & $48.50 \%$ & $51.50 \%$ & $23.35 \%$ & $76.65 \%$ \\
\hline Medidas estáticas & $85.03 \%$ & $14.97 \%$ & $37.13 \%$ & $62.87 \%$ & $12.57 \%$ & $87.43 \%$ \\
\hline Medidas dinâmicas & $89.82 \%$ & $10.18 \%$ & $39.52 \%$ & $60.48 \%$ & $17.37 \%$ & $82.63 \%$ \\
\hline $\begin{array}{l}\text { Utilidade das medidas para } \\
\text { melhoria da arquitetura de } \\
\text { software }\end{array}$ & $80.24 \%$ & $19.76 \%$ & $37.72 \%$ & $62.28 \%$ & $13.17 \%$ & $86.83 \%$ \\
\hline Conceitos de qualidade & $73.65 \%$ & $26.35 \%$ & $37.72 \%$ & $62.28 \%$ & $11.98 \%$ & $88.02 \%$ \\
\hline $\begin{array}{l}\text { Relação entre arquitetura de } \\
\text { software e qualidade }\end{array}$ & $74.25 \%$ & $25.75 \%$ & $33.53 \%$ & $66.47 \%$ & $13.77 \%$ & $86.23 \%$ \\
\hline Percentual médio & $\mathbf{8 1 . 0 9 \%}$ & $\mathbf{1 8 . 9 1 \%}$ & $\mathbf{3 7 . 7 2} \%$ & $\mathbf{6 2 . 2 8} \%$ & $\mathbf{1 4 . 6 3} \%$ & $\mathbf{8 5 . 3 7 \%}$ \\
\hline
\end{tabular}

Fonte: Autor

Analisando-se os percentuais da Tabela 22, verifica-se que, na média, $85,37 \%$ dos alunos se avaliaram com conceitos Bom ou Ótimo nos itens do questionário de avaliação.

A migração progressiva das respostas dos alunos entre as escalas definidas no questionário, ou seja, de Fraco para Médio, de Médio para Bom e de Bom para Ótimo, considerando as 3 aplicações do questionário, não é uma prova irrefutável que o estudante realmente aprendeu os conceitos de qualidade de arquitetura de software, mas é uma evidência, de aprendizado significativo. O padrão de migração de respostas para melhores níveis de conhecimento conforme os questionários de avaliação foram aplicados repetiu-se em todas as disciplinas nas quais o roteiro de ensino proposto foi utilizado.

\subsubsection{Avaliação dos artefatos produzidos pelos alunos}

Os artefatos produzidos pelos alunos nas disciplinas em que o roteiro foi aplicado também foram analisados pelo professor e pelos monitores das disciplinas para verificar se os conceitos de qualidade de arquitetura de software e técnicas para avaliação e medição dos atributos de qualidade foram corretamente aplicados.

Como resultado das disciplinas de graduação, foram formados 36 grupos de alunos entre os anos de 2007 e 2014. Cada grupo de trabalho produziu, em média, cinco artefatos durante a disciplina. Portanto, nesse período de aplicação do roteiro, 
foram elaborados aproximadamente 180 artefatos. Segue uma avaliação não somente dos cinco tipos de artefatos, mas também considerando o processo de elaboração dos mesmos pelos alunos:

- Plano de medição dos requisitos não funcionais: a produção deste artefato foi a que mais gerou dificuldade para os alunos, pois muitos deles tinham um conhecimento fraco sobre medidas e como aplicá-las na avaliação e medição de qualidade de arquitetura de software. Da população de 121 alunos de graduação que participaram do roteiro, 28,93\% avaliaram, no Questionário 1, 0 conhecimento como Fraco o conceito "Medidas em geral"; já em "Medidas de arquitetura de software", a mesma avaliação foi dada por $58,68 \%$ dos alunos; em "Medidas estáticas" o percentual foi de $45,45 \%$; e, finalmente, em "Medidas dinâmicas", 58,68\% dos alunos consideravam seu conhecimento fraco na $1^{\underline{a}}$. aula. Com a ajuda de exemplos práticos, os alunos conseguiram elaborar 0 Plano de medição e realizar a coleta das medidas e ao término da aplicação do roteiro, nenhum aluno se avaliava com fracos conhecimentos nos conceitos citados, conforme destacado em negrito na Tabela 23 a seguir

Tabela 23 - Percentual das respostas aos questionários dos 121 alunos de graduação que participaram do roteiro

\begin{tabular}{|l|c|c|c|c|c|c|c|c|c|c|c|c|}
\hline \multirow{2}{*}{$\begin{array}{l}\text { Conceito } \\
\text { Avaliado }\end{array}$} & \multicolumn{4}{|c|}{ Questionário 1 } & \multicolumn{3}{c|}{ Questionário 2 } & \multicolumn{3}{c|}{ Questionário 3 } \\
\cline { 2 - 13 } & Fraco & Médio & Bom & Ótimo & Fraco & Médio & Bom & Ótimo & Fraco & Médio & Bom & Ótimo \\
\hline $\begin{array}{l}\text { Medidas em } \\
\text { geral }\end{array}$ & $\mathbf{2 8 . 9 3} \%$ & $49.59 \%$ & $19.01 \%$ & $2.48 \%$ & $0.00 \%$ & $28.93 \%$ & $53.72 \%$ & $17.36 \%$ & $\mathbf{0 . 0 0 \%}$ & $6.61 \%$ & $53.72 \%$ & $39.67 \%$ \\
\hline $\begin{array}{l}\text { Medidas de } \\
\text { arquitetura } \\
\text { de software }\end{array}$ & $\mathbf{5 8 . 6 8 \%}$ & $36.36 \%$ & $4.96 \%$ & $0.00 \%$ & $0.00 \%$ & $47.11 \%$ & $47.93 \%$ & $4.96 \%$ & $\mathbf{0 . 0 0 \%}$ & $20.66 \%$ & $56.20 \%$ & $23.14 \%$ \\
\hline $\begin{array}{l}\text { Medidas } \\
\text { estáticas }\end{array}$ & $\mathbf{4 5 . 4 5 \%}$ & $42.15 \%$ & $11.57 \%$ & $0.83 \%$ & $1.65 \%$ & $33.06 \%$ & $45.45 \%$ & $19.83 \%$ & $\mathbf{0 . 0 0 \%}$ & $6.61 \%$ & $53.72 \%$ & $39.67 \%$ \\
\hline $\begin{array}{l}\text { Medidas } \\
\text { dinamicas }\end{array}$ & $\mathbf{5 8 . 6 8 \%}$ & $32.23 \%$ & $8.26 \%$ & $0.83 \%$ & $0.83 \%$ & $31.40 \%$ & $50.41 \%$ & $17.36 \%$ & $\mathbf{0 . 0 0 \%}$ & $9.92 \%$ & $49.59 \%$ & $40.50 \%$ \\
\hline $\begin{array}{l}\text { Utilidade das } \\
\text { medidas para } \\
\text { melhoria da } \\
\text { arquitetura de } \\
\text { software }\end{array}$ & $33.88 \%$ & $50.41 \%$ & $13.22 \%$ & $2.48 \%$ & $2.48 \%$ & $29.75 \%$ & $38.84 \%$ & $28.93 \%$ & $0.00 \%$ & $8.26 \%$ & $41.32 \%$ & $50.41 \%$ \\
\hline $\begin{array}{l}\text { Conceitos de } \\
\text { qualidade }\end{array}$ & $14.88 \%$ & $64.46 \%$ & $20.66 \%$ & $0.00 \%$ & $0.00 \%$ & $33.88 \%$ & $50.41 \%$ & $15.70 \%$ & $0.00 \%$ & $8.26 \%$ & $53.72 \%$ & $38.02 \%$ \\
\hline $\begin{array}{l}\text { Relação entre } \\
\text { arquitetura de } \\
\text { software e } \\
\text { qualidade }\end{array}$ & $32.23 \%$ & $47.11 \%$ & $19.01 \%$ & $1.65 \%$ & $1.65 \%$ & $28.93 \%$ & $43.80 \%$ & $25.62 \%$ & $0.00 \%$ & $8.26 \%$ & $52.07 \%$ & $39.67 \%$ \\
\hline
\end{tabular}

\section{Fonte: Autor}

- Especificação Funcional: este artefato foi somente elaborado no exemplo de aplicação do roteiro 2, no qual os alunos desenvolveram sistemas novos e 
precisavam detalhar as funcionalidades. As 8 especificações funcionais produzidas na Aplicação 2 do roteiro de ensino consideraram os valores esperados para cada um dos atributos de qualidade, sejam eles funcionais ou não funcionais;

- Especificação Técnica: na elaboração deste artefato, convém destacar a utilização do modelo de referência RM-ODP para estruturação da especificação, segundo os diferentes pontos de vista e o ATAM para definição dos valores dos atributos de qualidade a serem atingidos pelo sistema implementado. Essa documentação era feita de forma sucinta, contendo somente o necessário para subsidiar a implementação da prova de conceito e do sistema propriamente dito. $O$ processo de elaboração da especificação técnica foi bastante interessante do ponto de vista pedagógico, pois os alunos trabalhavam com o editor de texto e com a ferramenta de desenvolvimento em conjunto, ou seja, a especificação técnica já era permeada de vários artefatos da própria implementação do sistema, o que evidencia a abordagem prática sugerida pelo roteiro proposto;

- Implementação da prova de conceito: na visão do autor, a implementação da prova de conceito é um dos itens mais ricos do ponto de vista pedagógico, pois permite ao aluno exercitar uma série de competências que serão fundamentais em sua vida profissional, como por exemplo: avaliação de diferentes alternativas de solução e realização dos trade-offs entre elas, elaboração de hipóteses sobre determinada estratégia arquitetural e implementação rápida para comprová-la ou refutá-la, implementação dos pontos críticos da arquitetura de software, uso de simuladores, desenvolvimento em paralelo através do desacoplamento da programação para uma interface, uso de prova de conceito destrutiva para identificação de pontos fracos na arquitetura, entre outros. A implementação das provas de conceito realizada pelos alunos possibilitou exercitar as competências citadas e, segundo os comentários dos próprios alunos, a utilização de provas de conceito foi um dos aspectos mais importantes da aplicação do roteiro;

- Sistema implementado: durante a aplicação do roteiro nas disciplinas de graduação, tanto das melhorias arquiteturais em sistema existente, como no desenvolvimento de sistemas novos, os alunos adquiriram a percepção da importância de se medir os atributos de qualidade durante o processo de 
desenvolvimento do sistema e comparar os resultados com as necessidades derivadas do processo de negócio. Esse item também é muito significativo no processo de aprendizado dos alunos, visto que permite, por meio de evidências numéricas, atestar a qualidade do sistema. A apresentação do sistema pronto ao professor e monitores das disciplinas também possibilitou aos alunos enxergarem o sistema sob a perspectiva do negócio, e não somente sob o aspecto técnico.

Nas disciplinas de pós-graduação, em que o roteiro de ensino foi aplicado duas vezes no ano de 2013, foram produzidos dezoito artigos acadêmicos relacionados à avalição de arquitetura de software, qualidade e medição dos atributos de qualidade de arquitetura de software e propostas de melhoria em arquiteturas de software existentes.

Os artigos escritos pelos alunos utilizaram o referencial teórico ministrado durante as aulas, como o ATAM, RM-ODP, normas de qualidade, etc., e analisaram, de forma descaracterizada, os sistemas com os quais os alunos trabalhavam, o que possibilitou discussões práticas no decorrer das aulas.

A diversidade de formação dos alunos e de sua atuação profissional também enriqueceu a discussão sobre a importância dos requisitos não funcionais em diferentes processos de negócio. Por exemplo: foram escritos artigos sobre segurança em usina nuclear, em que o requisito segurança (safety) é crucial, como também artigos sobre sistemas de cobrança de telefonia celular, em que os requisitos de desempenho e rastreabilidade são fundamentais. Dos dezoito artigos entregues pelos alunos, um deles foi publicado na $1^{\text {a }}$ Conferência Latino-Americana de Segurança em SCADA (TI SAFE, 2014) e pelo menos 8 artigos se tornaram potenciais temas das dissertações de Mestrado dos alunos.

\subsubsection{Comentários dos alunos sobre o roteiro proposto}

Dos 167 alunos que participaram das aplicações do roteiro proposto, 64 registraram seus comentários nos questionários de avaliação, ou seja, 38,32\% dos alunos. Apesar de o questionário ter sido aplicado três vezes no decorrer das disciplinas, nenhum aluno registou suas considerações em mais de um questionário. 
A maioria dos alunos teceu considerações sobre o roteiro no questionário final, aplicado na última aula. Analisando-se as respostas, é possível classificá-las em quatro categorias:

- Constatação de aprendizado de novo conceito: nesta categoria de resposta, o aluno constata o aprendizado do novo conceito ou nova técnica que antes desconhecia ou tinha um conhecimento fraco. Um exemplo de comentário classificado nesta categoria corresponde ao apresentado a seguir:

Após o curso, percebo que minha capacidade de análise de questões avançadas sobre engenharia de software aumentou significativamente, ao ter compreendido o conceito e a importância de medições no contexto de utilização de visões de arquitetura e implementação de requisitos não funcionais.

Ganhei conhecimento sobre os assuntos abordados na disciplina, mas mais importante que isso, passei a ter uma visão arquitetural mais apurada. Os temas abordados são muito importantes, não só academicamente, mas profissionalmente, pois demonstrar conhecimento sobre tais assuntos passa a impressão de um professional mais maduro, que pode atuar numa área onde não há grande oferta de profissionais.

$\mathrm{Na}$ primeira aula, na minha visão, os conceitos de medidas estáticas e dinâmicas como por exemplo complexidade ciclomática, acoplamento, testes automatizados e testes de carga eram basicamente elementos técnicos e mecanismos utilizados em processo de desenvolvimento de sistemas. $\mathrm{Na}$ última aula, percebi a importância da necessidade de medidas para a avaliação tanto do produto como do processo de software, assim como a necessidade de métodos para identificação e coleta das medidas, e a arquitetura de software deve ser dirigida pelo processo de negócio, e não somente por demandas e direcionamentos técnicos.

- Sugestão: resposta na qual o aluno sugere uma melhoria para o roteiro proposto, como por exemplo:

A aula é boa, uma das melhores aulas de Engenharia de Software do curso. Isso se deve muito à abordagem que foca aspectos práticos e sua relação com a teoria. Sugestão: criar tarefas mais uniformes entre os diversos grupos. 
Creio que para melhor entender/solidificar os diferentes conceitos de medidas (estáticas, dinâmica e de arquitetura) seria interessante ter um pouco mais de testes práticos na aula em que são discutidas essas medidas.

Para a aprendizagem de conceitos relacionados às medidas, é sempre interessante a prática por meio de exercícios básicos para fixação dos conhecimentos, com o objetivo de evidenciar as relações existentes entre medidas, qualidade de arquitetura de software e qualidade em geral de forma clara e objetiva.

- Elogio: registro de elogio ao roteiro ou ao resultado de aprendizado por ele proporcionado, como citado a seguir:

O curso mudou a minha forma de se enxergar sistemas, pois agora entendo a importância dos requisitos não funcionais e sua influência na arquitetura de software e na qualidade final dos sistemas.

Os conceitos de qualidade foram bem abordados na disciplina, visto que os alunos foram incentivados a refletir sobre os problemas de qualidade dos sistemas de grande porte (desempenho, segurança, concorrência, etc.), o que não tinha sido feito em nenhuma outra disciplina.

Olhar a arquitetura de software, primeiramente, com a visão de negócio, e não apenas com a visão técnica, alterou a forma como encaro a Engenharia de Software.

- Crítica: aluno registra uma crítica a algum ponto do roteiro de que sentiu falta ou que não ficou suficiente claro, podendo ter prejudicado seu processo de ensino/aprendizagem. Algumas críticas ao roteiro podem ser vistas a seguir:

Ainda tenho um pouco de dúvidas/dificuldades em relação ao conceito de arquitetura de software.

Apesar de ter entendido os principais conceitos de medida, a efetivação prática de como medir não ficou completamente clara e consolidada. Acredito que tenha faltado um pouco de prática nisso durante a disciplina.

As relações entre medidas estáticas, dinâmicas e de qualidade de arquitetura de software não ficaram muito claras para mim. 
O gráfico da Figura 48 ilustra o percentual de cada categoria dos comentários individuais dos alunos registrados nos questionários de avaliação do roteiro. Os comentários dos 64 alunos foram reproduzidos no Apêndice $F$.

Figura 48 - Percentual dos comentários individuais dos alunos classificados por categoria

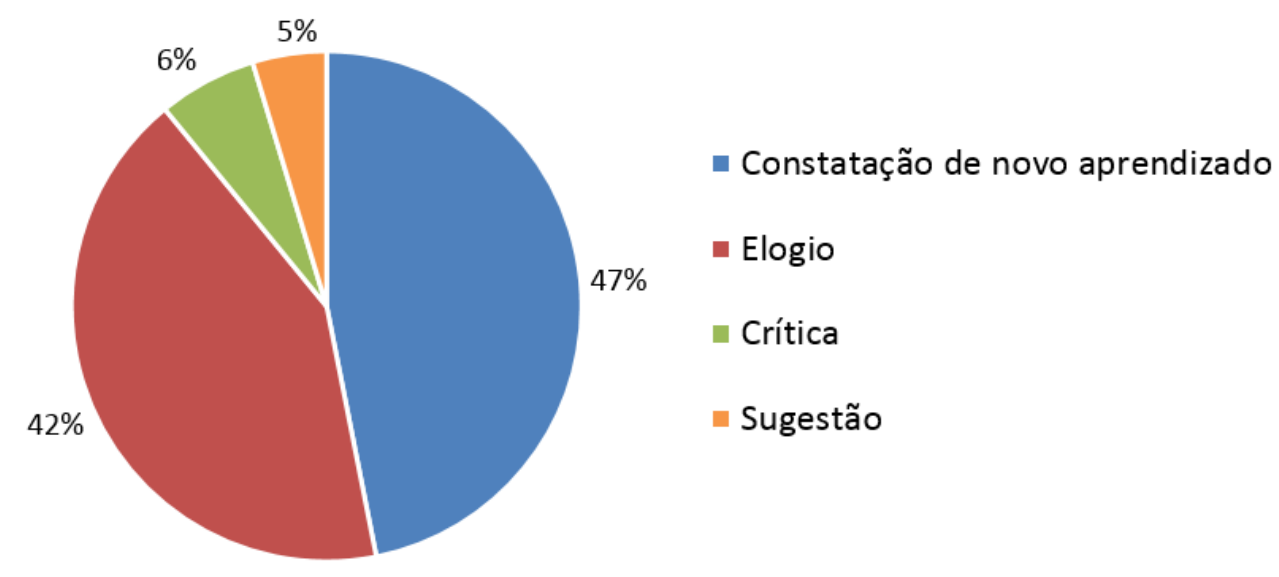

Fonte: Autor

Dos alunos que teceram suas considerações sobre o roteiro, $89 \%$ deles tiveram uma percepção positiva, seja por meio de novo aprendizado ou por elogios. A constatação de novo aprendizado é um indício da eficácia do roteiro proposto nesta tese

\subsection{RESUMO DAS CONTRIBUIÇÕES DO TRABALHO}

Neste trabalho de pesquisa, foi proposto um roteiro para o ensino de qualidade de arquitetura de software, guiada por atributos de qualidade, principalmente requisitos não funcionais, de forma prática, iterativa e dirigida pelo processo de negócio, visando auxiliar no processo de ensino/aprendizagem da importância dos atributos de qualidade de arquitetura de software e medição desses atributos durante todo o ciclo de vida de um sistema.

A importância da qualidade das arquiteturas projetadas pelos profissionais de computação justifica a existência de um roteiro para o ensino de qualidade de software. Esta pesquisa pode auxiliar no ensino de qualidade da arquitetura de software, contribuindo positivamente na formação dos Engenheiros de Computação, 
os quais terão um embasamento teórico e prático mais fundamentado sobre tópicos arquiteturais.

Os pontos positivos do roteiro proposto para o ensino de qualidade de arquitetura de software discutidos neste trabalho se resumem a:

- Abordagem prática e iterativa para o ensino de qualidade de arquitetura;

- Aprendizado centrado no aluno, o que exige uma atitude proativa por parte dos estudantes, que devem ser conscientizados da importância do processo de aprendido contínuo;

- Elevação do nível de abstração mental dos alunos, de código-fonte para arquiteturas de software;

- Proposta para o ensino de qualidade de arquitetura de software que permite evidenciar, através de medidas, se os atributos de qualidade atingidos pela arquitetura proposta satisfazem o processo de negócio;

- Uso de trade-offs baseados nos objetivos de negócio para tomada de decisões arquiteturais;

- Utilização de normas e métodos reconhecidos como ISO/IEC 9126, ISO/IEC 14598-5, ISO/IEC 10746-1 e o ATAM;

- Uso de técnicas para identificação, priorização e medicação de atributos de qualidade que pode ser utilizada durante a vida profissional dos alunos.

Entre as sugestões de melhorias no roteiro de ensino destacam-se:

- Aprimoramento da parte pedagógica do roteiro, com o suporte de profissionais da área de educação;

- Maior detalhamento dos conceitos às medidas estáticas, dinâmicas e de atributos de qualidade de arquitetura de software, conforme sugestão registrada por alunos nos comentários sobre o roteiro de ensino proposto;

- Utilização do roteiro proposto em outros cursos correlatos, como por exemplo, em disciplinas do curso de Ciência da Computação, Sistemas de Informação, Tecnologia de Informação, etc.;

- Possibilidade de customização do roteiro, visando aplicá-lo em outros contextos, tanto na academia como na indústria; 
- Uso de outros métodos de avaliação de aprendizado, além de questionários e análise dos artefatos produzidos e comentários registrados pelos alunos.

\subsection{TRABALHOS Futuros}

A partir deste trabalho, é possível derivar um conjunto de temas de estudo para futuras pesquisas. Neste sentido, propõem-se os seguintes trabalhos relacionados com o ensino de qualidade arquitetura de software:

- Customização do roteiro para o ensino de características mais especificas de qualidade de arquitetura de software, como por exemplo: sistemas de tempo real, manipulação de grandes volumes de dados, escalabilidade $\mathrm{e}$ manutenibilidade em ambientes largamente distribuídos, etc.;

- Aplicação da abordagem em cenários industriais que demandem aprendizado rápido e voltado para aplicação em projetos empresarias que atendam às necessidades de negócio da empresa;

- Adaptação do roteiro para cenários de aprendizado de bem específicos e com maior profundidade;

- Adaptação da abordagem proposta para uso em ensino a distância;

- Aplicação do processo Analytic Hierarchy Process (AHP) para avaliação dos trade-offs entre atributos de qualidade;

- Utilização de outras tecnologias de implementação, como por exemplo, a plataforma .NET da Microsoft;

- Aplicação do roteiro em outras áreas dentro da Engenharia de Computação.

\subsection{CONSIDERAÇÕES FINAIS}

Durante a aplicação do roteiro, os alunos tiveram a oportunidade de vivenciar de forma prática os aspectos relacionados à qualidade de arquitetura, principalmente dos requisitos não funcionais, bem como seus impactos na qualidade e a importância do alinhamento com os objetivos de negócio.

$\mathrm{Na}$ visão do autor, a maior contribuição do roteiro proposto neste trabalho é auxiliar para que o aluno desenvolva, inicialmente, a percepção e, gradativamente, o conhecimento da importância da qualidade da arquitetura de software, dos seus 
impactos na qualidade do sistema resultante e de como mensurar os atributos de qualidade para avaliar a qualidade do projeto, de tal forma a poder aplicá-los nos projetos em que trabalhar.

Dessa forma, por meio de sua conduta e atitude profissional, o próprio aluno pode potencialmente vir a se tornar um vetor de disseminação da importância dos conceitos relacionados à arquitetura de software e de qualidade de software, o que pode contribuir para o aprimoramento dos profissionais de computação. 


\section{REFERÊNCIAS BIBLIOGRÁFICAS}

ABRAN, A. Software metrics and software metrology. Los Alamitos: Wiley-IEEE Computer Society, 2010.

ACM/IEEE-CS JOINT TASK FORCE ON COMPUTING CURRICULA. Computer Engineering 2004. IEEE Computer Society Press, 2004.

ACM/IEEE-CS JOINT TASK FORCE ON COMPUTING CURRICULA. Computer science curricula 2013. ACM Press and IEEE Computer Society Press, 2013.

ALBIN, S. T. The art of software architecture: design methods and techniques. Hoboken: Wiley, 2003.

ANDRADE, R. M. Um framework para o ensino de arquitetura de software. 2005. 209 p. Dissertação (Mestrado) - Escola Politécnica da Universaidade de São Paulo, São Paulo, 2005.

ANDRADE, R. M.; ARAKAKI, R. Experimentos para o ensino de arquitetura de software baseado no metamodelo EML. In: XXXIII Congresso Brasileiro de Ensino de Engenharia. Anais...Campina Grande: ABENGE, 2005. Disponível em: <http://www.abenge.org.br/CobengeAnteriores/2005/artigos/SP-5-217292148351117773100281.pdf>. Acesso em: 12 fev. 2015.

ANJOS, E.; ZENHA-RELA, M. A framework for classifying and comparing software architecture tools for quality evaluation. In: 2011 International Conference on Computational Science and Its Applications - Volume Part V. Proceedings... ICCSA'11.Berlin: Springer, 2011. Disponível em:

<http://dl.acm.org/citation.cfm?id=2029427.2029452>. Acesso em: 24 fev. 2012.

ANGELO, M. F.; CRISTINA, B.; PIRES, M. G. Experiences in Project Development in the UEFS Computing Engineering Course Using Project-Based Learning. IEEE Technology and Engineering Education (ITEE), v. 8, n. 2, p. 1-5, 2013.

ARAKAKI, R. AQS - Disciplina arquitetura de software do Mestrado Profissional em Engenharia de Computação do IPT: planejamento das atividades do curso. São Paulo, 2013.[Notas de aula].

AUSUBEL, D.; NOVAK, J.; HANESIAN, H. Psicologia educacional. 2. ed. Rio de Janeiro: Interamericana, 1980.

AVELINO, V. F. MERUSA: metodologia de especificação de requisitos de usabilidade e segurança orientada para arquitetura. 2005. 277 p. Tese (Doutorado) Escola Politécnica, Universidade de São Paulo, São Paulo, 2005.

AVGERIOU, P. et al. Relating software requirements and architectures. Berlin: Springer, 2011.

AZUMA, M. Applying ISO / IEC 9126-1 quality model to quality requirements engineering on critical software. In: $3^{\text {rd }}$ IEEE Int. Workshop on Requirements for High 
Assurance Systems (RHAS). Proceedings...2004. Disponível em: < http://wpage.unina.it/paolo.melillo/tesi/Riferimenti\%20Normativi\%20e\%20Legislativi/A pplying\%20ISO_IEC\%209126-

1\%20Quality\%20Model\%20to\%20Quality\%20Requirements\%20engineering\%20on \%20critical\%20software.pdf >. Acesso em: 11 out. 2013.

BABAR, M. A.; ZHU, L.; JEFFERY, R. A framework for classifying and comparing software architecture evaluation methods. In: 2004 Australian Software Engineering Conference. Proceedings...IEEE, 2004.Disponível em:

$<$ http://ieeexplore.ieee.org/xpl/articleDetails.jsp?arnumber=1290484>. Acesso em: 4 abr. 2015.

BACHMANN, F. et al. Designing software architectures to achieve quality attribute requirements. IEE Proceedings - Software, v. 152, n. 4, p. 153, 2005.

BAGERT, D. et al. Guidelines for software engineering education. Pittsburgh: Software Engineering Institute, October 1999. (Technical Report CMU/SEI-99-TR032).

BARBACCI, M. R. et al. Quality attribute workshops. Pittsburgh: Software Engineering Institute, October 2003. (Technical Report CMU/SEI-2003-TR-016).

BARDRAM, J. E. et al. Exploring quality attributes using architectural prototyping. In: Lecture Notes in Computer Science (including subseries Lecture Notes in Artificial Intelligence and Lecture Notes in Bioinformatics). Proceedings... QoSA'05.Berlin: Springer, 2005. Disponível em: <http://dx.doi.org/10.1007/11558569_12> Acesso em: 30 jan. 2013.

BARONI, L. Algoritmos de navegação em tempo real para um sistema GPS de posicionamento relativo de precisão. 2009.125 p. Tese (Doutorado) - Instituto Nacional de Pesquisas Espaciais, São José dos Campos, 2009.

BARROS, B. M. DE. Tutorial de instalação do ambiente de desenvolvimento Java Petstore 2.0: material de apoio à disciplina PCS2420. São Paulo, 2008. [Notas de aula].

BARROWS, H. S. Problem-based learning in medicine and beyond: a brief overview. New Directions for Teaching and Learning, v. 1996, n. 68, p. 3-12, jan. 2006.

BASS, L.; CLEMENTS, P.; KAZMAN, R. Software architecture in practice. $3^{\text {rd }}$ ed. Boston: Addison-Wesley, 2012.

BECERRA, J. L. R. Aplicabilidade do padrão de processamento distribuído e aberto nos projetos de sistema abertos de automação. 1998. 176 p. Tese (Doutorado) - Escola Politécnica, Universidade de São Paulo, São Paulo, 2005.

BEVAN, N. Quality in use: meeting user needs for quality. Journal of Systems and Software, v. 49, n. 1, p. 89-96, 1999. 
BHATTI, S. N. Why quality ? ISO 9126 software quality metrics (functionality) support by UML suite. Software Engineering Notes, v. 30, n. 2, p. 1-5, 2005.

BLAKE, M. B. A student-enacted simulation approach to software engineering education. IEEE Transactions on Education, v. 46, n. 1, p. 124-132, fev. 2003.

$\mathrm{BOOCH}$, G. et al. Object-oriented analysis and design with applications. $3^{\text {rd }}$ ed. Boston: Addison-Wesley Professional, 2009.

BOOCH, G.; RUMBAUGH, J.; JACOBSON, I. The Unified Modeling Language User Guide. $2^{\text {nd }}$. ed. Boston: Pearson Education, 2005.

$\mathrm{BOSCH}$, J.; MOLIN, P. Software architecture design: evaluation and transformation. In: ECBS'99. IEEE Conference and Workshop on Engineering of Computer-Based Systems. Proceedings...Karlskrona: Psilander Grafiska, 1999. Disponível em: < http://www.computer.org/csdl/proceedings/ecbs/1999/0028/00/00280004.pdf>. Acesso em: 15 jan. 2013.

BOUD, D.; FELETTI, G. The Challenge of Problem-based Learning. London: Psychology Press, 1998.

BRITO, P. H. S. et al. Architectural-based validation of fault-tolerant software. In:Proceedings - $20094^{\text {th }}$ Latin-American Symposium on Dependable Computing, LADC 2009. Anais...Joao Pessoa: IEEE, 2009. Disponível em: <

http://ieeexplore.ieee.org/xpl/articleDetails.jsp?arnumber=5234313>. Acesso em: 18 fev. 2013.

BROY, M. Software quality: from requirements to architecture. In: WINKLER, D.; BIFFL, S.; BERGSMANN, J. (org.). Software Quality. Increasing Value in Software and Systems Development. Lecture Notes in Business Information Processing. Berlin: Springer, 2013. v. 133p. 1-2.

BUCCI, P.; LONG, T. J.; WEIDE, B. W. Teaching software architecture principles in CS1/CS2. In: $3^{\text {rd }}$. International Workshop on Software Architecture.

Proceedings....New York: ACM Press, 1998. Disponível em:

<http://doi.acm.org/10.1145/288408.288411>. Acesso em: 25 abr. 2015.

BUTTAZZO, G. C. Hard real-time computing systems: predictable scheduling algorithms and applications. New York: Springer, 2011.

CALLAHAN, D.; PEDIGO, B. Educating experienced IT professionals by addressing industry's needs. IEEE Software, v. 19, n. 5, p. 57-62, set. 2002.

CAMPOS, D. Psicologia da aprendizagem. Rio de Janeiro: Editora Vozes, 1986.

CAPILLA, R.; ALI BABAR, M.; PASTOR, O. Quality requirements engineering for systems and software architecting: methods, approaches, and tools. Requirements Engineering, v. 17, n. 4, p. 255-258, 2012.

CARVALHO, T. Introdução à Engenharia de Software. Campinas: Unicamp, 2001. 
CAVALCANTI, A. P. et al. An evaluation approach based on the problem-based learning in a software engineering master course. Journal of Technology

Management \& Innovation, v. 3, n. 2, p. 18-28, 2008.

CHAUDRON, M. Automated quality-driven optimization of software architecture (AQOSA) framework. Disponível em: <www.liacs.nl/ etemaadi/aqosa>. Acesso em: 10 jan. 2013.

CHUNG, G. K. W. K.; HARMON, T. C.; BAKER, E. L. The impact of a simulationbased learning design project on student learning. IEEE Transactions on Education, v. 44, n. 4, p. 390-398, nov. 2001.

CHUNG, L.; LEITE, J. P. On non-functional requirements in software engineering. In: Conceptual modeling: foundations and applications. Berlin: Springer, 2009. p. 363379 .

CHUNG, L.; NIXON, B. A.; YU, E. An approach to building quality into software architecture. In: 1995 Conference of the Centre for Advanced Studies on Collaborative Research. Proceedings...Toronto: IBM Press, 1995. Disponível em: <http://dl.acm.org/citation.cfm?id=781915.781928>. Acesso em: 10 jan. 2013.

CLASON, D. L.; DORMODY, T. J. Analyzing data measured by individual Likert-type items. Journal of Agricultural Education, v. 35, n. 4, p. 31-35, 1994.

CLEMENTS, P. et al. Documenting software architectures: views and beyond. $2^{\text {nd }}$ ed. Boston: Addison-Wesley, 2010.

CLEMENTS, P. et al. Exploiting software architecture to support requirements satisfaction testing. In: $19^{\text {th }}$ ACM SIGSOFT symposium and the $13^{\text {th }}$ European conference on Foundations of software engineering - SIGSOFT/FSE '11.

Proceedings...: ESEC/FSE '11.New York: ACM, 2011.Disponível em: <http://dl.acm.org/citation.cfm?id=2025113.2025198>. Acesso em: 14 mar. 2013.

CLEMENTS, P.; BASS, L. Business goals as architectural knowledge. In: Proceedings of the 2010 ICSE Workshop on Sharing and Reusing Architectural Knowledge SHARK 10. Proceedings...: New York, NY, USA: ACM, 2010. Disponível em: <http://portal.acm.org/citation.cfm?doid=1833335.1833337> Acesso em: 28 maio 2013.

CLEMENTS, P.; KAZMAN, R.; KLEIN, M. Evaluating Software architectures. Boston: Addison-Wesley, 2002.

COLLOFELLO, J. S. University/industry collaboration in developing a simulation based software project management training course. IEEE Transactions on Education, v. 43, n. 4, p. 389-393, 2000.

COMBLEY, R. Cambridge business English dictionary. Cambridge: Cambridge University Press, 2011. 
CÔRTES, M.; CHIOSSI, T. Modelos de qualidade de software. Campinas: Unicamp, 2001.

COUTINHO, C. H. et al. Developing a smart grids system as a PBL with agile method on computer engineering courses. In: $9^{\text {th }}$ International Conference on Information Technology, ITNG 2012. Proceedings...IEEE, 2012. Disponível em: $<$ http://ieeexplore.ieee.org/articleDetails.jsp?arnumber=6209173>. Acesso em: 15 abr. 2015.

CRONJÉ, J. Technology for education guidelines for technology-enhanced education at the University of Pretoria. Pretoria: University of Pretoria, 1997. (Technology Plan: Education for Technology).

CUGNASCA, P. S.; MELNIKOFF, S. S. S.; CAMARGO JR., J. B. Método de reestruturação curricular aplicado aos cursos de engenharia de computação da Escola Politécnica da USP. COBENGE 2014 - XLII Congresso Brasileiro de Educação em Engenharia, v. 1, p. 1-12, 2014.

CUNNINGHAN, D.; THOMAS, M.; KNUTH, R. The textbook of the future. Hypertext in a psychological perspective, 1993.

DEWAN, P.; RIEDL, J. Toward computer-supported concurrent software engineering. Computer, v. 26, n. 1, 1993.

DIAZ-PACE, J. A.; CAMPO, M. R. Exploring alternative software architecture designs: a planning perspective. IEEE Intelligent Systems, v. 23, n. 5, p. 66-77, 2008.

DICK, W. An instructional designer's view of constructivism. Constructivism and the technology of instruction: a conversation, v. 1, p. 41-44, 1992.

DOBRICA, L.; NIEMELÁ, E. A survey on software architecture analysis methods. IEEE Transactions on Software Engineering, v. 28, n. 7, p. 638-653, jul. 2002.

DOORNBOS, R.; LOO, S. Software Architecture. In: DOORNBOS, R.; VAN LOO, S. (org.). From scientific instrument to industrial machine. SpringerBriefs in Electrical and Computer Engineering. Dordrecht: Springer, 2012. p. 43-50.

DOS SANTOS, S. C.; FURTADO, F.; LINS, W. xPBL: A methodology for managing PBL when teaching computing. In: 2014 IEEE Frontiers in Education Conference (FIE) Proceedings. Proceedings...Madrid: IEEE, 2014. Disponível em: <http://ieeexplore.ieee.org/lpdocs/epic03/wrapper.htm?arnumber=7044178>. Acesso em: 15 abr. 2015.

DUFFY, T. M. et al. Designing environments for constructive learning. Berlin: Springer, 1993.

ELBERZHAGER, F. et al. Inspection and test process integration based on explicit test prioritization strategies. In: Software quality. process automation in software Development. Berlin: Springer, 2012. v. 94 p. 181-192. 
ESCOLA POLITÉCNICA DA USP. Grade Curricular: habilitação em Engenharia Elétrica - ênfase em Computação, 2013a. Disponível em:

$<$ https://uspdigital.usp.br/jupiterweb/listarGradeCurricular?codcg=3\&codcur=3031\&co dhab=1170\&tipo=N>. Acesso em: 23 mar. 2013.

ESCOLA POLITÉCNICA DA USP. Informações da disciplina: Laboratório de Engenharia de Software II (PCS2420), 2013b. Disponível em:

<https://uspdigital.usp.br/jupiterweb/obterDisciplina?sgldis=pcs2420\&nomdis=>. Acesso em: 23 mar. 2013.

ESCOLA POLITÉCNICA DA USP. Graduação - Modalidade Quadrimestral: normas e regulamentos, 2014. Disponível em:

<http://www.poli.usp.br/pt/ensino/graduacao/aluno/atendimento-ao-aluno/sobre-agraduacao-quadrimestral/normas-e-regulamentos.html>. Acesso em: 24 mar. 2015.

FAIRBANKS, G. H. Just enough software architecture: a risk-driven approach. Boulder: Marshall \& Brainerd, 2010.

FAROULT, S.; ROBSON, P. The art of SQL. Sebastopol: O'Reilly Media Inc., 2006.

FAVELA, J.; PEÑA-MORA, F. An experience in collaborative software engineering education. IEEE Software, v. 18, n. 2, p. 47-53, 2001.

FIGUEIREDO, R. M. DA C. et al. Teaching Software Quality in an Interdisciplinary Course of Engineering. In: $20107^{\text {th }}$ International Conference on the Quality of Information and Communications Technology. Proceedings...IEEE, 2010. Disponível em: <http://ieeexplore.ieee.org/lpdocs/epic03/wrapper.htm?arnumber=5654795>. Acesso em: 6 maio 2015.

FRANCH, X.; BOTELLA, P. Putting non-functional requirements into software architecture. In: $9^{\text {th }}$ International Workshop on Software Specification and Design. Proceedings...IEEE Computer Society, 1998. Disponível em:

<http://ieeexplore.ieee.org/xpls/abs_all.jsp?arnumber=667920' escapeXml='false'/>>. Acesso em: 24 fev. 2013.

FREEDMAN, A. M.; KAPLAN, H. I.; SADOCK, B. J. Compêndio de psiquiatria: ciências do comportamento e psiquiatria clínica. 7. ed. Porto Alegre: Artes Médicas, 1997.

GAGNÉ, R. M. Princípios essenciais da aprendizagem para o ensino. Porto Alegre: Editora Globo, 1980.

GAMMA, E. et al. Design patterns: elements of reusable object-oriented software. Boston: Addison-Wesley, 1994.

GARLAN, D. Software architecture. In: The future of Software engineering - ICSE '00. Proceedings....New York: ACM Press, 2000. Disponível em: <http://portal.acm.org/citation.cfm?doid=336512.336537>. Acesso em: 15 mar. 2013. 
GARTNER. IT Glossary: Internet of Things (loT), 2014. Disponível em: <http://blogs.gartner.com/it-glossary/internet-of-things/>. Acesso em: 12 mar. 2015.

GARTNER. About Gartner, 2015. Disponível em: <http://www.gartner.com/technology/about.jsp>. Acesso em: 12 mar. 2015.

GOLFARELLI, M.; RIZZI, S.; PROLI, A. Designing what-if analysis. In: $9^{\text {th }}$ ACM international workshop on Data warehousing and OLAP - DOLAP '06.

Proceedings...New York: ACM Press, 2006. Disponível em: $<$ http://portal.acm.org/citation.cfm?doid=1183512.1183523 >. Acesso em: 14 fev. 2015.

GORTON, I. Essential Software Architecture. 2. ed. Berlin: Springer, 2011.

GRUNDY, J.; HOSKING, J.; MUGRIDGE, W. B. Inconsistency management for multiple-view software development environments. IEEE Transactions on Software Engineering, v. 24, n. 11, p. 960-981, 1998.

GRUNSKE, L. Identifying "good" architectural design alternatives with multi-objective optimization strategies. In: International Conference on Software Engineering.

Proceedings... ICSE '06.New York: ACM, 2006. Disponível em:

<http://www.scopus.com/inward/record.url?eid=2-s2.0-

34247159635\&partnerID=tZOtx3y1>. Acesso em: 28 dez. 2014.

GUIMARÃES, J. H. N. O. Método para manutenção de sistema de software utilizando técnicas arquiteturais. 2008. 101 p. Dissertação (Mestrado) - Escola Politécnica, Universidade de São Paulo, São Paulo, 2008.

HANDFIELD, R. B. Effects of concurrent engineering on make-to-order products. IEEE Transactions on Engineering Management, v. 41, n. 4, p. 384-393, 1994.

HARRISON, N. B.; AVGERIOU, P. Leveraging architecture patterns to satisfy quality attributes. Lecture Notes in Computer Science, v. 4758, p. 263-270, 2007.

HILBURN, T. B.; HUMPHREY, W. S. Guest editor's introduction: the impending changes in software education. IEEE Software, v. 19, n. 5, p. 22-24, 2002.

HOFMEISTER, C.; NORD, R.; SONI, D. Applied Software Architecture. Boston: Addison-Wesley, 2000.

HRUSCHKA, P. Quality driven software architecture. In: BIFFL, S.; WINKLER, D.; BERGSMANN, J. (org.). Lecture Notes in Business Information Processing. Lecture Notes in Business Information Processing. Berlin: Springer, 2012. v. 94, p. $10-13$.

IEEE. IEEE Std 610.12-1990 - IEEE Standard Glossary of Software Engineering Terminology, v. 121990, n. 1, p. 1, 1990.

. IEEE Std 1061-1998 - IEEE Standard for a Software Quality Metrics

Methodology, p. i, 1998a. 
IEEE Std 830-1998 - IEEE Recommended Practice for Software Requirements Specifications, v. 1998, p. 40, 1998b.

IEEE Project: P2413 - Standard for an architectural framework for the Internet of Things (IoT), 2014. Disponível em:

<https://standards.ieee.org/develop/project/2413.html>. Acesso em: 8 nov. 2014.

IPT. Mestrado em Engenharia de Computação: disciplinas em engenharia de software, 2015. Disponível em:

<http://www.ipt.br/pos_graduacao_ipt/mestrados_profissionais/mestrado_em_engen haria_de_computacao-1/disciplinas_oferecidas/>. Acesso em: 5 mar. 2015.

ISO. ISO 9000:2005 - Quality management systems -- Fundamentals and vocabulary, p. 30, 2005.

ISO/IEC. ISO/IEC 14598-5:1998 - Information technology -- Software product evaluation -- Part 5: Process for evaluators, p. 35, 1998a.

ISO/IEC 10746-1:1998 - Information technology -- Open Distributed Processing -- Reference model: Overview, p. 76, 1998b.

ISO/IEC 10746-4:1998 - Information technology -- Open Distributed

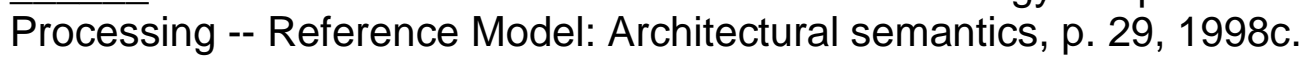

ISO/IEC 14598-1:1999 - Information technology -- Software product evaluation -- Part 1: General overview, 1999.

ISO/IEC 9126-1:2001 - Software engineering -- Product quality -- Part 1:

Quality model, p. 8, 2001.

ISO/IEC TR 9126-2:2003 - Software engineering -- Product quality -- Part 2:

External metrics, p. 86, 2003a.

ISO/IEC TR 9126-3:2003 - Software engineering -- Product quality -- Part 3: Internal metrics, p. 62, 2003b.

ISO/IEC TR 9126-4:2004 - Software engineering -- Product quality -- Part 4: Quality in use metrics, p. 59, 2004.

ISO/IEC 10746-2:2009 - Information technology -- Open distributed processing -- Reference model: Foundations, p. 22, 2009a.

ISO/IEC 10746-3:2009 - Information technology -- Open distributed processing -- Reference model: Architecture, 2009b.

ISO/IEC 25010:2011 - Systems and software engineering -- Systems and software Quality Requirements and Evaluation (SQuaRE) -- System and software quality models, p. 34, 2011. 
ISO/IEC 27002:2013 - Information technology -- Security techniques -- Code of practice for information security controls, p. 80, 2013.

ISO/IEC/IEEE. IEEE STD 12207-2008 - Standard for Systems and Software Engineering - Software Life Cycle Processes, p. 123, 2008.

. ISO/IEC/IEEE 24765:2010 - Systems and software engineering -Vocabulary, p. 410, 2010.

. ISO/IEC/IEEE 42010:2011 - Systems and software engineering -Architecture description, p. 46, 2011.

JACOBSON, I. et al. The essence of software engineering: the SEMAT kernel. Boston: Addison-Wesley, 2013.

JAZAYERI, M.; RAN, A.; LINDEN, F. VAN DER. Software architecture for product families: principles and practice. Boston: Addison-Wesley, 2000.

JONES, C.; BONSIGNOUR, O. The economics of software quality. Boston: Addison-Wesley, 2011.

KALATZIS, A. C. Aprendizagem baseada em problemas em uma plataforma de ensino a distância com o apoio dos estilos de aprendizagem: uma análise do aproveitamento dos estudantes de engenharia. 2008. 113 p. Dissertação (Mestrado) - Escola de Engenharia de São Carlos, Universidade de São Paulo, São Carlos, 2008.

KALMAR, R. et al. Effective Quality Assurance with Software Architecture Evaluation. ATZelektronik worldwide eMagazine, v. 6, n. 5, p. 22-25, 2011.

KAN, S. H. Metrics and models in software quality engineering. Boston: AddisonWesley Professional, 2002.

KAUR, K. et al. Static and dynamic complexity analysis of software metrics. World Academy of Science, Engineering and Technology, v. 56, 2009.

$\mathrm{KIM}, \mathrm{S}$. et al. A tactic-based approach to embodying non-functional requirements into software architectures. In: $12^{\text {th }}$ IEEE International Enterprise Distributed Object Computing Conference, EDOC 2008. Proceedings...IEEE, 2008. Disponível em: $<$ http://ieeexplore.ieee.org/lpdocs/epic03/wrapper.htm?arnumber=4634765>. Acesso em: 6 nov. 2012.

KOPER, R.; MANDERVELD, J. Educational modelling language: modelling reusable, interoperable, rich and personalised units of learning. British Journal of Educational Technology, v. 35, n. 5, p. 537-551, 2004.

KOPER, R.; VAN ES, R. Modelling units of learning from a pedagogical perspective. Online education using learning objects. New York: RoutledgeFalmer, 2004. p. 40-52, 2004. 
KRUCHTEN, P. The Rational Unified Process: an Introduction. $3^{\text {rd }}$ ed. Boston: Addison-Wesley, 2003.

LAGO, P.; VLIET, H. VAN. Teaching a course on software architecture. In: $18^{\text {th }}$ Conference on Software Engineering Education and Training, CSEE and T 2005. Proceedings...Ottawa: IEEE, 2005. Disponível em: < http://ieeexplore.ieee.org/xpls/abs_all.jsp?arnumber $=4698906 \&$ tag $=1>$. Acesso em: 2 ago. 2014.

LAPORTE, C. Y.; APRIL, A. Teaching software quality assurance in an undergraduate software engineering program. Software Quality Professional, v. 9, n. 3, p. 4-10, 2007.

LATTANZE, A. J. Architecting software intensive systems: a practitioner's guide. Boca Raton: CRC Press, 2008.

LIBÂNEO, J. C. Didática. 2. ed. São Paulo: Cortez, 1994.

LUCERO, S. Non-Anglo names confound U.S. social security. Disponível em: <http://catless.ncl.ac.uk/Risks/18.80.html>. Acesso em: 10 nov. 2012.

LUDESCHER, W. Modelo para avaliação da qualidade de projetos de planos de continuidade de negócios aplicados a sistemas computacionais. 2011. 275 p. Tese (Doutorado) - Escola Politécnica, Universidade de São Paulo, São Paulo, 2011.

MAGGI, L. As carreiras mais promissoras para os próximos dez anos. 2013. Disponível em: <http://veja.abril.com.br/noticia/educacao/as-quatro-carreiras-maispromissoras/>. Acesso em: 17 abr. 2015.

MALVEAU, R. C.; MOWBRAY, T. J. Software architect bootcamp. New Jersey: Prentice Hall, 2004.

MARINI FILHO, R. L. Aprendizagem baseada em problemas e o desenvolvimento de habilidades para a aprendizagem auto-dirigida. 2006. 163 p. Dissertação (Mestrado) - Setor de Educação, Universidade Federal do Paraná, Curitiba, 2006.

MATTSSON, M.; GRAHN, H.; MÅRTENSSON, F. Software Architecture Evaluation Methods for Performance, Maintainability, Testability, and Portability. In: $2^{\text {nd }}$ International Conference on the Quality of Software Architectures.

Proceedings...Vasteras: 2006. Disponível em: < http://www.bth.se/fou/forskinfo.nsf/0/3e821fbd7a66542cc1257169002ad63c/\$file/Mar tensson_lic.pdf >. Acesso em: 5 jul. 2013.

MCCASLIN, W. J.; LOWMAN, J. Mastering the techniques of teaching. $2^{\text {nd }}$ ed. San Francisco: Jossey-Bass Publishers, 1995.

MERRIAM-WEBSTER. Merriam-Webster's collegiate dictionary. Springfield: Merriam-Webster, Inc., 2003. 
MOREIRA, R. H. R. Programa Brasileiro da Qualidade e Produtividade em

Software - Artigos Ciclo 2011. Brasília: Ministério da Ciência e Tecnologia, 2012. Disponível em: <http://www.mct.gov.br/upd_blob/0222/222107.pdf>.

MULDER, M. C.; LIDTKE, D.; STOKES, G. E. Enterprise enhanced education: an information technology enabled extension of traditional learning environments. ACM SIGCSE Bulletin, v. 29, n. 1, p. 355-359, 1997.

NARAHARISETTY, P.; VANKA, S. Effectiveness of computer based management simulations - A case study. In: 2012 IEEE $4^{\text {th }}$. International Conference on Technology for Education, T4E 2012. Proceedings...IEEE, 2012. Disponível em: < http://ieeexplore.ieee.org/xpl/login.jsp?tp=\&arnumber=6305940\&url=http\%3A\%2F\%2 Fieeexplore.ieee.org\%2Fxpls\%2Fabs_all.jsp\%3Farnumber\%3D6305940>. Acesso em: 6 jan. 2014.

NASCIMENTO NETO, I. Roteiro de avaliação de arquitetura de software de um sistema escalonador de cargas batch de ambientes mainframe. 2012. $131 \mathrm{p}$. Dissertação (Mestrado Profissional) - Instituto de Pesquisas Tecnológicas do Estado de São Paulo, São Paulo, 2012.

NEUMANN, P. G. Computer related risks. New York: ACM Press/Addison-Wesley, 1995.

NOBRE, J. C. S. et al. Aprendizagem baseada em projeto (project-based learningPBL) aplicada a software embarcado e de tempo real. Anais do Simpósio

Brasileiro de Informática na Educação (SBIE), v. 1, n. 1, p. 258-267, 1 nov. 2006.

NORTHROP, L. Let's teach architecting high quality software. In:Software Engineering Education Conference. Proceedings...2006. Disponível em: < http://ieeexplore.ieee.org/xpl/login.jsp?tp=\&arnumber=1617323\&url=http\%3A\%2F\%2 Fieeexplore.ieee.org\%2Fxpls\%2Fabs_all.jsp\%3Farnumber\%3D1617323>. Acesso em: 26 set. 2014.

NUNES, E. R. Ensino de conceitos físicos no ensino médio e as contribuições dos objetos de aprendizagem. 2011. 300 p. Tese (Doutorado) - Faculdade de Educação, Universidade de São Paulo, São Paulo, 2011.

OBJECT MANAGEMENT GROUP. OMG Unified Modeling Language (Version 2.5), 2013. Disponível em: <http://www.omg.org/cgi-bin/doc?ptc/2013-09-05.pdf>. Acesso em: 12 mar. 2013.

OHLSSON, L.; JOHANSSON, C. Practice driven approach to software engineering education. IEEE Transactions on Education, v. 38, n. 3, p. 291-295, 1995.

OLIVEIRA, A.; RODRIGUES, R.; GARCIA, V. um mapeamento sistemático para problem based learning aplicado à ciência da computação. In: Anais do Workshop de Informática na Escola. Anais...Rio de Janeiro: Sociedade Brasileira de Computação - SBC, 2012. Disponível em: <http://www.brie.org/pub/index.php/wie/article/view/2127>. Acesso em: 09 abr. 2014. 
ORACLE. Java Pet Store 2.0, 2007. Disponível em: <http://www.oracle.com/technetwork/java/index-136650.html>. Acesso em: 23 fev. 2011.

PÁDUA, W. Using quality audits to assess software course projects. In: $22^{\text {nd }}$ Conference on Software Engineering Education and Training, CSEET 2009. Proceedings...IEEE, 2009. Disponível em:

$<$ http://ieeexplore.ieee.org/lpdocs/epic03/wrapper.htm?arnumber=4812692>. Acesso em: 13 jan. 2013.

PASTERNAK, T. Using trade-off analysis to uncover links between functional and non-functional requirements in use-case analysis. In: 2003 Symposium on Security and Privacy. Proceedings...IEEE Computer Society, 2003. Disponível em: <http://ieeexplore.ieee.org/lpdocs/epic03/wrapper.htm?arnumber=1245310 . Acesso em: 6 maio. 2015.

PAULA FILHO, W. P. Requirements for an educational software development process. In: $6^{\text {th }}$. Annual Conference on Innovation and Technology in Computer Science Education. Proceedings...New York: ACM, 2001. Disponível em: <http://dl.acm.org/citation.cfm?id=507758.377476>. Acesso em: 6 abr. 2015.

PAULISH, D. J.; BASS, L. Architecture-centric software project management: a practical guide. Boston: Addison-Wesley, 2001.

PERRENOUD, P. Construir as competências desde a escola. Porto Alegre: Artmed, 1999.

PERRY, D. E.; WOLF, A. L. Foundations for the study of software architecture. ACM SIGSOFT Software Engineering Notes, v. 17, n. 4, p. 40-52, 1992.

PETROSKI, H. Design Paradigms: case histories of error and judgment in engineering. Cambridge: Cambridge University Press, 1994.

PINNA, C. C. A. Um roteiro centrado em arquitetura para minimização de riscos e incertezas em projetos de software. 2004. 160 p. Dissertação (Mestrado) Escola Politécnica, Universidade de São Paulo, São Paulo, 2004.

POZO, J. Teorias cognitivas da aprendizagem. 3. ed. Porto Alegre: Artes Médicas, 1998.

PRASAD, G. V. R. J. S.; OJHA, A. Text, table and graph - which is faster and more accurate to understand? In: 2012 IEEE $4^{\text {th }}$. International Conference on Technology for Education, T4E 2012. Proceedings... Hyderabad: IEEE, 2012. Disponível em: < http://ieeexplore.ieee.org/xpl/login.jsp?tp=\&arnumber=6305953\&url=http\%3A\%2F\%2 Fieeexplore.ieee.org\%2Fxpls\%2Fabs_all.jsp\%3Farnumber\%3D6305953>. Acesso em: 18 nov. 2014.

PRESSMAN, R.; MAXIM, B. Software engineering: a practitioner's approach. $8^{\text {th }}$. ed. New York: McGraw-Hill, 2014. 
PUTNAM, J. R. Architecting with RM-ODP. Upper Saddle River: Prentice Hall, 2001.

QIN, Z.; XING, J.; ZHENG, X. Software architecture in advanced topics in science and technology in China. New York: Zhejiang University Press and Springer, 2008.

RAYMOND, K. Reference Model of Open Distributed Processing (RM-ODP): Introduction. In: Open Distributed Processing: experiences with distibuted environments. IFIP Advances in Information and Communication Technology. New York: Springer, 1995. p. 3-14.

REDDY, Y. V. R. et al. Guest Editor's Introduction: Computer Support for Concurrent Engineering. Computer, v. 26, n. 1, p. 12-16, 1 jan. 1993.

REIS, C. A. L. et al. Curso de residência em arquitetura de software: uma parceria UFPA, UNAMA e CESUPA com AmazonCorp, CTIC-UFPA e PRODEPA. 2011. Disponível em:

<http://www3.ufpa.br/webapsee/index.php?option=com_docman\&task=doc_downloa d\&gid=94\&ltemid=43\&lang=br>. Acesso em: 14 dez. 2014.

RIBEIRO, L. R. DE C. Aprendizagem Baseada em Problemas (PBL): uma experiência no ensino superior. São Carlos: EdUFSCar, 2008.

RIBEIRO, L. R. DE C. A aprendizagem baseada em problemas (PBL): uma implementação na educação em engenharia na voz do atores. 2005. 209 p. Tese (Doutorado) - Universidade Federal de São Carlos, São Carlos, 2005.

RIBEIRO, L. R. DE C. Radiografia de uma aula em engenharia. São Carlos: EdUFSCar, 2007.

RIBEIRO, L. R. DE C.; ESCRIVÃO FILHO, E. Aprendendo com PBL - aprendizagem baseada em problemas: relato de uma experiência em cursos de engenharia da EESC-USP. Revista Minerva-Pesquisa e Tecnologia, v. 6, n. 1, p. 23-30, 2009.

RICHARDSON, I.; DELANEY, Y. Problem based learning in the software engineering classroom. In: 22 ${ }^{\text {nd }}$. Conference on Software Engineering Education and Training, CSEET 2009. Proceedings...: CSEET '09.Washington, DC: IEEE Computer Society, 2009. Disponível em: <http://dx.doi.org/10.1109/CSEET.2009.34>. Acesso em: 10 nov. 2014.

ROCHA, C.; MALDONADO, C.; WEBER, C. Qualidade de software: teoria e prática. São Paulo: Prentice Hall, 2001.

ROSA, J. L. Psicologia e educação: o significado do aprender. 9. ed. Porto Alegre: EDIPUCRS, 2007.

ROSCA, D.; TEPFENHART, W.; MCDONALD, J. Software engineering education: following a moving target. In: $16^{\text {th }}$. Conference on Software Engineering Education and Training, 2003. (CSEE\&T 2003). Proceedings...Madrid: IEEE Computer 
Society, 2003. Disponível em:

<http://ieeexplore.ieee.org/xpls/abs_all.jsp?arnumber=1191370>. Acesso em: 11 jan. 2013.

SAATY, T. L. Método de análise hierárquica. São Paulo: Makron Books do Brasil Editora LTDA, 1991.

SANTORO, F.; BORGES, M.; SANTOS, N. Um framework para estudo de ambientes de suporte à aprendizagem cooperativa. Revista Brasileira de Informática na Educação, v. 4, n. 1, p. 51-68, 1999.

SANTOS, S. C. DOS et al. Applying PBL in software engineering education. In: $22^{\text {nd }}$. Conference on Software Engineering Education and Training, CSEET 2009.

Proceedings...IEEE, 2009. Disponível em:

<http://ieeexplore.ieee.org/articleDetails.jsp?arnumber=4812695>. Acesso em: 15 abr. 2015.

SAVIN-BADEN, M.; MAJOR, C. H. Foundations of problem-based learning. London: McGraw-Hill International, 2004.

SCHANK, R. C.; CLEARY, C. Engines for education. Hillsdale: Lawrence Erlbaum, 1995.

SCHMIDT, H. G. Foundations of problem-based learning: some explanatory notes. Medical education, v. 27, n. 5, p. 422-432, set. 1993.

SCHÖN, D. A. Educando o profissional reflexivo. Porto Alegre: Artmed, 2000.

SHAW, M. Software engineering education: a roadmap. In: Conference on The Future of Software Engineering. Proceedings...New York: ACM, 2000. Disponível em: <http://dl.acm.org/citation.cfm?id=336592>. Acesso em: 30 abr. 2014.

SHAW, M.; GARLAN, D. Software architecture: perspectives on an emerging discipline. Upper Saddle River: Prentice Hall, 1996.

SILVA, M. M. Proposta de um sistema para integração e desenvolvimento de projetos através de engenharia simultânea. 1996. 171 p. Dissertação (Mestrado) Escola Politécnica, Universidade de São Paulo, São Paulo, 1996.

SMOLANDER, K. What is included in software architecture? A case study in three software organizations. In: $9^{\text {th }}$. Annual IEEE International Conference and Workshop on the Engineering of Computer-Based Systems. Proceedings...: ECBS '02.Washington, DC: IEEE Computer Society, 2002. Disponível em: <http://dl.acm.org/citation.cfm?id=645303.648854>. Acesso em: 14 jun. 2014.

\section{SOFTWARE ENGINEERING INSTITUTE. Architecture Trade-off Analysis}

Method, 2003. Disponível em:

<http://www.sei.cmu.edu/architecture/tools/evaluate/atam.cfm>. Acesso em: 22 dez. 2012. 
SOMMERVILLE, I. Software Engineering. $9^{\text {th }}$ ed. Boston: Pearson Education, 2010.

BARBER, K.; HOLT, J. Software architecture correctness. IEEE Software, v. 18, n. 6, p. 64-65, 2001.

THE APACHE SOFTWARE FOUNDATION. Apache JMeter. 2013. Disponível em: $<$ http://jmeter.apache.org/>. Acesso em: 05 jan. 2014.

THOMAS, R. A practical experiment in teaching software engineering metrics. In: 1996 International Conference Software Engineering: Education and Practice.

Proceedings... Dunedin:IEEE, 1996. Acesso em: 01 fev. 2011.

TI SAFE. $1^{\text {a }}$ conferência latino-americana de segurança em SCADA, 2014.

Disponível em: <http://www.class2014.com.br/>. Acesso em: 30 jan. 2015.

VASCONCELLOS NETO, O. C. DE. Análise de disponibilidade em sistemas de software na web. 2009. 152 p. Dissertação (Mestrado em Sistemas Digitais) Escola Politécnica, Universidade de São Paulo, São Paulo, 2009.

VERKAMO, A. MAISA: metrics for analysis and improvement of software architectures. Disponível em: <http://www.cs.helsinki.fi/group/maisa/>. Acesso em: 2 jan. 2013.

VICHIDO, C.; ESTRADA, M.; SANCHEZ, A. A constructivist educational tool: software architecture for Web-based video games. In: $4^{\text {th. }}$ Mexican International Conference on Computer Science, 2003. ENC 2003. Proceedings... Tlaxcala: IEEE, 2003. Disponível em: < http://ieeexplore.ieee.org/xpl/articleDetails.jsp?arnumber=1232888>. Acesso em: 28 abr. 2011.

VOCKELL, E. L.; SCHWARTZ, E. The computer in the classroom. $3^{\text {rd }}$ ed. New York: McGraw-Hill, 1998.

WALEWSKI, J. W. Internet-of-Things architecture, 2013. Disponível em: <http://www.iot-a.eu/public/public-documents/d1.2>. Acesso em: 12 mar. 2013.

WILLIAMS, T. J. The Purdue enterprise reference architecture. In: Workshop on the Design of Information Infrastructure Systems for Manufacturing.

Proceedings...Amsterdam: North-Holland Publishing Co., 8 nov. 1993. Disponível em: <http://dl.acm.org/citation.cfm?id=647134.716786>. Acesso em: 14 mar. 2015.

WOHLIN, C. Software engineering research lab. Disponível em: <http://www.bth.se/com/serl>. Acesso em: 2 jan. 2013.

YEH, R. T. Educating future software engineers. IEEE Transactions on Education, v. 45 , n. 1, p. $2-3,2002$.

YIN, R. K. Estudo de caso: planejamento e métodos. 3. ed. Porto Alegre: Bookman, 2005. 
ZHANG, T. The Internet of Things promoting higher education revolution. In: $4^{\text {th }}$. International Conference on Multimedia and Security, MINES 2012. Proceedings... Nanjing: IEEE, 2012. Disponível em: <

http://ieeexplore.ieee.org/xpl/articleDetails.jsp?arnumber=6405813>. Acesso em: 20 mar. 2015.

ZHANG, Y. Project-driving and case teaching model in software engineering. In: DU, W. (org.). Informatics and Management Science II. Lecture Notes in Electrical Engineering. London: Springer, 2013. v. 205p. 145-151.

ZOWGHI, D.; COULIN, C. Requirements elicitation: A survey of techniques, approaches, and tools. In: Engineering and Managing Software Requirements. New York: Springer, 2005. p. 19-46. 


\section{APÊNDICE A - QUESTIONÁRIO UTILIZADO NO ROTEIRO DE ENSINO}

Neste Apêndice, reproduz-se o questionário de avaliação do roteiro proposto, o qual é respondido pelos alunos três vezes durante as disciplinas em que o roteiro proposto foi aplicado.

Durante o desenvolvimento desta tese, o roteiro foi aplicado dez vezes, sendo oito delas em disciplinas de graduação no curso de Engenharia Elétrica com ênfase em Computação e duas vezes em cursos de pós-graduação (modalidade Mestrado profissionalizante) em Engenharia de Computação, totalizando, portanto, 30 aplicações do questionário para uma população de 167 alunos, sendo 121 alunos de graduação (72,46\%) e 46 alunos de pós-graduação (27,54\%).

Antes de aplicar os questionários aos alunos, os conceitos questionados, a forma de responder e o objetivo da aplicação dos questionários eram bem explicados para o aluno. 
Disciplina: <Nome da Disciplina>

Aula:__ _ Data: DD/MM/AAAA

Questionário de Avaliação - №:

\begin{tabular}{|l|l|l|l|l|}
\hline \multirow{2}{*}{ Tópicos avaliados } & \multicolumn{4}{c|}{ Nível de Conhecimento } \\
\cline { 2 - 5 } & Fraco & Médio & Bom & Ótimo \\
\hline Medidas em geral & & & & \\
\hline Medidas de arquitetura de software & & & & \\
\hline Medidas Estáticas & & & & \\
\hline Medidas Dinâmicas & & & & \\
\hline $\begin{array}{l}\text { Utilidade das medidas para melhoria da } \\
\text { arquitetura de software }\end{array}$ & & & & \\
\hline Conceitos de qualidade & & & & \\
\hline Relação entre arquitetura de software e qualidade & & & & \\
\hline
\end{tabular}

Espaço para comentários:

Nome: 


\section{APÊNDICE B - RESULTADO DAS AVALIAÇÕES POR TURMA}

Neste Apêndice, são apresentados os gráficos contendo os resultados de cada turma na qual o roteiro foi aplicado. O roteiro para o ensino foi aplicado oito vezes em disciplinas de graduação, no período entre 2005 e 2014, para uma população de 121 alunos e duas vezes em disciplinas de pós-graduação ministradas no ano de 2013 para 46 alunos. A Tabela 24 apresenta a distribuição dos alunos ao longo dos anos, juntamente com o nome da disciplina na qual o roteiro foi aplicado.

Tabela 24 - Número de alunos que participaram do roteiro por turma no período entre 2007 e 2014

\begin{tabular}{|c|c|c|c|}
\hline Ano da turma & $\begin{array}{l}\text { Número de } \\
\text { Alunos }\end{array}$ & Nível & Disciplina \\
\hline 2007 & 18 & Graduação em Engenharia de Computação & $\begin{array}{l}\text { Laboratório de Engenharia de } \\
\text { Software II }\end{array}$ \\
\hline 2008 & 21 & Graduação em Engenharia de Computação & $\begin{array}{l}\text { Laboratório de Engenharia de } \\
\text { Software II }\end{array}$ \\
\hline 2009 & 18 & Graduação em Engenharia de Computação & $\begin{array}{l}\text { Laboratório de Engenharia de } \\
\text { Software II }\end{array}$ \\
\hline 2010 & 16 & Graduação em Engenharia de Computação & $\begin{array}{l}\text { Laboratório de Engenharia de } \\
\text { Software II }\end{array}$ \\
\hline 2011 & 8 & Graduação em Engenharia de Computação & $\begin{array}{l}\text { Laboratório de Engenharia de } \\
\text { Software II }\end{array}$ \\
\hline 2012 & 4 & Graduação em Engenharia de Computação & $\begin{array}{l}\text { Laboratório de Engenharia de } \\
\text { Software II }\end{array}$ \\
\hline 2013 & 17 & Graduação em Engenharia de Computação & $\begin{array}{l}\text { Laboratório de Engenharia de } \\
\text { Software II }\end{array}$ \\
\hline 2014 & 19 & Graduação em Engenharia de Computação & $\begin{array}{l}\text { Laboratório de Engenharia de } \\
\text { Software II }\end{array}$ \\
\hline 2013 - Turma 1 & 27 & $\begin{array}{l}\text { Pós-graduação em Engenharia de Computação } \\
\text { (Mestrado profissionalizante) }\end{array}$ & Arquitetura de Software \\
\hline 2013 - Turma 2 & 19 & $\begin{array}{l}\text { Pós-graduação em Engenharia de Computação } \\
\text { (Mestrado profissionalizante) }\end{array}$ & Arquitetura de Software \\
\hline Total & 167 & & \\
\hline
\end{tabular}

Fonte: Autor

Os gráficos com os resultados dos tópicos avaliados separados por turma estão presentes na raiz do CD que acompanha este trabalho, no arquivo Apendice B.pdf. 


\section{APÊNDICE C - TÓPICOS DAS DISCIPLINAS}

Este apêndice elenca os tópicos sugeridos na recomendação curricular elaborada em conjunto pela ACM e pelo IEEE (ACM/IEEE-CS JOINT TASK FORCE ON COMPUTING CURRICULA, 2004, 2013) nas disciplinas dos cursos de Engenharia de Computação e Ciência da Computação, listadas, respectivamente na Tabela 2 e na Tabela 3 , que abordam conceitos relacionados à arquitetura de software e à qualidade de arquitetura de software.

Também são listados os tópicos das disciplinas nos quais os princípios técnicos e pedagógicos do roteiro foram mapeados, tanto na aplicação do roteiro de ensino proposto neste trabalho em disciplina de graduação, descrito na Tabela 10, como em disciplinas de pós-graduação, conforme detalhado na Tabela 16. Por fim, descrevese as ementas das disciplinas nas quais o roteiro foi aplicado.

Seguem subsequentemente os tópicos das disciplinas do curso de Engenharia de Computação, conforme sugestão curricular elaborada em conjunto pela ACM e pelo IEEE (ACM/IEEE-CS JOINT TASK FORCE ON COMPUTING CURRICULA, 2004).

- Fundamentos de Programação

- História e visão geral;

- Paradigmas de programação;

- Construções de programação;

- Algoritmos e resolução de problemas;

- Estrutura de dados;

- Recursividade;

- Programação orientada a objetos;

- Programação concorrente e orientada a eventos;

- Uso de Application Program Interface (API).

- Engenharia de Sistemas de Computação

- História e visão geral;

- Ciclo de vida;

- Análise e elicitação de requisitos;

- Especificação de Requisitos funcionais e não funcionais;

- Projeto Arquitetural;

- Testes;

- Manutenção;

- Gerenciamento de projetos;

- Projeto concorrente de hardware/software; 
- Implementação de sistemas;

- Sistemas especialistas;

- Confiabilidade e tolerância a falhas.

- Engenharia de Software

- História e visão geral;

- Processos de software;

- Especificações e requisitos de software;

- Projeto de software / Arquitetura de software;

- Teste e validação de software;

- Evolução do software;

- Ferramentas e ambientes de software;

- Compiladores;

- Gerenciamento de projetos de software;

- Tolerância a falhas de software.

Os tópicos das disciplinas do curso de Ciência da Computação, conforme sugestão curricular elaborada em conjunto pela ACM e IEEE (ACM/IEEE-CS JOINT TASK FORCE ON COMPUTING CURRICULA, 2013) são listados a seguir:

- Linguagens de Programação

- Programação Orientada a Objetos;

- Programação Funcional;

- Programação defensiva e orientada a evento;

- Representação de programas;

- Compiladores;

- Geração de código;

- Sistemas de tempo de execução;

- Análise Estática;

- Construções de programação avançadas;

- Concorrência e Paralelismo;

- Semântica Formal;

- Lógica de programação.

- Fundamentos de Desenvolvimento de Software

- Algoritmos e projeto;

- Conceitos fundamentais de programação;

- Estruturas de dados fundamentais;

- Métodos de desenvolvimento de software.

- Ciência de Computação

- Introdução à Modelagem e simulação;

- Modelagem e Simulação;

- Processamento;

- Visualização Interativa;

- Dados, Informações e Conhecimento;

- Análise Numérica.

- Engenharia de Software

- Processos de Software;

- Gerenciamento de projetos de software;

- Ferramentas e ambientes; 
- Engenharia de requisitos;

- Projeto de software;

- Construção de software;

- Verificação e validação de software;

- Evolução de software;

- Confiabilidade de software;

- Métodos Formais.

Para contextualizar a aplicação do roteiro proposto em cursos de graduação, seguem os tópicos das disciplinas do curso de graduação em Engenharia Elétrica com ênfase em Computação da Escola Politécnica da Universidade de São Paulo (ESCOLA POLITÉCNICA DA USP, 2013a) que foram mapeadas com os princípios técnicos e pedagógicos do roteiro de ensino proposto, conforme descrito na Tabela 10:

- PNV2100 - Introdução à Engenharia

- Conceitos básicos em Engenharia;

- Introdução a métodos de projeto;

- Simulação de um pequeno projeto de Engenharia;

- Desenvolvimento de um projeto temático, compreendendo:

- Definição do problema e formação de alternativas de solução;

- Estabelecimento de critérios;

- Escolha e avaliação de soluções;

- Especificação da solução.

- Competição entre projetos de diferentes grupos e turmas

- Avaliação das competições e da disciplina como um todo;

- Visitas a empresas de Engenharia.

- PCS2419 - Laboratório de Engenharia de Software I

- Entendimento do sistema a ser desenvolvido;

- Apresentação de ferramenta Computer-Aided Software Engineering (CASE);

- Conceitos de controle de versão;

- Especificação dos requisitos de software;

- Desenvolvimento dos Modelos da Análise Orientada a Objetos:

- Modelo de casos de uso;

- Modelo de estrutural (diagrama de classes);

- Modelo dinâmico (diagrama de sequência e de estados);

- Protótipo da interface de usuário;

- Aplicação de uma técnica para revisão da Especificação de Requisitos;

- Desenvolvimento da arquitetura de software;

- Apresentação dos ambientes de desenvolvimento e seus componentes;

- Projeto do Banco de Dados;

- Implementação do sistema e do banco de dados;

- Testes do sistema;

- Elaboração do Plano de Aceitação;

- Processo de aceitação. 
- PCS2511 - Gerência, Qualidade e Tecnologia de Software

- Conceitos básicos de processo de software e de projeto de software;

- Gerência de projetos de software;

- Aspectos de planejamento e controle de projetos: escopo, prazos, custo, recursos humanos, comunicação, risco, contratação;

- Técnicas de estimativa de esforço de desenvolvimento;

- Conceitos de qualidade de produto e qualidade de processo;

- Modelos de qualidade;

- Modelos de maturidade;

- Trabalho de campo com empresas de software.

- MAC2166 - Introdução à Computação

- Breve história da computação;

- Noções de organização e funcionamento de computadores e programas;

- Conceitos de linguagens de programação:

- Entrada e saída;

- Comandos de atribuição, seleção e repetição;

- Expressões aritméticas, lógica e relacionais;

- Tipos de dados escalares e estruturados.

- Modularização de programas:

- Funções e procedimentos;

- Passagem de parâmetros;

- Escopo de identificadores.

- Prática de programação por meio de resolução de problemas, desenvolvimento de algoritmos, e teste e depuração de programas.

- MAC2301 - Laboratório de Programação

- Ambientes de programação;

- Ferramentas de desenvolvimento;

- Análise e técnicas de algoritmos;

- Estruturas de dados básicos;

- Tipos abstratos de dados.

- PCS2302 - Laboratório de Fundamentos de Engenharia de Computação

- Experimentos tratando dos seguintes assuntos:

- Autômatos;

- Gramáticas;

- Localização de padrões em textos;

- Formatadores;

- Dicionários;

- Expansores de macros;

- Editores de texto; Montadores (absolutos e relocáveis);

- Ligadores;

- Relocadores;

- Emuladores;

- Bibliotecas matemáticas.

- Uso dos mecanismos de abstração do paradigma orientado a objetos nos experimentos:

- Encapsulamento (conceito de tipos de objetos);

- Generalização e especialização (herança e polimorfismo).

- Padrão de documentação do código-fonte;

- Projeto e execução de plano de testes. 
- PCS2309 - Engenharia de Software I

- Sistemas automatizados: histórico e conceitos de Engenharia de Software;

- Problemas no desenvolvimento de software;

- Equipe de Projeto e usuários;

- Modelos de ciclos de vida de desenvolvimento de sistemas;

- Ferramentas da Análise Estruturada:

- Diagrama Entidade-Relacionamento;

- Dicionário de Dados;

- Diagrama de Fluxo de Dados;

- Diagramas de Transição de Estados.

- Modelo essencial e seus componentes;

- Ferramentas Orientadas a Objetos:

- Modelo de casos de uso;

- Modelo de classes;

- Modelo dinâmico;

- Projeto:

Diagramas UML.

○ Conceitos;

- Projeto estruturado;

- Projeto de interface homem-computador;

- Projeto de dados;

- Projeto orientado a objetos.

- Testes de sistemas;

- Manutenção de sistemas de software.

- PCS2401 - Modelagem e Simulação de Sistemas Computacionais

- Conceitos e classificação de modelos: modelagem discreta e contínua;

- Metodologia de análise de desempenho;

- Métricas de desempenho;

- Modelos de sistemas de eventos discretos;

- Modelagem por simulação de eventos discretos;

- Estrutura e componentes de simuladores de eventos discretos;

- Ferramentas de simulação;

- Análise estatística de dados de entrada, geração de números aleatórios, validação do simulador e análise estatística dos resultados da simulação;

- Modelagem através de redes de Petri temporizadas;

- Modelagem e análise de desempenho através de modelos analíticos de redes de filas;

- Análise de filas simples;

- Redes de filas abertas e fechadas;

- Leis Operacionais:

- Algoritmo do valor médio;

- Algoritmo de convolução;

- Análise por decomposição hierárquica;

- Estudos de casos: sistemas de computação e sistemas de comunicação de dados.

- PCS2410 - Engenharia de Software II

- Histórico sobre bancos de dados;

- Conceitos e terminologia; 
- Modelo Entidade Relacionamento;

- Diagrama Entidade Relacionamento;

- Modelo Integration DEFinition for Information Modeling (IDEF1X);

- Conceito de chaves;

- Modelo relacional;

- Transformação de modelos lógicos em tabelas;

- Dependências Funcionais;

- Normalização;

- Linguagens de acesso e manipulação de um BD: álgebra relacional e SQL;

- Conceitos básicos sobre Bancos de Dados Orientados a Objetos;

- Restrições de Integridade;

- Meios físicos de armazenamento;

- Indexação;

- Processamento de consultas;

- Conceito de transações em bases de dados;

- Recuperação de paradas e falhas;

- Bases de dados distribuídas;

- Controle de acessos concorrentes;

- Segurança de dados;

- Conceitos básicos de data warehouse e data mining.

- PCS2419 - Laboratório de Engenharia de Software I

- Entendimento do sistema a ser desenvolvido;

- Apresentação da ferramenta CASE;

- Conceitos de controle de versão;

- Especificação dos requisitos de software;

- Desenvolvimento dos modelos da Análise Orientada a Objetos

- Modelo de casos de uso

- Modelo de estrutural (diagrama de classes),

- Modelo dinâmico (diagrama de sequência e de estados), com apoio de ferramentas CASE;

- Protótipo da interface de usuário;

- Aplicação de uma técnica para revisão da Especificação de Requisitos;

- Desenvolvimento da arquitetura de software;

- Apresentação dos ambientes de desenvolvimento e seus componentes;

- Projeto do Banco de Dados;

- Implementação do sistema e do banco de dados, utilizando linguagens adequadas;

- Testes do sistema;

- Elaboração do Plano de Aceitação;

- Processo de aceitação.

- PCS2420 - Laboratório de Engenharia de Software II

- Conceitos sobre componentes e objetos distribuídos;

- Padrão de arquitetura OMA/CORBA;

- Conceito de Web Service;

- Utilização do processo unificado;

- Desenvolvimento de um único sistema, baseado na integração de componentes;

- Organização das equipes para o desenvolvimento paralelo;

- Casos de uso; 
- Modelo de Classes e relacionamentos; classes de interface, armazenamento e controle;

- Modelagem da parte dinâmica;

- Projeto

- Detalhamento do modelo de análise;

- Mapeamento em bancos de dados.

- Elaboração e revisão do plano de aceitação;

- Tratamento de erros;

- Processo de aceitação.

- PCS2430 - Requisitos de Sistemas Computacionais

- Conceitos de confiabilidade, disponibilidade, manutenabilidade, testabilidade, segurança e dependabilidade;

- Estudo de defeito, erro e falha;

- Falhas de Modo Comum, entre elas a Compatibilidade Eletromagnética em Sistemas Computacionais;

- Conceito de Computação Tolerante a Defeito;

- Técnicas de Projeto para Alcançar Tolerância a Defeitos: redundância de hardware, de software, de informação e temporal;

- Conceito de Taxa de Falhas, Função Confiabilidade, Tempo Médio entre Falhas, Tempo Médio para Falhar e Tempo Médio para Reparo;

- Técnicas de Avaliação de Sistemas Tolerantes a Defeitos

- Análise de Modos de Falhas e Efeitos;

- Análise por Árvores de Falhas

- Análise de Sistemas através de Modelos Combinatórios de Markov;

- Conceitos de confiabilidade e segurança de software.

- PCS2453 - Sistemas Operacionais

- Conceitos básicos;

- Administração de recursos;

- Entrada e saída;

- Multiprogramação;

- Administração de memória;

- Memória real e virtual;

- Alocação particionada, paginada, segmentada;

- Virtualização de memória;

- Administração de processos;

- Job scheduling;

- Process scheduling;

- Sincronização e comunicação;

- Deadlock;

- Administração de dispositivos;

- Dispositivosde entrada e saída e de armazenamento;

- Spooling;

- Administração de informação;

- Sistemas de arquivos e diretórios;

- Métodos de acesso e proteção de acesso;

- Compartilhamento;

- Interfaces com o usuário e com os programas;

- Tópicos de projeto: Modelagem de sistemas; 
- Simulação. Técnicas de simulação: determinística, estatística, dirigida por eventos;

- Simulação de schedulers.

- PCS2582 - Segurança da Informação

- Definição de serviços de segurança da informação;

- Modelos de segurança:

- Sistemas de comunicação Sistemas de processamento de dados;

- Política de segurança:

- Tipos de políticas;

- Papel da confiança;

- Tipos de controle de acesso;

- Exemplos de políticas.

- Caracterização da segurança como um processo e não como um produto;

- Ciclo contínuo de uma política de segurança:

- Análise de risco;

- Requisitos de segurança;

- Definição da política;

- Implantação da política;

- Acompanhamento e auditoria.

- Mecanismos criptográficos de segurança:

- Criptografia e sua evolução histórica;

- Mecanismos de substituição e transposição;

- Cifra de Vigenère;

- One-Time-Pad;

- Internet-RC4.

- Criptografia de chaves públicas: seu uso em certificação Digital;

- ICP-Brasil;

- Mecanismo de autenticação:

- Senhas e segredos;

- Tokens e cartões;

- Biometria.

- Vírus e sistemas antivírus;

- Sistemas de detecção de intrusão;

- Arquitetura de sistemas de Firewall;

- Redes Privadas Virtuais.

- PCS2511 - Gerência, Qualidade e Tecnologia de Software

- Conceitos básicos de processo de software e de projeto de software;

- Gerência de projetos de software;

- Aspectos de planejamento e controle de projetos: escopo, prazos, custo, recursos humanos, comunicação, risco, contratação;

- Técnicas de estimativa de esforço de desenvolvimento;

- Conceitos de qualidade de produtro e qualidade de processo;

- Modelos de qualidade;

- Modelos de maturidade.

- PCS2554 - Engenharia de Informação

- Sistemas de informação;

- Sistemas distribuídos de informação;

- Engenharia simultânea;

- Interface homem-máquina; 
- Computação corporativa;

- Sistemas de workflow e automação de negócio;

- Sistemas de suporte à decisão;

- Sistemas de chão de fábrica.

Para contextualizar a aplicação do roteiro proposto em cursos de pósgraduação, seguem os tópicos das disciplinas do curso de pós-graduação (Mestrado profissionalizante) em Engenharia de Computação do Instituto de Pesquisas Tecnológicas (IPT, 2015) que foram mapeadas com os princípios técnicos e pedagógicos do roteiro de ensino proposto, conforme descrito na Tabela 16:

- Arquitetura de Software

- Conceitos básicos de arquitetura de software;

- Relação entre arquitetura de software e qualidade de software;

- Requisitos funcionais e não funcionais;

- Arquitetura de software e o processo de negócio;

- Visões arquiteturais;

- Processo de definição de arquitetura de software;

- Descrição de arquitetura de software;

- Métodos de avaliação de arquitetura de software;

- Padrões arquiteturais;

- Transformação e modernização de arquiteturas de software;

- Modelos de arquiteturas corporativas.

- Arquitetura orientada a serviços

- Conceitos de web services e Extensible Markup Language (XML);

- Histórico comparativos das arquiteturas até o surgimento da arquitetura orientada a serviço;

- Princípios de orientação a serviços;

- Etapas típicas para a adoção de uma arquitetura orientada a serviço;

- Exemplos de implementações de arquiteturas orientadas a serviço;

- Desenvolvimento de projeto de arquitetura orientada a serviço com web services;

- Banco de Dados

- Requisitos e arquitetura de um sistema de banco de dados;

- Metodologia de projeto de banco de dados;

- Modelagens conceitual, relacional, orientada a objetos e objetorelacional;

- Normalização e desnormalização;

- Engenharia reversa de banco de dados;

- Linguagens de acesso e manipulação de dados;

- Processamento de consultas;

- Transações e controle de integridade;

- Introdução a datawarehouse, modelagem e operações;

- Qualidade de dados.

- Engenharia de Requisitos de Software

- Principais aspectos da engenharia de requisitos centrados na visão do produto de software; 
- Problemas e soluções para a gestão dos requisitos com a Engenharia de Software;

- Principais técnicas para a elicitação e análise dos requisitos de software

- Critérios para a elaboração da especificação de requisitos de software; Estratégias para o rastreamento de requisitos de software do ponto de vista da gestão de requisitos.

- Gestão de Projetos de Tecnologias da Informação e Comunicação

- Introdução a segurança da informação;

- Níveis de classificação da informação;

- Segurança da informação;

- Organização do Security Office;

- Política de segurança; COBIT;

- ISO/IEC 17799:2005 - Information technology -- Security techniques -Code of practice for information security management

- Equipe de resposta a incidentes;

- Investigação forense;

- Plano de contingência;

- Análise de risco em ambientes de TI;

- Auditoria de sistemas.

- Interação Humano - Computador e Usabilidade

- Aspectos psicofisiológicos da interação humano-computador;

- Diálogo humano-computador;

- Usabilidade e ciclo de vida;

- Perfil de usuário;

- Análise de tarefas do usuário;

- Apresentação do instrumento de coleta de perfil;

- Heurísticas de projeto de interfaces;

- Heurísticas para web;

- Modelo conceitual e prototipação;

- Apresentação do protótipo;

- Avaliação de usabilidade;

- Experimento - interação humano-computador;

- Apresentação dos trabalhos de inspeção heurística.

- Processos de Desenvolvimento de Software com ênfase em Unified Process (UP) e Métodos Ágeis

- Desafios da Engenharia de Software;

- Evolução histórica das Metodologias de Desenvolvimento;

- O Processo Unificado (UP);

- O UP e a UML;

- Fundamentos e fases do UP;

- Principais papeis, artefatos e disciplinas no UP

- Laboratório de UP;

- Adaptação e extensão do UP: OpenUP;

- O Manifesto Ágil;

- Princípios e Valores;

- Fases do Processo Ágil;

- A Programação Extrema, do inglês, Extreme programming (XP);

- Práticas do XP;

- Laboratório da Programação Extrema;

- Adaptação e extensão do XP. 
- Qualidade e melhoria do processo de geração de software

- Conceitos sobre qualidade;

- Desenvolvimento, Manutenção, Gerenciamento;

- Gerência de requisitos;

- Garantia de qualidade e Gerência de configuração de software;

- Verificação e Validação: Inspeções de software e Testes;

- ISO/IEC 9001, ISO/IEC 9000-3 e ISO/IEC 9126;

- ISO/IEC 12207 e ISO/IEC 15504;

- CMMI;

- Melhoria de Processos do Software Brasileiro (MPS-BR);

- IEEE Std 1062 - Aquisição de software;

- CMMI - Aquisition.

- Sistemas Web

- Histórico e as características da internet e da web;

- Sistemas web e seus componentes típicos;

- Aspectos de engenharia de software relacionados a sistemas web;

- Segurança e personalização de sistemas web;

- Projeto e a implementação de um sistema de e-commerce.

- Tecnologias de Informação e Organizações

- Modelo das cinco forças de Michael Porter;

- Modelos de Planejamento de Negócios (Business Plan);

- Evolução histórica da tecnologia da informação, estado da arte e tendências futuras;

- Criação e renovação de vantagens competitivas;

- Tl e estratégias de negócios: exemplos;

- Internet e comércio eletrônico;

- Sistemas de produção e cadeia logística: exemplos;

- Segurança, fraude privacidade;

- Uso de modelos matemáticos para solução de problemas de gestão.

- Testes de Software

- Princípios de Testes de software, limitações, conceitos básicos e Terminologia;

- Técnicas de projeto de casos de teste;

- Teste funcional;

- Teste estrutural;

- Teste estáticos e dinâmicos;

- Planejamento da atividade de testes;

- Automação das atividades de testes;

- Testes em software orientado a objetos;

- Testes em software para internet;

- Ferramentas de suporte aos Testes de software.

- Tópicos Especiais da Engenharia de Requisitos de Software

- Especificações e representações de requisitos de software: linguagem natural, notações diagramáticas e especificações formais;

- Orientação a metas na engenharia de requisitos: tipos de metas e comparação com alguns enfoques usuais;

- Modelagem de metas e análise de riscos em modelos de metas;

- Análise semiformal de requisitos;

- Introdução à modelagem conceitual de requisitos; 
- Conhecimento do domínio da aplicação e ontologias para domínios específicos: análise de domínio e análise de requisitos de software;

- Classificação e decomposição de problemas: padrões e reuso de requisitos;

- Requisitos de software e restrições arquiteturais.

Segue o conteúdo da ementa da disciplina Laboratório de Engenharia de Software II do curso de graduação em Engenharia Elétrica com ênfase em Computação oferecido pela Escola Politécnica da Universidade de São Paulo (ESCOLA POLITÉCNICA DA USP, 2013b). O roteiro de ensino proposto foi aplicado nessa disciplina no período de 2007 a 2014.

Objetivos: Os alunos aprendem a organizar e controlar as atividades de um projeto para obter um único sistema integrado. Este processo de desenvolvimento está baseado em uma arquitetura que permita o exercício de conceitos avançados de Engenharia de Software: gestão, paralelismo, integração entre equipes e desenvolvimento usando componentes.

\section{Programa Resumido}

Conceitos sobre componentes e objetos distribuídos. Padrão de arquitetura OMA/CORBA. Conceito de web service. Utilização do processo unificado. Desenvolvimento de um único sistema, baseado na integração de componentes. Organização das equipes para o desenvolvimento paralelo. Casos de uso. Modelo de Classes e relacionamentos; classes de interface, armazenamento e controle. Modelagem da parte dinâmica. Projeto: detalhamento do modelo de análise, mapeamento em bancos de dados. Elaboração e revisão do plano de aceitação. Tratamento de erros. Processo de aceitação.

Segue o conteúdo da ementa da disciplina Arquitetura de Software do curso de pós-graduação (Mestrado profissionalizante) em Engenharia de Computação oferecido pelo Instituto de Pesquisas Tecnológicas (ARAKAKI, 2013). O roteiro proposto foi aplicado nessa disciplina no ano de 2013:

\section{Etapas da disciplina}

- Etapa 1 - Revisão de Conceitos

- Etapa 2 - Estabelecer as Metas dos Projetos

- Etapa 3 - Avaliação e Diagnóstico da Arquitetura do Sistema X

- Etapa 4 - Planejamento do Projeto e Estabelecimento dos Artigos Técnicos 
- Etapa 5 - Implementação

- Etapa 6 - Apresentação dos Resultados e do artigo

\section{Resultados por Etapa}

- Etapa 1 - Revisão de Conceitos

- Identificação dos Conceitos de Engenharia de Software;

- Identificação de Conceitos de Arquitetura de Software;

- Alinhamento de Conceitos e Terminologia.

\section{- Etapa 2 - Estabelecer as Metas dos Projetos}

- Meta 1 - Estudos: Arquitetura de software, tecnologia e métodos;

- Meta 2 - Projeto: Manutenção corretiva e/ou evolutiva;

- Meta 3 - Projeto: Avaliação arquitetural (ATAM);

- Temas:

- Web 2.0;

- AJAX - Usabilidade;

- Internet Transacional (Bancos, comercio, treinamento) Usabilidade;

- Internet Transacional (Bancos, comercio, treinamento) Mobilidade;

- Medição Arquitetural;

- Monitoração Arquitetural;

- Mecanismos de Monitoração

- Etapa 3 - Avaliação e Diagnóstico da Arquitetura de Software de sistema real

- Diagnóstico - Visão Enterprise;

- Diagnóstico - Visão Information;

- Diagnóstico - Visão Computation;

- Diagnóstico - Visão Engineering;

- Diagnóstico - Visão Technology.

- Consolidação do Diagnóstico

- Etapa 4 - Planejamento do Projeto e Estabelecimento dos Artigos

\section{Técnicos}

- Com base na etapa 2;

- Equipes: 2 a 3 alunos;

- Estrutura do artigo;

- IEEE (América Latina): de 9 a 12 páginas.

- Etapa 5 - Implementação e Apresentação dos Resultados

- Especificação de requisitos;

- Especificação de projeto (infraestrutura e componentes);

- Execução; 
- Testes e medições;

- Coleta e análise dos dados;

- Apresentação do escopo planejado;

- Apresentação dos resultados obtidos;

- Discussão do conhecimento assimilado.

- Etapa 6 - Publicação dos Artigos

- Base conceitual - referências bibliográficas;

- Contribuição dos autores;

- Plano de publicação.

A Tabela 25 detalha o conteúdo ministrado em cada aula da disciplina Arquitetura de Software, de acordo com as etapas supracitadas:

Tabela 25 - Ementa da disciplina Arquitetura de Software do curso de pós-graduação (Mestrado profissionalizante) em Engenharia de Computação oferecido pelo

\begin{tabular}{|c|c|c|c|}
\hline Etapa & Aula & $\begin{array}{r}\text { Atividades } \\
\end{array}$ & Conceitos/Resultados \\
\hline Etapa 1 & 1 & $\begin{array}{l}\text { - Conceitos de ESW } \\
\text { - Conceitos de Arquitetura } \\
\text { - Terminologia }\end{array}$ & $\begin{array}{l}\text { Alinhamento de Terminologia, } \\
\text { Normas e Modelos de arquitetura. }\end{array}$ \\
\hline \multirow{2}{*}{ Etapa 2} & 1 & $\begin{array}{l}\text { - Estabelecer metas do trabalho: estudo, manutenção ou } \\
\text { avaliação arquitetural; }\end{array}$ & $\begin{array}{l}\text { Identificação das Metas } \\
\text { Arquiteturais, caracterizadas por } \\
\text { atributos de qualidade. }\end{array}$ \\
\hline & 2 & $\begin{array}{l}\text { - Estrutura de um Artigo } \\
\text { - Requisitos Preliminares de Manutenção Corretiva } \\
\text { - Requisitos Preliminares de Manutenção Evolutiva }\end{array}$ & \multirow{2}{*}{$\begin{array}{l}\text { Ciclo de negócio da arquitetura de } \\
\text { software (ABC - Architectural } \\
\text { Business Cycle); } \\
\text { Documentação de arquitetura (1/2): } \\
\text { Como considerar as visões, } \\
\text { stakeholders e a utilidade dos } \\
\text { documentos? }\end{array}$} \\
\hline \multirow{2}{*}{ Etapa 3} & 2 & $\begin{array}{l}\text { - Metodologia para o Diagnóstico da Arquitetura } \\
\text { - Roteiro para o Diagnostico } \\
\text { - Organização dos projetos e equipes. }\end{array}$ & \\
\hline & 3 & $\begin{array}{l}\text { - Preparação dos Itens } \\
\text { - Coleta das Informações (documentos e sistemas) pelas } \\
\text { equipes } \\
\text { - Estruturação do Artigo }\end{array}$ & $\begin{array}{l}\text { Criação de Arquitetura: Metas de } \\
\text { qualidade, táticas arquiteturais, } \\
\text { mecanismos. }\end{array}$ \\
\hline Etapa 4 & 4 & $\begin{array}{l}\text { - Estruturação do artigo. } \\
\text { - Referências: RM-ODP, 4+1; IEEE } 1471 .\end{array}$ & $\begin{array}{l}\text { Avaliação de Arquitetura ATAM (1/2) } \\
\text { Aplicação da avaliação na criação } \\
\text { de arquitetura. }\end{array}$ \\
\hline \multirow{6}{*}{ Etapa 5} & 5 & $\begin{array}{l}\text { - Modelagem e Especificação de Projetos; } \\
\text { - Validação da Estrutura do Artigo; } \\
\text { - Entrega Crítica: Estrutura do artigo que será produzido em } \\
\text { itens e tópicos que demonstrem o conteúdo do artigo; } \\
\text { - Modelo de artigo para IEEE - América Latina. }\end{array}$ & Apresentação 1 \\
\hline & 6 & $\diamond$ Detalhamento do Plano de Implementação. & $\begin{array}{l}\text { Documentação arquitetural (2/2): } \\
\text { Estrutura, elaboração, notação e } \\
\text { normas; }\end{array}$ \\
\hline & 7 & $\diamond$ Execução/Medição e escrita do artigo; & Projeto arquitetural - táticas: \\
\hline & 8 & $\diamond$ Execução/Medição e escrita do artigo & Projeto arquitetural - patterns: \\
\hline & 9 & $\diamond$ Execução/Medição e escrita do artigo & Avaliação de arquitetura ATAM \\
\hline & 10 & $\diamond$ Execução/Medição e escrita do artigo (Plantão Dúvidas) & $\begin{array}{l}\text { Avaliação de arquitetura do projeto } \\
\text { da disciplina. }\end{array}$ \\
\hline \multirow{3}{*}{ Etapa 6} & 11 & $\diamond$ Apresentação do Resultados Obtidos & Apresentação 1/2 \\
\hline & 12 & $\diamond$ Elaboração do texto do artigo & $\begin{array}{l}\text { Apresentação 2/2 } \\
\text { Rescaldo da Disciplina }\end{array}$ \\
\hline & 13 & $\diamond$ Entrega do Artigo (Entrega na Secretaria) & Entrega Final \\
\hline
\end{tabular}

Fonte: adaptado de Arakaki (2013) 


\section{APÊNDICE D - TECNOLOGIAS E FERRMAENTAS UTILIZADAS}

Neste apêndice reproduzem-se as principais tecnologias e ferramentas utilizadas durante a aplicação do roteiro para o ensino/aprendizagem de qualidade de arquitetura de software:

- Plataforma Java

- Java 2 Standard Edition 1.4.2;

- Java 2 Standard Edition 1.5.0;

- Java 2 Standard Edition 1.6.0.

- Ferramentas de modelagem

- Astah Professional 6.6.3;

- Microsoft Office Visio 2007;

- Microsoft Office Visio 2010.

- Ferramentas de desenvolvimento

- Eclipse IDE for Java EE Developers;

- NetBeans 4.0;

- NetBeans 5.0;

- NetBeans 6.0;

- Subversion;

- Ant.

- Frameworks para desenvolvimento Web

- Django;

- Rails para a linguagem Ruby.

- Ferramentas de suporte ao desenvolvimento (plug-ins)

- Sun Java System Application Server 8 (J2EE Support).

- Web Servers

- Tomcat 6.0.37;

- Tomcat 7.0.37.

- Application Servers

- Java System Application Server Platform Edition 8;

- Glassfish 2.1. 
- Sistemas de gerenciamento de bancos de dados

- MySQL 5.1;

- Java Hibernate;

- Java Persistence API.

- Microcomputadores

- BeagleBone Black;

- Raspberry PI model B;

- Microcontroladores

- Arduino Uno.

- Sensores

- Sensor de fumaça e gás inflamável MQ2;

- Sensor de temperatura BMP180;

- Sensor de temperatura LM35;

- Sensor de temperatura e umidade DHT22;

- Sensor de qualidade do ar MQ5;

- Sensor de movimento PIR SE-10.

\section{- Componentes}

- Módulo Bluetooth 2.0 HC-05;

- Módulo leitor RFID ID12-LA;

- Módulo GPS BU-353 GPS Receiver,

- Módulo GPS Ultimate GPS Breakout;

- Módulo Wi-fi TP-Link TL-WN723N ver. 3.0;

- Módulo 3G com Chip GSM;

- Módulo Acelerômetro MMAB 152;

- Módulo de criptografia AES 128 bits XBEE 4214A;

- Protoboard para integração dos componentes.

Durante a aplicação do roteiro, foi produzido um tutorial para instalação do ambiente de desenvolvimento do sistema Java Pet Store de autoria de Barros (2008), com o objetivo de auxiliar os alunos que participaram da aplicação do roteiro em disciplinas de graduação nas quais o sistema Java Pet Store foi utilizado. Esse tutorial está disponível na raiz do CD que acompanha este trabalho, no arquivo Apendice D.pdf. 
Para os casos que a instalação não fosse bem sucedida, mesmo após várias tentativas do aluno e auxílio dos monitores, como mecanismo de contingencia foi criada uma máquina virtual Linux com o ambiente desenvolvimento configurado. 


\section{APÊNDICE E - TRABALHO DOS ALUNOS}

Neste apêndice, é apresentada uma pequena parte dos trabalhos desenvolvidos por alunos que participaram das aplicações do roteiro de ensino nas disciplinas de graduação e pós-graduação. Segue a lista de trabalhos apresentados:

- Trabalhos produzidos em disciplina de graduação usando o sistema Pet Store:

- Trabalho 1 - Concorrência e Acesso Simultâneo - Pool de acesso sem fila (com timeout);

- Trabalho 2 - Segurança e Desempenho - Proteção contra componentes maliciosos;

- Trabalho 3 - Segurança e Desempenho - Compra segura por web service;

- Trabalhos produzidos em disciplina de graduação em projetos de Internet das Coisas (IoT):

- Trabalho 4 - Sistema de apoio para pessoas da $3^{\text {a }}$. idade;

- Trabalho 5 - Sistema de automação residencial;

- Trabalho 6 - Sistema de segurança em veículos.

Os trabalhos dos alunos estão disponíveis na raiz do CD que acompanha este trabalho, no arquivo Apendice E.pdf. 


\section{APÊNDICE F - COMENTÁRIOS DOS ALUNOS}

Os comentários dos alunos que participaram do roteiro proposto foram registrados pelos estudantes que desejaram fazê-lo nos questionários de avaliação aplicados durante as disciplinas. Do total de 167 alunos que participaram do roteiro, 64 deles registraram seus comentários, ou seja, 38,32\%. Os comentários registrados são reproduzidos abaixo:

Aluno 01: Curso produtivo. O tempo em sala foi muito bem aproveitado. Houve grande aprendizado prático e saudáveis discussões.

Aluno 02: O curso mudou a minha forma de se enxergar sistemas, pois agora entendo a importância dos requisitos não funcionais e sua influência na arquitetura de software e na qualidade final dos sistemas.

Aluno 03: Eu tinha conhecimento de que havia formas de se fazer medidas para determinados tipos de aplicação, mas não sabia como realizá-las ou mesmo como criar situações especificas de monitoração como inúmeras conexões simultâneas em um servidor. O curso serviu para esclarecer essas dúvidas.

Aluno 04: Meu conhecimento era teórico e baseado principalmente em medidas estáticas. Após diversas medições práticas, o conhecimento foi ampliado para medidas coletadas dinamicamente.

Aluno 05: Aprendizado de diversas técnicas de medidas e aplicação na prática de monitoração em runtime.

Aluno 06: $O$ curso foi de grande utilidade, oferecendo grande quantidade de informações. É necessário a aplicação da disciplina em mais de um semestre para cobrir o vasto conteúdo.

Aluno 07: Projeto bastante proveitoso e interessante. Proporcionou ao grupo uma boa noção sobre monitoração e impactos dos logs em um sistema. 
Aluno 08: Houve uma familiarização com medições na prática, tanto estática como dinâmica. Foi importante o contato com ferramentas de medições, técnicas de injeção de dependências e geração de logs de controle.

Aluno 09: A metodologia aplicada nesta disciplina foi muito mais voltada para a parte prática, o que foi muito bom pois incorpora a teoria através da realização do aprendizado diretamente no software. Muito bom!

Aluno 10: A disciplina complementa vastamente os aspectos não abordados em disciplinas teóricas e na disciplina Laboratório de Engenharia de Software I.

Aluno 11: Após o curso, percebo que minha capacidade de análise de questões avançadas sobre engenharia de software aumentou significativamente, ao ter compreendido o conceito e a importância de medições no contexto de utilização de visões de arquitetura e implementação de requisitos não funcionais. Ganhei conhecimento sobre os assuntos abordados na disciplina, mas mais importante que isso, passei a ter uma visão arquitetural mais apurada. Os temas abordados são muito importantes, não só academicamente, mas profissionalmente, pois demonstrar conhecimento sobre tais assuntos passa a impressão de um professional mais maduro, que pode atuar numa área onde não há grande oferta de profissionais.

Aluno 12: Ficou evidente a necessidade da realização de medidas para levantamento das limitações do sistema, assim como o uso de medidas para comparação de sistemas.

Aluno 13: Abordagem muito interessante para a verificação de requisitos não funcionais.

Aluno 14: Pude entrar em contato com vários tipos de medição, podendo selecionar qual tipo seria mais relevante para determinada funcionalidade e para realizar as comparações do sistema antes e depois de alguma otimização.

Aluno 15: A matéria foi muito produtiva. Praticamente toda a implementação foi feita em aula. Isso foi muito bom. A abordagem da matéria foi muito boa e não cansativa. Apesar de ter que vir aos sábados, foi muito gratificante ver o projeto render 
e avançar. As dicas dadas pelo professor e monitores foram muito aproveitadas também. Só tenho elogios a essa matéria.

Aluno 16: A matéria como um todo foi muito bem planejada. As aulas e o tempo para a execução das atividades permitiram que a maior parte da programação fosse feita em sala de aula garantindo comprometimento total.

Aluno 17: Os conceitos de qualidade foram bem abordados na disciplina, visto que os alunos foram incentivados a refletir sobre os problemas de qualidade dos sistemas de grande porte (desempenho, segurança, concorrência, etc.), o que não tinha sido feito em nenhuma outra disciplina.

Aluno 18: A ideia de introduzir provas de conceito em uma etapa anterior ao processo de desenvolvimento agilizou o andamento, evitando documentações desnecessárias. Nesse sentido, o curso se diferenciou bastante das demais disciplinas, fornecendo aos alunos um outro conceito de processo de desenvolvimento de software.

Aluno 19: Os requisitos não funcionais ficaram mais palpáveis.

Aluno 20: A prova de conceito foi uma boa forma para entendermos e aplicarmos a modelagem ágil e se mostrou uma forma melhor de construção de arquiteturas do que somente documentação e implementação no fim do projeto. Certamente usarei o método de provas de conceito em projetos futuros.

Aluno 21: O método utilizado no laboratório foi bastante produtivo. As aulas em paralelo com o projeto desenvolvido ajudaram muito no desenvolvimento de uma nova abordagem de projetos de software. No caso do meu grupo, o objetivo principal era o de se obter melhorias no código e foi bastante interessante o contato com ferramentas de medição e com os problemas enfrentados pelos outros grupos.

Aluno 22: O Pet Store não apresenta quase nenhuma documentação, diagrama de classe, diagrama de sequência...nada. Só o código. Isso dificultou o entendimento de parte do sistema, fazendo com que muito tempo fosse usado para desvendar certos aspectos do sistema. $O$ aspecto positivo é que isso nos mostra a importância da documentação. 
Aluno 23: Ainda tenho um pouco de dúvidas/dificuldades em relação ao conceito de arquitetura de software.

Aluno 24: A disciplina foi em geral muito boa e útil para o aprendizado de novos conceitos como desempenho, medições, qualidade e testes de software. Foi interessante também trabalhar sobre um código fonte pronto para melhorar. Os pontos negativos foram a falta de documentação do projeto o que dificultou e atrasou muito a sua implementação.

Aluno 25: O curso prove uma boa noção de medidas, tanto sob o aspecto de medição como sob o aspecto de diagnosticar atributos e comportamentos de um sistema através delas. Além disso, a estrutura do curso está muito boa na medida em que permite uma evolução lógica do progresso de melhoria de um sistema:

- Por que melhorar;

- Como melhorar;

- Medidas para definir o que melhorar;

- Encontrar pontos de modificação baseados nos resultados da medição;

- Efetuar a modificação;

- Nova medida para evidenciar as melhorias;

- Evidenciar que o programa continua com suas funcionalidades;

- Fornecer orientações para o desenvolvimento da documentação de cada etapa.

Aluno 26: Ganhei conhecimento sobre os assuntos abordados na disciplina, mas mais importante que isso, passei a ter uma visão arquitetural mais apurada. Os temas abordados são muito importantes não só academicamente, mas como profissionalmente, pois demonstrar conhecimento sobre tais assuntos passa a impressão de um professional mais maduro, que pode atuar numa área na qual não há grande oferta de profissionais.

Aluno 27: Acho que a disciplina está de acordo como o que foi proposto no início do curso e em particular, gostei do modo como foi dada: uma abordagem mais dinâmica e moderna. Poderíamos ter mais disciplinas como essa, abordando outras áreas da computação. 
Aluno 28: Eu gostei das aulas. Eram mais práticas e realmente nos deram a ideia de estarmos mais preocupados com a qualidade do sistema e não apenas com a documentação.

Aluno 29: O curso foi bastante interessante e contribuiu para o melhor entendimento de diversas disciplinas, inclusive matérias cursadas em outros anos, cujos conceitos ficaram mais claros.

Aluno 30: A aula é muito boa. Uma das poucas do curso em que realmente abordamos aspectos práticos e que nos serão muito úteis na vida profissional.

Aluno 31: A aula é boa, uma das melhores aulas de Engenharia de Software do curso. Isso se deve muito à abordagem que foca aspectos práticos e sua relação com a teoria. Sugestão: criar tarefas mais uniformes entre os diversos grupos.

Aluno 32: Antes do curso não sabia que arquitetura de software evoluía em tantos aspectos, nem da existência e importância das provas de conceito.

Aluno 33: O curso está sendo muito útil ao meu ver, principalmente porque o que estamos aprendendo pode ser amplamente explorado no mercado. Conceitos de qualidade e de medida para melhoria de um produto são aspectos fundamentais na vida do engenheiro e, portanto, estão sendo de grande valia para nosso aprendizado.

Aluno 34: Gostei muito da transmissão de conhecimento do "mundo real" por parte do professor e dos monitores.

Aluno 35: Gostei muito do curso.

Aluno 36: Achei muito interessante a participação de mais pessoas dando palestras e ajudando no projeto, visto que pelos diferentes backgrounds presentes, agregou bastante nos conhecimentos que foram passados para nós.

Aluno 37: Achei o curso produtivo e esclarecedor. Conseguimos entender o conceito de trade-off bem como as ações a serem tomadas para a decisão sobre cada trade-off. 
Aluno 38: A aula foi bastante ilustrativa sobre o ponto de vista da prática de engenharia mostrando alguns exemplos de empresas e decisões de negócio.

Aluno 39: Os conhecimentos que possuía anteriormente atribuo à minha experiência com a POLI-Jr. Lá participei do Núcleo de SI (Sistemas de Informação), porém envolvendo muito mais a criação de sistemas. Quanto às aulas, estou satisfeito com o curso (mesmo no sábado!). Sinto que realmente aprendi.

Aluno 40: O tratamento das classes que interferem nos bancos de dados (escopo do Projeto), ajudou a compreender um pouco mais os problemas típicos de segurança das informações no que tange aos modos de ataque (em termos de código) ou modos de proteção.

Aluno 41: Apesar de antes do curso, conhecermos alguns conceitos não sabíamos como utilizá-los e nem o que cada um significava para uma arquitetura. Agora, mesmo não tendo conhecimentos avançados do assunto, pelo menos sabemos onde entra cada conceito.

Aluno 42: Esta é uma das poucas disciplinas com equipe de professores que tenta refletir o aprendizado em sala com os problemas práticos da prática de engenharia.

Aluno 43: A matéria tem contribuído para o exercício de uma visão mais crítica em relação ao desenvolvimento de um projeto de um sistema de software. Além disto, contribuiu para exercitarmos a relação entre arquitetura do sistema, a implementação e testes. Os três componentes, operados em conjunto, contribui para a melhoria da qualidade do sistema.

Aluno 44: Foi possível compreender a utilidade de medidas estáticas para visualizar o funcionamento do programa e medidas dinâmicas para comprovar possíveis pontos fracos do sistema evidenciado a necessidade da implementação de modificações.

Aluno 45: Achei o curso muito bom com a sua abordagem com um viés mais prático. Certamente, as palestras sobre métodos ágeis e técnicas de desenvolvimento de software foram muito úteis, mas a aplicação da análise das medidas no 
desenvolvimento do projeto foi muito preciosa em termos de aprendizado. Foi possível detectar a necessidade das medidas, assim como o aumento na qualidade do produto gerado ao final de sua análise.

Aluno 46: No início do curso, acredito que a maioria dos meus conhecimentos em medidas se referiam às ligações (hardware e software) obtidos nas disciplinas de Arquitetura de Sistemas Computacionais e Modelagem. Ao término da disciplina, meu conhecimento foi melhorado, sobretudo em quantificar parâmetros de medição.

Aluno 47: Com o curso ficou evidente os impactos de medidas na arquitetura.

Aluno 48: Dificuldade inicial com tecnologias e conceitos não conhecidos. A adaptação foi conseguida de forma gradativa e satisfatória. $O$ desenvolvimento do projeto nos permitiu vivenciar uma situação real: surgimento de um problema e a especificação de uma solução envolvendo tecnologias não conhecidas, exigindo flexibilidade e bases sólidas de conhecimento por parte do engenheiro. Podemos também desenvolver a habilidade de entender e propor soluções para problemas que não tínhamos a menor ideia do porquê aconteciam inicialmente.

Aluno 49: Creio que para melhor entender/solidificar os diferentes conceitos de medidas (estáticas, dinâmica e de arquitetura) seria interessante ter um pouco mais de testes práticos na aula em que são discutidas essas medidas.

Aluno 50: Ainda tenho um pouco de dúvidas/dificuldades em relação ao conceito de arquitetura de software. Apesar de ter entendido os principais conceitos de medida, a efetivação prática de como medir não ficou completamente clara e consolidada. Acredito que tenha faltado um pouco de prática nisso durante a disciplina.

Aluno 51: Na primeira aula, na minha visão, os conceitos de medidas estáticas e dinâmicas como por exemplo complexidade ciclomática, acoplamento, testes automatizados e testes de carga eram basicamente elementos técnicos e mecanismos utilizados em processo de desenvolvimento de sistemas. Na última aula, percebi a importância da necessidade de medidas para a avaliação tanto do produto como do processo de software, assim como a necessidade de métodos para 
identificação e coleta das medidas, e a arquitetura de software deve ser dirigida pelo processo de negócio, e não somente por demandas e direcionamentos técnicos. '

Aluno 52: A disciplina possibilitou-me avaliar a arquitetura de software utilizando indicadores voltados para o negócio da empresa.

Aluno 53: No item conceitos de qualidade, diminui minha avaliação de nível de conhecimento, pois entendi que ainda existe muito ainda para ser aprendido e praticado para que se torne conhecimento efetivo em qualidade de software com 0 passar das aulas.

Aluno 54: A aula é muito boa e clara, porém é fácil esquecer os que foi dado nas aulas passadas.

Aluno 55: Para a aprendizagem de conceitos relacionados às medidas, é sempre interessante a prática por meio de exercícios básicos para fixação dos conhecimentos, com o objetivo de evidenciar as relações existentes entre medidas, qualidade de arquitetura de software e qualidade em geral de forma clara e objetiva.

Aluno 56: Talvez eu tenha mais experiência pratica do que a base teórica em relação às medidas, ou seja, dada a teoria, conseguiria associar com a prática.

Aluno 57: As relações entre medidas estáticas, dinâmicas e de qualidade de arquitetura de software não ficaram muito claras para mim.

Aluno 58: O ATAM, principalmente a utility tree, permite definir de forma clara e mensurável quais requisitos devem implementado no sistema.

Aluno 59: Olhar a arquitetura de software, primeiramente, com a visão de negócio, e não apenas com a visão técnica, alterou a forma como encaro a Engenharia de Software.

Aluno 60: Os pontos de vista da RM-ODP servem como balizadores para a definição de uma arquitetura de software cujos atributos de qualidade implementados atendem o processo de negócio da empresa. 
Aluno 61: As provas de conceito permitiram constatar que a escolha arquitetural não era adequada para resolver o problema de desempenho, o que permitiu que o grupo alterasse a estratégia o mais rápido possível.

Aluno 62: A integração dos diversos componentes da solução (hardware, software, sensores) foi mais tranquila devido às fases de prototipação e prova de conceito.

Aluno 63: As atividades práticas da disciplina contribuíram bastante para a minha formação como engenheiro de computação.

Aluno 64: A integração dos componentes utilizados na solução de loT possibilitou-me enxergar como elaborar provas de conceitos pode diminuir as chances de falha na implementação. 
276 


\section{APÊNDICE G - DIFERENÇAS ENTRE ISO/IEC 9126-1 E ISO/IEC 25010}

Neste apêndice são listadas as diferenças entre as normas ISO/IEC 9126-1 Software engineering - Product quality (ISO/IEC, 2001), utilizada neste trabalho, e sua versão revidas, a ISO/IEC 25010 - Systems and software engineering - Systems and software Quality Requirements and Evaluation (SQuaRE) - System and software quality models (ISO/IEC, 2011), pulicada em 13/09/2012. Na versão revisada, os mesmos atributos de qualidade presentes na ISO/IEC 9126-1 Software engineering Product quality foram mantidos e os seguintes itens foram incorporados (ISO/IEC, 2011):

- Cobertura de contexto foi adicionada como uma característica de qualidade de uso, com as subcaracterísticas de flexibilidade e completude de contexto;

- Segurança foi adicionada como uma característica, ao invés de uma subcaracterísticas de funcionalidade, contendo as subcaracterísticas de confidencialidade, integridade, não repúdio, autenticidade e responsabilidade;

- Compatibilidade, incluindo interoperabilidade e coexistência foram adicionados com característica na nova versão da norma;

- As seguintes subcaracterísticas foram adicionadas às características de qualidade de produto existente:

- Completude funcional;

- Capacidade;

- Proteção a erros dos usuários;

- Acessibilidade;

- Disponibilidade;

- Modularidade;

- Reusabilidade.

- Quando apropriado, definições genéricas foram dadas para estender o escopo para sistemas computacionais, ao invés de utilizar somente definições especificas para a área de software;

- Visando conformidade com as diretivas da ISO/IEC, quando possível as definições foram baseadas em normas já existentes da ISO/IEC. 
A Tabela 26 lista as diferenças entre as características e subcaracterísticas definidas nas normas ISO/IEC 25010 e ISO/IEC 9126-1:

Tabela 26 - Diferenças entre as características e subcaracterísticas entre as normas ISO/IEC 25010 e ISO/IEC 9126-1 (ISO/IEC 25010, 2011)

\begin{tabular}{|c|c|c|c|}
\hline Tópicos da ISO/IEC 25010 & ISO/IEC 25010 & ISO/IEC 9126-1 & Observações \\
\hline 4.1 & Qualidade em uso & Qualidade em uso & $\begin{array}{l}\text { Qualidade em uso agora é um } \\
\text { sistema de qualidade }\end{array}$ \\
\hline 4.1.1 & Efetividade & Efetividade & - \\
\hline 4.1 .2 & Eficiência & Produtividade & $\begin{array}{l}\text { Conceito de eficiência } \\
\text { alinhado com a ISO/IEC } 25062 \\
\text { e ISO 9241-11 }\end{array}$ \\
\hline 4.1 .3 & Satisfação & Satisfação & - \\
\hline 4.1.3.1 & Utilidade & - & $\begin{array}{l}\text { Sem subcaracterísticas } \\
\text { anteriores }\end{array}$ \\
\hline 4.1.3.2 & Confiança & - & $\begin{array}{l}\text { Sem subcaracterísticas } \\
\text { anteriores }\end{array}$ \\
\hline 4.1.3.3 & Prazer & - & $\begin{array}{l}\text { Sem subcaracterísticas } \\
\text { anteriores }\end{array}$ \\
\hline 4.1.3.4 & Conforto & - & $\begin{array}{l}\text { Sem subcaracterísticas } \\
\text { anteriores }\end{array}$ \\
\hline 4.1 .4 & Mitigação de risco & Segurança $(\text { safety })^{22}$ & - \\
\hline 4.1.4.1 & Mitigação de risco econômico & - & $\begin{array}{l}\text { Sem subcaracterísticas } \\
\text { anteriores }\end{array}$ \\
\hline 4.1.4.2 & $\begin{array}{l}\text { Mitigação de riscos de } \\
\text { segurança e saúde }\end{array}$ & - & $\begin{array}{l}\text { Sem subcaracterísticas } \\
\text { anteriores }\end{array}$ \\
\hline 4.1.4.3 & Mitigação de riscos ambientais & - & $\begin{array}{l}\text { Sem subcaracterísticas } \\
\text { anteriores }\end{array}$ \\
\hline 4.1 .5 & Cobertura de contexto & - & $\begin{array}{l}\text { Item de qualidade implícito } \\
\text { tornou-se explícito }\end{array}$ \\
\hline 4.1.5.1 & Completude de contexto & - & $\begin{array}{l}\text { Nova subcaracterística (é } \\
\text { importante que um produto } \\
\text { seja utilizável em todos os } \\
\text { contextos de utilização } \\
\text { requeridos) }\end{array}$ \\
\hline 4.1.5.2 & Flexibilidade & - & $\begin{array}{l}\text { Nova subcaracterística } \\
\text { (permite que o produto seja } \\
\text { utilizado em novos contextos } \\
\text { de uso) }\end{array}$ \\
\hline 4.2 & Qualidade do produto & Qualidade interna e externa & $\begin{array}{l}\text { Qualidade interna e externa foi } \\
\text { combinada como qualidade do } \\
\text { produto }\end{array}$ \\
\hline 4.2 .1 & Adequação funcional & Funcionalidade & $\begin{array}{l}\text { Novo nome é mais preciso, e } \\
\text { evita a confusão com outros } \\
\text { significados de } \\
\text { "funcionalidade" }\end{array}$ \\
\hline 4.2.1.1 & Completude funcional & - & $\begin{array}{l}\text { Cobertura das necessidades } \\
\text { declaradas }\end{array}$ \\
\hline 4.2 .1 .2 & Corretude funcional & Precisão & Novo nome mais genérico \\
\hline 4.2.1.3 & Adequabilidade funcional & Adequação & $\begin{array}{l}\text { Cobertura das necessidades } \\
\text { implícitas }\end{array}$ \\
\hline- & - & Interoperabilidade & $\begin{array}{l}\text { Item movido para } \\
\text { Compatibilidade }\end{array}$ \\
\hline- & - & Segurança (security) ${ }^{22}$ & Nova característica \\
\hline 4.2 .2 & Eficiência do desempenho & Eficiência & $\begin{array}{l}\text { Renomeado parara evitar } \\
\text { conflitos com a definição de } \\
\text { eficiência da ISO/IEC } 25062\end{array}$ \\
\hline
\end{tabular}

Continua

22 Visando facilitar o entendimento, para a característica de segurança, optou-se por manter o texto em inglês dada a diferença entre os conceitos security e safety. 
Continuação

\begin{tabular}{|c|c|c|c|}
\hline 4.2.2.1 & Comportamento no tempo & Comportamento no tempo & - \\
\hline 4.2.2.2 & Utilização de recursos & Utilização de recursos & - \\
\hline 4.2.2.3 & Capacidade & - & \begin{tabular}{|l|} 
Nova característica \\
(particularmente relevante \\
para sistemas computacionais)
\end{tabular} \\
\hline 4.2 .3 & Compatibilidade & - & Nova característica \\
\hline 4.2.3.2 & Coexistência & Coexistência & Movido de Portabilidade \\
\hline 4.2.3.3 & Interoperabilidade & - & Movido de Funcionalidade \\
\hline 4.2 .4 & Usabilidade & - & $\begin{array}{l}\text { Item de qualidade implícito } \\
\text { tornou-se explícito }\end{array}$ \\
\hline 4.2.4.1 & $\begin{array}{l}\text { Reconhecimento da } \\
\text { adequação }\end{array}$ & Compreensibilidade & Novo nome é mais preciso \\
\hline 4.2.4.2 & Aprendibilidade & Aprendibilidade & - \\
\hline 4.2.5.3 & Operabilidade & Operabilidade & - \\
\hline 4.2.4.4 & Proteção a erros do usuário & - & $\begin{array}{l}\text { Nova característica } \\
\text { (particularmente relevante } \\
\text { para atingir mitigação dos } \\
\text { riscos) }\end{array}$ \\
\hline 4.2.4.5 & $\begin{array}{l}\text { Estética da interface de } \\
\text { usuário }\end{array}$ & Atratividade & Novo nome é mais preciso \\
\hline 4.2.4.6 & Acessibilidade & - & Nova subcaracterística \\
\hline 4.2 .5 & Confiabilidade & Confiabilidade & - \\
\hline 4.2.5.1 & Maturidade & Maturidade & - \\
\hline 4.2.5.2 & Disponibilidade & - & Nova subcaracterística \\
\hline 4.2.5.3 & Tolerância a falhas & Tolerância a falhas & - \\
\hline 4.2.5.4 & Recuperabilidade & Recuperabilidade & - \\
\hline 4.2 .6 & Segurança (security) & Segurança (security) & $\begin{array}{l}\text { Sem subcaracterísticas } \\
\text { anteriores }\end{array}$ \\
\hline 4.2.6.1 & Confidencialidade & - & $\begin{array}{l}\text { Sem subcaracterísticas } \\
\text { anteriores }\end{array}$ \\
\hline 4.2.6.2 & Integridade & - & $\begin{array}{l}\text { Sem subcaracterísticas } \\
\text { anteriores }\end{array}$ \\
\hline 4.2.6.3 & Não-repudiação & - & $\begin{array}{l}\text { Sem subcaracterísticas } \\
\text { anteriores }\end{array}$ \\
\hline 4.2.6.4 & Responsabilidade & - & $\begin{array}{l}\text { Sem subcaracterísticas } \\
\text { anteriores }\end{array}$ \\
\hline 4.2.6.5 & Autenticidade & - & $\begin{array}{l}\text { Sem subcaracterísticas } \\
\text { anteriores }\end{array}$ \\
\hline 4.2 .7 & Manutenibilidade & Manutenibilidade & - \\
\hline 4.2.7.1 & Modularidade & - & Nova subcaracterística \\
\hline 4.2.7.2 & Reusabilidade & - & Nova subcaracterística \\
\hline 4.2.7.3 & Analisabilidade & Analisabilidade & - \\
\hline 4.2.7.4 & Modificabilidade & Estabilidade & $\begin{array}{l}\text { Novo nome mais preciso, pois } \\
\text { combina modificabilidadde e } \\
\text { estabilidade }\end{array}$ \\
\hline 4.2.7.5 & Testabilidade & Testabilidade & - \\
\hline 4.2 .8 & Portabilidade & Portabilidade & - \\
\hline 4.2.8.1 & Adaptabilidade & Adaptabilidade & - \\
\hline \multirow[t]{2}{*}{ 4.2.8.2 } & Instalabilidade & Instalabilidade & - \\
\hline & - & Coexistência & Movido para Compatibilidade \\
\hline 4.2.8.3 & Modificabilidade & Modificabilidade & - \\
\hline
\end{tabular}

Fonte: adaptado de ISO/IEC (2011) 